University of New Hampshire

University of New Hampshire Scholars' Repository

Spring 1991

\title{
The special artist in American culture: A biography of Frank Hamilton Taylor (1846-1927)
}

Nancy Louise Gustke

University of New Hampshire, Durham

Follow this and additional works at: https://scholars.unh.edu/dissertation

\section{Recommended Citation}

Gustke, Nancy Louise, "The special artist in American culture: A biography of Frank Hamilton Taylor (1846-1927)" (1991). Doctoral Dissertations. 1645.

https://scholars.unh.edu/dissertation/1645

This Dissertation is brought to you for free and open access by the Student Scholarship at University of New Hampshire Scholars' Repository. It has been accepted for inclusion in Doctoral Dissertations by an authorized administrator of University of New Hampshire Scholars' Repository. For more information, please contact Scholarly.Communication@unh.edu. 


\section{INFORMATION TO USERS}

This manuscript has been reproduced from the microfilm master. UMI films the text directly from the original or copy submitted. Thus, some thesis and dissertation copies are in typewriter face, while others may be from any type of computer printer.

The quality of this reproduction is dependent upon the quality of the copy submitted. Broken or indistinct print, colored or poor quality illustrations and photographs, print bleedthrough, substandard margins, and improper alignment can adversely affect reproduction.

In the unlikely event that the author did not send UMI a complete manuscript and there are missing pages, these will be noted. Also, if unauthorized copyright material had to be removed, a note will indicate the deletion.

Oversize materials (e.g., maps, drawings, charts) are reproduced by sectioning the original, beginning at the upper left-hand corner and continuing from left to right in equal sections with small overlaps. Each original is also photographed in one exposure and is included in reduced form at the back of the book.

Photographs included in the original manuscript have been reproduced xerographically in this copy. Higher quality $6^{n} \times 9^{n}$ black and white photographic prints are available for any photographs or illustrations appearing in this copy for an additional charge. Contact UMI directly to order.

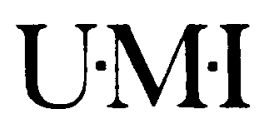

University Microfilms internationa!

A Bell \& Howell Information Company 300 North Zeeb Road. Ann Arbor. MI 48106-1346 USA

$313,761.4700 \quad 800.521-0600$ 

Order Number 9131287

The Special Artist in American culture: A biography of Frank Hamilton Taylor (1846-1927)

\author{
Gustke, Nancy Louise, Ph.D. \\ University of New Hampehire, 1991
}

Copyright $(1991$ by Guatke, Nancy Louice. All rights reserved.

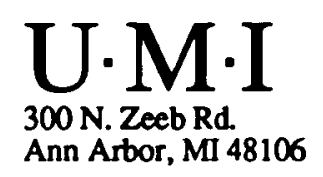



THE SPECIAL ARTIST IN AMERICAN CULTURE:

A BIOGRAPHY OF FRANK HAMILTON TAYLOR (1846-1927)

BY

NANCY LOUISE GUSTKE

BS Michigan State University, 1969

MFA University of Florida, 1984

DISSERTATION

\section{Submitted to the University of New Hampshire in Partial Fulfillment of the Requirements for the Degree of}

\section{Doctor of Philosophy}

in

History

May, 1991 
ALL RIGHTS RESERVED

(C) 1991

Nancy Louise Gustke 
For Larry . . 


\section{ACKNOWLEDGMENTS}

This dissertation could not have been completed without the assistance and support of a great many people. First and foremost are the members of my committee. Chairman Robert Mennel has encouraged my development of this project from the day I first inquired about the doctoral history program. His unfailing commitment to my research on Frank Taylor, and thoughtful criticism of my work, have been enormously beneficial. Bill Harris' astute comments on the manuscript kept my focus on the central theme. And his perceptive insights on current scholarship have added to the depth of my analysis. Charles clark not only guided me as graduate director, but as a former newspaperman, aided in the examination of Taylor's fournalistic importance. To Roy Craven I owe the inception of this project. As former director of the University Gallery at the University of Florida, his purchase of Taylor's watercolors and wash drawings led to my work on an exhibition, catalog, and thesis. His continuing enthusiastic interest in my research, and belief in its artistic and historical significance, confirmed my decision to continue an investigation of Taylor. Finally, to committee member William Jones, who was asked to assume the duties posthaste, I owe a confidence in my abilities as an historian. 
Throughout my graduate program at New Hampshire he has helped me hone my academic skills.

I particularly want to thank Bob and Claire Taylor and their daughter Marsha for allowing me access to the family archives, and for the wonderful invitations to Shady Ledge. They provided insight only family members can impart, and helped me better understand Frank Taylor -- especially his summer life on Round Island. Also Ellzabeth Taylor Hyde who has provided exciting new family knowledge. I look forward to continuing to expand our knowledge of their artistic relative.

Everyone in the Thousand Islands embraced this project and gave so generously of their time. Special recognition goes to Virginia Minnick, librarian of Clayton's Hawn Memorial Library. Her knowledge of the area was, and is, invaluable. Verda Corbin, Jean Wells, and Mary Herrick, widows of Lester J. Corbin, William H. Wells, and Harold E. Herrick, Jr., graciously shared the material their husbands had collected on Frank Taylor. At the Antique Boat Museum, former curator Kurt Hasselbalch and librarian Phoebe Tritton, directed me to important contacts as well as archival material on Taylor and the Thousand Islands in general. Jack Brown of Mallorytown, Ontario, provided valuable leads to Taylor gleaned from exhaustive research on other prominent Thousand Islanders. And Charles Dunham's historical knowledge on Taylor was of utmost importance to my comprehension of the artist's interactions with the Thousand 
Island community. In addition I would also like to thank Linda and Joe Kenney, Mr. and Mrs. David Smith, Lois Jean MacFarlane, Ann Potter, Cathy Anderson, Gerry Kirkey, Don Abbott, Betty Grant, Mary Brooks Mercier, Ted Cornell, and Jack and Ann Vosburg.

In Philadelphia the staff at the Historical Society of Pennsylvania deserve special praise, in particular Rachel Dach, Linda Stanley, and Marcy Silver. They guided me to important Taylor resources -- some literally buried in the stacks. Lou Meehan provided me with excellent transparencies. Bob Eskind at the Atwater Kent Museum has been a wealth of information on the museum's Taylor holdings which he continues to uncover. At the Philadelphia Maritime Museum Jane Allen and Lisa Brenner provided information and access to their Taylor drawings and engravings. Bruce Laverty at The Athenaeum, Irene Coffee at the Franklin Institute, and Robert Denious at Duane, Morris \& Heckscher also provided access to Taylor watercolors, drawings, and pamphlets. In addition I would like to thank Mrs. Joseph Carson for her interest and assistance. Also Marshall Jackel whose warehouse discovery set this entire project in motion. And Peter and Ruth Clark who provided shelter and sustenance as well as contacts during my Philadelphia visits. The members of the Philadelphia sketch Club provided access to their archival records and valuable assistance in locating additional Taylor drawings. The kindness and friendship they extended made me understand why Taylor found 
this group an important source of companionship and inspiration. Special thanks to William F. Patman, John F. Nemeth, Michael Kuncevich, and Morris Goldsmith.

In Florida I would like to thank Charles B. Simmons, Director, and Joan Runkel, Curator of The Henry Morrison Flagler Museum for their assistance. Also Larry Perkins, Curator of Collections at the Samuel P. Harn Museum of Art for his continuing interest in the important Grant trip sketches.

At the University of New Hampshire financial support for my research was provided by the Gunst Fund, two Central University Research Fund Grants, a Summer Teaching Fellowship, and a Dissertation Fellowship. These awards made possible my travel to the Thousand Islands and Philadelphia, critical to my data collection. Jeanne Mitchell, History Department Secretary, and graduate student Tony Lamanni, willingly handled long-distance details for which I am forever grateful.

Finally, I want to thank my parents, Harry and Vivian Shuman, who have been a source of encouragement and inspiration. Also my husband's parents, Stanley and Rita Gustke, who have continually supported my efforts. And most of all, my thanks to a wonderful husband whose faith in me has been unfailing. 
TABLE OF CONTENTS

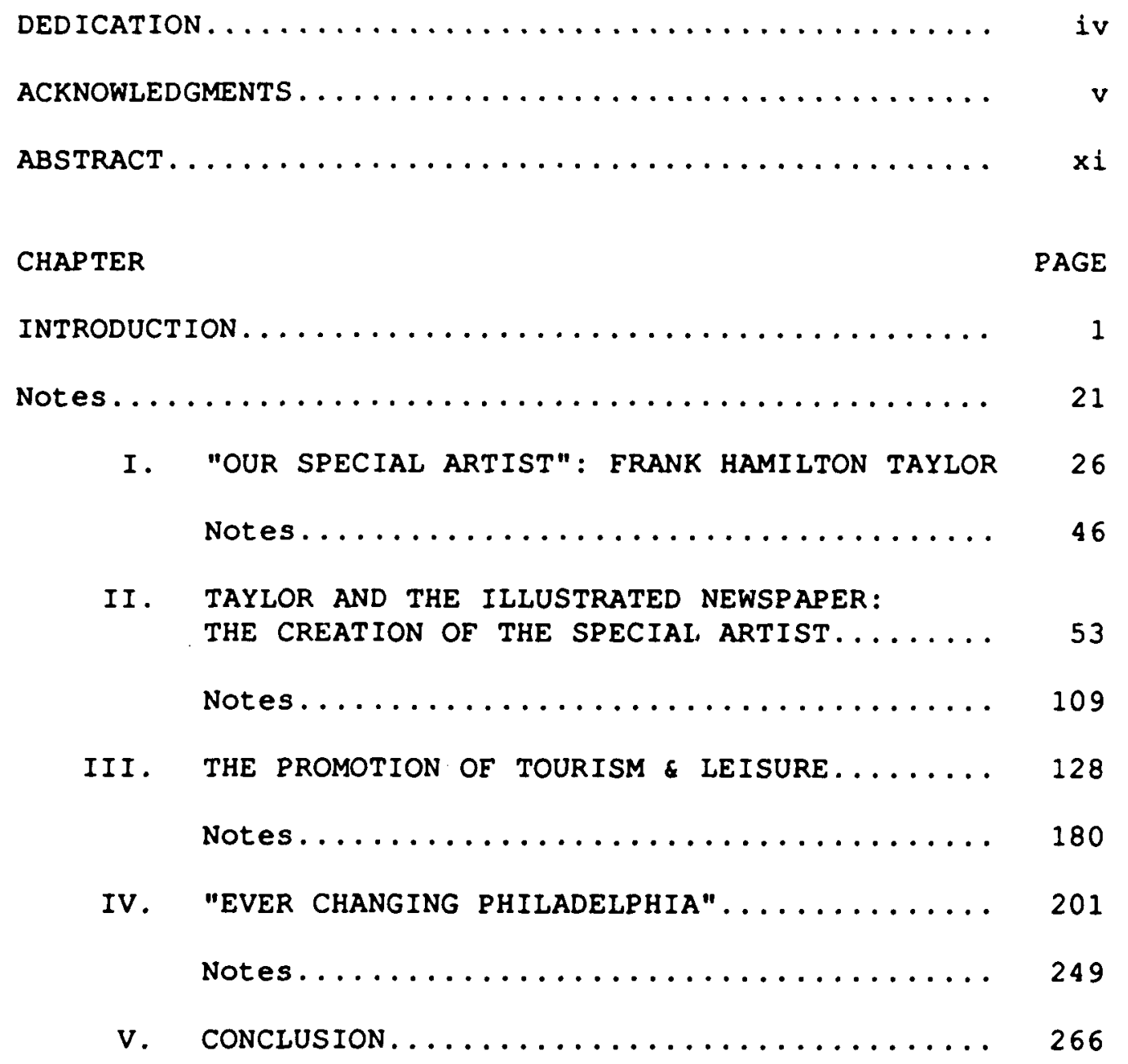

BIBLTOGRAPHY........................ 272

APPENDICES .......................... 290

A. FIGURES ..................... 291

B. "ODE to TAYLOR"................. 325

C. CHRONOLOGY: FRANK HAMILTON TAYLOR...... 327 
D. WOOD ENGRAVINGS AFTER SKETCHES BY FRANK

H. TAYLOR ................ 330

E. ERANK H. TAYLOR WATERCOLORS \& DRAWINGS.... 337 


\title{
ABSTRACT
}

THE SPECIAL ARTIST IN AMERICAN CULTURE:

A BIOGRAPHY OF FRANK HAMILTON TAYLOR (1846-1927)

\author{
by \\ Nancy Louise Gustke \\ University of New Hampshire, May, 1991
}

As a Special Artist (newspaper illustrator) for papers such as the New York Daily Graphic and Harper's Weekly, author and illustrator of numerous guidebooks, and astute recorder of Philadelphia, Frank Hamilton Taylor left a unique visual and written record of late nineteenth, early twentieth century American life. His work provided the growing, increasingly literate urban middle class with information about their country from the excitement of the Centennial Exposition to the tragedy of lives lost at sea. In addition, Taylor's documentation of leisure pursuits, particularly in the Thousand Islands area of New York, helped define what constituted recreation for the expanding non-manual work force who sought escape from the regiment of daily life. And his Philadelphia series of watercolors and wash drawings provide an almost microscopic view of the urban environment, capturing the city's ethos.

Gifted artists, Specials like Taylor went beyond the mere recording of facts. They invested those facts with charm and spirit. Their portrayal of the American scene, and 
fascination with the country's diversity, foreshadowed important shifts in American art as the historic symbols of Europe were no longer requisite. The growing outdoor movement also owed a dept to the Special Artist who made Americans aware and proud of the country's incomparable landscape.

The images of the Special Artist, besides informing, could also be a powerful persuasive tool. Taylor's documentation for Harper's Weekly of Ulysses S. Grant's trip to Florida, Cuba, and Mexico in 1880 for example shows a commanding, decisive figure. Exactly the perception Grant's political advisors wanted in order to distance the former president from his scandal-ridden administration, and allow him to seek a third Republican party nomination. Taylor's tourist guidebooks, often done for the country's burgeoning railroads were arguably equally manipulative, describing where the rallroads wanted people to vacation, not just popular tourist destinations.

Taylor represents the skilled Special Artist whose contributions to American art, journallsm, and the development of American culture have been undervalued. His sketches, watercolors, and engravings are important primary research documents. And his life is a three-dimensional representation of the Gilded Age values he recorded on paper. 
INTRODUCTION

\begin{abstract}
No biography is complete unless it reveals the individual within history, within an ethos, and a social complex.'
\end{abstract}

Erank Hamilton Taylor (Fig. 1, Appendix A) through his work as Special Artist (newspaper lllustrator) and author, significantly impacted the development of American culture in the late nineteenth century. At the same time his life reflects many of those elements of change which were manifested by a growing middle class as it assumed its position in society. ${ }^{2}$ Through a study of his drawings, tourist guidebooks, lectures, and news articles it is possible to gain insights into the evolution of this middle class culture as it emerged after the Civil War. ${ }^{3}$

Taylor's life serves as what Barbara Tuchman called "a prism of history" as it illuminates various facets of the American experience -- industrialization, urbanization, the outdoor movement and a new leisure ethic, historic preservation, and the rise of pictorial fournalism and realism in American art." In a biography says Tuchman, the universal is encompassed in the particular thereby facilitating a greater understanding of history. What emerges here, then, is an interesting new personal perspective on history which had national significance. This study of Frank H. Taylor is not in the traditional outlook of the elites or the new social 
history's view from the "bottom up," but from the aspect of the new non-manual household whom Stuart Blumin says were creating a new middle-class consensus. ${ }^{5}$

As a Special Artist Taylor offers a unique birdseye view, if you will, into the Gilded Age and the emergence of the Proyressive Era. Unfortunately Special Artists as a distinct group have received little scholarly attention from historians of American history, journalism, or art, although they made unique contributions to each field. It is imperative, however, to understand what defined the Special Artist in order to fully appreciate the powerful influence Taylor and his fellow Specials had on society.

The term was commonly used by nineteenth century illustrated newspapers like Harper's Weekly and Erank Leslie's Illustrated Weekly (see Chapter II] to refer to those artists either on staff, or free-lance, who lllustrated (and sometimes also wrote) the news. ${ }^{6}$ Typically, a caption under the newspaper engraving(s) might read "From sketches by our Special Artist," and the artist may or may not have been identified. Other times as in the August 30, 1879 issue of Harper's Weekly in a composite of several engravings showing "Bits of New Jersey Coast Scenery," the credit line read "From sketches by F. H. Taylor." Taylor often referred to himself as a Special Artist. The cover of his book about the American Society of Civil Engineers' Southern Excursion in 1877 noted that it was "written and sketched by the 'Special."' In addition many newspaper clippings found in 
his scrapbooks refer to Taylor as a "Special Artist." That these artists were considered an important part of the nation's 1llustrated press is suggested by Taylor's carlcature sketch accompanying a lecture on the "Making of a Newspaper" where on the note-holder to the left of the editor(?) are slips denoting the various components of the paper's assembly including one labeled "Specials" (Fig. 2).8 Winslow Homer, perhaps the nation's best known Special even characterized himself in the line of duty during the Civil War as part of his Iife in Camp series (Fig. 3).

As Homer's humorous sketch suggests, the Special Artist did not usually have the luxury of a studio and its amenities, nor the advantage of time when recording a news event. The need for on-the-spot coverage meant that he might be sketching "In the heart of a seething mob... lor executing] clever portrait outlines in a railway carriage travelling at fifty miles an hour." 9 In addition, to obtain the most interesting view the Special often eschewed the straightforward approach, instead "climbing to inaccessible colgns of vantage from which to sketch."10 Editors, of course, needed the sketch as rapidly as possible requiring the Special to work quickly but with accuracy -- not always an easy task. Harry Barnett who wrote an article on Special Artists in 1883, and who was both a reporter and artist, noted that it was "much less difficult to write a column or so of fairly accurate and picturesque description than to make a comprehensible sketch of a scene which may only have 
existed for a few minutes."11 The Special Artist wrote Paul Hogarth:

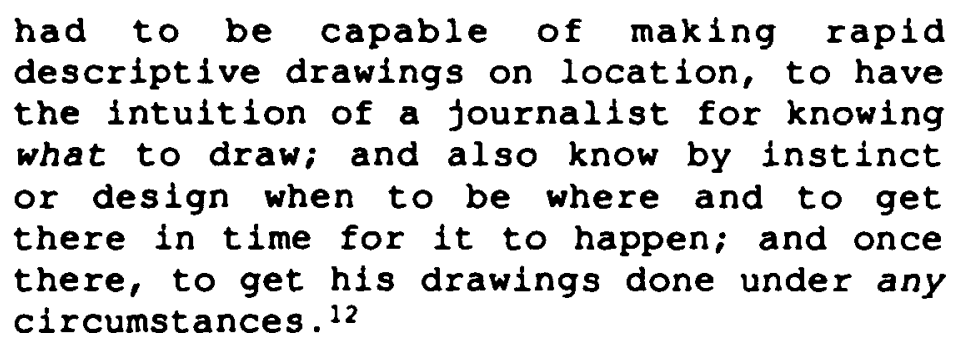

Another important quality was the ability to be a diplomat, for as Barnett noted, no matter how many letters of Introduction were provided or the authority accorded his or her journal, the Special must come in contact with people, many of whom would be unpleasant, or at the least uncooperative.13 The Special Artist had to possess an "affability tempered with firmness" or, in some cases, "a touch of gold or silver" to open doors at first locked against him.14 "His personal bearing, and the 'relations' he could establish with the powers that be" as well as his "tact and discretion" were often what ultimately determined his ability to obtain a true and accurate picture of an event. ${ }^{15}$

But besides the rapid recording of factual details and the ability to obtain an interesting view, a good special Artist had to be able to "record leading facts with artistic charm, and with some suggestion of human interest and human sentiment."16 He had to possess what Barnett refers to as "imagination," i.e. the ability to transfer to his sketch the idea that is present "In every incldent, in every pageant, in 
everything worth pictorial record."17 Even though he did not always have the time to paint great pictures, said Barnett, the special had to be able to see them in his mind and transfer the essentials to paper. These qualities set the Special Artist apart. They also made his views appealing to a mass readership, helping to humanize a sometimes forbidding world of increasing complexity.

This "Special Artist" designation for this unique group of 1llustrated fournalists has over the years disappeared, however. It seems odd that so definitive and descriptive a term should be discarded or perhaps not understood by modern writers who clumsily search for the appropriate nomenclature, referring to Special Artists at varlous times as artist correspondents, artist reporters, newspaper 1llustrators, artist-illustrators, or art-journalists. This confusing terminology not only dilutes the importance of these unique individuals, but by falling to be collectively designated into a recognizable group, they have in effect been cast into obscurity. Certainly artists like Homer and Remington have received academic analysis, but only recently has their early work as newspaper specials received the attention it deserves. But even this is often only as a precursor to what is considered their major work in oils, watercolors, and bronze. And yet, a careful analysis reveals that their early training as consummate reporters of American life contributed to the nation's cultural development and significantly affected their entire artistic careers. ${ }^{18}$ 
Other factors have also contributed to the misunderstanding of this group of artists. Sometimes Special Artists are mistakenly grouped together with literary illustrators as in the exhibition catalog The American Personality: The Artist-Il lustrator of Ife in the United States, 1860-1930.19 However, they were journalists as much as artists. While their illustrations were as narrative as those of $N$. C. Wyeth, for example, whose work accompanied many of Robert Louis Stevenson's stories, the Special recorded actual events -- he could not (ethically) fabricate the facts. 20 while Special Artists were illustrators, they must be recognized as a separate group fust as the Luminists have been distinguished from the Hudson River School painters. Hogarth also correctly separates the special from the early artist-travellers and artists such as Karl Bodmer who accompanied wealthy patrons like the German prince, Maxmilian, on their grand tours.21 These artists were not restricted by ridged time frames or the need to record an event under any conditions in order to satisfy their editor's demands. While recorders of the world around them, these artists do not exclusively fit the category of Special Artist. Another reason Special Artists have not been studied as a distinct group may be the fact that much of their original art work has been destroyed, leaving only the wood engravings to remind us of the skill and dedication involved in securing the primary sketch.22 Taylor's substantial body of extant work allows for a more thorough 
analysis of this artistic genre. A comparison of Taylor's original sketches with the engravings, discussed in detail later, lllustrates that the engravings were often excellent translations of the artist's field sketch. Even though in many instances only the engravings remain, they can provide, as Mason Jackson predicted in 1885, "an inexhaustible storehouse for the historian."23

There were hundreds of artists like Taylor who roamed the country often risking their lives to bring scenes of unique events, disasters, natural and man-made wonders, and dally experiences to the eyes of readers. Names like Alfred R. Waud and Theodore R. Davis may be known to a few Civil War historians who have noted their names on the pages of Harper's Weekly. along with Homer's, but what of Charles Stanley Reinhart, Thure de Thulstrup, Charles Graham, Charles J. Taylor, William Thomas Smedley, and Mary Hallock Foote to name a few? They too deserve attention for their contributions to the development of a new cultural identity. Taylor stands as a symbol of the possibilities for historical knowledge and interpretation the Special Artist can provide. The 1llustrated newspaper also falls "between the cracks" of historical research sometimes being incorporated in studies of newspapers in general, or magazines, but more often than not overlooked entirely further contributing to the Special Artist's anonymity. Gunther Barth's discussion of the metropolitan press in the late nineteenth century as a contributor to urban cultural development for example, while 
excellent, fails to acknowledge the debt owed to illustrated weeklies. ${ }^{24}$ Barth notes the urban press used human interest stories and the sequencing of news events to maintain reader interest. But the illustrated press had been doing the same thing on a national level since the Civil War. ${ }^{25}$ Human interest was the main concern for papers like Harper's Heekly. Fletcher Harper's aim notes Eugene Exman in his history of the Harper firm, was to be "the best family newspaper in the world," giving "sound views on political, social, and moral questions" as well as "carry articles on travel, adventure, art, and literature." Finally it would "present well-edited views, both foreign and domestic."26 And it was the Special Artist's skill in finding that human interest that made the papers so popular.

As for sequencing, Taylor's coverage of the Centennial Exposition in Philadelphia for the New York based Daily Graphic was begun well before the exhibition opened, and eventually the paper issued a weekly supplement "devoted exclusively to illustration of [Philadelphia] and interesting Centennial objects."27 Taylor's coverage for Harper's Weekly of Ulysses S. Grant's trip to Florida, Cuba, and Mexico was run over a period of three months appearing in ten issues. The stories were of the former president's meetings with the local citizenry, his visit to exotic locations, and descriptions of local color. These narrative "human interest" stories were designed to make a national readership feel closer to their famous general who easily mingled with people 
like themselves. Just as importantly, Harper's Weekly hoped that readers would want to find out about the ex-president's next stop, and, therefore, buy subsequent issues of the paper.

Barth also discusses the role of the urban press in dealing with political machines, but again does not mention that the illustrated weeklies had long seen it as part of their responsibility to fight city hall. He is correct in noting that the metropolitan press helped make urban diversity understandable, but Harper's Weekly and Eraak Leslie's were doing the same for a nation, and it is quite likely that the urban papers were capitalizing on a recognized success. Weeklies like Erank Leslie's made both urban and rural families knowledgeable about activities on the Boston Common, festivities in New Orleans, and cowboy life on the great plains. They popularized events such as the Centennial Exposition, and covered shipwrecks along the midAtlantic coast. Taylor's views for Harper's Weekly for example besides those of the "Jersey Coast" included such diverse topics as "Law and Moonshine -- Crooked Whiskey in Western North Carolina," "Centennial Celebration of the Battle of Newtown [Rhode Island]," and "A Tobacco Mart in Lynchburg, Virginia." These engravings provided the readers an understanding of the country, and feeling of being a part of it in the same way Barth credits the urban press served the city's inhabitants. One could imagine that many rural citizens who opted to move to the city, or even visit for a 
special event, did so with less apprehension and intimidation because of the articles and engravings in the illustrated weeklies.

Just as Barth overlooks the role of the illustrated newspaper in urban cultural development, so too does Chrlstopher wilson in his essay of the "Rhetoric of Consumption."28 His focus is on post-Civil War national magazines like Maclure's, and the Saturday Evening Post which he correctly notes took a more journalistic, realistic approach to news, quite different from established monthlies like Harper's, Scribner's, and The Atlantic. These latter periodicals served to retain the victorian cultural values of "tradition, restraint and cultivation" writes wilson, while the new magazines were "a crucible of modern consumer culture."29 The more fournalistic style of the articles and change in the approach to the reader, or consumer as wilson would have $1 t$, did not blossom overnight in the form of Maclure's, the Rest, or the Ladies'Home Journal. Illustrated weeklies had already targeted a large audience that wanted news, stories, and general information and were eager for a publication that provided more tangible benefit than a scribner's, fust as they wanted to know more than what was occurring within their urban boundaries. The growing nonmanual work force Blumin describes did not inherit the "gentle reader" philosophy of the upper class, but they were interested in obtaining information that would make them more knowledgeable about the world they lived in. Harper's 
Weekly, Erank Leslie's, and other illustrated newspapers met their needs. That a new breed of monthly evolved from this format is a logical progression as new editors targeted an increasing desire for helpful hints and guides to an improved lifestyle. Wilson also cites the importance of a new "rhetoric" In targeting a less elite leadership as if the practice was unique. But illustrated weeklies had already paved the way with brief headlines and the use of illustrations to convey information about lifestyles and products in a quick, straightforward manner.

These 1llustrated papers certainly influenced public opinion through their editors' comments and control of content which wilson attributes to the monthly magazines. This control was achieved through pictures as well as words. During the Civil War, for example, Harper's Weekly was a staunch supporter of the Union cause, and its illustrations were aimed at showing the northern troops in the best light. And as described later, Taylor's coverage of the Grant trip was also designed to influence readers by the positive portrayal presented. Whether this control was an organized plan to manipulate the lower classes as Wilson proposes was the intent of Maclure's and other "new" magazines, the power of the pictorial press -- and the new periodicals relied heavily on pictures -- had been established as soon as the Ilustrated London News hit the stands in the early $1840 \mathrm{~s}$. Barth and wilson generate effective arguments about the role of fournalism in creating and/or changing American 
cultural development. What they both overlook, however, is the critical role of the illustrated weekly in paving the way for a more realistic reportorial approach to subject matter and therefore the Special Artists who created those 1llustrations. From the beginning papers like Harper's Weekly were aimed at a less cultured reader, but one who was aware of changes in his environment and wanted to know more about them. The 1llustrated papers could also afford large art departments initially too expensive for the metropolitan press. Only with the ability to inexpensively reproduce photographs could the dailies take over, eventually eclipsing their weekly predecessors. P. T. Barnum who knew well the power of visual enhancement to influence his clientele is reported to have said "He who is without a newspaper is cut off from his species." "30 There is no doubt he had an illustrated newspaper in mind. This biography of Taylor aims to put the role of the illustrated newspaper, and the critical Special Artist, in proper perspective.

In Taylor's role as Special Artist he often documented travel destinations as well as the sites and scenery along the train or steamship journey. His articles appeared in Harper's Weekly, Harper's Monthly, Llppincott's, and the Daily Graphic along with tourist guidebooks produced by the railroads and independent companies. They, along with articles by other Specials, encouraged many Americans to explore their country. By studying Taylor's travel articles and tourist guidebooks it is possible to gain insight into 
where and why the middle class went on vacation at a time when new ideas about leisure were emerging. Chapter III is a detailed discussion of the role Taylor played in promoting tourist destinations, particularly for the burgeoning railroads anxious to increase ridership. Many rallroad companies also had interest in subsidiary tourism operations making promotion and advertising of increased importance. They were well aware the value illustrations had in enticing travelers. Wilson's description of a consumer culture influenced by magazine advertisements controlled by powerful editors could easily be applied to the Robber Barons who governed the nation's railroads and who used illustrations, as in the case of Yellowstone, to create, as well as maintain, tourist destinations. ${ }^{31}$

Whether Taylor was aware of the ultimate manipulative power of his work can only be speculated. But he did actively promote the Thousand Islands of northern New York as a haven of clean air, fresh water, and free of disease which would certainly benefit developers. A careful analysis of his writings though suggests that his main motive was to inform, letting the reader make up his own mind. Unlike wilson, Taylor seemed to credit the reader with the ability to think for himself.

Illustrations in travel articles and guidebooks provide twentieth century historians with information about Gilded Age leisure. Outdoor activities constitute the principle subjects of these illustrations and extensive descriptions 
were often provided about vacation life. Taylor himself enjoyed the outdoors, and fishing and boating views make up the majority of his extant watercolors of the Thousand Islands region. He offers a glimpse into the summer life of the middle class who could now afford to escape from their structured urban lifestyle for a week, a month, or in Taylor's case the entire summer.

Of course the writlngs of Ralph Waldo Emerson and Henry David Thoreau as well as popular prints of works by the Hudson River School painters had already created an outdoor awareness. But Lewis Mumford notes in The Brown Decades there was a change in attitude toward the land that renewed the city's contact with it, humanizing the landscape fust as newspapers humanized the city and the nation. ${ }^{32}$ The sketches, and Taylor's own life show how Americans were dealing with the eternal urban, rural conflict -- creating what Leo Marx calls the middle landscape. ${ }^{33}$

Leisure activities that took advantage of fresh air and open spaces became increasingly popular. At first cemeteries on the city's periphery offered open space for public relaxation, but a growing citizenry soon demanded designated recreational space and urban parks such as New York's Central Park and Fairmont Park in Philadelphia developed, integrating the landscape with the city. Then as the middle class became more economically stable they sought recreational pleasures outside the city that they had read about and seen illustrated in various publications. And as Phyllis Peet so 
correctly points out, even for those who were unable to afford to participate, the 1llustrations "enabled the reader to visualize these events, providing [a] vicarious experlence."34 Again the Special Artist's sketches would facilitate the acculturation Barth attributes to the metropolitan daily and the control wilson ascribes to the new monthlies. ${ }^{35}$

As a Special Artist Taylor was an astute observer of his surroundings, and after his retirement from the rigors of travel and demands for deadlines, he increasingly turned to recording what he called "Ever Changing Philadelphia." His accurate portrayals and descriptions of the late nineteenth, early twentieth century urban landscape have been preserved in watercolors, wash drawings and lithographs he made from approximately 1915 until his death. The final chapter deals with this period of his life as he used his artistry and talent for grasping the essential meaning of a situation to record a city he loved. His Philadelphia series reveals much more than interesting, well designed and executed city views. These works document changes in the urban landscape as the city became the primary dwelling place for Americans in the post-bellum years. We are offered a view of Philadelphia's accommodation to change from the perspective of an accomplished visual-journalist. These are not just the romantic images of an old man, but records of urban history. Taylor shows, just as Warner's twentieth century study of Philadelphia, the city's evolution into an industrial 
metropolis. How the city's heritage of privacy both helped its creation as well as hindered its sustained excellence. What the historian finds here is a visual record of how the urban landscape accommodated technological change. Taylor had in fact been recording Philadelphia's progress since the Centennial Exposition in 1876 when he was assigned by the Daily Graphle to head the paper's Philadelphia Bureau, making him acutely sensitive to those changes. His sketches show the physical, and thereby implied economic, domination of the Pennsylvania Railroad in the center of the city's business district with its massive Broad street station, and the Philadelphia and Reading Rallroad's splder web like presence as its Columbla Avenue bridge crosses the Schuylkill to reach out to the rich hinterlands just as the toll roads and canals had earlier. Industriallzation along the city's two waterfronts was also recorded.

Taylor did not, however, forget that the city was made up of people, and their participation in the environment was an important element whether riding the trolly in from the suburbs or chatting with neighbors behind the new office buildings that dominated the Center City skyline. Just as his sketches for the illustrated papers contained the elements of human interest, so too did his later watercolors and washes. The historian can glean a great deal of factual information about the daily interaction of urban residences from this series. They offer what Sam Bass warner laments is 
the often difficult task for the historian, the reconstruction of everyday ife. ${ }^{36}$

Taylor also recorded the architectural experimentation In the city such as that surrounding Washington Square. His sketches visually verify the heterogeneous nature of some of its neighborhoods which retained citizens in the central business district even as the ubiquitous trolly allowed commuters to live increasingly away from their work place. His views of Fairmont Park and boating activity on the Schuylkill document the desire for urban recreation, just as his Thousand Island watercolors and engravings recorded the pursuit of leisure as an escape from the confinement of the city, and paved the way for tourism as an industry. More than "pretty pictures," they reveal the life, the vitality of the middle class, as they struggled to carve out their own place in the nation's cultural development.

Taylor saw himself as an historlan, and his excellent books Valley Forge: A Chronology of American_Herolsm, and Bhiladelphia in the civil War, demonstrate his thorough investigation of the facts -- traits not unlike those he used as a Special Artist. His Philadelphia series offers the twentieth century historian of Philadelphia and urban history in general, raw data about what daily life was like for the middle-class urban resident, and what that middle class felt was important to record for the future. There were other artists and writers who concentrated on the city's ills, crime and corruption, the plight of the poor, and the trials 
of the immlgrants, and these aspects have increasingly received scholarly attention. Historians have also traditionally studied the ruling upper class as disseminators of cultural values, and manipulators of those beneath them thereby controlling the nation's destiny, and certainly Philadelphia had its share of famous and powerful personages. ${ }^{37}$ But Taylor offers a view of Blumin's non-manual worker who was rising in the Gilded Age to a position of increasing importance and influence.

Taylor was a participant and patron of that group, democratizing the country -- both urban and rural -- to the literate, upwardly mobile, non-labor class. As a special Artist he was provided opportunities to visit and record the American landscape as well as associate with some of the nation's most powerful men in Ulysses S. Grant and Philip Sheridan, Fletcher Harper, Henry Morrison Flagler, and George Pullman. ${ }^{38}$ Taylor was then able to provide his insights on the country, and the men who influenced its development, to the general populace through wood engravings of his work. His dedication to artistic principles and his formal and informal study with artists like Christian Schuessele, Thomas Eakins, Thomas Anshutz, and Joseph Pennell contributed to the quality of his work and his philosophical outlook. These drawings and the accompanying articles were not intellectual discourses, but human interest documents that personalized the complex urban environment of the late nineteenth century. 
Taylor's life shows a man who was able to rise from a working-class family to one of moderate wealth and prestige -- the goal of Horatio Alger's heroes. He took advantage of technological innovations such as photolighography and saw them as useful tools that would make items, in this case reproductions of his sketches, available to middle-class families. ${ }^{39}$ His contemporaries were his clientele, one reason perhaps he did not feel the need to paint large oils that only the wealthy could afford or see. Taylor's work was always aimed at a popular audience.

He also expressed the decidedly Ruskin Victorian view of a morality to art and life, again providing the modern historian with insight into late nineteenth century thought. Taylor had inherited in Philadelphia a moralistic, realistic philosophy that began with William Penn and was artistically expressed in the works of Benjamin West, Charles Willson Peale, Thomas Eakins and Frank Furness. Taylor's discussion in his lectures to artists and students of the responsibility of artists to produce well-designed drawings and bulldings speaks to that philosophy that art could and should enrich everyone's life. ${ }^{10}$

Special Artists like Taylor provided the nation with realistic and artistic views of their country. They foreshadowed changes in American art as their factual portrayals of American life validated that the country's artists did not need to "look for its themes to the historic symbols of Europe."41 For too long they have been overlooked, 
grouped generally with book and magazine illustrators whose subject matter was the interpretation of fiction. The Special Artist was an interpreter of facts and should be recognized as an important contributor to the development of American art and fournalism, the dissemination of cultural values, and documentarians of American history. Their lives and work can provide future historians new insight into the Gilded Age as they were the "window" to the nation. And scholarly attention given to the Special Artist may help rescue field sketches and other extant works from the trash barrel -- nearly the fate of Taylor's Grant series. Finally it may focus renewed attention on the early works of artists like Thomas Moran, Edwin Aust in Abby, Frederic S. Church, Charles Dana Gibson, and others who began their careers as Specials and what effect their journalistic background had on their later careers. Taylor's life provides a wonderful beginning to the story of the Special Artist. 


\begin{abstract}
'Leon Edel, Writing hives: Principia Biographica (New York: W. W. Norton, 1984), p. 14 .

${ }^{2}$ For a discussion of the development of the middle class in America see Stuart M. Blumin, The Emergence of the Middle class: Social Experience in the American city, 1760-1900 (Cambridge: Cambridge University Press, 1989).

'Taylor's drawings also reflect the contributions Special Artists made to what Lewis Mumford referred to in The Brown Decades as a new power and integrity in American art as it embraced the industrial age. Lewis Mumford, The Brown Decades: A Study of the Arts in America 1865-1895 (1921; rpt. New York: Dover Publications, 1971). TFor an excellent analysis of the evolution of the definition of culture in the nineteenth century see Raymond Williams, culture and Society 1780-1950 (New York: Columbia University Press, 1958).
\end{abstract}

"Barbara W. Tuchman, "Biography as a Prism of History," Telling lives, Marc Pachter, ed. (Washington, DC: New Republic Books, 1979), p. 134.

SBlumin, The Emergence of the Middle Class, p. 297. Blumin describes this consensus as a "specific set of experlences, a specific style of living, and a specific social identity."

6It was not a term applied only to artists who covered military conflicts, although war specials like winslow Homer, Frederic Remington, and Howard Chandler Christy have remained more visible.

'Frank Hamilton Taylor, Becords of the Southern Excursion of the Amertcan society of civil Engineers (Philadelphia, 1877).

${ }^{8}$ Another indication of the high regard in which Special Artists were held is found in a clipping "Sketches by the Wayside" from the scrapbook at the Atwater Kent Museum in Phlladelphla attributed to Taylor. The writer notes "When we glance at a pictorial paper, and after admiring a grand picture of some realistic scene read that it was sketched by a special artist we are presumed to imagine that that artist 
is some grand personage to be thought of, read about and wondered at, but not to be approached. But all specials are not that $k$ ind of fellows by any manner of means and Mr. Frank H. Taylor, special artist of the N. Y. Graphic, is not especially. He is to be admired and even wondered at but he is not unapproachable."

${ }^{9}$ Harry V. Barnett, "The Special Artist," Cassells', The Magazine of Art, 6 (1883), p. 163.

${ }^{10}$ Ibid.

${ }^{11}$ Ibid.

12 Paul Hogarth, The Artist As Reporter (London: Studio Vista, 1967), p. 23. p. 166 .

${ }^{13}$ Barnett, "The Special Artist," The Magazine of Art,

${ }^{14}$ Ibid.

15 Ibid.

16 Ibid.

17 Ib1d.

${ }^{10}$ Homer scholars for example, write that an important contribution to American art was his record of daily life, yet that is exactly what he did as a special Artist be it skaters in Central Park or a sharpshooter waiting in a tree. His early newspaper training no doubt sharpened his visual skills, and even when he changed his career he continued to, as Mumford said, be "an historian and illustrator of our society." Mumford, The Brown Decades, p. 91.

19 The American Personality: The Artist-Illustrator of Life in the United States, 1860-1930 (Los Angeles: The Grunwald Center for the Graphic Arts, UCLA, 1976).

${ }^{20} \mathrm{~N}$. C. Wyeth worked as a Special Artist for Saribner's publishing articles on sheepherding in the western United States. Ibid., p. 172. ISpecial Artists did sometimes create their compositions in the studio. A Vanity fair illustration of 1861 depicted a Special Artist in his paper's art department office sketching a "battle" of toy soldiers. Sally Mills, "The Sharpshooter, 1866," Wlaslow Homer: 
Raintings of the civil War, Marc Simpson, ed., ISan

Francisco: The Fine Arts Museums of San Francisco, 1988), pp. 163-264. The pressure to meet deadlines sometimes also led to "creative" production methods. When Thure de Thulstrup was asked to do the Harper's Weekly cover showing the funeral procession for Ulysses S. Grant, he had to draw the background material ahead of time. Since he could not be sure of weather conditions, he "spotted a few umbrellas among the crowd" as they could serve as protection from sun or rain, "and in either event could cover the art department." He also "tinted the sky in a way that would be appropriate for rain clouds." No matter what the final conditions -- it turned out to be a clear day -- the groundwork was laid. Eugene Exman, House of Harper: One Hundred and Fifty Years of Publishing (New York: Harper Row, 1967), p. 119.

${ }^{21}$ Hogarth, The Artist As Reporter, p. 23.

22 Some artists worked directly on the wood block [see Chapter II] leaving no paper trail, and as the design was engraved, the original sketch was destroyed. In addition, most of the wood blocks were eventually destroyed leaving only the newspaper engravings as a record of the work of artist and engraver.

${ }^{23}$ Mason Jackson, The Pictorial Rress: Its Oriain and Progress (London, 1885; rpt. Detroit: Gale Research Company, 1968), p. 361 .

${ }^{24}$ Gunther Barth, "Metropolitan Press," City People: The Bise of Modern City culture in Nineteenth-Century America (New York: Oxford University Press, 1980), pp. 58-109. IIlustrated newspapers which originated in England in the 1840 s were generally issued on a weekly basis due to the labor intensive process of wood engraving [see Chapter II] necessary to produce the illustrations. The one exception was the New York Daily Graphle which in 1872 utilized a patented process of photo-lithography to reproduce sketches faster and less expensively. While a dally, the Graphic's format was similar to Harper's Weekly and other illustrated weekly newspapers and should be considered as such.

${ }^{25}$ The sequencing of stories also influenced the development of the comic strip and perhaps the mind-set which led to the motion picture in its frame-by-frame images which narrated a story. The later work of Winslow Homer also shows evidence of this sequential narration in his series depicting a deer in the forest -- first drinking from a stream, then 
fallen, and finally being pulled to shore. It is also seen in the Gulf Stream and After the Hurricane where a lone black sallor at first withstands a violent storm and later is seen lying on the sand as if washed ashore.

${ }^{26}$ Eugene Exman, House of Harper (New York: Harper \& Row, 1967), p. 80 .

27 "The New York Graphic," unpaginated scrapbook of miscellaneous clippings about FHT, probably assembled by him, located at the Atwater Kent Museum, Philadelphia, Pennsylvania (hereafter cited as AKM).

${ }^{28}$ Christopher P. Wilson, "The Rhetoric of Consumption: Mass-Market Magazines and the Demise of the Gentle-Reader, 1880-1920," The culture of Consumption: Critical sssays in American History 1880-1980, Richard Wightman Fox and T. J. Jackson Lears, eds. (New York: Pantheon Books, 1983), pp. 39-64.

${ }^{29}$ Ibld., p. 24.

${ }^{30}$ Barth, clty people, p. 61 .

${ }^{31}$ These few powerful men who also controlled much of the nation's land were also causing writers like Henry George to warn of the "burden upon all subsidiary activities and processes if they were permitted free rein." Mumford, The Brown Decades, p. 21.

${ }^{32}$ Ibid., p. 43.

${ }^{33}$ Leo Marx, The Machine in the Garden: Technology and the Pastoral Ideal in Amertaa (New York: Oxford University Press, 1964).

34Phyllis Peet, "Americans At Leisure," The American Rersonality, p. 41.

${ }^{35}$ In her discussion of leisure peet also comments about illustrations of special events surrounding holidays that appeared increasingly after the $1860 \mathrm{~s}$ with drawings by Homer of Thanksgiving, Christmas, Valentines Day, and the Forth of July as well as Thomas Nast's creation of the American version of Santa Claus. These views not only provided a guide to accepted holiday behavior but were a boon to retallers and advertisers who capitalized on the increasing popularity of elaborate celebrations. Whether intended or 
not, the Special Artist set in motion the "culture of consumption." Ibid., pp. 42-43.

${ }^{36}$ Sam Bass Warner, Jr., The Private City: Philadelphia in Three Periods of Its Growth (Philadelphia: University of Pennsylvania Press, 1968), p. 162.

${ }^{37}$ For background on Philadelphia's elites see E. Digby Baltzell, Rhiladelphia Gentlemen: The Making of a National Upperalass (Glencoe, IL: The Free Press, 1958).

${ }^{38}$ Of course another way to look at this would be to see Taylor as the artist of the Robber Barons, being manipulated by them as he was himself manipulating the minds of others.

${ }^{39}$ These views were in line with the writings of Englishman William Morris who belleved in art for the people. His ideas along with those of John Ruskin were popular in America as well. For an excellent commentary on the influence of Morris and Ruskin on cultural development see Raymond Wilson's chapter "Art \& Society: A. W. Pugin, John Ruskin and William Morris" in Culture and Society 1780-1950 (New York: Columbia University Press, 1958), pp. 130-161. For additional information on the Ruskin tradition in America see Roger B. Stein, John Ruskin and Aesthetic Thought in America, 1840-1900 (Cambridge, MA: Harvard University Press, 1967).

${ }^{40}$ This is the philosophy Mumford attributes to the creative spirits of the Brown Decades such as John and washington Roebling and $H$. $H$. Richardson in their designs for the Brooklyn Bridge and rallroad stations. It is also the philosophy Russell Lynes describes when he says the late nineteenth century American artist "wanted by any means he could to warm the climate of the arts in a civilization that he looked on as primarily commercial and whose sights he belleved he could help ralse to higher things." Russell Lynes, The Art-Makers: An Informal History of Painting, Sculpture and Architecture in Nineteenth-Century America (1970; rpt. New York: Dover Publications, Inc., 1970), p. 3. Taylor was definitely a product of his time.

11Mumford, The Brown Decades, p. 97. 


\section{CHAPTER I}

"OUR SPECIAL ARTIST": FRANK HAMILTON TAYLOR

That man is the richest who, having perfected the functions of his own life to the utmost, has also the widest helpful influences both personal and by means of his possessions over the lives of others.

Ruskin

Frank Hamilton Taylor was a largely self-taught artist, fournalist, and publisher who embodied the American spirit of the nineteenth century in its fascination with industrial development, consumerism, and increased emphasis on leisure. ${ }^{2}$ Taylor recorded this dramatic story in lllustrated newspapers, travel guides, and books. His legacy of sketches and writings allows us to view the American scene as it shifted from agrarian to urban. His was not the romanticized view of the country offered up by the Hudson River School or Longfellow, but one closer to the realism of Homer and Twain. Like the boys of the Horatio Alger novels he worked hard and took advantage of opportunities presented to achieve a successful life of comfort and respect. But he also believed that his work should bring a better quality of life to others. That good design should be the right of everyone. Taylor's descent into obscurity following his death has been due in part to the fact that much of his original art 
work was dispersed when his drawings were sold at auction. Only now is it possible again to perceive the extent of his corps of works. In addition, his role as a documenter of American life is one often ignored by scholars who contend that Special Artists did not pursue a greater truth beyond the scene or event recorded. Yet Taylor's work does reflect cultural change.

Taylor was born in Rochester, New York on April 21, 1846, the first of eight children of Ezra and Harriet Hamilton Taylor. ${ }^{3}$ His parents had moved to central New York from New England and settled in an area that offered job opportunities and security. Ezra is listed in the 1850 census as a carpenter and folner. There were two children, Frank 4 and Louis 2 , and flve teenage relatives. 4 These additional family members may have been boarders to help with living expenses, or possibly Ezra and Harriet were assisting other family members by providing housing for their older chlldren. In 1860 Ezra was listed as a manufacturer, and there were five more Taylor children in the home, including two sets of twins, but no relatives. By 1870, after Frank's departure, the famiiy's fortunes were such that his mother had an Irish servant to help with the six remaining children.5 Frank Taylor's writing manual from Rochester High School, now in the collection of the Historical society of Pennsylvania, confirms his attendance at the city's public schools. In 1863, probably right after graduation, he enlisted in the Rochester Grays Battery Light Artillery. ${ }^{6}$ He 
was, however, eager to participate in the struggle of the Civil War. His unit was assigned to guard state property at Albany, New York during the New York City draft riots. Taylor served for two months, and in July of the following year he enlisted as a private in Company $E$ of the 54 th Regiment of the New York National Guards. His regiment was one of several called by the state governor to serve 100 days because of a rebel force that had invaded Maryland. The eleven companies of the 54 th served at Elmira, New York where Company $E$ was assigned to guard duty at the new prison camp. ${ }^{8}$ Sickness at the camp was rampant, in part due to the poor health of the 4,425 prisoners who had arrived by the end of July -- a number that soared to 9,619 one month later. The added burden of poor sanitary conditions caused over 3000 prisoners to perish, many from malaria. 9

Taylor himself became ill while stationed at Elmira, and was reported on sick leave at Rochester from September 18 until he mustered out on November 10.10 There was a hospital at Elmira, but as Clay Holmes notes in his treatise on the prison camp, "the enfeebled prisoners became sick so fast that adequate care could not be given. . . "11 Apparently Taylor's ailment was serious, as he was sent back to Rochester rather than receiving treatment in Elmira. Years later, when discussing his initial visit to the Thousand Islands of northern New York, Taylor commented that he was recovering from the effects of malaria and hay-fever. At this later time, he had just returned from an assignment that 
included travel in Cuba and Mexico where there were serious malaria epidemics, yet it is possible that his first exposure to the disease was at Elmira.

Taylor never forgot the Civil War. ${ }^{12}$ He was fond of telling war stories despite his brief four months of active service, and was a loyal member of Philadelphia Post $\$ 2$ of the Grand Army of the Republic. He enfoyed his preferred status as a veteran which expanded as he grew older and there were fewer and fewer Civil War soldiers remaining. In 1907, at the age of sixty-two Taylor applied for a military pension. Part of the application required a selfdescription. He noted that he was 5, 7-1/2" tall and fair complected, his normal weight was 140 pounds, with blue eyes and light brown hair. He further indicated that he had a mole over his left eye and that the index finger on his right hand was stiff.13 His pension was granted, with increases received as a result of the Acts of May 11, 1912, March 4, 1913 and June 10, 1918. His pension at the time of his death was $\$ 65$ per month.

Taylor stayed only briefly in Rochester after his discharge. Just two months prior the conclusion of the war he moved to Phlladelphia to begin an apprenticeship in a 11thography establishment. 14 He and the country would begin a new life together.

Philadelphia in 1865 was already a city established in the arts and sciences and no doubt Taylor anticipated finding work as well as artistic stimulation.15 After all, the city 
had fostered such important American artists as Robert Feke, Benjamin West, and the inimitable Peale family. More importantly for Taylor, Philadelphia was at the forefront of the publishing scene, particularly in the field of lithography. The first American lithograph was printed in Philadelphia in 1818 by Bass Otis, and although for a time Boston and New York overshadowed developments in the Quaker city, in the mid-nineteenth century Philadelphia had regained its position as a publishing stronghold.26 In a lecture to the Philobiblon Club in 1923, Taylor recalled that one of his Instructors at the old Academy of Fine Arts was Professor Schuessele, credited with producing the first color lithograph in the United States. ${ }^{17}$

Taylor's career decision was a sound one as the lithography business continued to be prosperous. In 1873, Taylor opened a printing and publishing business with Ferdinand Smith, an engraver, at 113 South Fourth Street.18 The venture was somewhat tenuous, "backed by more enthusiasm and hope than capital" he noted.19

Despite his exiguous beginnings, Taylor must have had confidence that his publishing career would prosper, because prior to entering his partnership with Smith, he entered another partnership with Margaret "Maggie" Gilkenson Johnston, whom he had met on his first day in Philadelphia. ${ }^{20}$ They were married by the Reverend J. W. Claxton at the Protestant Eplscopal Church of the Advent, $1303 \mathrm{~N}$. 6th Street, Philadelphia on October 19, 1870.21 The former Miss 
Johnston had recently graduated with a teaching certificate from the city's Girls Normal School. She received a laudatory letter of recommendation from the school which noted that she was "eminently qualified to make a successful teacher."22 During their early married years the couple lived with Margaret's mother and continued to do so even after the birth of their son Frank Walter on March 8, 1874.23 Walter, as he was known, would later recelve the formal art training his father never had, and achleve success as an illustrator in his own right.

Eighteen hundred seventy-four was also a significant one for the firm of Taylor \& Smith which participated in the Franklin Institute's two month exhibition. ${ }^{24}$ The Institute, a memorial to Benjamin Franklin and his love of science, occasionally held such exhibitions to showcase for the public the latest scientiflc discoveries and innovations. The 1874 Exhibition was remarkable as one reporter noted, for the "great preponderance of machinery in motion."25 This was a prelude to the celebration on a grand scale two years later at the Centennial Exposition, appropriately in the same city, and which would bring Taylor added fame.

The partners' exhibit included a number of presses as well as a complete workshop. Demonstrations were given of traditional lithography, and wood engraving printing methods, along with the new process of photolithography which their firm introduced to the city. ${ }^{26}$ Visitors could see the several stages if each printing method, from design to final printing 
from stone or block. Exhibitors were even provided the opportunity of having their machinery sketched, engraved, and printed "within the walls of the building." 27 While embracing the latest technical innovations, evidence of Taylor's iffelong appreciation of history is seen in his inclusion of the Ephrata press "which was old when the [American]

Revolution was a thing of the future. . . "28 Borrowed from the Historical Society, where it remains today, it was prominently displayed and operated by a veteran pressman who ran off "'lighting editions' at 250 an hour," in comparison to the 15,000 impressions made during the same time on the new "Universal" press. 29

Taylor noted that part of the demonstration of the new photolithographic process was the distribution each evening of miniature (7" $\times 5-1 / 2 "$ ) copies of the front page of the local papers. ${ }^{30}$ A correspondent for the Rress wrote that the print was smaller than any type available yet "perfectly distinct" so that the "whole page can easily be read, even down to the stock quotations."31 Another article called the demonstrations the "greatest 'hit' of the Exhibition."32 Chromolithographed trade cards which enumerate the various printing services offered by the firm were also printed and presented as souvenirs of the exhibition. Taylor and Smith were awarded a bronze medal for color printing. ${ }^{33}$

The exhibition was also the scene of one of Taylor's earliest hot air balloon ascensions, a sport for which he held a life-long interest. A later balloon journey under- 
taken while on assignment for the New York Dadly Graphic was to prove important in his recognition as one of the most prominent Special Artists of the times. Ballooning was quite popular in the mid-nineteenth century, and Taylor had no reservations about the ascent. It exemplifies his almost insatiable curiosity about the world around him and his desire to report on it for the benefit of his fellow citizens who might be denied such opportunities. His interest in this flight, as on subsequent ones, was to obtain sketches which could be used in articles, as well as to experience "the pleasure of a ride in a charlot, such as the monarches of the orient, in their wildest dreams or luxury, ne'er hit upon."34 Taylor's design and artistic abllities, particularly his skill in pen and ink drawing, led him next to a successful assoctation as a "Special" with the Daily Graphic, which billed itself as "The Only Illustrated Daily Newspaper in the World." The paper was established in 1872, and to reproduce its illustrations, ploneered the use of the photolithographic process whereby photographs made from pen drawings were transferred to stone. Besides a New York office the paper had a Philadelphia bureau headquartered in the New York Mutual Insurance Company Bullding. Taylor was art director and given charge of the 1llustration of news events from Philadelphia southward. Taylor noted that with the establishment of the paper he saw an opportunity to utilize his skill in pen drawing. ${ }^{35}$ Not only were such artists scarce, he sald, but because he always provided the 
accompanying text "which few illustrators attempted [he] had a busy time of it."36 It was his work for the Graphic that gained Taylor national exposure, first for his coverage of a Cleveland to Pennsylvania balloon flight, and later for his detafled coverage of the Centennial Exposition.

Following his work with the Daily Graphic, which failed financially around 1878, Taylor wrote and illustrated guidebooks and published articles in many of the Philadelphia papers, including the Times, Rress, and Public Ledger. In 1879 he was writing and illustrating for both Harper's Weekly and Harper's Monthly. He especially cherished his assignment in 1880 by Harper's Weekly to cover the southern sojourn of former President and Mrs. Ulysses S. Grant. ${ }^{37}$ He wrote in a portfolio of sketches and newspaper clippings that the trip "was like a stately picturesque dream." For rather than being an outside observer recording the journey, Taylor was included in the presidential party, even escorting the former president's niece on occasion.

In 1881 another Harper's Weekly assignment profoundly influenced his life when he traveled to Clayton, New York on the St. Lawrence to document the unique qualities that made the Thousand Islands appeal to so many summer vacationers. He fell in love with the area, and purchased a lot on Round Island. ${ }^{38}$ By 1882 his cottage, christened Shady Ledge, was completed along with an "ornate" boathouse with second floor studio, and the Taylor family began their yearly visits to 
the St. Lawrence archipelago arriving from Philadelphia in late June and returning to the city usually in mid-September. A copy of the dally summer paper on the st. Lawrence, which included a chronicle of the activities of the area's summer residents, noted in 1893 that Taylor had recently been put in charge of the illustrative feature of the Philadelphia Rublic ledger. ${ }^{39}$ Taylor had previously supplied the paper with, as he notes, "desultory articles, of an industrial sort, the result of much wandering. . ."40 Taylor's successful career continued, and that same year he wrote and 1llustrated the Estes' Standard Guide to the Thousand Islands.

Always the adventurer, a prerequisite for a Special Artist, Taylor explored the St. Lawrence area for scenic views and stories which would be of interest to publishers and readers alike on both sides of the border. In 1896 he painted two watercolors in Jones Falls, Ontario, on the Rideau Canal; one of the locks and the other of the Hotel Kenney.41 The choice of subject matter in these two pictures is a reflection of Taylor's appreciation of nature and history, and his seemingly lifelong comprehension of the fact that while industrialization provided wonderful new opportunities, its benefits should not come at the expense of heritage and the environment. Also, subjects like those at Jones Falls appealed to the urban reader who needed a respite from the congested city life, even if it could only be achleved vicariously. Here Taylor's delicate brushwork 
captures a serene setting filled with history and with appeal to both American and Canadian readers.

A note should be made here about Taylor's New York City connections between 1878 when his first article appears in Happer's Weekly, and 1893 when he was appointed art director for the Public Ledger. During this fifteen year period, Taylor was traveling almost continually in the employment of New York based companies, including Leve \& Alden, the American Bank Note Company, and the Giles Company all of whom published tourist guidebooks. He made at least three trips to the southern part of the United States, the Bahamas, and Cuba, at least two of which were for the Harper firm. He also traveled at least as far west as Colorado probably on an assignment to document the scenery, hotels, and attractions along the route of the Sante Fe Railroad.

Whether Taylor actually resided in New York during this period is uncertain. He stated on many occasions that he was an almost lifelong resident of Philadelphia, yet he is not listed in the city directories between 1885 and 1889 . Earlier, and possibly during these years he boarded in the home of his mother-in-law. This situation would have allowed him to travel without worrying about the care of his wife and son, both of whom he seems to have cared for deeply. In 1889 he is listed as residing in Philadelphia at 1526 Centennial Avenue, and in 1892 he moved to his last address, 4819 Springfleld Avenue. The records of the Philadelphia Sketch 
Club show him on the inactive rolls from 1879 to 1892 with a note that he was possibly in New York City.

Because Taylor was not a studio artist for any of the New York firms, perhaps he only needed to travel to New York at the completion of an assignment or to discuss new itinerarles, thus allowing him to reside in Philadelphia between travels and eliminating the need for a costly second residence. Certainly New York was an easy train ride from Philadelphia, and he could always be reached by telegraph if needed. What becomes increasingly clear, however, is that during this time he was away from home for extended periods, and his professional ties were primarily in New York City. The establishment of a New York base would seem logical as the city was becoming the headquarters for many of the best illustrators, and Taylor already enjoyed a national reputation via his Daily Graphic work. In addition he knew artists like A. B. Frost and W. A. Rogers who had worked in Philadelphia (and in Frost's case for the Daily Graphic), who had moved to New York and who could have introduced Taylor to the art network there. 12 Perhaps if he had not received the Rublic Ledger offer, Taylor might have eventually made New York City his permanent residence.

After 1893, when he took his staff position at the Rublic ledger, Taylor continued to work as writer, artist, and publisher; but his subject matter concentrated increasingly on Philadelphia and the Thousand Islands, and he was apparently less likely to accept lengthy travel assign- 
ments. By 1900, his success had allowed him to purchase a new home in the fashionable Victorian neighborhood west of the Schuylkill near the University of Pennsylvania. He was part of the migration away from the center of the city which occurred as the street cars and trolly lines made it possible for residents to live some distance from their place of work. ${ }^{43}$

In 1905 Taylor was commissioned by the Valley Forge Park Commission to write and illustrate the Commission's first publication "designed as a historical handbook and souvenir guide for the use of visitors who toured the park."44 The publication was popular enough to be reissued in 1911, 1916, 1920 and 1922. Two of Taylor's wash drawings appear in varlous issues, one showing the types of soldiers in General Howe's army in Philadelphia, and the other of the National Memorial Arch built to honor George Washington. The remalning 1llustrations were photographs which he noted in the preface were "mainly. . . by the author."45

In 1911 he was commissioned by the city of Philadelphia to write and illustrate his best known work, a book about the city's involvement in the Civil War. Rhiladelobia in the Civil War 1861-1865, published in 1913, remains a major research tool for historians because of its detailed record of participants and events. This was his last documented publication other than the varlous editions of the valley Forge book, a fitting way to bring to a close his publishing 
career. It was not an end to his sketching, however, which continued until his death.

Providentially, in 1920, one month before the death of his wife, Taylor was elected president of the Philadelphia Sketch club, a long-time dream, helping to relieve his grief. The organization played a pivotal role in his life because its members accepted him without the usual requirement of formal fine art training and because it gave his life a sense of continuity. ${ }^{46}$ Taylor had foined the Sketch Club in 1869, just four years after he moved to Philadelphia, and he remained an active member until his death. Founded in 1860, on the eve of the Civil War, by student artists discontented with the "antiquarian" practices of the Pennsylvania Academy of Eine Arts, the Club was, as Taylor noted, on the occasion of its 40th anniversary, "committed. . to men who love Art, not for profit, but because it is in them and they must."47 It was home to many prominent artists including Thomas Moran, Ridgeway Knight, A. B. Frost, Thomas Anshutz, F. Cresson Schell, and Joseph Pennell. Thomas Eakins, an honorary member, taught classes there and participated in some of the club activities.

Through Taylor's organization, the club published the Rortfolio, the first issue appearing in January of 1874 . It was called by one reporter "The most thoroughly artistic publication ever undertaken in Philadelphia. . . "48 Each issue contained photolithographed copies of drawings furnished by club members. The cover "which is embellished 
by a graceful design, bearing the title of the work" was drawn by Taylor, and his sketches are included in five of the twelve numbers 1ssued during its one year run. ${ }^{49}$ Each number contalned from four to six plates and sold for fifty cents a single issue or five dollars for a yearly subscription. The problem, as noted in the History of the Philadelphia Sketch club, was in "procuring from the members examples of their best work without prospect of remuneration."50 More than 2,100 copies were printed and the club received a small profit along with recognition from the press and others for their efforts.

Taylor became Club president at seventy-eight years old.51 With the death of his wife of nearly fifty years, and the marriage of their son walter a few years earlier, Taylor was "very much alone in the large house he maintained on Springfield Avenue."52 His presdential duties and the camaraderie the Club provided no doubt helped him through this period of bereavement. The Sketch Club history notes that he was present for all but one meeting. In 1921 he was succeeded as president by a man he had earlier befriended, and a close friend of his son, Joseph Pennell.

In 1921 Taylor again faced personal tragedy when walter was suddenly taken 111 on a July visit to Shady Ledge. He was rushed to the hospital in Ogdensburg but died, at age forty-seven, of ptomaine poisoning. Walter had become one of the nation's leading illustrators, and was particularly remembered for his illustrations published by Charles 
Scribner's Sons. He had just been appointed instructor of illustration at the Pennsylvania Academy of Fine Arts and was to begin teaching in the fall. He was an Academy graduate, and while a student there had been awarded a traveling scholarship in 1896 allowing him to visit the art centers of Europe and study independently in Paris. In 1898 he opened a studio in Philadelphia at 1912 Walnut Street. His work recelved excellent notice; it was distinguished by superb draftsmanship and "his drawings had a velvety richness that was the result of his mastery of the charcoal medium." 53 Walter's death devastated his father. Walter had been the first male infant born to a member of the sketch club who had married after admittance to the club. At the time the proud father was presented with an inscribed silver loving cup to mark the occasion, and Walter was henceforth known as the "Club Baby." Walter was again part of the Club festivities in 1895 when he performed for "the members and his beaming father. . a delightful dance done in full ballet costume" at the thirty-fifth anniversary celebration. 54 Upon Walter's death, the Club purchased one of his drawings from his widow for $\$ 100$. A memorial exhibition of his colored drawings was organized by the gallery of $M$. Knodler and Co. The majority of his works were sold at auction.

In a letter to his sketch club friend and fellow special Artist, F. Cresson Schell, Frank Taylor's reaction to his son's death and the support he knew he would derive from his association with his colleagues is painfully clear: 
August 5th, 1921

Dear Schell,

Please say to the kindly circle of our associates of the $P$. S. C. that I will in due time acknowledge their most comforting messages. I cannot as yet, go there to meet them. The good old club must be, hereafter, the refuge for my leisure hours. The good-will of the members will help me greatly through what may yet be left of life to me.

$$
\text { Sincerely, Frank H. Taylor } 55
$$

Taylor kept busy with his drawings of Philadelphia but completely alone, he relied on the club for stability in his 1ife. At seventy-five he traveled by trolly the four and one half miles from his west Philadelphia home to the club. On one such visit in October of 1921 he stepped in front of a parked car into the path of a delivery truck. He was taken first to the Club where the secretary insisted he be examined at nearby Jefferson Hospital. He was then transported back to his Springfield Avenue home where he wrote a few days later that the injuries were "confined to the muscles and nerves, bones all to the good."56 Perhaps his many years of spirited travel left him a resilient individual.

Taylor recovered from this misfortune and was able to give a lecture "with slides" to the Philobiblon club on November 30,1923 , on the development of the art of lithography titled "Lithography - Photo Lithography and Photo Engraving."57 Here he fondly recalled his early years in the city after his migration from New York, and the establishment 
of his business with "Ferd" Smith. The business he noted was continued by Smith's sons and remained the only firm in the city still engraving on wood.

The following year the Sketch Club presented Taylor with a framed testimonial which included a sketch of the Clubhouse by Edward H. Suydam, and hand lettered text which read: "1869-1924 To Frank H. Taylor on the 55th anniversary of his membership in the Philadelphia sketch club the Members present this testimonial of their respect and esteem, October 1924." And one year later at a dinner in his honor he was presented with a billiard cue, blllards being one of his favorite pastimes.

His health, however, steadily declined. By February of 1926 he was confined to his home, although still seemingly in good spirits and busy painting. He wrote to the club on the 27 th "I keep occupied with my usual work, when hand and head are busy there is no time for worry and in my case there is no real reason for it. . ." 58

In March 9, 1927 Taylor was declared "an alleged weakminded person" in the Court of Common Pleas of Philadelphia and placed under the guardianship of the Commonwealth Title Insurance and Trust Company. He was placed in Burn Brae Sanitarium, Delaware County, Pennsylvania and died there of "acute bronchitis" on May 25, 1927.59 Taylor was interred at Laurel Hill Cemetery in Philadelphia where he was buried with his wife and son along with his wife's sister, Christiana S. 
Johnston, who died in 1921, one year after Margaret Johnston Taylor, and the same year as walter.

His will was probated on June 2, 1927. He bequeathed his home on Springfield Ave. to Mrs. Mina Harvey and her daughter Miss Mary Martha Harvey. 60 The remainder of his estate including "Shady Ledge" was left to his surviving brothers Clifford B. and Berton E. Taylor and his sister Jennie A. Taylor. His series of old Philadelphia drawings, prints, and negatives were to be sold at auction unless purchased by the Historical Society of Pennsylvania. The proceeds of the sale were to be given to Mrs. Harvey and her daughter. The Society chose not to purchase the drawings. In recent years, many have since returned to the Historical Society as gifts and bequeths. The Atwater Kent Museum, which specializes in Philadelphiana, and the Philadelphia Maritime museum have also received some of Taylor's Philadelphia drawings. In addition, a group of twenty-one washes and watercolors are owned by the old Philadelphia law firm of Duane, Morris and Heckscher, purchased by one of the founding family members who wanted to recall the city as it was when the firm began.

Taylor was remembered by his Sketch Club comrades as an "artist, historlan, and phllosopher, who had sampled many varled and venturesome experiences,... [who] looked upon unfolding life with the heart of a youngster."61 His death brought to a close the era of the special Artist reporter as advances in photography and printing allowed the camera to 
capture the fast action scenes once only the purview of the Speclal. His love of the watercolor medium, dedication to accuracy in capturing a story, and interest not only in new ideas but appreciation of the foundations they were based on, would now have to be carried on by other artists and journalists. 


\section{CHAPTER NOTES}

${ }^{1}$ Quoted by Frank H. Taylor (hereafter cited as FHT) during speech to the Philadelphia Sketch Club, (hereafter cited as PSC) October, 1907, at a ceremony to honor C. Few "Fewey" Seiss who served as Club secretary for over twentytwo years. Sidney C. Lomas, History of the Philadelphia Sketch Club, (Philadelphia: Philadelphia Sketch Club, 1935), p. 469. Taylor too believed that he should help others, and saw his role as Special Artist one in which he could impart information about the country to his fellow citizens.

2In a speech to art students, possibly at the Philadelphia Academy of Fine Arts, Taylor stated that he was occasionally a student at the Academy when it occupied the building on Chestnut Street, although he is not listed in the Academy student records. This statement would indicate he did have limited academic training. In addition, Taylor's association through the Philadelphia Sketch Club, with other prominent artists and illustrators including Thomas Anshutz, Thomas Eakins, A. B. Frost and W. A. Rogers, no doubt provided additional training albeit on an informal level. Meetings at the Sketch Club included weekly sketching exercises which were critiqued by other members. Records indicate that Taylor attended many of these sessions and would be expected to participate thereby gaining critical analysis from some of the country's most prominent artists. FHT, Manuscript Collection 84:32, Historical Society of Pennsylvania, (hereafter cited as HSP) Box 2, Folder 3 and PSC, Philadelphia Collecting Project, Archives of American Art, Smithsonian Institution, Microfilm Rolls 3664, 3665, $3666,3919,3920$.

3The 1860 New York Census shows two six year olds, a girl Jannet and a boy James. The 1870 and 1880 New York Census records show only a girl, Jennie of the corresponding age. Either James died in which case there were nine children, or the census taker mistook the one child, Jennie for two children.

${ }^{\circledR} 1850$ New York Census records.

51860 and 1870 New York Census records. Harriet would bear one more child, Hattie, who is listed in the 1880 census as a daughter, age two. 
6Affidavit by Taylor dated May 24, 1916 as part of an application for pension. Pension application files, Military Service Branch, (NNMS) National Archives and Records Administration, Washington, DC.

'Frederick Phisterer, New Yock in the War of the Rebellion 1860-1865, 3rd ed., (Albany: J. B. Lion Company, 1912), p. 49. The reglment was commanded by Col. Charles $N$. Clark. Company $E$ later became the eighth separate company of the National Guard of the state.

BCorrespondence to the author from Timothy Decker, Curator of Collections, Chemung County Historical Soclety, Elmira, NY, dated May 1, 1990.

9Thomas E. Byrne, "Elmira's Civil War Prison Camp: 1864-65," The Chemung Historical Journal, V. 10, No. 1, September, 1964, pp. 1282, 1286. For additional information about the camp also see Clay $W$. Holmes, The Elmira Prison Camp: A History, (New York, 1921).

10Company Muster Roll for FHT, NNMS, National Archives.

"Holmes, The Elmira Prison Camp, p. 43.

12 For an analysis of how the war influenced American thought see George M. Fredrickson, The Inner Clyil War: Northern Intellectuals and the crisis of the Union (New York: Harper \& Row, 1965).

${ }^{13}$ This curious bit of information leads one to question if the artist was forced to use his left hand, or did he use his right hand and accommodate this physical inconvenience. Being left-handed would have proved difficult, however, not inconceivable, in the nineteenth century as the use of the right hand was generally preferred. It is question that may remain forever unanswered.

14 In lecture notes from a speech he gave on February 10, 1915 Taylor mentions, for the only time, being in Boston prior to his arrival in Philadelphia. He equates this with Benjamin Franklin's similar circumstances, but says "Any further resemblance to the great Philosopher is doubtful." There was no indication as to how long he was in the city or for what reason, but it was probably briefly and in connection with his subsequent apprenticeship in Philadelphia. FHT, Manuscript files, HSP, Box 2, Folder 3. Pension form No. 
3-447, NNMS, National Archives and FHT, Autograph Collection, HSP, 1923.

15 It is interesting to note here that his later pension application files state that his profession at the time of enlistment was artist. The career decision was apparently an early one although there exist no extant works from this perlod of his life. Pension form $N$. 3-447 completed by Taylor on May 15, 1908, NNMS, National Archives.

${ }^{16}$ For additional information on the development of lithography in Philadelphia see, Nicholas Wainwright, Rhiladelphla in the Romantic Age of Lithography, (Ph1ladelphia: H1storlcal Soclety of Pennsylvania, 1982.)

${ }^{17}$ FHT, Autograph Collection, HSP.

${ }^{18}$ The building is no longer extant, and the property is part of the Independence National Historical Park.

${ }^{19} \mathrm{FHT}$, Autograph Collection, HSP.

20FHT, Manuscript Collection, HSP, Box 2, Folder 3.

${ }^{21}$ Pension form N. 3-389 completed by Taylor on April 3, 1915, NNMS, National Archives.

${ }^{22}$ Letter from the Girls Normal School dated January 8, 1869. Miss Taylor fit the profile of the typical teacher noted by Dorothy $G$. Beers in her article "The Centennial City, 1865-1876" as being a white female under the age of twenty-five who continued to live with her parents while employed. Beers also notes that the annual salary was less than $\$ 450$ which was lower than that of other large cities. Russell F. Weigley, ed., Rhiladelphia: A 300-Year Histery, (New York: W. W. Norton, 1982), p. 447.

${ }^{23} 1880$ Pennsylvania Census records.

${ }^{24}$ The exhibition was seen as a prelude to the upcoming Centennial. It proved so popular -- 267,638 paying visitors or approximately one-third of the city's population -- that its initial one month run was extended because the judges were unable to perform their duties, due to the large crowds. Report of the Twenty-Seventh Exhibition of American Manufacturers, Held in the city of Philladelphia From October 6 to November 12,1874 by the Eranklin Inst itute (Philadelphia: Franklin Institute, 1874), pp. 3, 225, 229. 
25 "Novelties of the Exhibition," AKM scrapbook.

${ }^{26}$ Taylor said he and his partner had learned about the new photo-lithographic process and together with a young chemist, Anson D. Partridge, solved the problem and began to use this process in their business. FHT, Autograph Collection, HSP.

27mThe Franklin Institute Exhibition," AKM scrapbook.

${ }^{20}$ Ibid., "A Feature."

${ }^{29}$ Ibld., "Journalism."

${ }^{30}$ FHT, Autograph Collection, HSP.

31 "Journalism," AKM scrapbook.

32Ibid., "The Franklin Institute."

${ }^{33}$ Franklin Institute Exhibition Report, p. 199.

34Ibid., FHT, "The Air-Ship Franklin."

${ }^{35} \mathrm{His}$ proficiency at pen and ink drawing he sald was due in part to his creation of emblematic borders for writing masters who created resolutions for various Philadelphia organizations. FHT, Manuscript flles, HSP, Box 2, Folder 3.

${ }^{36}$ Lecture to the Plastic Club, p. 5., FHT Manuscript files, HSP, Box 1, Folder 4.

${ }^{37}$ Nancy I. Gustke, "A Stately Picturesque Dream,_." Scenes of Florida, Cuba, and Mexico in 1880, (Gainesville: University Presses of Florida, 1982).

${ }^{38}$ This was a misnomer as the island is actually oblong, being approximately one mile in length and a quarter mile in width. 1893.

39 "Home News, "On The St__Lawrence, Vol $x$, No. 52, 7 July,

${ }^{40} \mathrm{FHT}$, Autograph Collection, HSP.

${ }^{11}$ They were probably for a story about the famous waterway although to date, no such corresponding article has 
surfaced. The view of the hotel may have been painted as a gift to the hotel owners as it has remained in the family. The other watercolor which shows the locks which the hotel faces, was not part of the Kenney family estate, but later purchased by Mr. Mrs. Joseph Kenney the current owners, and both are now displayed in the historic structure. The hotel was founded in 1877 by Thomas and Eleanor Kenney and became immediately popular with fishermen and pleasure boaters. Two years after Taylor painted it, it was written up in a guidebook, Ricturesque Rideau Route, noting "It [the hotel] is a favorite resort for yacht owners and men of seminautical appearance lounge around and exchange fish stories." IBegun in 1827 the Rideau Canal linking Kingston to Ottawa was originally conceived in 1815 after the War of 1812 and the Napoleonic wars left Britain still in control of Upper Canada. In encouraging settlement and reflecting concern with another attempted invasion by the United States, an internal navigation system was bullt which would provide a secure route for troops and supplies eliminating sole reliance on the St. Lawrence with its possibly hostile borders. The projected disturbances never materialized, however, and by the turn of the century the waterway played host to luxury steamboats escorting tourists through the picturesque locks. Hotels such as the Kenney welcomed visitors from both sides of the river as evidenced by their flying both the Stars and Strips and the Union Jack as Taylor carefully recorded. Here tourists could enjoy the outdoors and find rellef from the congestion of city life. IThe steamer Taylor shows ready to descend the locks at Jones Falls is the James Swift built at Kingston in 1893 and licensed to carry one hundred passengers. It was one of five single-purpose passenger steamers that plied the waterway after 1885 offering luxury accommodations. It was damaged by fire in 1899 and subsequently completely refitted and renamed the Rideau King which allowed the Rideau Lakes Navigation Company to continue its popular and profitable service between Kingston and Ottawa and Montreal. Taylor would make many sketches of these steamers and the locks along the canal for articles and area guidebooks.

12The June 22, 1874 issue of the Daily Graphic, p. 857, contains a composite of seven illustrations under the title, "The Regatta of the Schuylkill Navy at Philadelphia, on Wednesday and Thursday Last" including signed sketches by Taylor and Frost. The Philadelphia Maritime Museum, 85.67.1. It is possible that as head of the Graphic's art department Frost worked for Taylor and may have been hired by him. 
${ }^{13}$ For an analysis of the evolution of the street car system on urban America, see Sam Bass Warner, Jr., Street Car Suburbs: The Process of Growth in Boston, 1870-1900, (New York: Atheneum, 1974), and Kenneth T. Jackson, crabarass Erontier: The Suburbanization of the United States (New York: Oxford University Press, 1985), pp. 103-115.

14Harlan D. Unrau, Administratlve History, Valley Forge National Historical Park, (Washington, DC: U.S. Department of the Interior, 1984), p. 109.

45FHT, Valley Eorge: A chronicle of American Heroism, (Philadelphia, James w. Nagle, 1911), p. 5. The 1905 and 1911 editions were both published by Nagle a Philadelphia publisher with whom taylor frequently collaborated. The 1916 edition was published by J. W. Lippincott, and Taylor had other associations with this large publishing house. All three editions were copyrighted by Taylor. The last edition was published by Daniel J. Voorhees who was the proprietor of the Washington Inn at Valley Forge and copyrighted by Voorhees. Taylor also did the map for the Philadelphia \& Western Railway Co. advertisement which appeared in the 1911 edition.

${ }^{46} \mathrm{Clubs}$ were important in Philadelphia and were formed for fust about every group. As Nathanlal Burt and wallace $E$. Davis note in their essay on the city's "Iron Age 1876-1905" in Welgley's Philadelohia, p. 520, "Philadelphians liked to express themselves not as individuals but in groups." They also note that the propensity to establish clubs was a reflection of the city's "conformist atmosphere."

17Lomas, History of the Philadelphia Sketch club, p. 367.

48nThe Fine Arts, The Philadelphia Sketch Club Rortftile," AKM scrapbook.

${ }^{49}$ Ibid.

${ }^{50}$ Lomas, History of the Philadelohia Sketch Club, p. 69.

${ }^{51}$ Secretary's notes December 4, 1925. At a mid-day dinner in his honor. Taylor notes that during his early days as a member when he served as the Treasurer, there were one or two occasions when there was no quorum and he was able to elect himself President Pro-Tem. PSC, Archives of American Art, Smithsonian Institution, Roll 3665. 
52Lomas, History of the Philadelphia Sketch Club, p. 672

${ }^{53}$ Dumas Malone, ed., Dictionary of American Biography, V. 18 (New York: Charles Scribner's Sons, 1936), p. 322. Walter was described by his friend Joseph Penell as "'the last of the American 1llustrators." " He had been an instructor for lllustration at the Art Students' League in New York and the School of Design for Women, Philadelphia. In 1915 he was awarded a gold medal of honor for illustration at the Panama-Pacific Exposition. His oil and charcoal portraits included in addition to Pennell, the painter John McLure Hamilton, sculptor R. Tait McKenzie and actors George Arliss and otis Skiner.

54Lomas, History of the Philadelohia sketch club, p. 316.

55Ibid., p. 709.

${ }^{56}$ Ibid., p. 710.

57FHT, Autograph Collection, HSP. Taylor had made glass slides of his many drawings of Philadelphia landmarks, many of which are in the collection of the HSP and the AKM.

${ }^{58}$ Lomas, History of the Philadelphia Sketch club, p. 824.

${ }^{59}$ Burn Brae was established in 1859 by Dr. R. A. Given. It was a private hospital near the village of Clinton for patients with nervous and mental diseases. It had room for forty patients, twenty of each sex, and sat on twenty-five acres. Henry Graham Ashmead, Histery of Delaware County, Upper Darby Township, (Philadelphia, L. H. Everts \& Co., $1884)$, p. 538 .

${ }^{60}$ These women are not relatives. Possibly Mrs. Harvey was Taylor's housekeeper.

${ }^{61}$ Lomas, History of the Philadelohla Sketch Club, p. 710. 
TAYLOR AND THE ILLUSTRATED NEWSPAPER:

THE CREATION OF THE SPECIAL ARTIST

so far as a man looks the truth in the face and uses his art to make that truth clear is his work worth considering.

The Craftsman 1

The addition of illustrations to newspapers in the midnineteenth century created the need for Special Artists. The popularity of the new format was overwhelming, and editors were pressed to search out artists who would be willing to travel, often at a moment's notice, to the scene of a fire, war, shipwreck, parade or gala event. Whether these developments were natural or man-made was of no concern as long as their press coverage sold papers. The artists were really plctorial journalists. Their objective was to record accurately, or "truthfully" what they saw -- occasionally, as in Frank Taylor's case, with text as well as illustrations. Taylor's considerable ability at both meant he was in great demand; it also accounted for his increased earnings. 2 Taylor also felt his writing abilities developed his powers of observation. He said, "It helps the picture maker to put his impressions also into words. It serves to fix the memory of 
things seen and experienced." 3 The intent was to place the viewer at the event as it happened.

By necessity Special Artists were generally denied the luxury of time to study the subject matter or incident at hand, in part because events were often instantaneous, and also because newspapers wanted the images as soon as possible. This frequently required risking life and limb to get a story.

An example of Taylor in action, displaying his ability to be continuously on call and willing to put himself at risk, was described by an unidentifled reporter for the Miners' Journal in a story filed on February 1, 1878.4 He wrote that a number of the press had gathered that day in Philadelphia, despite a severe storm, to record the activ1ties of the State Fencibles, a highly skilled military drill unit. Just after the performance commenced, news of a fire sent the reporters off to cover that story. However, the report of another, even worse disaster, the wreck of the steamer Metropolis off the North Carolina coast, sent the reporters immediately in search of information about passengers and cargo.5 Meanwhile, the reporter noted, "Mr. Frank H. Taylor, the New York Graphte artist, was prowling - about that less favored portion of the city, willow Street wharf, and through great danger gained in that locality a true description of the vessel."6 The reporter also noted that Taylor had then left early that morning for 
the scene of the wreck, "and from his facile pen and pencil we shall soon have an 1llustrated account of the sad affair."7

Taylor wasted no time in obtaining what information he could in Philadelphia and then immediately traveled to the disaster site, where elghty-five lives were lost. Timely coverage of such disasters could prove difficult as Taylor had noted a year earlier when he filed reports from kitty Hawk, North Carolina, on the wreck of the Huron in which one hundred lives were lost. ${ }^{8}$ In the text, which was accompanied by "a vivid picture of the storm beaten shore," Taylor noted the difficulty in relaying information back to Philadelphia because the great distance between the wreck and where the bodies were found required constant retracing of the area. In addition, the only transmission wire available belonged to the government, and was usually tied up with official business.9 To a good Special who knew the value of "live" coverage, any delay in transmitting visual and written news back to the paper was troublesome and could mean a loss of readership and income.

The human suffering and loss created by these shipwrecks prompted Taylor to file a report from Norfolk, Virginia for the Philadelphia Rress following the Metropelis disaster, on the fallings of Congress to support safety standards for the dangerous mid-Atlantic coast. ${ }^{10}$ Artists had long been aware of the persuasive power of their lllustrations to reinforce a particular point of view or to apply political pressure. Frank Leslie's crusade against "swill milk" and Thomas Nast's 
exposure of Tammany Hall corruption are two examples of reform crusades in which the newspapers, and particularly their illustrations, were catalysts for action.11

Dramatic events and persuasive visuals were the stock in trade of illustrated newspapers. Polltically charged pictorial representation of news was not a new ldea; but advances in printing technology, however, now facilitated it on a grand scale. Prior to the nineteenth century, illustrated journalism had been limited to broadsides and newsbooks. These early publications were often the work of popular craftsmen, and utilized a single illustration to dramatize a point, or depict an event, or both. Professional artists were rare.12 More often the creators of these works were limners whose main occupation was sign painting, or artisans for whom illustration was ancillary. The works were occasionally accompanied by descriptive text, but because a large portion of the population was 1lliterate, the message had to be clearly evident from the drawing alone. Even in the nineteenth century many Americans could barely read, and it was the illustrations that sold the papers. A picture was, therefore, literally worth a thousand words.13 An excellent example of eighteenth century illustrated journalism is Paul Revere's famous broadside, "The Boston Massacre," printed in 1770. Though not an artist, Revere was a skilled craftsman, and familiar with the engraving process. Politically astute, he knew the value of quickly reporting the altercation to the general populace. While Revere used 
some "journalistic license" in depicting the events of March 5, his graphic representation of the unarmed colonists being maimed and murdered by British gunfire was so popular that furors in the trial of Captain Preston, who had been Captain of the Day, were told to disregard the "'prints exhibited in our houses.'14

Revere again used visual images to lllustrate the "massacre" when he included five coffins to accompany the story of the death of Patric Carr in the March 19 issue of the Boston Globe. ${ }^{15}$ Each coffin contained the initials of one of the five colonists who was killed, along with a sinister skull which had no lower Jaw, leaving the upper teeth hanging, and crossed bones beneath. In a newspaper devoid of illustrations, the dramatic coffins and article banded in black served to draw the reader's attention and spark the curiosity of the non-reader who could easily glean the intended message. Primarily a means to inflame activism against the British, both the broadside and illustrated Globe article were also good business. The broadside, which sold for elght pence, spawned numerous imitations by artists who no doubt wanted to take economic advantage of the emotional intensity generated by the event. ${ }^{16}$

Revere's broadside was a copperplate engraving, and the coffins of the Boston Globe were woodcuts. Both methods of producing multiple printed images had existed for centuries, but had inherent limitations which prevented their use in the high volume newspapers of the nineteenth century.17 The 
reintroduction of the wood engraving technique allowed the London Illustrated News to first capitalize on pictorial journalism in 1842. The successful formula was copied in Europe in papers like LiJllustration in Paris (1843) and La Illustracion in Madrid (1848), and in America with Erank Leslie's Illustrated Newspaper (1855) and, possibly the most famous, Harper's Weekly (1857).18

The copperplate engraving process used by Revere and artists like Theodore de Bry who engraved John White's illustrations of Virginia for his book A Briefe and True Beport of the New Found Land of Viralola, is intaglio printing. The design is incised into the metal, the ink is forced down into the cut-out surfaces, the plate is then wiped clean, and the recessed ink transferred by pressing the paper into the incised lines. The range of values and width and depth of lines allows for a great degree of artistic expression. However, the copperplate could not be run simultaneously on the same press with the wood type used in newspapers and books into the twentieth century. For a copperplate engraving to accompany a newspaper article on the same page would require two separate printing operations or press runs. This might be cost-effectlve for a book, but not economical when thousands of heavily illustrated copies of newsprint were issued each week. In addition, the image became weaker as increased numbers were pulled.

The woodcut represented another long-established means of obtaining an image in print. ${ }^{19}$ This method was compatible 
with wood type because unlike engraving on metal, the image to be reproduced was left in relief, the remainder, or all the white parts, were cut away. ${ }^{20}$ woodcuts are made along the grain of the wood, on the plank; and can be as large as the plank. The softness of the wood allows for ease in cutting, and the artist uses knives, gouges and chisels to create what is usually a bold, straightforward design. The woodcut though was too soft to withstand the enormous numbers of impressions, upwards of 100,000 copies, required for the nineteenth century newspapers. ${ }^{21}$

The answer for the illustrated press was wood engraving. Like the woodcut it is a relief method of printing, but the end grain of a very hard wood, preferably boxwood, is used and the artist uses different tools: a graver, scraper and tint tool. These instruments produce precise, delicate marks that allowed artists like the pioneer Thomas Bewick to create subtle tones by the buildup of many thin lines.22 The wood engraving process allows for a lively, more spontaneous line in comparison to the more controlled lines of the woodcut.

Boxwood, however, as well as pear, the cheaper substitute, were only available in small sizes. Of necessity for newspaper illustration, blocks were uniformly cut, usually 3-1/2" $\times 2 "$, and 1" thick, or 72 points high, to conform to the height of the type. This required that the blocks be bolted together to accommodate larger images. A $16^{\prime \prime} \times 22^{\prime \prime}$ double page spread in Harper's Weekly, such as 
Taylor's Erom Vera cruz to Mexice of April 3, 1880, would require the assembly of thirty-six blocks. ${ }^{23}$

The Special Artist did not generally draw his sketch on the blocks when reporting from the field.24 Rather, sketches from the Special Artist were posted back to papers like Harper's Weekly, where they were redrawn on the block (s) by staff artists and then engraved by another group of artisans. On many occasions the special had only time to make an outline of the scene and then used notes to advise the staff artist what additional elements were needed to complete the scene. ${ }^{25}$

An example can be seen by comparing Taylor's sketch General Grant and Party are Shown Some Elortda Products and the corresponding engraving the Vistt to Crange Park-Display of Fruits and Vegetables from the February 21,1880 issue of Harper's Weekly. ${ }^{26}$ (Figs. 4 5) Differences between the two works are immediately obvious, and a cursory glance at Taylor's sketch might elicit the opinion that it was poorly executed. This was not the case, however. Taylor's primary objective was to record the facts, the critical elements of the scene, not necessarily to produce a finished drawing. Here he depicted the arrangement of the tables and the basic placement of the Florida produce which was on display for the former president. He carefully notes the location of the three major participants, President and Mrs. Grant, and the host, Mr. Benedict, so there was no confusion on the part of the staff artist. Taylor merely outlined the crowd of people 
in the background as it would be unnecessary to include detalls, which could easily be furnished in the redrawing. Other critical elements were included such as the large tree, heavily draped in Spanish Moss, which framed the scene and supported the observation platform. Taylor wrote on the front of the sketch "see note on back." There he provided the staff artist additional information to assist in the final drawing on the blocks. Taylor noted that "two tables were arranged at right angles under a group of trees. . . ." He identified the various types of vegetables and fruits on display, and that "bouquets of flowers were interspersed." He also included a small pencil portralt of $\mathrm{Mr}$. Benedict and enclosed a photograph of the scene. ${ }^{27}$

When Taylor's sketch arrived at Harper's art department, the head of the department, Charles Parsons, determined the size it would appear in the paper (in this case 5-1/2" $\times$ 7", whereas the sketch was 7" $\times$ 9-3/4"), and assembled the appropriate number of blocks. Then one or more staff artists or draftsmen would draw on the blocks, using the sketch, as well as Taylor's additional instructions and supplemental material as a guide. Editorial decisions might determine the rearranging of certain elements for emphasis or the elimination of portions deemed objectionable; however, the intent was that it was "all. . . done without doing any violence to the general truth of the representation, and with due consideration for the particular conditions of the moment, 
such as the amount of finish and distribution of light and shade suitable for rapid engraving and printing." 28

The staff artist had to reduce or enlarge the sketch and draw it on the blocks in reverse in order to duplicate the original drawing when printed.29 Once the general outline was completed, the blocks were disassembled and individual artists would fill in the details, being careful with margins and merging tones. In many cases these men were specialists In rendering spectfic elements such as people or landscapes, and would be provided only the blocks containing theif expertise. ${ }^{30}$ w. A. Rogers, a Special Artist for Harper's Weekly and friend of Taylor's, notes that each man had to hold in his mind the tone that would pervade the entire composition, or the completed picture would not hold together when the blocks were reassembled. ${ }^{31}$ Taylor's sketch of the Carnival parade in Havana was probably handled in this manner which would account for the fact that it is cut approximately in half, separating the upper portion containing the architectural and landscape elements from the lower half containing the figures. This would be particularly necessary if the decision to use this sketch for the cover was a last minute occurrence, requiring tt to be quickly redrawn and engraved on the blocks. 32

In certain instances one artist might execute the entire sketch on the block and be allowed to sign his name as artist. An example is the engraving, A Erench canadian Village on the st. Lawrence, after Taylor's sketch, for his 
article "A Canadian Pligrimage," which he wrote and illustrated in 1882 for Harper's New Montily Magazine. ${ }^{33}$ in the lower left hand corner is the signature C. Graham, Indlcating Graham was the only artist to work on the block. 34 Charles S. Graham, the highest pald staff artist at Harper's at the time, translated many of Taylor's field sketches onto the blocks. Graham was a specialist in landscapes, and Rogers belleved he had the "finest sense of perspective of any artist . . [he] ever knew. ${ }^{35}$ That Parsons continually chose some of his best artists to execute Taylor's work reflects his high regard for this talented Special Artist. ${ }^{36}$

The French Canadian engraving also carries another signature, that of $C$. Mayer, in the lower right hand corner, followed by the initials sc for sculptor. This is the signature of the engraver and meant, like the artist, that he was responsible for executing the entire block. ${ }^{37}$ For once the drawing was completed, the blocks were then sent to the engraver(s). Due to the ever-present time constraints of publication, it was not often that one engraver had the opportunity to carve the entire block, thus earning the right to place his signature on the finished design. More often, as in the case of the detail work of the drawing, the blocks were divided among those engravers whose speciality the blocks contained. If time allowed, prior to distribution a master engraver would take the pre-assembled blocks and cut across all the folns, giving the individual engravers a guide 
to follow as to the general direction and character of the lines.

The process of engraving the blocks was a laborious one, involving cutting away those portions of the block which would not carry ink, and effectively translating the various lines and shadings of the sketch. ${ }^{38}$ An engraver like Mayer sat at a high table, preferably in front of a north facing window to obtain the greatest amount of indirect light. The block was either set on a sandbag or secured to the table in some fashion. A large magnifying glass, a necessity for such intense and delicate work, would be attached to a swing arm in order to adjust to any angle. In the evening a fish bowl filled with water would be placed in front of an oil lamp to create a temporary lens to focus light directly on the block. The engraver had to be constantly concerned about the block warping thereby becoming it unusable. His hands would be warm and moist, and too much contact with the block could prove disastrous. Even his breath could be a potential problem, so a paper screen called a mentonniere was sometimes worn over the nose and mouth. As an additional precaution, the block was always placed flat on its face when it was not being worked. It would take from ten to twelve hours to complete a 4" $\times 5 "$ block. The artists and engravers for Leslie's and Harper's Weekly were often required to work long hours when a major news story needed coverage. During the Civil War they would sometimes work thirty-six hours straight to complete the 1llustrations for the next issue. ${ }^{39}$ 
Once the individual blocks were completed, they were reassembled and bolted back together. The engraver, or the master engraver in cases where the blocks were completed by different artisans, would then carefully examine the junctions to assure the images were visually integrated and properly aligned. ${ }^{0}$ In those cases where the blocks had been subdivided, the master engraver might also be required to touch up the blocks to achleve as uniform appearance as possible. Any significant alterations or mistakes in engraving could be corrected by inserting a plug into the block. A tapered hole was bored in the block around the area in question, and a resin-coated plug of the same shape and wood composition was inserted in the hole and gently hammered in for a tight fit. ${ }^{11}$

Once all the blocks were engraved, reassembled, and bolted together, they were ready for the final step of electroplating, which prevented any warping during the large press runs. This was a method of coating a wax mold of the engraving with copper by electrolysis. The thin copper shell was then removed from the mold, backed with metal, and finally mounted on wood ready for printing. 12

The printing process, from the Special Artist's field sketch to final engraving, was thus an involved one which required the contributions of at least one other artist and the engraver, but more often was the result of many skilled hands. Artists who did not understand this process were often critical of the results of the final engraving, and in 
the hands of the unskilled, this was sometimes a problem. However, when the Special utilized the linear qualities of the engraving process, i.e., strong outlines, simplified form, and sharply defined areas of light and shadow, while using tone -- reproduced by the engraver by minute parallel IInes -- to enrich his 1llustration, the beauty of the final engraving could be maximized.

Probably no one understood this concept better than Winslow Homer, perhaps the most famous of Harper's artists. He recognized that engraving was basically a line medium, and used that knowledge gained during his early apprenticeship at Bufford's lithographlc firm to create some of the finest engravings found in Illustrated newspapers.43 Unlike Taylor, however, Homer spent little time as a Special in the field, and was more often in a position to draw directly on the blocks, so designated by his signature or initials. This allowed him greater control of the final outcome, because even though he was not responsible for the engraving, the need for an intermediary to redraw the sketch on the block was eliminated. Taylor was fortunate in that, during his tenure at Harper's, some of the most talented artists like Graham and Thure de Thulstrup, were assigned to redraw his work. Because Taylor, like Homer, began his training in a lithography studio, and in addition had experience with his own printing business, he too was aware of the visual elements necessary for an effective engraving. Taylor's architectural sketches, such as those he did in Mexico City 
during the Grant trip, are excellent examples of his incorporation of these ideas of line and shadow, which would enhance the final engraving.

The first true illustrated newspapers were, as mentioned above, European and designed to serve an ever expanding, literate middle class. It was not long, however, before readers in the United States were ready to support such an enterprise, and the entrepreneur who recognized this was Frank Leslie. Leslie was an Englishman who Immigrated to America in 1848 after rising to chlef of the engraving room of the London Illustrated News. He knew first-hand the operations of an lllustrated weekly paper, and after beginning with a partnership venture, he launched Erank Leslie's Illustrated Newspaper in 1855. Leslie's 1llustrations revolutionized American magazine publishing because they pictured events no more than two weeks old. In addition, some of the illustrations were so large at $2^{\prime} \times 3^{\prime}$ that they had to be folded into the paper. 14

Leslie's motto was "never shoot over the heads of the people." Unlike publications such as Harper's Monthly and the Atlantic, which were almed at a cultural elite, Leslie's paper was designed for the masses. It covered all aspects of Iife, music and drama, fine arts, sports, books -- and had serialized fiction. There was a well organized art staff of six artists including Leslie himself. By its third year, Leglie's circulation had reached one hundred thousand.45 
Taylor's association with Leslie's seems to have been that of free-lance artist probably because he already had a busy career underway in Philadelphia. Like any free-lance artist Taylor tried to maximize his earnings by submitting items to any publication where his talents might be welcomed. Taylor's first sketch for Leslie's appeared in the September 7 1ssue of 1872. It depicted the launch of the new steamship Rennsylyanla, bullt by the Willlam H. Cramp and Sons Shipyard. The page was divided in half horizontally with the engraving made from Taylor's sketch, occupying the upper half of the page. The lower half contained a clrcular engraving of the Honorable Thomas $A$. Henderick of Indiana from a photograph by Mathew Brady.

Taylor's documentation of the launch, and the engraving's juxtaposition with a Brady photograph, allows us to analyze the Special Artist's reportorial role. For there was a history here that went beyond the launch of a new ship and the excitement generated by the event, as cheering crowds of well-wishers were depicted both on the docks and in smaller vessels surrounding the new ship. The Rennsylvanta was the first iron steam screw to cross the Atlantic, departing Philadelphia on May 22, 1873 bound for Liverpool -- part of America's, and the city's, increasing commercial prominence at sea as the country's industrial power rose. ${ }^{46}$ The ship's builder, William Cramp and Sons Ship and Engine Building Company, cited by Burt and Davis as one of the "cornerstones" of Philadelphia's Iron Age, supplied the 
nation with merchant and war vessels from the days of the clipper ships through World War I. ${ }^{47}$ These included record breaking transatlantic passenger steamers like the St_L Louis, the battleship USS Maine, and even J. P. Morgan's yacht cersair. The company supplied naval warships not only to the United States but to Russia, Turkey and Japan. Charles Cramp was even decorated by the Czar. The Cramp firm thus represented not only America's burgeoning technological dominance, but also its growing intervention in world affairs as the explosion of the Maine led to war with Spain. And the corsair symbolized the rising power of United States industrial capitalism. Taylor was thus illustrating an age as well as an event.

That Taylor's sketch should also be accompanied by an engraving of a Brady photograph is prophetic because it foreshadows the eventual replacement of the special Artist and wood engraver by the photojournalist. In the late 1800s, photographic equipment was still cumbersome and exposure time too slow to capture anything but the most staid situations. It was no match for the artist's quick hand in the field of battle or at a disaster. New developments were impending, however, that would move photographic images to the forefront. One was the development of the roll-film camera by George Eastman. This eliminated the need for the photojournalist to transport his darkroom with him which, in addition to faster film, improved lenses, and the flash, allowed for capturing the immediate image once reserved for 
the Special. As W. A. Rogers succinctly stated, "now a photographer goes out with his camera and -- click! -- he has it all in half the wink of an eye."48 Another important development was the ability to reproduce shades of gray, or halftones, in the newspaper by the use of a ruled glass "screen" which fragmented the picture into dots of various sizes. This meant photographs and sketches no longer had to be engraved, a tremendous savings. While firms like Harper's did not immediately dispense with their large art departments, they soon eliminated the wood engravers. And eventually, the Special and staff artists were replaced with photofournalists. ${ }^{49}$ So the illustrators of the industrial age, the Specials, became its victims.

Taylor would eventually work for Harper's Weekly, Leslie's chief rival, which was established just two years later in 1857. It was the New York Daily Graphic, however, that launched Taylor's career as a Special Artist. Established in 1872, the Graphic took 1llustrated fournalism one step further, from weekly to daily publication. Recognizing the increased popularity of illustrated papers, the owners felt a daily paper, heavily endowed with visual images, would be well received. This would not have been possible, however, without what they called "the Graphic Process of which the publishers are the sole proprietors."50 This "secret" process was that of photolithography, whereby "photographs made from pen drawings or from wood cut prints, were transferred to stone in shape for further use." 
The photolithographic engraving process used by the Graphic was invented by William A. Leggo of Montreal.51 Leggo and George E. Desbarats conceived the idea of issuing a daily journal in New York, and they raised $\$ 750,000$ to finance the venture. They planned to publish not only the dally paper but also individual engravings, and do "all sorts of photolithographic work for the public." The stock sold publicly for $\$ 20-\$ 30$ a share. Shortly after organization Leggo sold his interest, and Desbarats, who would later end up bankrupt along with the company, became manager. He brought J. H. and C. M. Goodsell brothers of New York to Montreal, where they arranged with the company directors, headed by Sir Francis Hinks, to "conduct the manufacturing establishment of the company, and publish the Graphic." Desbarats was to remain in Montreal and publish the Canadian Illustrated News.

The Daily Graphic considered itself "A Model Journal of News, Society, Art, and Literature," and "especially and emphatically a paper for the home." Like Leslie's and Harper's Weekly, it aimed to appeal to the common man. The Graphic provides a unique national perspective on what nineteenth century America felt was important to document as the country grew more urban and industrial, coped with problems of overcrowding, dealt with technological changes including electricity and transportation, and increased its presence on the world scene. The aculturation process Barth notes was the role of the metropolitan press. Why then has 
the Graphic been overlooked by historians of art, fournalism, and Americana? The answer is unclear, especially when we consider that the Graphic served as a training ground for many of the artists who would later become famous for their connection with Harper's Heekly. ${ }^{52}$ The Graphic's pioneering effort in providing a heavily illustrated paper on a daily basis deserves more recognition in the evolution of pictorial fournallsm. No doubt its quick demise is partially responsible for the lack of scholarly attention, and even Leslie's and Harper's Weekly are not given the study they deserve. Taylor headed the Graphic's Philadelphia art bureau. Philadelphia was, along with Boston and New York, one of the major cities in the United States, and one of the primary forces in industrial technology with companies such as Bethlehem Steel and the Baldwin Locomotive works. Therefore, it was prudent to locate an auxillary office there. Taylor's bureau was responsible for news from Philadelphia southward. This responsibility contributed to his and his readers' geographical and cultural knowledge of the country beyond the urban landscape, and provided both with an appreciation for the varlety of American life.

While Taylor would cover many events in and around the city, it was his assignment in July of 1875 to accompany aeronaut Samuel A. King on his balloon flight from Cleveland that placed him at the forefront of the profession. ${ }^{53}$ An unidentified Cleveland writer describing the impending balloon launch commented on Taylor and the Graphic: 
Mr. Taylor is art correspondent of the New York Graphle and arrived in this city yesterday. Besides writing a description of the ascent and the aerial trip Mr. Taylor will take several sketches of the balloon and the surroundings, which will duly appear in the Graphte. Mr. Taylor represents the Graphic at Philadelphia, and in his capacity of a "free lance" of the press goes to any part of the country where he thinks material may be found for that species of illustrated journalism of which the Graphic is the sole unrivalled (sic) representative in this country. He is a gentlemen whose natural genius for art is strengthened and developed by wide experience and culture and the numbers of the Graphic containing his illustrations from Cleveland will, without doubt, be very attractive. ${ }^{54}$

Taylor concelved ballooning as freedom from the labyrinth of life on earth, and a similar fascination attracted the American population. It was in this context that Taylor reported his aeronautical exploits, and his illustrations provided the opportunity for readers to experience the excitement and danger of the event at no risk to themselves, even if aerial extravaganzas never made it to their towns. Taylor's flight with king in 1875 was not only entertainment for the approximately thirty thousand spectators, but also good press for the Daily Graphic. ${ }^{55}$ That this launch was what we now call a "media event" is reinforced by accounts in contemporary news clippings; indeed journalists were the only passengers.56 Taylor provided national exposure, and four cleveland journalists, Will E. Chapman of the Herald, E. W. Lightner of the Rictorial Werld, John C. Covert of the Leader and Robert Pierce of the Rlain 
Dealer, would give local coverage; and a photographer, D. N. Hatfield, would make souvenir images available at his studio. Not to be eliminated from the economic opportunities presented, the local music publishing house, S. Brainard's Son's issued The Grand Ascension March which a Cleveland reporter labeled a new "aeronautic march . . Iively, anlmated and melodious." A lithograph of the balloon Buffalo appeared on the cover. ${ }^{57}$

At the time, the Buffalo was the largest successful balloon ever built in the United States at 91,000 cubic feet. Named for the city in which it was built, it was a present from several of the municipality's businessmen -- good advertising they probably thought. Its lnitial launch was made from Buffalo, New York, on July 4, of 1873. The next flight from that city later that year took King and his passengers over the Alleghenies into New Jersey, crossing five states and covering a distance of five hundred fifty miles. The balloon's first ascent from Cleveland was in July of 1874 with a party of eight traveling almost the total length of Lake Erie and landing in the Michigan wilderness. With this exciting history, and one of the nation's premier balloonists at the helm, it is no wonder huge crowds were attracted one year later on July 6, 1875 .

As usual, Taylor reported the event for more than one paper. His descriptions of the fourney were carried in all the Cleveland papers, and were illustrated in the Dafly Graphte. His Graphic sketches appeared in the July 20 issue 
on a full page spread with twelve vignettes consecutively numbered so the readers could follow the writer's voyage into "cloudland," plus a sketch of Professor King (Fig. 6). He recorded the public's fascination even with the inflation process (nos. 1 and 2), and then the dramatic launch in (no. 3) which took place at 4:30 in the afternoon accompanied by a salute from the city artillery as the party glided upward, while a band played the new Brainard march.

After a picturesque sall, including a complimentary midair dinner of roast chicken, a toast to the Union, and the dropping of ribboned dispatches (no. 4) the party landed in Portage County Ohio at 8:30 p.m. A tent was pitched and christened "Camp Birchard," as it was on Judge Birchard's farm they had descended. The camp site quickly became a local attraction, and area residents were arriving into the early morning hours to congratulate King and catch a glimpse of the balloon. Taylor depicted the "Late Callers" at the bottom center of the page. At 9:00 a.m. the next morning Professor King was aloft again, accompanied by only Taylor and Hatfield, the remainder returned to cleveland by train. Before departing, however, the entire party was invited to the home of a nearby farmer, Mr. F. Beckwith, "where he regaled them with a bounteous repast."

The three remaining aeronauts salled into Pennsylvania, crossing the state line, Taylor reported, at about 10:30 a.m. After about four hours, traveling at a rate approaching sixty miles per hour, and at a height of three miles, they saw the 


\begin{abstract}
Allegheny Mountains. A traveling storm cloud disturbed their flight, however, and sent them plummeting to earth, where "a crash of trees, [and] a tossing indescribable... [made them] fully awake to the fact we were in the midst of giant pines and mountain oaks." (nos. 11 and 12) The balloon was lodged forty feet above the ground, and except for a slight tear in the fabric, it and the passengers were unharmed. The local citizenry, who had been watching the Buffale during the storm, quickly came to the rescue. After the men were safely on land and the airship was carefully extracted from her lofty position, trees were felled in order to provide a clearing (no. 12). How could any reader fail to enjoy the freedom of space, the excitement of travel and risk of danger so dramatically fllustrated, and not appreciate the artist responsible?
\end{abstract}

Taylor's next major assignment for the Graphic, to cover the Centennial Exposition in Philadelphia, confirmed his position as one of the nation's top Special Artists. 58 As head of the "Philadelphia Art Bureau" Taylor and his staff of artists had an office on the Exhibition grounds in the northwestern tower of Machinery Hall. They were extremely busy because, in addition to various illustrated articles throughout the week, the paper had a Thursday supplement "devoted to pictorial illustration of the great centennial enterprise." 59

During the Centennial Taylor befriended a young illustrator named Joseph Pennell.60 In The Adventures of an 
Illustrater, Pennell recalled his first encounter with

Taylor:

I even tried to make comics for Harper's Weekly and to force my way on to the Daily Graphic of New York -- the first American daily illustrated newspaper in which large original drawings have been used to any extent -- as a special correspondent capable of running to fires in Philadelphia. Once I went to some celebration at [the Centennial] and got up with the 'special artists' there -- and I worked giddlly until I was asked by some inquisitive fool what I was working for -- then I was nearly thrown out and quite disgraced as an imposter by the real artists, who pointed to Frank H. Taylor, the official correspondent of the Graphic. But he was decent to me then and afterwards, for he knew that I wanted to be an illustrator. ${ }^{61}$

Throughout his life Taylor encouraged young artists, in part because he believed good art was important for a healthy nation.

Newspaper articles and illustrations such as those by Taylor and his staff in the Dajly Graphic played a critical role in the success of the Exposition. On May 10, opening day, a crowd of 186,272 saw Emperor Dom Pedro of Brazil and President Grant pull the levers that started the giant Corliss Engine, said to be the "'largest ever assembled on the North American continent." 62 Within two days, however, the numbers had diminished to just under 13,000. Fair sponsors were predictably worried; and their concerns continued as a record heat wave, a repeat of the sweltering days of the 1776 debates, sent temperatures up to $100^{\circ} \mathrm{F}$ for ten consecutive days, resulting in an average daily atten- 
dance of only 35,000. Gradually, however, the dissemination of information about the fair, particularly through 1llustrations such as those by Taylor, of the magnificent bulldings and unique exhibits, piqued the country's curiosity. Average daily attendance rose to 102,000 in October, and 176,000 by November. ${ }^{63}$ The fair was, after all, a success.

The Exposition pald homage to America's industrial prowess. Dorothy Beers notes that the Centennial excursion fares offered by that industrial giant, the railroad, coupled with the anticipation of excitement generated by the press, brought in a middle class who had heretofore been unaccustomed to long vacation trips.64 Such a luxury, once the exclusive domain of the rich, was now within the reach of an ever-growing segment of the population. Better informed and eager to know more, they were reaping some of the benefits that industrialization provided. Beers views the Centennial as "the country's f1rst mass tourist mecca."65 Taylor would capitalize on this influx of "new" tourists after the Centennial ended in a series of illustrated lectures entitled "The Pilgrims of $76 . " 66$ The artist's caricatures of the fictional visiting family of Ephraim Tuff, a farmer from Bucks County, Pennsylvania, were projected on a large screen by means of a stereopticon as Taylor narrated. In the story, Mr. Tuff reads about the "Centennial show down at Philadelphia" in the newspaper where "sometimes they throwed in big pictures. . . " His patriotism is also evoked as he explains that his daughter sallie read "how it 
was the duty of every true American to go and form a part of the great host of the Sons of Ereedom, who were doing homage at their country's birthplace." He feels particularly worthy as "we lost our eldest son in the fight [Civil War], an' we think our title to an interest in the doin's of this nation is a good one. . . ."

Mr. Tuff and his family took the train to the "metropolis" and the "misadventures" of the novice traveler soon began. They were approached by a man on the train claiming to represent the "'Great Original Mutual Accommodation Lodging House Agency Limited." He convinced Mr. Tuff that his lodging circulars were bogus and secured them lodgings with one of the most "aristocratic families of the city." This of course turned out to be the real sham, and Mr. Tuff ended up at a foundry some four miles from the city. The family finally made it to the Exhibition grounds the following day, after first taking one of the cars marked 'To the Exposition' going in the opposite direction. Their troubles naturally did not end there. After being swindled out of change trying to buy a guide book, and being refused admittance to the elevated railroad for not having the correct change, Mrs. Tuff determined she had best be responsible for the money and then headed off for the main building with her daughter. In the meantime, Mr. Tuff, thinking he saw a familiar face outside the grounds, goes through the exit turnstile, or as he said "I made a path through a sort of ten rall whirligig" whereby after discovering he was 
mistaken as to the man's ldentity, found he could not reenter the fair, and he had no money to purchase another ticket. At the end of the day the family, with some difficulty, was reunited and took the next train home, where Mr. Tuff reflected that from then on they would experience any further travels by simply reading about them in the papers. Taylor's lecture was a laugh at the naivete of the "country bumpkin," but also a commentary on the necessary complexities of city Iife, and the loss of innocence that resulted.

These comic sketches were very popular and Taylor also published them in book form. ${ }^{67}$ They are very similar to Homer's satiric "Life in Camp" lithographs.68 Nineteenth century American humor, notes Marc Simpson in his essay on Homer's oil The Bright side, was "'distinguished from that of 'the rest of mankind,'. . . In its extreme breadth and strength of absurdity . . There is no attempt at subtlety - a plain, square exaggeration carried to the utmost confines and generally calling up some irresistibly laughable figure.'n69 Taylor's caricatures are typical of this type of broad American humor. His familiarity with the works of Homer and his assoclation with A. B. Frost and W. A. Rogers, whose comic sketches were seen in the pages of the Graphtc and Haxper's Weekly, place him among the country's most recognized caricaturists. ${ }^{70}$ Whether he was influenced by or influenced these men cannot be determined, but his work equally represented the humor of the day. 
Not all the sketches presented at these lectures were intended to eliclt laughter, however. Taylor, who billed himself as "Special Artist, New York Daily Graphic," also drew a number of charcoal sketches which, as one reporter said, "brought vividly to mind things we had all grown famlliar with at the exposition."71 "Mr. Taylor's effort" the same reporter added "was gratifying in the extreme, and the management of the Working Men's Club [where this particular lecture was held] deserve the thanks of the community for providing such entertainments at the merely nominal admission fee of ten cents."72 Taylor capitalized on the success of the Exposition, and in particular the pride of Philadelphians in their contribution to the nation's industrial progress, as well as Americans' ability to laugh at themselves. Taylor's Graphte assignments at the Centennial included another balloon ascension with Professor Samuel King, which left from the Catholic Fountain Terrace at $5 \mathrm{p.m}$. on August 4, and designed of course to promote the Exhibition during the lean dog days of summer. ${ }^{73}$ Some 45,000 visitors watched as the eight men (six were journalists) and one woman (King's daughter) went aloft. Taylor was in charge of four Antwerp carrier pigeons which carried dispatches to the waiting public. The second to be released carried a note by Taylor which read as follows: 
[By Pigeon Express]

Left Centennial grounds ten minutes ago, and are now in the lower clouds at a height of 3,000 feet. The scene is grand beyond any description and the Centennial buildings look like playing blocks. Elm Station on the Pennsylvania rallroad, five miles from Philadelphia is just below us. We threw out a number of coples of The Graphic and soon after the balloon rose rapidly. Our speed is now about twenty-five miles per hour and is rapidly increasing. We can see Norristown, which is about eighteen miles above Philadelphia, very distinctly. I will send you more later. F.H.T.74

The balloon landed at $8 \mathrm{a} . \mathrm{m}$. the following day after a moonlit ride over New Jersey and a morning view of New York Harbor. The group passed out newspapers during their evening stop at the King of Prussia hotel, and, no doubt, told area residents about the other wonders to be viewed at the Exposition. It should be noted here that lengthy fourneys were a King trademark who Crouch calls "the most proficient aeronaut active in the United States between 1860 and 1900 - . and the most scientific balloonist of his generation."75

Taylor's work for the Graphic continued, but unfortunately the paper would soon fold. A poem by an unknown author written near the beginning of the Centennial saw at the time only a promising future for the paper and its chlef artist, who had, according to the author, also seen the benefits of weod engraving: 


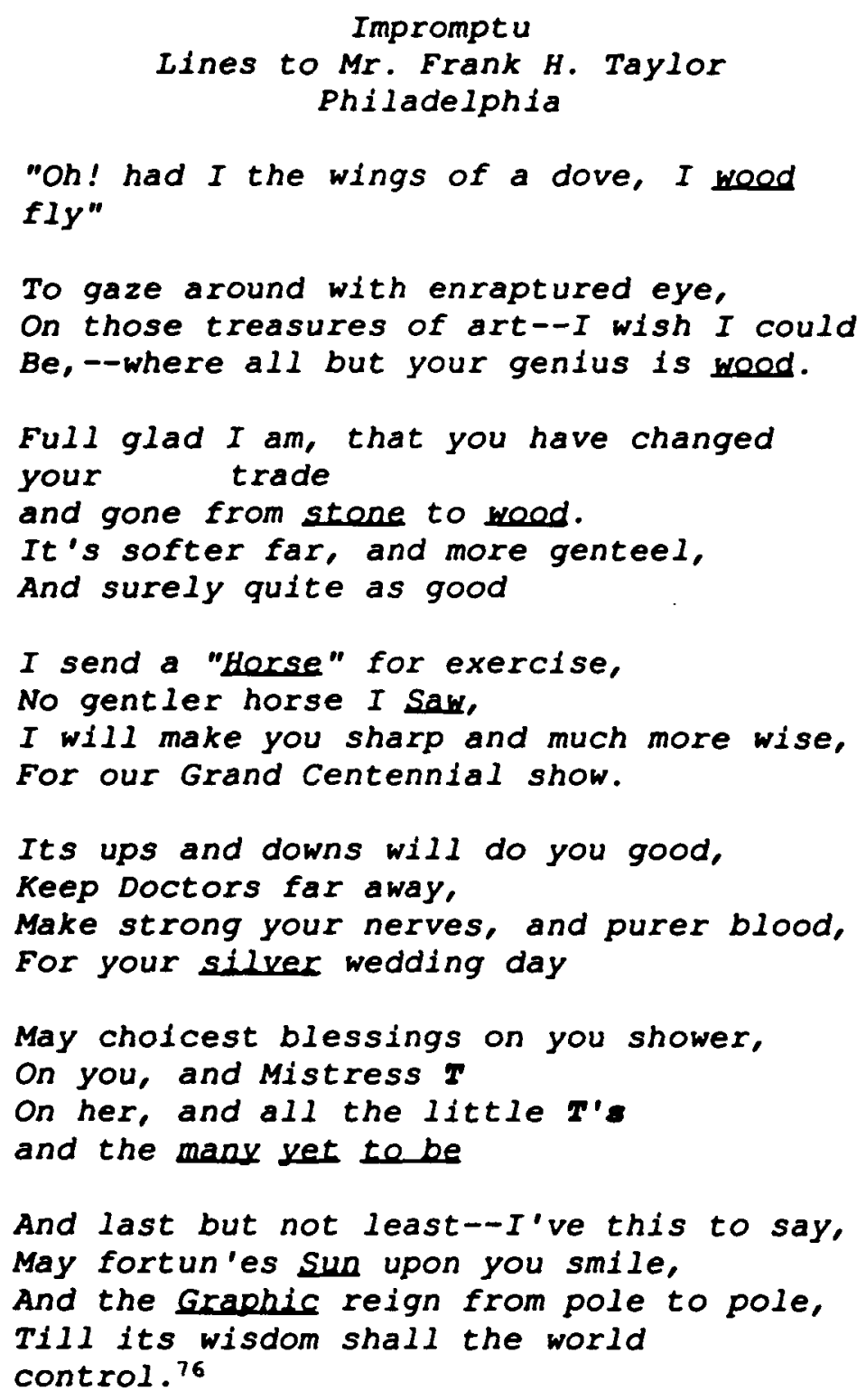

One of Taylor's final Graphle assignments would lead not only to a book, but to his association with Harper's Weekly, America's premiere illustrated newspaper. This last major story as a Graphic Special Artist was to cover the "Southern Excursion" of the American Society of Civil Engineers. The Society was to hold their annual meeting in New Orleans, and 
Taylor accompanied the group, sending back sketches and articles for the Graphle as well as letters to the Philadelphia Eventing Herald. The "excursionists" expressed their desire for a remembrance of their trip, and Taylor complied. The book, Becords of the Southern Excursion of the American Society of civid Enaineers, (1877) was, as Taylor notes in the Preface, not concerned with technical matters, "but rather to note the many little incidents, relaxations and minor occurrences, which tend to make the days of such an occasion pass upon the golden wings of pleasure."77 Thls anecdotal work is reminiscent of Taylor's Centennial sketches of Ephriam Tuff, but as with the lecture, not all the pages are filled with caricatures such as the one showing some the englneers trying to sleep despite "the swarms of insatiate mosquitoes" which preyed upon the helpless victims. He also carefully recorded picturesque scenes like the Alabama Bayou, the local architecture and people of New Orleans, as well as a few of the engineering aspects of the fourney, such as the construction and placing of a gabion. ${ }^{78}$ Taylor made it clear that he was cognizant of his responsibility to deal with the "intricacies of engineering science." He stated he planned to produce an "unabridged and exhaustive . . hand-book for the use of the profession" which he would mail gratis to all members of the excursion."79 The civil engineers obviously enjoyed Taylor's wit and artistic abilities, but they also, no doubt, respected his understanding of their profession. 
Civil engineers were in large part responsible for the physical changes in the nineteenth century landscape. They constructed bridges, roads, dams, and harbors. They epltomized man's subjugation of the environment and believed firmly in the ability of technology to solve many of the nation's 1lls. Taylor's books and articles confirm this belief in progress, and they were appreciated beyond the conflnes of the engineers themselves. Two unidentified news clippings attest to the mass appeal of his book. In one, the writer notes the illustrated pamphlet from the pen of "one of the most accomplished artists and newspaper correspondents in the country . . makes as lively and entertaining an article as one could wish to read."80 In the other, the writer describes the book as containing "most admirably" all that was "picturesque, odd, or characteristic" and "what fun there is in the pages [for] those who are fortunate enough to get the book. . . " 81

In addition to this book, Taylor would later write Derrick's Hand-Book of Retroleum which contained "the data of all important events in the history of the petroleum region; The Handbook of the Lower Delaware Biver, which discussed the commercial operations of the waterway and was issued by the Philadelphia maritime exchange; a Histery of the Alan wood Iron and Steel Company of Philadelohia; The Philadelphia Electrical Handbook as part of the International Electrical Congress held in St. Louis; a book on the Rert and city of Phlladelphia for the 12th International congress of 
Naviaation, and a Souventr book for the National Assoctation of Master Plumbers. (See Bibliography for list of Taylor's publications.) These works place Taylor at the hub of technological change and show technology's influence on art. The stripping away of excess to admire the beauty of the structure itself, like the Roebling' Brooklyn Bridge, and the appreciation of life without all the ornamentation of victorian soclety -- this is what Taylor and other Special Artists drew and what writers like Howells and Twain, artists like Eakins and Homer, and architects like Sullivan and Root expounded upon. It was an American approach to art, an appreciation of the country in a practical, realistic way. 82

One of the engineering works visited by the civil engineers and recorded by Taylor, the jetties at the south pass of the Mississippi Delta, became the subject of the artist's first illustrated article for Harper's Weekly (March 2, 1878).83 Taylor is quite detailed in his description of the construction of the jetties and in particular the mats made of willow branches that were sunk using heavy stones. "The effect," Taylor wrote, "is to confine the impetuous waters of the river in a channel and profect the current, heavy with sediment, far out into the deep waters of the gulf." Harper's Weekly apparently felt a story of this technical operation would be of interest to its readers who would appreciate the advancements man was creating in "taming" nature. 
Clearly, Taylor's reputation as one of America's premiere Special Artists made possible his entrée into the art department of the Harper publishing company.84 And quite an impressive art department it was, headed from 1861-1889 by Charles Parsons. Arriving in New York from England in 1830 at nine years of age, Parsons had apprenticed at Endicott Co. lithographers, making many prints, particularly with marine themes, for Currier and Ives. At Harper's he nassembled one of the most talented teams of illustrators in publishing history," which included E. A. Abby, A. B. Frost, Howard Pyle, C. S. Reinhard, Frederic Remington, and winslow Homer.85 He was also a champion of the watercolor medium, which only recently has been accorded the legitimacy once reserved for olls.86 Joseph Pennell wrote in h1s memolrs that he felt "American Art began in the department of Charles Parsons," in large part because "he encouraged artists to express their own ideas, to develop their own style, to paint what they actually saw."87

Harper's Weekly was the brainchild of Fletcher Harper, youngest of the four Harper brothers who together established the publishing empire. ${ }^{88}$ Initially book publishers, their first experiment at a serial publication was in 1850 with the Harper's New Monthly Magazine. Fletcher Harper, who championed this broadening of the publishing base, soon had more material than could possibly be used in the Monthly, and thus, In 1857, Harper's Weekly rolled off the presses. Fletcher Harper had a unique abllity to target public 
opinton. He was aware of the popularity of Erank Leslie's Illustrated Newspaper, and felt Harper's was well equipped to enter the arena. He also realized the illustrations which were critical to Leslie's and his own Monthly would be a key element in the success of his new venture. Reaching out to a broad middle-class readership and with the financial backing of the Harper firm, it is no wonder that the Weekly soon became the leading national weekly newspaper. Under Parsons' supervision, Harper's usually had six to eight artists on permanent staff who worked on both books and periodicals. In addition, there were many artists like Taylor, who worked on a free-lance basis. ${ }^{89}$ They might send sketches and articles in on speculation as Frederic Remington did initially, or work on spectfic assignments, as Taylor did in covering Grant's 1880 trip through Florlda, Cuba, and Mexico.90 Artists recelved approximately $\$ 75-\$ 150$ per sketch, less if his sketch was returned, more if the paper retained the drawing because they then kept control of its republication. 91

Always the entrepreneur, Taylor requested the return of his sketches from the Grant trip which later proved economically prudent. There was a severe earthquake while the Grant party was in Havana, noted in the February 28 issue of the beekly, which reported that "the palace rocked fearfully, and Mrs. Grant and the other ladies were terribly frightened, but it did not disturb the serenity of Generals Grant and Sheridan in the least."92 Hardest hit was the small town of 
San Cristobel, approximately seventy-five miles southwest of the capitol, and Taylor took a train out to inspect the damage. Five extant wash drawings detail the destruction in this town of 6,000 . The sketches were probably submitted to Harper's Weekly for a supplemental story, but for some reason the editor chose not to use them, and, as requested, they were returned to Taylor. Six years later when Charleston, South Carolina was ravaged by an earthquake, Taylor resubmitted his sketches, this time to the Mechanical News, because, as he wrote, "the recent event at Charleston had led me to overhaul a considerable pile of old memoranda of travel."93 The engraved sketches, with some alterations, appeared on the cover of the October 15, 1886 1ssue. ${ }^{94}$ Taylor's last major assignment for Harper's Weekly was his coverage of the Grant trip, and placed him at the pinnacle of his work as a national newspaper Special.95 A little background concerning the historical significance of Grant's southern sojourn is required for an analysis of some of the extant sketches and the corresponding engravings. This trip has received relatively sparse attention in most Grant biographies, but at the time, was given broad coverage, and provided the means of focusing the nation's attention on the former President's ability to relate to all classes of people both on his own and foreign soll. The reason for this attention was part of a calculated strategy to have Grant receive the Republican nomination for president at the 1880 Chicago convention in June. ${ }^{96}$ Because his renomination bid 
falled, and Grant was essentially removed from the political picture, the trip, which might have been seen as a brilliant campalgn strategy, has become a historical footnote, and Taylor's role as documenter has been forgotten as well.

The southern trip was not part of the original plan concelved by Grant's advisors. After the scandals of his second administration, the Republican Party, but not Grant, survived, and Rutherford B. Hayes was sworn in as President on March 5, 1877. In order to reestablish his popularity with the American voters, Grant needed to remove himself, literally, from the corrupt elements of his administration, so he was ushered off on a two-year tour of Europe. Taylor documented the Grants' departure for England on the steamship Indiana. The trip itself, however, was covered by John Russell Young, a reporter for the New York Herald, and eventually his articles were published and lavishly illustrated in a two volume book, Around the World with General Grant. 97

Young reported the royal treatment accorded the Grants' as they wound their way across the European countryside. In England, where they visited their daughter Nellie, they dined privately with Queen Victoria. They were also warmly received by Prime Minister Bismark in Berlin. The exploits of the Grants and the detailed coverage were intended to remind the citizens of the United States of the prestige st11l commanded by their former president and war hero. This, in turn, it was surmised, would lead to a renewed enthusiasm and 
appreclation for Grant which could be converted into delegate votes at the convention. Speculation about Grant's political motives arose, but Grant continually denied seeking reelection. On one occasion when pressed for comment, he impatiently replied that "he knew what the presidency was, and had all he wanted." 98

The grand plan was for Grant return to San Francisco approximately three months prior to the Republican convention. As the former president traveled across the country on way to his adopted hometown of Galena, Illinois, finally settling in Philadelphia, he would, it was hoped, recelve constant acclaim and arrive at the convention on a great wave of enthusiasm. Historians like William B. Hesseltine agree that if this scenario had been followed, Grant's candidacy would have been nearly assured.99 However, when no steamship service was available to transport the Grant party from Tokyo to Australia, Grant decided to return to the United States, docking in San Francisco in October, 1879, six months ahead of schedule.

The problem posed by the premature arrival was to maintain enthusiasm for Grant over a nine month period.100 The Grants' reception in San Francisco was enthusiastic and included a five hundred voice chorus to welcome the returning couple. The coming-home parties continued as they slowly made their way to Philadelphia, but in the end, the strain of sustaining the euphoria was evident. In addition, it was 
increasingly difficult to deny renomination plans when there were meetings with top Republicans at nearly every stop. Grant's backers, and probably Grant himself, could see the problem, and realized that sitting in Philadelphia from November to June would do nothing to facilitate the cause. Therefore, it was decided that he should travel south, visiting various southern states and then sailing on to Cuba and Mexico. Grant had anticipated such a journey when he wrote to a friend before leaving Japan, "then I will probably go south -- possibly to Havana and Mexico -- to remain unt 11 April."101 This trip, like the world tour before it, received extensive coverage, and Taylor's sketches indicate the adulation accorded the Grants as they made their way from Fernandina to Key West, then on to Havana, Vera Cruz and Mexico City.

There is no account for the reason Harper's Weekly selected Taylor, one of their newest Special Artists, to document the Grant trip. Of course Taylor, by this time, had a reputation as a highly skilled special working for the now bankrupt Daily Graphic, but equally important may have been the fact that he had been in Cuba the previous year and published an article, "Street Scenes in Havana" in the April issue of Harper's New Monthly Magazine. Two months later his article "Through Texas" appeared in the Monthly. He had also published six articles for Harper's Weekly in that year, two of which dealt with the South. These articles might have reinforced Taylor's ability to interject humor into his 
writing and his skill at capturing the interesting elements of a journey. (See Appendix D for list of all Taylor's articles for the Harper firm.)

An additional qualification may have been Taylor's friendly, outgoing nature. As one of the reviewers of his book concerning the Civil Engineers' "southern excursion" commented, "He must be a capital fellow in a pleasure party."102 It is true that a special Artist needed to be adaptable to his surroundings and could often obtain a more probing story if he could gain the respect and confidence of those being covered. ${ }^{103}$ Homer, for example, was welcomed as part of McClellan's Peninsular Campaign forces, and Remington knew that his riding skills must be equal to those of the cowboys he was capturing on paper if he was to gain entrée into the inner circle. Taylor apparently had the ability and confidence to feel comfortable with any group, be it civil engineers or the heroes of the Civil war. Taylor was not only accepted by the Grants, but was also the escort "on all occasions" for Mrs. Grant's niece, Miss Kate Felt. In short, the Grants liked him.

Taylor's sketches of the Grant's southern trip, besides documenting an important aspect of American political history, also provide one of the most complete extant sets of drawings for an article made by a Special Artist.104 Unlike Taylor, many Special Artists did not request the return of their sketches. Hundreds, therefore, remained on file at Harpers for example, and during a move by that firm's art 
department, were destroyed -- once used they were little valued. In addition, because some Special Artists drew directly on the block, the original drawing was eradicated as 1t was engraved. ${ }^{105}$ There are sketch books such as James Taylor's which survive, but these drawings were not designed with engraving in mind.106 Taylor's collection is unique and allows for a closer analysis and better understanding of the Special as he creates the story as it is engraved for the public.

The Grant party which set off from Philadelphia on December 30, 1879, consisted of General and Mrs. Grant, their son Fred Dent Grant and his wife, two nieces of Mrs. Grant, and Lt. General Philip Sheridan and his wife.107 Sheridan had been one of the few soldiers, Sherman being the foremost, in whom Grant had complete confidence during the civil War. He was Grant's only commanding general present at Appomatox. Their friendship continued after the war, and their wives enfoyed each other's company. It was a distinguished party which rendezvoused at Fernandina, and one which Harper's Weekly knew would be of interest to its readers. The paper's pro-Republican stance was also a factor in its extensive coverage.

Taylor met the party in the small town of Fernandina Beach on Florida's northeast coast. The stop included a trip to Georgia's Cumberland Island, where Grant paid a visit to the grave of "Light Horse Harry" Lee of Virginia, a Revolutionary War hero and father of Grant's Civil War 
adversary, Robert E. Lee. Henry Lee was buried in the cemetery on the grounds of the Dungeness Plantation, built by the family of Lee's close friend and fellow general, Nathanael Greene. Harper's Weekly coverage of the Grant trip began on February 7 with an article on "Grant's First Visit to Florida" accompanied by a one-page composite of five engravings from Taylor's sketches, including the visit to Dungeness and Henry Lee's grave. It seems to have been a calculated political move to portray Grant in the most favorable and patriotic light, having him pay homage to those who struggled for America's freedom as well as showing respect for a man who believed that the Union could not survive, but who had been gracious in defeat.

Several of Taylor's original wash drawings done in and around Fernandina provide insights into his skill as a Special Artist. Taylor's careful attention to accuracy can be seen in his depiction of the city's wharf area where hundreds of citizens turned out to "welcome the distinguished visitors," although formal ceremonies were delayed till the following day, as Grant arrived on the Sabbath. ${ }^{208}$ A comparison of Taylor's sketch of the wharf at the end of Center Street with the 1886 Sanborn fire map, which indicated not only a building's location but its height and material of construction, confirms the accuracy of Taylor's architectural rendering and perspective.109 Because the town has changed very little since the turn of the century, modern photographic views from the same vantage 
point reconfirm his attention to detall. Th1s means of course that the drawings are evidence not only of a special event, but also building design, construction materials, placement, as well as street layout.

Taylor's watercolor The Fernandina Band, "Pumpklo" Leader, (Fig. 7) shows five black boys playing a varlety of homemade instruments as they join in the festivities to honor the former president. Here Taylor captures not only a light hearted moment, but also carefully renders the clothing worn, information not well documented for the southern black population. Special Artists would often make small study sketches of interesting people and their accouterments or of architectural features they might later incorporate into a finished drawing. Taylor, no doubt, had a sketchbook filled with such studies, although it has yet to be discovered. Works like the one of the Band, though, indicate his attention to all the elements important in accurately reporting a story. A Special Artist did not create the subjects for illustration, he recorded what was actually there and took care to include supplemental materlal which would make a story more substantive and retain the reader's attention.

This did not mean he was incapable of capturing a mood or sketching a scene that held a meaning beyond the immediately obvious. One such work, and perhaps his best, is entitled simply Aflerida Beach. (Fig. 8) With relatively few brush strokes Taylor conveys the sense of vast expanses of 
oceans and sand. The small dark solitary figure looking out to sea, which provides visual balance to the windswept follage on the shore, is probably Grant. Taylor used a minimal amount of gray wash, and a few deft brush strokes to form the scene, showing a mastery of the medium.

This horizontal landscape is not unlike the more finished luminist paintings of artists like John F. Kensett. John I. H. Baur defined Luminism as follows:

expression through a subjectivity so powerful that
the artist's feeling is transferred directly to the
object, with no sense of the artist as
intermediary. It is thus a realism that goes far
beyond 'mere' realism, to be touched, in some
instances, with super-real overtones and, in
others, to register that magnified intensity that
turns realism into a form of impersonal
expression.110

To say that Taylor was a luminist is incorrect, but to say that he was influenced by the work of these artists, whose paintings he would have seen on exhibit in Philadelphia and at the Centennial, is quite accurate. Taylor's depiction of Grant on the Florida beach does go beyond "mere" realism. It evokes a feeling of a man the world saw as a glant, who at one time controlled the fate of the United States as an undivided nation, reduced against the grandeur of nature, pondering his fate, which may now be beyond his control.

Not as direct perhaps, in this picture, is the Japanese influence in the use of the delicate, minimal line and controlled wash to define the landscape features. There is 
also the use of the diagonal to draw the viewer's eye from the foreground up to and around the shoreline, ending in the solitary, contemplative figure. Taylor would have been exposed to certain Japanese elements indirectly through the works of Homer and directly in the exhibition of woodblock prints at the Japan Pavilion at the Centennial.111

Two additional elements deserve mention here in regards not only to this specific wash drawing but others Taylor made during the trip. First is the subtle use of brushed-on white highlights, here used on the cresting ocean waves and as well as the sandy beach. This opaque white was called Chinese White and was used to supply strong lights and also to cover errors in drawing. It was said that "discrimination in the use of white is one of the tests of the capable craftsman."112 Second is Taylor's use of a cream, or in a few instances a blue-gray paper for his sketches. This was advantageous to the artists because the mid-range value allowed for the use of Chinese White for highlights, light gray washes for modeling and shading, and solid black for outlines. It was equally beneficial for the staff artists and engravers in New York, because the light cream color was the same color as the wood blocks, which made translation of the sketch much simpler and eliminated the need to whitewash the block.113 The Grant party travelled the short distance to Jacksonville by train, and from there took a steamer down the St. John's River to Sanford. There the former president participated in a ground-breaking ceremony for the South 
Florida Railroad. From there they boarded the steamer Osceela for a trip on the scenic Oklawaha River to Silver Springs. Named after the famous seminole chief, the osceela was a twenty-nine passenger recessed sternwheeler, part of the tourist operation begun by $H$. L. Hart a year prior to the Civil War. Taylor's sketch and the Haxper's Weekly engraving (Figs. $9 \& 10$ ) symbolize the lush Florida landscape described in the accompanying article:

\begin{abstract}
The steamer esceola carried the delighted tourists along a water lane boarded by overhanging cypress and palmetto trees, from which long festoonings of gray moss drooped pendent. The transparency of the waters as the boat turned into the tributary from Silver Springs was greatly admired. Thousands of water fowl of brilliant plumage sped away from the approaching boat, and that monarch of the florlda lowlands, the alligator, was frequently seen.114
\end{abstract}

A comparison of the sketch with the engraving demonstrates that while both are striking images, the "feel" or "mood" of the sketch is softer compared to the crispness when transferred to wood. This is not a criticism, but a statement of fact. Each has its own merits, but the two images can never be equal, and to compare them as if that were true would be a disservice to both artist and engraver. The Harper's art editor, Charles Parsons, must have realized this sketch would make a dramatic full-page illustration and assigned one artist, whose initials GP appear on the lower left, to redraw the sketch onto the block. Parsons was correct in his assessment, as the engraving, unfortunately 
usually uncredited, is still used to represent florida in print on everything from a record dust jacket to tourist publications. 115

More telling of the relationship between Special Artist and the art department staff are the design alterations which occurred in New York. Taylor correctly placed cypress knees in the marshy right foreground, which became large unfolding leaves in the hands of the staff artist and engraver(s). This was probably due to the fact that they had never traveled to Florida, and the unfamiliar black triangular shapes were not identified by Taylor. More often than not, the Special Artist's drawing was not as complete as this one of the Oklawaha, and the art department staff would improvise accordingly. This wash drawing was probably finished in Taylor's hotel room since the special would often only have time for short sketching sessions.116

Grant's visit to Florida was celebrated at every stop, and his past administrative fiascoes were apparently forgotten. St. Augustine officials even persuaded him to visit their city, though it was not on the scheduled itinerary. The town's people put on an elaborate parade, followed by five days of balls, a fishing expedition, and a reception at Ft. Marion (Castillo de San Marcos). No engravings of the city appeared in Harper's Weekly, but three watercolors, one of the fort, one of the city gate, and one of the oldest house, were included in Taylor's portfolio.117 It is doubtful these paintings were intended for use in the 
newspaper, as it would have been difficult for the artist/ engraver in New York to reinterpret the color gradations into black and white lines on the block. However, a good Special never missed an opportunity to sketch, and there was always the chance, if one paper did not use the submitted drawings, another would.

The final Florida stop was in Key West, where an evening reception was held for the Grant party. Taylor's wash drawing (his only one of the city) captured the excitement of the evening parade. Palm branches decorated the houses, Chinese lanterns and torches lighted the route, and a tripartite evergreen welcoming arch was constructed in front of the Russell House Hotel. Interestingly Taylor included in the lower left corner, a man waving a Cuban flag. At that time, there were approximately 4,000 Cuban refugees living in Key West, many of whom had turned out to honor Grant. In addressing.the crowd Grant said, "the Cubans or any other refugees in this country would always find a free home with us . . they would prosper in their adopted country and never desire to leave it."118 The flag and its bearer were edited out of the Harper's Weekly engraving, most likely because Spanish-American relations were tense, and it was not prudent to flaunt America's support of Cubans.

The politically sensitive island, however, known as the Pearl of the Antilles, was the party's next stop. A subtle show of American support perhaps, although America's relations with spain were a matter seemingly never publicly 
approached during the trip. The offlcial intent was for Grant to see Havana and the Cuban countryside, acting as goodwill ambassador, which is how he was portrayed by Taylor and thus appeared in Harper's Weekly. Taylor's extensive coverage of the arrival and visit to the capital city include both black and white wash drawings and watercolors.119

Taylor and Byron Andrews, correspondent of the Chicago Inter-ocean who was the only other journalist on the trip, were honored during the carnival festivities by the journalists of Havana, who gave a dinner for them at the Casino. Andrews wrote on February 11, "The leading papers were represented, and there were [many journalists] in attendance besides one or two of the prominent literary men of the city, among whom was Antonio Sellen, the poet who has translated the favorite works of Lord Byron into Spanish Verse."120 The position of journalists for the former president accorded Taylor and Andrews special privileges they might not otherwise have received.

The party next set sail for Mexico, foregoing a visit to the Yucatan peninsula because of rough seas, which forced them to anchor off the coast of Progresso awaiting better weather.121 A determined delegation from Merida, however, "battled through the surf at great risk in order to express the regrets of their people that the weather had rendered it impossible for the General to visit [the City]."122 The steamer lity of New York was also anchored off the Progresso coast on its way home to New York, and Taylor took the oppor- 
tunlty to forward his notes and sketches back to his editors. Later he wrote, "my last letter, dated off Progresso, was finished in fear and trembling lest the waiting boat, which bobbed about alongside, should return to the homeward-bound ship without taking my mail."123 The importance, and difficulty, of posting letters and sketches back to waiting editors was always a concern of the Special Artist. Lost material could mean lost income or the necessity of reconstructing drawings and notes when recall would be less than perfect. 124

The Grant party finally reached Vera Cruz on the $18 \mathrm{th}$ of February. That afternoon the party left by train for Mexico City with stops in Cordova and Orizaba. In Cordova Grant and Sheridan inspected a coffee plantation and Taylor saw an opportunity to create a politically calculated composition. Taylor's wash drawing showing the two generals on horseback was designed to remind the Harper's Weekly readers of Grant's glory days when the decisive military strategist was inspecting his soldiers. One is tempted to believe it may have helped persuade some delegates to recall the former president, the man who saved the Union, and overlook his first indecisive tenure as chief executive. Compositionally Taylor used the arched plantain leaves, which shaded the smaller coffee plants from the hot sun, to frame the General. The foreground entrant figures of picker and child, like the viewer, stop to look at Grant, whose dark suit and top hat clearly make him the central figure in a sea of light gray 
washes. Taylor was well aware of the necessary compositional elements which would allow him to make Grant the focus of this sketch.

Two sketches completed in Mexico City were designed to further emphasize Grant's military and political accomplishments for the Harper's Weekly readers. One was of the gate at Molino del Rey or "The King's Mill." This was the scene of a fierce battle during the Mexican war on September 8, 1847 in which Grant won his captaincy and where Mrs. Grant's brother Fred was wounded.125 Taylor noted on the drawing that while he was sketching the gate, Grant was telling Sheridan that it was here he captured his first prisoner.126 The sketch along. with three others, was engraved for the April 17 issue of Harper's Weekly accompanying an article entitled "The Battlefields of Mexico" in which Taylor describes what Grant considered one of his most pleasurable visits.127 Taylor's final, and now fragmented, sketch found in the portfolio documented the Grant party's audience with Porfirio Diaz, the President of Mexico. As Taylor would later note in an article on "The Benevolent Despot" which he wrote for Beoklovers Magazine in 1904, the meeting "initiated the beginning of a commercial invasion of Americans . . . and represent[ed] investments of capital above $\$ 500,000,000 . " 128$ This new invasion from the north was designed to bring the two nation's closer -- the war was for both generals, part of the past. 
Taylor's wash drawing shows Grant and Diaz sitting on either slde of Maties Romero, who acted as translator, while Sheridan and Fred Grant stand close by. ${ }^{129}$ Taylor wrote the names of each man on the sketch to avoid confusion in New York, as it is doubtful any of the staff artists and engravers were familiar with Mexican political flgures. Taylor's interest here seemed not one of composition but rather accuracy of recording the event's details, for he carefully noted the architectural elements of the room along with the window treatments, wallpaper and carpet design and furniture. One gets a sense of scale and simple grandeur even in the limited gray tonality of this plece. These final drawings emphasize Grant's political and foreign policy expertise and were designed to demonstrate his ability to introduce American investment into new arenas. It was a high note to end on.

It was here that Taylor left the Grants, returning to New Orleans and then to New York and Philadelphia to take on new assignments rather than continue with the visitors who traveled to San Antonio, New Orleans, Memphis and Hot Springs on their way back to Philadelphia. Upon Taylor's arrival in the Louisiana port city, he was interviewed by a reporter from the Philadelphia Times who noted that while Taylor was a young man he "is acknowledged as a journalist of both experience and perception. His forte is observation, and hence he speaks intelligently on what he sees."130 When asked about Grant's willingness to accept a third nomination, 
Taylor assured the unidentified reporter that political aspirations were the furthest thing from the former president's mind and the trip was purely for pleasure. This was, of course, untrue and Taylor was well aware of Grant's intentions. In a lecture entitled "Reminiscences of Half a Century" given in 1915, Taylor related that on a train in Cuba Grant "read [a] telegram from the Penna. delegation that they were solid for him."131 Taylor did his best to represent Grant in the most positive light, and was probably disappointed when he covered the June Republican convention in Chicago for Harper's Weekly and Grant failed to win the renomination bid. 132

Taylor's work for Harper's Weekly continued throughout 1880. He covered the Democratic convention in Cincinnati in July, and was bäck in Chicago in September for a meeting of the Knights Templar, and finished the year in Tennessee reporting on rugby. After that his work appeared infrequently in Harper's Weekly and Erank Leslie's. Hayfever and malaria, he said, had forced him to slow down somewhat, prompting a trip to document the resort area of the Thousand Islands for Harper's Weekly readers in 1881.133 His work increasingly focused on tourist brochures, and his acceptance of the Philadelphia Ledger offer to head their newly created art department, effectively ended his Special Artist life of constant travel. However, the plein-air approach to his sketching, with its focus on nature, and his honest recording of what was before him -- both hallmarks of 
the profession, and attributes of what art historlans term "American Realism" -- would remain. He became his own Special Artist in a way, recording what he wanted and working independently.

The Special with the big weeklies had a different role, too, as increasingly sketches were directly reproduced without the intervening engraving process. Years earlier Taylor had told two of the Harper brothers during a trip to Florida that the wood engraver would soon no longer be needed.134 And while the Special Artist worked side by side with the photo-Journalist during the Spanish-American War, increasingly photography would supplant the field sketch. Many Specials, like Howard Pyle and N. C. Wyeth, turned to book illustration, commercial art, or like Homer and Remington switched to oils. On-the-spot news sketches were no longer used except in instances where a camera was prohibited, such as in today's courtrooms.

While Taylor lamented the passing of the wood engraving profession, he was ever optimistic about the future of illustration and drawing. He said "Those who despair have failed to adapt their methods to modern conditions" something he notes he always tried to do.135 Taylor saw a new democratization of art as a result of the increasing number of artists who would be entering the commercial arena after studying at art school. Their superior work would constantly be before the public who, as a result, would be exposed to good design on a daily basis, not just when visiting a museum 
or exhibition, and this good design would improve the quality of their dally lives. Taylor felt that one of the responsibilities of artists was to bring good design to the average citizen, which the special artist did on a mass scale. He felt that the "old reverence for art, its mystery" was gone, and instead thousands of artists have learned the new processes "and the influence of thelr work has leavened the whole lump of the people."136 He himself had a successful career after his employment with the Graphic and Harper's Weekly. He utilized his skills of observation and love of history to produce illustrated books and articles (using brush and camera) through the turn of the century. Always optimistic, he seemed to embody the nineteenth century philosophy that technological change could be a positive influence on American life. 
CHAPTER NOTES

The Craftsman, 17 (December, 1909), p. 266.

2FHT, Manuscript Collection, HSP, Box 1, Folder 4.

${ }^{3}$ FHT, Manuscript Collection, HSP, Box 2, Folder 3.

4 "Gathering News," Miners' Journal, filed from Philadelphia, February 1, 1878, AKM Scrapbook.

${ }^{5}$ The Metropelis was an 198' long, 879 ton steam screw which foundered January 31, 1878 four and one half miles north of Life Station No. 4 and three miles south of Currituck Light, NC. Eighty-five lives were lost along with a cargo of general stores. Bruce D. Berman, Encyclopedia of American Shipwrecks (Boston: Mariners Press, Inc., 1972), p. 134 .

6 "Gathering News," AKM scrapbook.

Inid.

${ }^{8} \mathrm{FHT}$, "Scene of the Huron Wreck," New York Daily Graohic, filed December 3, 1877, Kitty Hawk Station, North Carolina; and "At the Huron Wreck," Philadelphia Rress, filed November 30, 1877, Kitty Hawk, North Carolina, AIM Scrapbook. The Huron, a 541 ton steam screw, went down on November 24, 1877 a short distance off shore from Nags Head, North Carolina. Berman, Encyclepedia ef American Shipwrecks, p. 134 .

${ }^{9} \mathrm{FHT}$, "Scene of the Huron Wreck," AKM scrapbook

${ }^{10} \mathrm{FHT}$, "The Lost Metropolis, Philadelphia Rress, filed February 3, 1877, Norfolk, Virginia, AKM scrapbook.

${ }^{11}$ T:e "swill milk" scandal was the result of dairy cows, which supplied New York City with milk, being fed distillery refuse. This practice both poisoned the cows and contaninated their milk, although the animals continued to produce until they died. Leslie, who believed it was possible to influence an audience more from pictures than words, showed the horrors of dying cows and milk in open barrels causing a public outcry. The end result was a law 
passed by the state legislature which ended the practice. The dairies and distilleries were part of the Tammany Machine which controlled New York City. John William Tebbel, The American Magazine: A Compact History (New York: Hawthorn Books, 1969), pp. 116-117. IThomas Nast, political cartoonist for Harper's Weekly began his attack on the Tweed Ring on September 11, 1869. Despite a threat by $W$. M. "Boss" Tweed to have the Board of Education reject all Harper text books on hand as well as future bids, and the offer of onehalf million dollars to Nast to "give up 'this Ring business," the publisher and artist stood their ground, and Nast continued to caricaturize "Tweed and his cohorts as vultures, gallows birds, and men in prison stripes." So powerful were the images, that Tweed is quoted as saying "I don't care so much what the papers write about me -- my constituents can't read, but damn it, they can see pictures." Just before the November election of 1871, Nast printed his double spread cartoon using the now famous tiger as a symbol for Tammany Hall, and the Ring was destroyed. Exman, House of Harper, pp. 87-89. For additional insight into the Tweed Ring and the "boss" system that grew out of the rapid growth of American cities in the nineteenth century, see William L. Riordon, Rlunkitt of Tammany Hall, (New York: E. P. Dutton, 1963).

${ }^{12}$ The great German woodcut artist Albrecht Dürer, for example, is known to have created illustrated broadsides for public distribution at fairs in the fifteenth century.

${ }^{23}$ For more information on education in America, see Daniel Calhoun, The Intelligence of the People (Princeton: Princeton University Press, 1973).

${ }^{19}$ According to Donald H. Mugridge and Helen F. Conover in their book An Album of American Battle Art 1755-1918 (1947; rpt. New York: DaCapo Press, 1972), the print "was arranged completely in accord with whig propaganda." Revere shows the soldiers in what was to become a symbol of British military strategy during the Revolution, in a straight line firing point blank at the colonists. Ester Forbes, however, in Pawl Bevere and The Werld He Lived In (Boston: Houghton Mifflin Co., 1942) notes that a diagram of king Street, proportedly by Revere, was in evidence at the trial which accurately indicated the location of the victims and soldiers suggesting the author was at the scene. The diagram, however, presents an entirely different image than the famous engraving. 
25Donald H. Cresswell, comp., The American Revelution in Drawtings and Prints: A checklist of 1785-1790 Graphics in the Library of conaress, forward by Sinclair H. Hitchings (Washington: Library of Congress, 1975), p. 263.

${ }^{16}$ Forbes, Raul Revere and the World He Idyed In, pp. 160163. While many copies of the print were avallable, Revere's was the most dramatic, and reflects his political as well as economic interest. Henry Pelham, stepbrother of American expatriot artist John Singleton Copley, issued an engraving a few days after Revere. In an angry letter of March 27, 1770, he accused Revere of plagiarism, a common practice among engravers at the time.

${ }^{17}$ Steel engraving was also used for illustrations, particularly in the United States. The process was used by Godey's Lady's Book and Graham's Magazine, both published in Philadelphia. While it could withstand a greater number of Impressions, up to 30,000 , than either a copperplate or woodcut, its hard surface required long hours of craftsmanship for each illustration and still required a separate press. Albert F. Moritz, America the Picturesoue in Nineteenth Century Engraving (New York: New Trend, 1983), p. 11. In his HSP lecture on November 20, 1923, on printing, Taylor noted that the two publications "were usually embellished with one or more steel plates." He went on to say that steel engraving was the first to feel the competition of the new, more economical printing methods.

${ }^{18}$ Hogarth, The Artist as Reporter, p. 15.

${ }^{19}$ The woodcut was used to perfection by the Japanese in their Ukiyoe block books.

${ }^{20}$ Ibid., p. 7.

${ }^{21}$ Moritz, Ricturesque America, p. 31.

${ }^{22}$ Thomas Bewick (1753-1828) is credited with

rediscovering and revolutionizing the art of wood engraving. He approached the block as if it were black and the lines as white, rather than the traditional view of a white block on which black lines were drawn. Through a build up of white lines, he was able to create shadings that took wood engraving from a facsimile reproduction to a medium of artistic expression as seen in his A General History of Quadrupeds and British Birds. David M. Sander, Wood Engraving: An Adventure in Printmaking (New York: The Viking 
Press, 1978); pp. 14-18. Also see Wlll1am J. Linton, Amertcan Hood Fingraving: A V1ctorian H1story (Watking Glen, NY: American Life Foundation Study Institute, 1976).

${ }^{23}$ Exam, House of Harper, p. 76.

${ }^{24}$ This was not always the case. W. A. Rogers wrote that he and Charles Graham, another Harper's Weekly artist, spent, "Many a night out on the road.. . [fuggling] architecture and figures back and forth on a wood block under a single gas jet in a hotel bedroom." $W$. A. Rogers, A World Worth While: "A Record of "Auld Acquaintance" (New York: Harper \& Brothers, 1922), P. 15. Also, Robert Taft in discussing the Western 1llustrations of Frenzeny and Tavernier, notes that "The artists draw their sketches on wood before sending them to the engraver." Robert Taft, Artists and Illustrators of the 0ld West 1850-1900 (New York: Bonanza Books, 1953), p. 96 .

${ }^{25}$ Hogarth, in his The Artist as Reporter, pp. 26-27, describes the Special's "shorthand" note taking of events and uses Frank Vizetelly's sketch Confederates Burning cotton Near Memphis, which was engraved for the Illustrated London News, August 9, 1862, as an example.

$26 " G e n e r a l$ Grant in Florida," Harger's Weekly, 24, no. 1208 (21 February 1880), pp. 116-117.

${ }^{27}$ What the photograph was of is not known. Possibly it showed the same event as a photographer was on the scene. This is not the only time Taylor made use of photographs to supplement his sketches. When the Grant party was in Vera Cruz, Taylor wrote he "ransacked the photographers' shops for vistas and found a lot of good views, getting some glimpses in my search of the queer inner life of the Mexican seaport." The photographs would not only serve as guides when composing sketches, but as mentioned above, might also accompany the sketches back to New York to provide specific details for the staff artists and engravers. FHT, untitled article, University of Florida Portfolio (hereafter cited UF Portfoliol. This is the original portfolio of sketches and miscellaneous clippings purchased by the University Gallery at the University of Florida, Gainesville, now part of the permanent collection of the Samuel $P$. Harn Museum of art at the University of Florida.

28 Jackson, The Picterial Press, p. 320. 
${ }^{29} \mathrm{~A}$ coat of Chinese white (an opaque white paint) or a zinc oxide and ggg white paint was sometimes used to coat the block to provide a paper-like surface on which to draw, and rendered the graving marks in greater contrast to the background. This white coating needed to be applied in a very thin layer so as not to add moisture to the block, which might cause warping, and to facilitate the adherence of ink to the surface.

${ }^{30}$ William Rogers the cartoonist and caricaturist who replaced Thomas Nast noted that Parsons quickly determined the expertise of his new recruits and discovered he [Rogers] "could draw very round wheels," and he was himself "in danger of being handed down to posterity as the wheelwright of Harper's Weekly." Rogers, A World Worth While, p. 67.

${ }^{31}$ Rogers, A world werth while, p. 14 . While this division of labor could lead to sloppy work, Rogers said Parsons and E. A. Abby saw to it that that did not happen on the pages of Harper's publications.

32As was often the case in the Grant Series sketches, Taylor 1dentified Grant and Mrs. Grant, in this instance with an asterlsk, even though it would have been clearly evident to the New York art department that the former president and first lady were the occupants of the four-in-hand. The Cuban flag on the top of the tobacco factory was eliminated in the engraving. "Grant in Cuba," Harper's Heekly, 24, no. 1210 (6 March 1880), pp. cover, 148, 151.

${ }^{33} \mathrm{FHT}$, "A Canadian Pilgrimage," Haxper's New Monthly Magazine, 64 (1882), pp. 501-504.

${ }^{34}$ Sometimes the artist's name or initials would be followed by del. for delineator.

${ }^{35}$ Rogers, A world Worth while, p. 15. Charles Graham (1852-1911) was a self-taught artist who started as a scenic artist for Hooley's Theater in Chicago and then moved to New York City. In the early 1870's he served as a topographer for the Northern Pacific Railroad. He joined the Harper firm in 1877 and was one of their most prolific Western 11lustrators. From 1891-93 he covered the Columbian Exposition. He began his free-lance career in 1892 and did work for the American Lithographic Company. He was best known for his skill at perspective and landscapes. Robert Taft noted that "he never 'broke loose from the scenlc foreground.' But if one can get past that in his pictures of 
the Slerras and Rockies 'no truer pictures were ever made of the mountains and all their naked ruggedness." "The highest paid artist on Parson's staff, he was earning a top salary of $\$ 50 /$ week by 1883. Taft, Artists and Illustrators of the $21 d$ West, pp. 181-183; Rogers, A World Werth while, p. 114; The American Personality, p. 158.

36Besldes Graham, two other well-known artists W. Snyder, and $T$. Thulstrup completely redrew Taylor's sketches on the block. Willard P. Snyder was born in Philadelphia in 1853 and was a staff artist for Harpers in the $1880 \mathrm{~s}$ and $90 \mathrm{~s}$. Thur de Thulstrup was born in Sweden in 1843 and served in the French army. He studied art in Paris, and at the Art Students' League in New York City. He illustrated for the Daily Graphic, Harper's Weekly, Leslies, Scribner's, Century and cosmopelitan. The American Persenality, pp. 169-170. TThere are many other artists' initials associated with Taylor's sketches that have yet to be identified. Only recently has scholarly attention been given to identifying these men.

${ }^{37}$ Kenneth Lindley, The Woodbleck Engrayers (New York: Drake Publishers, 1970), p. 47. Names of many of the engravers have yet to be thoroughly researched and many may have been lost. No information on Mayer has been located to date.

${ }^{38} \mathrm{An}$ example is the engraving of the sailor's uniforms in Taylor's sketch of the arrival of the Grant Party at Vera Cruz. Taylor made a note and a small thumb-nall sketch that indicated the uniforms were to be all white requiring the time consuming process of carving out this area.

${ }^{39}$ Exman, House of Harper, pp. 76-77.

${ }^{10} \mathrm{Through}$ close examination, it is often possible to detect the joins in the blocks on a printed engraving.

11Lindley, The Woodbleck Engravers, p. 75.

${ }^{42}$ This was not done until the steam presses of the nineteenth century made the pressure so great.

${ }^{43}$ For additional information on Homer's work as a newspaper illustrator see Lloyd Goodrich, The Graphic Art of Winslow Homer (New York: Museum of Graphic Art, 1968); Philip C. Beam, Winslow Homer's Magazine Engravings (New York: Harper Row, 1979); and E. P. Richardson, "Winslow Homer in Harper's Weekly," Art in America, No. 4 (1963), pp. 89-92. 
44John William Tebbel, The American Magazine: A Compact History (New York: Hawthorn Books, 1969), p. 119.

15Ibid., p. 116.

16Russell F. Weigley, ed., Rhiladelohiai_A 300-Year

History (New York: W. W. Norton and Company, 1982), pp. 269271.

${ }^{47}$ Ibid., pp. 479-480.

${ }^{48}$ Rogers, A world Worth while, p. 15.

${ }^{19}$ It is interesting to note that technological breakthroughs which gave rise to illustrated newspapers and created the demand for Special Artists also created the "first visual medium derived directly from the scientific revolution" which eventually replaced the special -photography. Many artists like Eakins embraced the new technology whether in creating artistic photographs or using pictures as aids in recording information. Remington's portrait The correspondent, symbolizes the rise of the photofournalist as he takes his Kodak into the field to document the news.

p. 434 .

${ }^{50}$ The Dafly Graphic, 8, no. 769 (27, August, 1875),

51 "The Pictorial Elephant," report flled from Montreal, February '9, 1877, and "The Rise and Fall of the Graphic Company," New York Sun, December 26, 1876, clippings from the AKM scrapbook. Photolithography itself was not new. Lodowlck H. Bradford patented a process "that produced a positive print from a positive transparency," in 1858, and Jullus Bein who served as the superintendent of the New York Lithographic, Engraving, and Printing Company in the late $1860 \mathrm{~s}$ advertised in 1868 that his firm did photo-lithographic work. Peter C. Marzio, The Democratic Art. Pictures for a 19th-Century America (Boston: David R. Godine, 1979), p. 58.

52The paper provided a fertile proving ground for a number of young artists including A. B. Frost, W. A. Rogers, Charles J. Taylor, and E. W. Kemble. Rogers in his reflections noted that the meeting spot for the Graphic artists in New York was "the Ann Street side of Mouquin's restaurant." Here the aspiring artists, which included, he noted, Frank Taylor, could soclalize with the established 
artists the Graphic had enticed from Paris and Vienna such as the caricaturist Theodore Wust, lithographer Louis Aubron, and war artist Thure de Thulstrup. Aubron, said Rogers, was a communist as well as a master of architectural drawing. He was employed by Géróme for assistance in elaborate perspectives. By placing Taylor at this rich artistic table, Rogers confirms not only Taylor's New York connections, but his entrée into the bohemian art world of that city. Rogers, A World Worth While, pp. 6-7.

${ }^{53} \mathrm{FHT}$, "A Cruise in the Buffalo," New York Daily Graphic, 8, no. 736 (20 July, 1875), cover.

54"The Balloon 'Buffalo.'" Unidentified clipping from a Cleveland newspaper of July, 1875 included in the UF portfolio.

55The paper had previously sponsored its own balloon malnly as publicity for the financially unstable illustrated daily even though they announced that "this voyage is one of scientific inquiry and not for public gain." "It was conceived and constructed by Washington Harrison Donaldson and John Wise for the purpose of making the first transAtlantic flight. The two balloonists reached an agreement with the Goodsell brothers on June 27, 1873 although Wise had reservations about the Goodsells' intentions fearing, as was the case, that they would "milk the flight for all the publicity it was worth." The publishers even issued a new paper, the Balleon Graphle, on August 9, 1873 and sold tickets to the assembly area. Wise was also disturbed because muslin not silk had to be used in order to remain within the allowed budget. The finished balloon measured one hundred ten feet high and one hundred feet in diameter with a gas capacity of approximately six hundred thousand cubic feet. Wise eventually withdrew his support, convinced as the project proceeded, that the balloon was unsound. During the September 12 inflation, a large rip developed in the fabric and the balloon collapsed. Donaldson was convinced that it could be salvaged, and the balloon was disassembled and restitched at half the original size and christened the New Graphic. The reformed balloon was launched on October 7 at 9:15 a.m. It did succeed in achieving flight but around noon, near New Canaan, Connecticut, the passengers abandoned the air ship in heavy winds and rain. ITwo years later, while working for P. T. Barnum, Donaldson made his last flight, an attempt to fly from Chicago across Lake Michigan, a distance of one hundred twenty miles. Donaldson and his passenger disappeared after being spotted by a schooner that 
evening. Taylor wrote a letter to the Editor of the Philadelphia Iimes on July 22, titled "From One who has Salled with Donaldson, signed "Hope," stating that "a balloon properly constructed and furnished with a drag rope of good length could, and should, outsail the limits of any of the northern lakes." Taylor further stated that "Professor Donaldson has more than once cut the basket away and taken to the ring of the aerostat, and he certainly would have done so in the present instance if unable to keep above water otherwise. He may come out of the woods yet." Although the body of Donaldson's lone passenger Newton S. Grimwood was found washed ashore on a Lake Michigan beach; Donaldson himself, as Taylor predicted, apparently survived the flight. A man claiming to be the famous aeronaut was found in late August by a fishing party traveling up the Montreal River in a hut fifty miles south of Lake Des Quinzes. He died shortly thereafter of complications of gangrene. Tom D. Crouch, The Eagle Aleft (Washington, DC: Smithsonian Press, 1983), pp. 439-440. FHT, "From One who Has Sailed with Donaldson," AKM scrapbook.

${ }^{56}$ See numerous clippings about the balloon launch in the Taylor UF Portfolio.

57"The Balloon 'Buffalo," " UF Portfolio.

${ }^{58}$ An unidentifled clipping from a Philadelphia newspaper announcing the death of the artist noted that his "sketches of the Centennial in 1876 won him a nation-wide reputation." This was, the article sald, "primarily because of their artistic merit and because they appeared in the first dally illustrated newspaper in the world." PSC microfilm, Role 3920, frame 412, Archlves of American Art. IFor additional documentation about the Centennial. Exposition and Philadelphia see John Mass, The Glerious Enterprise: The Centennial Exhibition of 1876 and $\mathrm{H}$. J. Schwarzmann. Architect-in-chlef (Watkins Glen, NY: American Life Foundation, 1973).

${ }^{59} \mathrm{An}$ unidentifled press clipping in the AKM scrapbook entitled "The New York Graphic" reports that "This influential journal has recently given some very handsome illustrations of Philadelphia scenery, and it now announces that, hereafter, it will issue every week, a supplement devoted exclusively to illustrations of our city and interesting Centennial objects. IFrank $H$. Taylor, the wellknown artist, will have supervision of the matter, and we can, of course, depend upon having it well done. . . ." 
60Joseph Pennell (1857-1926) studied with Thomas Eakins at the Pennsylvania Academy of Fine Arts. He was best known for his pen and ink landscape and architectural views of Europe. His illustrations appeared in Scribnex's, Century, and Harper's Monthly, and in the works of William Dean Howells, Henry James, and Mrs. Schuyler Van Rensselaer among others. He retained close ties with Philadelphia, his place of birth, and was an active member of the Philadelphia Sketch Club, serving as 1ts president in 1921. He was a close friend of $F$. Walter Taylor's, and wrote a commentary on the artist for a memorial exhibition of his colored drawings. Uncataloged folder of FHT and FWT clippings and memorabilia, HSP .

61 Joseph Pennell, The Adventures of An Ildustrator. This passage is also recorded in the PSC History (p. 85) where Lomas notes that Pennell always said this happened at Valley Forge but Taylor remembered it as happening at the Centennial.

62Dorothy Gondos Beers, "The Centennial City 1865-1876," Rhiladelphia, Weigley, ed., p. 466.

${ }^{63}$ Ibid.

64 Ibid., p. 467.

${ }^{65}$ Ibid.

${ }^{66} \mathrm{Miscel}$ laneous press clippings and lecture announcements from the AKM scrapbook.

${ }^{67} \mathrm{FHT}$, The Pilarims of 76 , or our late Visiters. A bound collection of twenty photo-lithographs, entered according to an Act of Congress, 1876, HSP, Bd 61 T213.

${ }^{68}$ These twenty-four small souvenir cards were published in Boston by Louis Prang in 1864. Lloyd Goodrich, The Graphic Art of Winslow Homer (New York: Museum of Graphic Art, 1968), p. 10, pls. 21-24.

69Marc Simpson, "The Bright Side: 'Humorously Conceived and Truthfully Executed," "Winslow Homer Paintings of the civil War, Simpson, ed., p. 48.

${ }^{70}$ Frost's humorous sketches, most often of American rural subjects, also appeared in many of the PSC's Rertfolio 
numbers. Frost is perhaps best remembered for his illustrations of Joel Chandler Harris' Uncle Remus stories. Rogers" "humorous, satirical, and political illustrations appeared in Harper's publications for nearly twenty years as well as in Puck, Life, St Nicbelas, Century, the New York Herald, and the Washington Post. The American Rersonality, pp. 156-157. For additional background on Frost see Henry M. Reed, The A. B. Erost Book (Rutland, VT: Charles E. Tuttle Co., 1967).

71 "Local News, \&C," unidentified clipping, AKM scrapbook.

${ }^{72}$ Ibid.

${ }^{73}$ Unidentified clippings from AKM scrapbook and UF Portfolio.

${ }^{74}$ Unidentified clipping signed "Alberto," UF Portfolio.

75It is this interest in science that makes $\mathrm{king}$ the logical choice for the Centennial committee, whose idea was certainly to turn a profit, but also to showcase American ingenuity and put Philadelphia back into the picture as a cosmopolitan city of innovation and daring where it was in 1776, not the stepchild of New York it had become.

${ }^{76} \mathrm{Handwritten}$ page from the AKM scrapbook.

77 "I llustrated Becord of the Southern Excursion Written and sketched by the "Special," Records of the southern Excursion of the American Society of Civil Engineers (Philadelphia: FHT, 1877).

${ }^{78} \mathrm{~A}$ gabion is a cylinder filled with stones and sunk in water, used in laying the foundations of a dam or jetty.

${ }^{79}$ The book has not yet been located.

${ }^{80}$ Unidentified clipping from the AKM scrapbook.

81"New Publications," clipping from the AKM scrapbook.

82Robert Henr1, "one of the leading exponents of American Realism" said "there is only one reason for the development of art in America, and that is that the people of America learn the means of expressing themselves in their own time and in their own land." Marianne Doezema, American Real1sm and the Industrial Age (Cleveland: The Cleveland Museum of 
Art, 1980), p. 8. IFor additional background on nineteenth century art and its cultural influence see Russell Lynes, The Art Makers: An Informal Histery of Painting Sculpture and Architecture in Nineteenth Century America (New York, 1970; rpt. New York: Dover, 1982; Lynes, The Tastemakers, New York: Dover, date; and Mumford, The Brown Decades.

83"The Mississippi Jetties," Harper's Weekly, 22, no. 1105 (2 March 1878), pp. 177-178.

${ }^{84}$ This and his connections with Graphic artists like de Thulstrup, Frost, and Rogers who were now working for the Harper firm.

${ }^{85}$ Exman, House of Harper, p. 103. See also Charles Rarsons and His Demain: An Exhibition of $19 t h$ Century American Illustration (Montclair, NJ: Montclair Art Museum, 1958).

86winslow Homer, who said he would be remembered for his watercolors, no doubt received encouragement and advice from Parsons. Homer may have initially been attracted to the medium because his mother was an accomplished watercolorist a fact which could perhaps substantiate recent psychological profiles which suggest Oedipean and homosexual tendencies in the artist. Henry Adams, "Mortal Themes: Winslow Homer," Art In America, 71, no. 2 (1983), pp. 113-126. TWhether or not this is the case, the medium is one which is reflective of American values. Its transparency, where mistakes are not concealed is like the American personality where nothing is hidden: what you see is what you get. This does not mean that thought did not go into the concept, but unlike the refinement of oils, watercolors appear fresh, impulsive, brash.

${ }^{87}$ Exman, House of Harper, p. 19.

${ }^{88}$ Ibid, pp. 80-93.

${ }^{89}$ There is no documentation that this was the working relationship Taylor had with Harper's. It is certainly possible that he was on a permanent retainer, but there is no documentation to indicate specific contractual arrangements. Eugene Exman points out that many of the art department records were destroyed during a relocation that would place it closer to the editors of the Monthly and Weekly which further complicates verification of the relationship between artist and publisher. Exman, House of Harper, pp. 103, 114. 
${ }^{90}$ Remington's first sketch for Harper's was submitted on a piece of wrapping paper stuffed into a small envelope and sent to Parsons. Exman notes that the art editor was accustomed to receiving well protected sketches, but the informality of Remington's package and the Wyoming postmark raised his curiosity. He was, of course, impressed by the offering and soon sent the artist a check and tear sheet. Ibid., pp. 114-115.

91Unfortunately much of this record keeping material was destroyed so it becomes necessary to rely on secondary sources for confirmation of reimbursement figures. Artists sketches were generally not copyrighted, something Taylor would take care to do with his later drawings of Philadelphi3, and as a result, the papers could sell the reproduction rights. This was done in part, Eugene Exman notes, to recoup the additional money paid the artist if the paper retained the sketch. For an entrepreneur like Taylor, who was aware of the potential value of his work, it is unlikely any of his drawings remained with the publisher. ITaylor also enjoyed reminiscing about his exciting adventures as a Special Artist, and, in particular, this 1880 trip with General Grant. In 1926 he wrote a note which was affixed to the portfolio of sketches documenting this assignment. In it he said, "I still treasure these sketches and prints. How much they recall to me. How like a stately picturesque dream it now seems to me at the age of eighty years!" UF Portfolio.

92 "General Grant in Cuba," Harper's Weekly, 24, no. 1209 (28 February, 1880), pp. 132, 135.

93 "Recollections of a Cuban Earthquake," The Mechantcal News, 14, no. 15, (15 October, 1886), pp. cover, 229.

${ }^{94}$ Of the four engravings shown on the cover, there is no extant corresponding sketch for Figure 1. Corresponding sketches for figures 2 and 4 are among the specific earthquake wash drawings mentioned above. Figure 3 "Title Wave" offers an interesting look at the ingenious utilization of existing materials by the special while also demonstrating the need to be careful in attributing accuracy to every sketch. This engraving is based on Taylor's watercolor of a placid seaside country house at Charrina, near Havana, now engraved in reverse, being beaten by a tidal wave. Certainly it $1 s$ quite possible this cottage did suffer tidal storm damage, since Taylor wrote in 1880 that local papers told of 
a destructive tidal wave along the coast, and Taylor is quite accurate in his depictions of events, but one has no verification that this particular cottage suffered the fate portrayed.

95 He had assembled the sketches into a portfolio in 1926 one year prior to his death. The sketches contain pencil notations which were done at the time of drawing. They also contain information written in pen at a later date. The penmanship suggests these ink notations were written prior to 1926 perhaps shortly after the trip when events were st1ll fresh as there is only one noticeable mistake when he labeled the dancing of the zapoteo as having been viewed in Cuba when it was seen in Mexico.

96 James P. Jones, ed., "Grant Forecasts the Future of Florida," The Florida Historical Quarterly, 29 (1960-1960), pp. 52-54. Also see William B. Hesseltine, Ulysses S. Grante, Rolitician (New York, 1935).

${ }^{97}$ For additional information on Grant and his renomination bid see William S. McFeeley, Grant: A Biography (New York: W. W. Norton \& Co., 1981).

${ }^{98}$ McFeeley, Grant, p. 479.

${ }^{99}$ Ibid., pp. 478-479.

${ }^{100}$ The cross-country journey was well covered by Harper's Weekly, but not by Taylor.

${ }^{101}$ McFeeley, Grant, pp. 478-479.

102 "New Publications" clipping from AKM scrapbook.

103w. A. Rogers in his writings noted that "The pursult of news pictures carries an artist into little intimate assoclations, for a day or two at a time, with all sorts of people, and it is surprising how much alike all people are at close range." Rogers, A World Werth While, p. 34.

${ }^{104}$ Recently the sketchbook of James Taylor, Special Artist for Leslie's, has been published. This sketch book contains drawings James Taylor used to prepare the sketches forwarded to Leslie's as well as wash drawings he did later when reminiscing about his adventures with Philip Sheridan in the Shenandoah Valley. It does not contain the sketches actually forwarded to the paper, nor has a scholar compared 
the drawings in the sketch book with the engravings which subsequently appeared in the paper. This would make an excellent research project and bring to light another special Artist for whom a body of material is extant. The James $E_{\text {. }}$ Taylor Sketchbook (Dayton, OH: Morningside House, Inc. 1989).

${ }^{105}$ Exman, House of Harper, p. 103.

${ }^{106}$ See Julian Grossman, Eche of a Distant Drum: Winslow Homer and the civil War (New York: Harry N. Abrams, Inc., 1974).

${ }^{107}$ Byron Andrews, the reporter for the Chicago Interecean, was the other reporter assigned to the presidential party, and presumably served as escort for the other niece.

108 "General Grant in Florida," Harper's Weekly, 24, no. 1206 (7 February 1880), pp. 84, 91.

109 It should be remembered that Taylor worked with two of the finest perspective artists in the country, Charles Graham and Louls Aubron. Rogers, A Werld Werth While, pp. 6-7.

110 Barbara Novak, American Painting of the Nineteenth Century (New York: Harper \& Row, 1979), pp. 96-97.

111 Japanese wood block prints would have also been of interest to him as an engraver, and he no doubt studied their effective and efficient use of line. The extent of the Oriental influence on Homer has been the subject of debate among art historians. Lloyd Goodrich who was one of the premier Homer scholars felt that "'the Japanese parallels in his [Homer's] work seem less a result of conscious imitation - . than of an underlying affinity between his vision of nature and that of Oriental printmakers.'" Novak, American Painters of the Nineteenth Century, pp. 166-167. William Rogers also saw an oriental approach in the "sincerity" of his work which "went straight to nature for... inspiration - . All that was there was true but nothing unnecessary or fussy found a place in the drawing. His method was not unlike that of the Japanese artist, Hiroshigi." Rogers, $A$ World worth while, pp. 235-236. Taylor too had a love for the beauties nature, and no doubt appreciated Homer's American interpretation of this age-old artistic culture. Also, his training as a Special, like Homer's, meant a focus on the most important elements of the subject without the need for unnecessary embellishment. 
112 James Thorpe, English Illustration: The Nineties (New York: Hacker Art Books, 1975), p. 12.

${ }^{113}$ Rogers notes that when Homer drew directly on the block, he used the "light, warm tone" of the boxwood as his lightest gray, "deepining it with a wash of India ink and painting in one or two high lights with white." A world Worth While, p. 235.

114"Oklawaha," Haxper's Weekly, 24, no. 1207 (14, February 1880), pp. 100, 110.

${ }^{115}$ Seraphim Record S-60212 "Music of Deluis," Album 2, Elorida Suite Dance Rhassody, No, 2/Over the Hilis and Far Away. Sir Thomas Beecham conducting the Royal Philharmonic Orchestra. Elerida, Insight Guides (Hong Kong: Apa Productions, 1982), p. 42 .

116 A more finished drawing such as this would not be completed on the spot. When the special had time, he would use his daily sketches to compose a more finished composition, one which would probably earn him a higher price from the editor and possibly be used again for other articles. Since Taylor did write and illustrate tourist publications, a finished drawing of the Oklawaha, one of Florida's earliest tourist attractions, would seem a logical choice. Only one year later he drew a map of the St. Johns River for the Leve \& Alden tourist publication department, and two years later he produced a brochure on the uplands of Florida for the Florida Central and Western Railroad.

${ }^{117}$ The oldest house is framed by an elongated palm tree which reaches out into the street. An early twentieth century photo of this historic site taken from the same vantage point shows the building and tree exactly as Taylor recorded them. The house remains one of the city's historic attractions, but the tree has since disappeared.

$110 " G e n e r a l$ Grant in Florida," Harper's Weekly, 24, no. 1208 (21 February 1880), p. 117.

1190 one in particular, Bread for the Peer, a rather labored watercolor, lacking in the vibrancy and spontaneity which Taylor was capable of, is interesting for what is on the reverse, a pencil sketch of horses in the surf with Morro Castle in the background. This sketch was probably done during Taylor's 1879 visit to Havana and a finished version was engraved for the Harper's Monthly article. He probably 
used this rough outline sketch as a basis from which to prepare a more finished black and white wash drawing which would have been forwarded to Harper's. None of Taylor's work from the 1879 trip has surfaced except for this sketch. It is possible he did not ask that the earlier sketches be returned, although that seems unlikely given his desire to preserve much of his work. The scene is an interesting one and Taylor wrote about this unique activity in the Harper's Montbly article: "Close by the battery at the end of the Prado a peculiar and exciting scene may be witnessed every morning. Here the surf rolls up with free stride against the shore. Just where a little bay is formed in the coral rock several hundreds of horses are undergoing an inspiring seabath . . Without this refreshing process the horses would soon droop under the climate, and even with it they are all sleepy and sad."

${ }^{120}$ Byron Andrews, "Grant in Cuba," Chicago Inter-Ocean, filed February 11, 1880 from Havana, UF portfolio.

${ }^{121}$ Taylor's wash drawing of the rough trip, Voyage to Vera cruz, Mexico, shows the deck of the steamship at about a 45 degree angle with some of the passengers, and particularly a woman in the lower left foreground, having difficulty navigating. The subject and point of view are very similar to Winslow Homer's Homeward Bound which appeared in Harper's Weekly on December 21, 1867. It was completed on Homer's return trip from a year long visit to Parls. Homer placed all the flgures on the lower side of the ship with only a woman's billowing skirt crossing the center line, as it listed during rough seas, exhibiting an understanding of the Japanese elements of placing the balance off center to create tension. (It has been suggested by some Homer scholars that his introduction to the oriental was in Paris.) Taylor's ship-board scene, while not as artistically effective as Homer's, also shows a comprehension of the elements that create a feeling of movement and instability through asymmetry. Taylor had probably seen and admired Homer's Harper's Weekly works and more recently been exposed directly to the Japanese approach to art during the Centennial.

122EHT, "With Grant," Philadelphia Times, filed from Orizaba, Mexico, February 18, 1880, UF portfolio.

${ }^{123}$ Ir.1d.

124Special Artist, James E. Taylor, who reported on Sheridan's activities in the Shenandoah valley in 1864 for 
Leslie's, describes the extent to which the special would go to retrieve a packet of sketches rather than lose them: "We had barely finished our meal when a tumultuous sound requiring no explanation greeted our ears from without, when instinctively a rush is made. TThe troopers crowd through the doors to secure their mounts and away while Peck and I dash into the yard. We could hear the clatter of horses tearing like mad down the pike and whistling minnies splashing against courthouse wall, and to accelerate our movements, if that was at all necessary. Shells began exploding about, the enemy having got a battery in position at the west end of the town to enfilade the pike. IThe 'boy' having our nag in charge had lit out at the first alarm, and we had no lightsome task getting our nags into the alley, but finally succeeded, and once mounted, we whirled wildly away and down a side street in preference to joining the stampeding blue coats on the bullet swept street. IWe had not proceeded far when I missed my satchel with its valuable contents, which in my excitement I had left on the yard bench. To forsake my garnered material and sketch pad was out of the question, and risk its recovery I determined. I had to set-to with 'Tom' to make him obey the bit and in my struggles to make him face the house my hat dropped off. To dismount and recover it amidst $z$ ipping bullets was no easy task but I finally managed it, and after using my spurs freely on his flanks I got him to the Sappington. My supreme trail came when I dismounted to lead the animal into the yard, as I dared not let go of the bridle. Finally I dragged him to the bench and recovered the prize. To remount was equally difficult owing to the pandemonium reigning, but that too, though seemingly an age, was finally accomplished, when the frantic animal dashes away with his charge at locomotive speed for the exit, without getting winged, thanks to Providence." The James E. Tayler Sketchbook, p. 241-242.

${ }^{125} \mathrm{Grant}$ and Fred Dent were roommates at West Point and through visits to the Dent household, Grant met and married Julia Dent. It was at the wall surrounding Molino del Ray where Grant found Dent wounded and loosing blood. After refreshing him with his canteen, Grant dragged his friend and future brother-in-law to safety. John Y. Simon, ed., The Rersonal Memories of Julia Dent Grant (New York: G. P. Putnam's Sons, 1900), p. 315.

${ }^{126}$ This information was written on ink on the wash drawing. 
127"The Battlefields of Mexico," Harper's Weekly, 24, no. 1216 (17 April 1880), p. 144. Grant was always interested in Mexico dating from his first exposure to the country during the Mexican-American War. He later tried unsuccessfully to establish the Mexican Southern Railroad. In a note to a group of Mexican journalists shortly before his death Grant wrote that "She [Mexico] has all the conditions; she has the people, she has the soil, she has the climate, and she has the minerals" to make for a prosperous country. Thomas Chaplin Braman, "Ulysses S. Grant and Mexico," Diss. University of Florida 1964, p. 67. Also see Chapter V, "ExPresident Ulysses S. Grant" in David M. Pletcher's book Rails, Mines, and Progress (Ithica: Cornell University Press, 1958) pp. 149-181. It is interesting to note here that the surname Taylor was one which would have evoked strong memories for Grant as General (and later President) Zachary Taylor was one of the heros of the Mexican War. Sheridan also had a Taylor in his past, the previously mentioned James E. Taylor, Special Artist with Erank Leslie's who documented the General's Shenandoah command.

${ }^{128} \mathrm{FHT}$, "President Porfirio Diaz: The Benevolent Despot of Mexico," Beoklovers Magazine 3 (1904), p. 767.

$129^{\circ}$ omero became minister to the United States under Mexican President Juarez, and first met Grant in 1864 on a visit to the General's City Point Headquarters during the Civil War.

130"Grant in Mexico, Philadelphia Times, UF Portfolio.

${ }^{131}$ HSP Manuscript Collection, Box 2, Folder 3.

132 "The Republican National Convention, Chicago," Harper's Weekly, 24, no. 1225 (19 June 1880), pp. 392-394, 396.

133 "Among the Thousand Islands, Harper's Weekly, 25 (18 August 1880), pp. 549-550.

${ }^{134} \mathrm{HSP}$ Manuscript Collection, Box 1, Folder 4.

${ }^{135}$ Ibid.

${ }^{136 \text { Ibid. }}$ 
THE PROMOTION OF TOURISM \& LEISURE

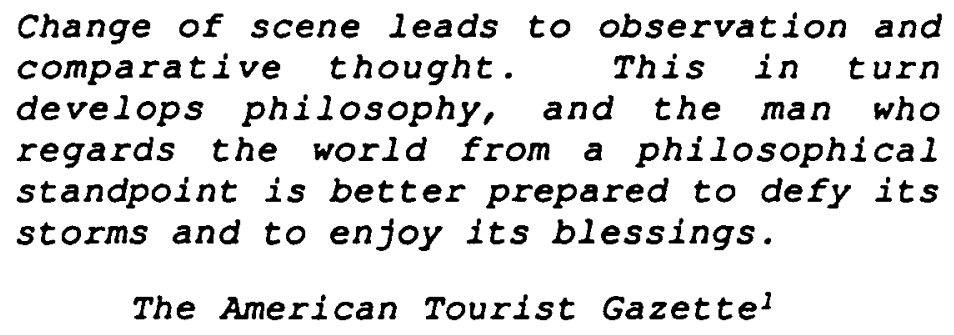

During the nineteenth century a new attitude toward leisure began to expand and enrich the quality of life for the American middle class.2 This new mind-set did not, however, require a European Grand Tour, long de riguer for the elite; it could be achieved by visiting the wonders of America so recently made accessible by the railroads. ${ }^{3}$ The Idea that travel was healthy for the mind fit comfortably with the new concerns for education espoused by John Dewey who believed that "all education proceeds by the participation of the individual in the social consciousness of the race."4 The benefits of travel also reinforced new thoughts for overall physical health that stressed participation in outdoor activities as a relief from the confinement and stress of industrial labors.5 In addition, the widely read writings of naturalists John Muir and later Aldo Leopold encouraged a nation to explore the scentc beauty of the 
country's wilderness which "gives definition and meaning to - . life."6 It seemed, in fact, as if Americans were almost required to travel if they wanted to improve themselves and their country.

All this interest in exploration was for the general population, of course, not new, although the emphasis on travel for its own sake rather than for purely economic reasons was. ${ }^{7}$ What was new was an increased awareness of the many unique places to visit in one's own country so richly described and illustrated in newspaper articles and tourist guidebooks, such as Frank Taylor's forty-eight page guide to New England and the St. Lawrence River, Away Down East: Or My Unexpected Vacation." Travel literature was both popular and profitable, as one publisher noted; "'Travels sell about the best of anything we get hold of . . They don't always go with a rush, like a novel by a celebrated author, but they sell longer, and in the end pay better." "9

Travel literature, of course, had been available to the privileged classes since the days of the Greeks, and Herodotus could be considered in some ways the first travel writer. However, it was Marco Polo's account of his journey to Cathy, that can be considered the first true travel guide. Its innumerable, widely published translations made the Milinol's descriptions of exotic places accessible to the masses -- at least in theory.

While Polo did not illustrate his "travels," his accurate, detailed accounts of flora and fauna, native peoples, 
and architecture seemed to demand visualization. Initially this was often on maps, such as in the Catalan Atlas of 1375 and the Erau Mauro mappamundi of 1459, where images of the sojourn most frequently appeared. This was a logical development as writers increasingly favored scientific accuracy over myth, evidenced in the more realistic depiction of continents and their contents -- besides, cartographers needed illustrations to fill in the vast spaces of unexplored interiors. Elaborately illustrated maps even became interior decoration, as can be seen in many of Vermeer's paintings. Renaissance and Baroque mapmakers such as Willem Blaeu produced "coffee table" atlases that graced the interiors of the new Dutch middle class, for whom travel and exploration brought new found wealth, and were in essence illustrated guidebooks. Polo's descriptions, and maps based on his accounts, prompted Columbus to set sall for China, only to discover a new world full of its own unique qualities that would in turn attract men like John white to write and illustrate what they saw, and encourage travel and exploration to America. Ilke their nineteenth century counterparts, the citizens of seventeenth-century Europe realized the wealth of knowledge to be gained by exposure to new thoughts and ideas, and the excitement this exploration could generate. 10

Economic and political reasons remained the predominate motivation for travel until the industrial revolution, for even though the middle class could read about the marvels to 
be seen, adequate and inexpensive transportation was lacking. The railroads made remote locations accessible to an increasingly curious clientele. For nineteenth-century lllustrators like Taylor, the numerous railroad companies offered an additional source of income as they eagerly produced illustrated brochures, which described and showed the exciting views to be seen along their routes.11 Entrepreneur that he was, Taylor's honeymoon was even courtesy of the Philadelphia and Reading Railroad, which provided a special car and locomotive for the couple, enabling the new bridegroom to prepare sketches for an illustrated folder for the company's Reading and Lehigh Valley Line. 12

Taylor's ability to write the descriptions as well as produce the illustrations again proved advantageous, and made him a sought after special. He was essentially, as a travel writer, performing the identical task as a newspaper Special, 1.e., traveling to a site to gather information for an 1llustrated article. And, in fact, he was pursuing his career as a travel writer at the same time he was working for the Daily Graphle and Harper's Weekly. This was in part because he seems to have enjoyed traveling in whatever capacity, but also because as a new husband and then father, he needed to establish a strong financial base for his family.

The honeymoon excursion was apparently not the only time Taylor was able to include his family in his work or was provided spectal accommodations by the sponsoring rallroad. In a news clipping found in the Atwater Kent Museum scrap- 
book, the writer notes that "Mr. Taylor of the New York Graphic, his wife and son were provided a 'diminutive traveling car,' pulled by the Ariel of the Philadelphia and Reading Rallroad."13 The writer goes on to note that the guidebook to be prepared by Taylor would disseminate "a knowledge of our resources (the imposing character of the coal region of Pennsylvania) and a general idea of the topography of the country as well as of the natural fitness of many parts of the region for summer resorts. . . ." The fact that coal collieries were viewed as highlights of the trip attests to the nineteenth century view that industrial operations were sources of interest for the tourist who could, of course, continue on his travels to some quiet, picturesque location. Coal was, however, important for Pennsylvanta's, as well as the nation's economy, and many collieries were operated by the railroads, who depended on the natural resource for power. Featuring the mining process was thus in the company's best interest.

As a Special Artist, Taylor traveled over much of the North American continent, recording dramatic events and items of interest. He seemed to find enjoyment in every location, but during a trip to the Thousand Islands in northern New York, while on assignment for Harper's Weekly, Taylor found his own personal leisure destination.14

Recovering, he noted, from the effects of malaria and hay-fever, and exhausted from ten years of constant travel, he found in this St. Lawrence River archipelago, (Fig. 11) a 
peace from the demands of his nineteenth-century urban existence. ${ }^{15}$ This change of scene would also allow him time to reflect on his life, and may have influenced his decision to devote more of his time to his family, concentrating his work on the places he loved most, Philadelphia and the Islands. This love for both urban and rural -- needing each in order to fully appreciate life -- was reflective of the times. There was a realization and appreciation, even glorification of industrialization in America whlle, simultaneously the agrarian values espoused by Jefferson still remained important. Taylor and others seemed to justify the dichotomy through active participation in outdoor activities; and if possible, living a part of their lives in each world, appreciating the cultural values of both.16

The Thousand Islands area of the St. Lawrence could serve as a microcosm of nineteenth century leisure values. The area played a significant role in the history of North America, in part because it is one of the narrowest passageways on the important seaway linking the Great Lakes with the Atlantic, but in particular because of the protection the islands afforded for attackers, smugglers, and fugitives, between often hostile nations. The region was originally home to the Confederacy of the Iroquols, whose five-member nation included the Mohawk, Onondaga, Seneca, and Cayuga. The French began explorations there in the 1600s, establishing permanent settlements for New France in a territory rich In furs. In addition, Jesuit missionaries, such as Father 
Simon La Moine, began efforts to convert the Indians to the Roman Catholic faith. Cognizant of the excellent trade possibilities, the British had also laid claim to trade in the area by 1720 , offering better and cheaper goods than the French. Tensions between the two colonizing countries were not limited to the Thousand Islands, of course, and England declared war in 1756. The final battle of what was known in America as the French and Indian war was fought in the Thousand Islands on Isle Royal (now Chimney Island, New York), where the British under Major General Jeffrey Amherst, hero of the battle of Louisburg, attacked and defeated the French at Fort de Lévis. ${ }^{17}$

Unfortunately the peace declared in Paris was shortlived. The newly acquired land of Quebec, formerly New France, had been seen by many of the colonists south of the St. Lawrence as a prime area for free western settlement. However, the Quebec Act of 1774 not only allowed French civil law to remain in effect, but granted special protection to the Catholic Church, making the province undesirable to many, and magnifyir.g tensions with Britain, whose "Intolerable Acts" had already placed a great straln on the mother country's relationship to her thirteen original colonies. This time when war was declared, the fortifications along the St. Lawrence were strengthened with British and American loyalist troops, as the waterway became a supply line for materials on their way to Forts Oswego, Niagara, Detrolt, and Michilimacinac. 
At the conclusion of the war many American loyalists fled to the Canadian side of the river, but it was not until 1791, when the Province of Quebec was divided, and the Thousand Islands region became part of the new Protestant-led Upper Canada, with its capital York (now Toronto), that the northern side of the river began to develop commercially. As Mary Beacock Fryer has noted, this placed "the Canadian side of the St. Lawrence. . . within the mainstream of provincial life," resulting in the establishment of thriving settlements on the north shore. ${ }^{18}$ By contrast, American settlement along the Thousand Islands shoreline was sparse, in part due to the "presence of Brit1sh regulars at Fort Oswegatchie lOgdensburg, New York) and Carleton Island, but also because the area was remote from the main population centers of New York state. . . "19

Again, however, peace was elusive. When the young United States declared war with Great Britain in June of 1812, the Congressional representatives of the upper St. Lawrence voted against the War Hawks. During the war, illicit trade in American cattle and grain developed as Canadian farmers smuggled goods across the narrow channel in order to meet the imposed demands of supplying the British regulars and Canadian militia. In this way the farmers were able to retain their own best stock and supplies, often hiding thelr prized cattle in the woods and on the islands. Fryer notes that "it was one of the ironies of that conflict that they [the Canadians and British] were fed -- and in some 
instances equipped indirectly ... by the enemy itself." She also theorizes that had the Americans taken full advantage of the vulnerability of British supply lines as they passed through the islands from Montreal to the western forts, the annexation of Upper Canada would probably have become a reality. The islands, of course, provided a myriad of hiding places where "American troops could make hit and run attacks on the Canadian convoys," utilizing the guerilla tactics which were so successful in their war for independence. In the end, little changed except that Carleton Island with its Fort Haldimand, became part of New York State. ${ }^{20}$

The Treaty of Ghent brought an unstable peace that would not become permanent until the end of the $1860 \mathrm{~s}$, when the United States resolved its internal conflicts and Canada became a Dominion.21 During this flfty year period of increased settlement on both sides of the river, Clayton in New York, and Kingston in Upper Canada, emerged as important shipbuilding centers. The Village of Clayton also became the headquarters for timber raft construction as wood was sent downriver to Montreal or Quebec City for export overseas. While the forests around the Thousand Islands had been generally logged over by 1840 , rafting remained a staple on the river into the 1880 s when Taylor was writing about the colorful industry for an article entitled "St. Lawrence Summer Iffe."22 The event was part of the local flavor which a Special Artist knew would be of interest to readers and which future visitors might wish to experience, just as 
European travelers wanted to meet the native tradesmen of Venice and Constantinople. ${ }^{23}$

The raft, as Taylor wrote and illustrated, was really three rafts bound together extending a third of a mile. The "timber was already squared, and lay half a dozen stlcks deep. All of these thousands of immense pieces were securely bound without injuring the wood with peg-holes." On the raft were the anchors "as large as those of a frigate," dug-out canoes, "one or two tents, in which the men slept," and a shanty for the boss and his gang-foreman where they "even indulged in the luxury of straw mattresses in their bunks." "The force upon such a raft . . numbers about thirty men, and they can take two rafts, or groups of rafts to Montreal monthly." Taylor not only recorded what he considered to be "one of the most picturesque of life-upon-the-river incidents," but suggested to his nineteenth-century readers that "considerable enfoyment can be had in rowing out to them [the rafts] mooring your boat and talking.. . to the swarthy, good natured crew." Such were to be the halcyon days of summer, once tourism became an important economic force in the islands.

Other developments were necessary, however, before the area could become a tourist destination. Of primary importance was the building of a canal to bypass the restrictive rapids on the upper St. Lawrence and deepen the old canal at Lachine, thus allowing larger ships, which had been using the Rideau Canal, to pass through the Thousand Islands region. 
The first St. Lawrence Seaway was completed in 1848. This brought increased economic prosperity to the Islands. The Rideau Canal then became a popular route for passenger steamers such as the James Swift, which Taylor recorded readying to descend the locks at Jones Falls. The Canadian and American governments also built seventeen lighthouses along the narrow channel so pilots would no longer have to moor their vessels at night.

The retooled waterway was a boon not only to freight traffic, but also increasingly to passenger steamers which brought tourists to the islands. In 1850 the first railway came to the St. Lawrence when Ogdensburg became the terminus of the Rome, Watertown, Odgensburg Railway, linking the south shore to the more populous southern portion of New York, with through connections to New England. Rallways linking the north shore communitles with Toronto, Ottawa, and Montreal also increased visitation to the island region, which until the 1870 s remained mainly agrarian. As Fryer notes, "The notion that people should have recreation, or take holidays, was [still] totally foreign to the local people. $" 24$

Fishermen were among the first "tourists" to discover the Thousand Islands, which had and still has "some of the best, if not the best, muskellunge fishing in North America" as well as an "abundance of plke, plckerel, bass [and], perch. . ."25 While changes would occur in tourists' reasons for visiting the Islands, it was fishing and its 
accouterments that fostered the region's economic development. This was, of course, fishing for sustenance not of the body, but of the spirit -- the eternal struggle of man against nature, but in a more "civilized" atmosphere where one's life was not dependent on the outcome. Taylor expressed this philosophy when he described fishing at the Thousand Islands in his guidebook for the Crossmon Hotel at Alexandrla Bay, New York:

The desire to catch a fish rests dormant in every
human breast, only requiring favoring circumstances
and ample leisure to arouse the lmpulse honestly
inherited from remote ancestors of nomadic
tendencies. The question of liking or disliking
flsh as an article of food has little bearing upon
the matter of ensnaring the victim, for having once
captured, rejoiced over and exhibited the creature,
all interest in its subsequent disposition ceases.
At least in most instances. IThe element of
uncertainty attending every phase of angling
doubtless accentuates the pleasure of the
undertaking. 26

For Taylor, an avid fisherman, there was an added desire to paint fish, and some of his best work is exhibited in his watercolors of individual bass chasing the bait. Perhaps the artist's respect for this felsty aquatic opponent is what contributed to his lively portrayal among a body of work that, while picturesque, is essentially passive.27 In the three extant watercolors of small- and largemouth Bass (Fig. 12 is one example), Taylor's adept handling of the medium allows the viewer to sense the vibrancy of the moment as the fish dives under the crystal clear waters of the St. 
Lawrence, or suddenly breaks through the surface into the colorful sunlight.

The realism is journalistic, as there is a story here, although the "reporter" does not reveal the final outcome. These paintings are not unlike Homer's who was palnting the Adirondack trout not far away. ${ }^{28}$ Taylor had, no doubt, seen his contemporary's exquisite watercolors of game fish, and felt a kinship with another fisherman who also felt compelled to preserve the experience. The transparency of the medium and the use of color is what Homer historian Lloyd Goodrich described as the "visual sensuousness" in Homer's Adirondack works, a term that can be equally applied to Taylor's Bass series. 29

The only known public exhibition of Taylor's paintings of flsh was at the 1893 Chlcago World's Fair when two watercolors, one of a plckerel and one of a bass (along with an oil painting of a muskellunge by Miss C. L. R. Child), appeared with the award winning display of Gardner M. Skinner's fluted trolling spoons. ${ }^{30}$ Himself a part of the Thousand Islands fishing mystique, Skinner developed his famous fluted blade spinner in 1874, no doubt in part to capitalize on the number of fishermen who were seeking out the large game fish of the upper St. Lawrence. The flutes, noted Skinner, were added to "increase the reflection, thereby multiplying the attractiveness as well as strengthen the Spoon, without Increasing the weight." 31 The beauty of the assembled bait was recognized by the World's Falr Judges 
who awarded Skinner the only medal in the fishing and tackle category. Five years later Skinner was again honored with an award and special medal, this time in Bergen, Norway, for his contribution to sport fishing. ${ }^{32}$ The beauty of the "machine," an appreclation of the purity of form, elevated these lures to an art form, and as such were appreciated by Taylor the artist/fisherman on more than one level. ${ }^{33}$

Another award winner at the Columbian Exposition, and an integral component of what Taylor termed the "piscatorial climax" of the Thousand Island fishing experience, was the St. Lawrence River Skiff, Canoe, and Steam Launch Company, also of Clayton, builder of the "famous St. Lawrence River Skiff." The skiff, revered in the region, was an essential element because a reliable, easily maneuvered boat, initially required by boatmen, was vital to the requilte fishing guide as tourism increased and "anglers" replaced "fishermen."34 Taylor's most reproduced painting, Muskie Elshing on the St. Lawrence, (Fig. 13) shows a guide with his two-man party in a classic st. Lawrence skiff as they land a prize muskellunge. 35

At flrst glance the craft appears as an descendant of the canoe and/or Adirondack guldeboat; but in fact it is a unique and indigenous design. ${ }^{6}$ A canoe was light, flimsy, unstable, and difficult to maneuver in the wind. The guideboat needed to be light enough to portage, restricting its suitability to mountain streams or placid lakes. What was needed on the open waters of the St. Lawrence was something strong and stiff enough to withstand high seas, hence the 
skiff. Bertha Fry Hall, daughter of Lucien Fry, one of Clayton's celebrated nineteenth century skiff builders wrote: "'there is nothing more seaworthy than a good St. Lawrence skiff. I have rowed across the river in a gale when all the freighters were anchored or tied up."'37 This stability was one of the skiff's most celebrated qualities and touted in the St. Lawrence River Skiff, Canoe and Steam Launch Company catalogs, which included a drawing (probably by Taylor) of an average (145 $\mathrm{lb}$. ) welght man standing on the gunwale (Fig. 14). ${ }^{38}$ Note was made in the accompanying descriptive caption that this was "No Trick." For the angler, of course, this meant that he could safely lean over the side to gaff or net a heavy fish without falling overboard. ${ }^{39}$

The skiff's interior was also designed to accommodate the angler's needs. As shown in Taylor's watercolor, and described by him in an article first written for the Mechanical News but reproduced in various publications:

Snug seats are placed for and aft. These are detachable for sponging out. The stern seat is fitted with an arm-chair, cane-seated and backed, without legs. Five feet forward of this is another seat with a similar chair, and upon the thwarts between them are catches to hold trolling rods. . . The two chairs face, and behind the last names is a fish box, which is exactly in the center of the boat. This box serves as a seat for the rower when alone in the boat, in which case he rows stern forward. 40 
The box also served as a seat for the guide, the two facing seats allowed the two city anglers to converse during their leisurely day on the water. 11

In the background of Taylor's watercolor is another boat. This too is a skiff, but sprit rigged for sailing -- a true test of one's seamanship as the boat had no rudder. 12 In fact, Taylor began his article about skiffs by noting the craft's salling reputation. "Every visitor to the Thousand Islands, who is at all au fait in the matter of sailing, must admire the grace, speed and capabilities of the St. Lawrence River Skiff, and no less the skill and daring with which it is handled upon the breezy and often tempestuous open waters between the islands." 43 In an unsigned 1889 article from Eorest and Stream, the author notes that "steering. . . [is] done by trimming the sheet and changing the balance of the boat. The boatman brings her up into the wind by moving aft, handling her as perfectly as could be done by a rudder." 44 The sail made the already streamlined boat even faster, aiding guides in reaching prime fishing grounds and providing a break from rowing. Competition among guides was spirited, particularly between those of clayton and its Canadian neighbor, Gananoque Ontario, with annual sailing regattas held to determine "bragging rights." The skiff Taylor detailed in the foreground of his watercolor was 1dentified by skiff historian Harold E. Herrick, Jr., as one bullt by Charles Estes of Alexandria Bay, New York.45 The artist himself, however owned at least 
one built by Xavier Colon of Clayton, credited with being the original designer of the St. Lawrence River Skiff. Colon began his skiff building business in 1870 .

Colon built individual boats; but a dentist, Dr. A. Bain, saw greater potential, and in 1873 "persuaded a group of wealthy summer residents to invest in a skiff-building company."46 The boats were built in a factory, and in $1885 \mathrm{~A}$. Bain \& Co. (Colon was reduced to shop foreman), published its first catalog including illustrations by Frank Taylor, noting that the company was producing approximately twenty-five skiffs each week. By 1893 the company had become the St. Lawrence River Skiff, Canoe \& Steam Launch Co. and exhibited their prize winning skiffs at the World's Fair in Chicago. 17 Skiff building had evolved "from a cottage industry to factory production for sale to private buyers, to hotels and skiff liverles, and then to bullding skiffs for export to regions far outside the Thousand Islands area."48 With products like Skinner's spoons and St. Lawrence River Skiffs, industrialization, along with a healthy tourist 1ndustry encouraged by promotional materials produced by special Artists like Taylor, could lead to prosperity in even remote areas.

Taylor's concern for preservation, while enjoying the benefits of industrialization, was evident in his interest in the sport fishing economy of the Thousand Islands. In 1884 "The Angler's Association of the St. Lawrence River" was formed out of a concern over net fishing. Taylor feared 
"that this vast aquarium might, some day, be 'fished out." 49 The Association lobbied for legislation that would restrict netting, which, they argued, trapped game fish, not only reducing the number of fish available for the sportsman, but consequently affecting the entire tourist economy. The Association eventually succeeded in facilitating an agreement between the Canadian and U. S. governments placing "all of the Island system . . [1nto] an International Park." They also worked with the state of New York on a hatchery program to release "vast numbers of muskellunge fry... In the river; [so that] one of these days that splendid fish which is the objective of many a long day's work in the skiff will be far more plentiful than at present."so

Taylor's letterhead for the Association, which includes the reproduction of his 1894 watercolor, shows an "angler" proudly displaying a large bass while his partner and guide continue fishing in the abundant waters of the St. Lawrence. 51 The scene represents all that was picturesque about nineteenth century flshing in the Thousand Islands, where one could spend a leisurely day on the water and be guaranteed both a good catch as well as a fine time achleving it. One is reminded here of a passage from Kenneth Graham's wind in the willows: "There is nothing -- absolutely nothing -- half so much worth doing as simply messing about in boats."

The Thousand Islands might have remalned a quiet farming community which catered to and benefited from the seasonal fisherman if it had not been for George M. Pullman, bullder 
of the famous railway sleeping cars, who invited president Grant and Philip Sheridan to his island home, "Castle Rest" in July of 1872. Pullman, an avid fisherman, was one of the first of the wealthy elite to purchase an island and erect a cottage. He was a strong supporter of the region as a summer resort, no doubt in part because of his "belief in the civilizing effects of beauty" and also because increased rail travel to the area would stimulate demands for more of his railway cars.52 At the time, demand for property was slow, so Pullman approached Andrew Cornwall and his partner Walton, developers who owned most of the islands, with a plan that illustrated Pullman's understanding of the power of publicity. "'What we want to do, Andrew," Pullman sald, "'is to make much of the General's visit here and it will advertise the islands as no other thing we can do. To have the President of the United States as our guest is quite an honor.'"53

In his booklet A souvenir of the Thousand Islands, James Bayne, brother of the dentist and skiff promoter A. Baine, described the presidential visit and its subsequent effect on the Islands:

When Grant and Sheridan arrived the walk from the landing was covered with carpet, and island and cottage gaily decorated with bunting. . . The crowd of newspaper correspondents that followed heralded abroad every movement of the presidential party, every trip among the 1slands, every fish caught and every place they stopped for lunch. The news was eagerly sought and read. Soon the river was dotted with boats, both large and small, of 
every form and variety. The islands and main shore swarmed with all classes of people from every part of the country; public receptions were given by both Grant and Sheridan and from that time there was a great demand for the islands. 54

It is interesting to note that the two generals, who a few years hence were to play such an important role in Taylor's life during their travels to Mexico, were the two men whose publicized visit to the Islands prompted papers like Harper's Weekly to assign their Special Artists to cover the area. This led in turn not only to Taylor's purchase of his own 1sland property, but also to a second career as a Special Artist promoting the Thousand Islands in newspaper articles and guidebooks. Grant was also running for office in 1872. Undoubtedly the visit to Pullman's island haven did nothing to stem the criticism of Grant's opponents who charged that the president "long depended on and favored some of the richest of the nation's capitalists" despite his claim to appeal to workers' votes, with posters showing he and running mate Henry Wilson as "the tanner and the cobbler."

Taylor's 1881 article in Harper's Weekly was accompanied by a full-page engraving (Fig. 15) consisting of seven sketches (redrawn on the blocks by Charles Graham) which depicted the region during the height of its popularity as a summer resort, and provided the viewer with an appreciation for the beauty of the Islands as well as the recreational opportunities to be enfoyed.55 For those who could afford 1t, or wanted to see what the upper middle class was building, 
Taylor detailed two Victorian cottages replete with exposed framing and encircling porches $(\$ 2 \& 3)$. In the foreground of $\# 2$ is a naptha steam launch which could carry more passengers than a skiff and, of course, did not require rowing -these boats were often used to tow four or five skiffs to a distant fishing ground. This scene also records the popularity of viewing the islands in the evening when cottage lights would dot the waterway.

It is Taylor's view of Alexanderia Bay (\$5), however, which really reflects the Islands' emergence as a tourist destination, as it includes two of the areas most famous resort hotels -- The Thousand Island House in the center and the Crossmon House on the left, as well as the many passenger steamers which transported guests to their Island destinations. The Crossmon House, for which Taylor prepared a tourist brochure in 1901, was one of the oldest hotels in the Islands and representative of the region's economic changes. It began life as a small ten-room fisherman's lodge known as Smith's Tavern. In 1848 it was purchased by Charles Crossmon, and with some modiflcations became Crossmon's Hotel, which, Taylor writes, "began the modern story of the Thousand Islands; the first chapter in the romance of a real fairy land."56 The hotel was enlarged twice, before final additions were made in 1881 bringing the total rooms to 300 , and it henceforth became known as the Crossmon House. The impressive structure offered far more than a room and simple meals for fishermen. There were now suites with 
private bathrooms for families, "elegantly" furntshed drawing rooms, a main dining room overlooking the river where tables were set with "costly china, silver, cut glass, and the finest linen, and supplied with the rarest fruits and delicacies," along with a separate children's dining room for those in the charge of nurses. An orchestra offered morning concerts in addition to dinner music in the drawing rooms and evening dancing. There were provisions for tennis, and croquet, as well as guides for fishing. In the evening, a fireworks display was often held, and the "rows of colored lights [which] illuminate the verandas, and shine from its many towers, [shed] . . . a wealth of color upon the water."57 Taylor's watercolor, which appeared on an earlier page of the Crossmon's 1901 brochure, summarized all that was considered picturesque about a sumer stay in the Islands for the middle classes. Along with the obligatory Crossmon House in the background he included a sailing skiff, naptha launch, and steamer, while in the foreground the fortunate hotel guests who have hired a boatman for a day's flshing prepare to enjoy a pleasant Shore Dinner. ${ }^{58}$ From the skiff the guide has produced a table and provisions as he prepares the sumptuous meal, while the angler displays his trophy catch to his wife. What could be more ideal, and what reader in New York City, Buffalo, or Philadelphia could not imagine a wonderful summer away from the hectic life of the city. This scene invokes as well the "receptive" recreational philosophy of Frederic Law Olmsted, who thought parks should provide 
tranquility and rest to the mind; and in many ways at the turn of the century the Thousand Islands was a large public park; while not entirely free, the varlety of accommodations allowed a wide range of incomes as well as the local inhabitants to enjoy the scenery. While the large hotels catered to the visitor who could not afford to erect his own cottage, or remain the entire season -- usually mid-June to late September -- another lodging alternative was available in the form of religious camps. Revivalism was quite prevalent in the late $1800 \mathrm{~s}$ among older Protestant denominations, whose philosophy at the time was one of "defense of the status quo," with no overt social concern. And, having a camp in the Thousand Islands among some of the wealthiest of the nation's industrialists no doubt did nothing to reduce growing criticism that the church was abandoning the working class.

It was Theodore Roosevelt who correctly noted that "The Methodists represent the great middle class, and in consequence are the most representative church in America."59 The Methodists were one of the strongest proponents of this Individualistic idealism, and their 1,000 acre Thousand Island Park on Wellesley Island was one of the largest camps in the region. ${ }^{60}$ The summer resort was the inspiration of Reverend J. F. Dayan, who persuaded other New York City Methodists to Invest in an area of clean alr and fresh water, a welcome relief from the city. ${ }^{61}$ Susan Smith notes in $B$ History of Recreation in the Thousand Islands that originally 
the camp rented or sold tent lots, but, it was not long before cottages replaced the temporary canvas, and a thriving community was established. She also notes that one of the ways Thousand Island Park raised funds was to levy "A small head charge. . against all tour boat passengers and [charge] the large steamboat companies. . a yearly rate."62 However, no boats were permitted to dock on Sundays. ${ }^{63}$ The Methodists were not adverse to making money while enjoying their holiday.

The park had a tabernacle for extensive camp meetings, and Taylor wrote in 1881 that "Sunday school, temperance, and educational conventions occur here during the summer." In 1883, the Park opened the Thousand Island Park Hotel with rates graded according to room location: $\$ 2, \$ 3$, or $\$ 4$ per day -- 50 cents less if two persons occupled one room.64 The Park Association, like other religious camps in the region, was not exclusive, and members of other denominations were invited to purchase cottages and stay at the hotel, their only desire was "to keep children of the resort away from 'harmful influences.' "65

The religious parks and even the hotels, espoused family values, and, as mentioned above, this may have been part of the area's attraction for Taylor. As the structure of nineteenth century family life continued to evolve with a separation between work and home, the opportunity to spend time as a family unit became increasingly important. This aspect of the leisure experience was highlighted in tourist 
brochures like the one Taylor produced for the Crossmon which boasted that "The Crossmon is preeminently the children's hotel." The conservative middle class saw in the promotional literature produced by individual hotels, railroad and steamship companies, church camps, and others, accounts of healthy, safe places for their families to spend their precious leisure time.66

The Islands' appeal for Taylor was perhaps initially the area's quiet beauty. As noted, part of the attraction of the Harper's Weekly assignment was his "hope of recovery from the combined effects of malaria and hay-fever," which had been "hammering away for some months at a constitution somewhat strained by persistent over-work."67 The constant travel, required by a Special Artist to remain at the peak of his profession, was perhaps taking its toll on a man who seemed to cherish his family. In a scrapbook of letters Taylor assembled are two from his young son walter written during the 1879 Christmas season when Taylor was on the Grant tour. ${ }^{68}$ The younger Taylor described his gifts from St. Nicholas and enclosed a present for his father in the form of a drawing of a giraffe, and urged his "Papa" to return home soon. No doubt Taylor saw in the acquisition of island property, and the subsequent erection of a summer cottage and boathouse with studio, a partial answer to his desire to remain close to family and friends. He also knew he could find sufficient opportunities for work in the preparation of brochures and 
guidebooks on the Thousand Island area, thus providing him with the means to maintain his upper middle-class lifestyle. In 1881 Round Island Park, where Taylor's "Shady Ledge" would soon appear, was a denominational resort, "loosely connected with the Baptists" who had already built "a large and imposing hotel."69 The 150 acre island, two miles off shore from Clayton, had been plotted into 441 building lots, winding drives and lawns. ${ }^{70}$ One of the cottages, Sans Souci (without a care), Taylor included in his Harper's Weekly Island montage $(\$ 3)$. The island was managed by the Round Island Park Corporation, "a stock company with a capital of $\$ 50,000, "$ who controlled the hotel, store, pavilion, sale of lots, sanitary measures, and beautification and improvement projects. Taylor and other property owners were in essance "leesees" with an "unlimited 'water privilege,' and as pretty a glimpse of the broad river as you could wish." Taylor noted in later descriptions of Round Island, promotional pieces to be sure, that his investment would undoubtedly appreclate in value, which indeed it did.

For Taylor the Thousand Islands represented the best place to spend one's summer leisure time, and of all the locations in the islands, Round Island was the pinnacle of perfection. The isolation of the small island kept the multitudes away, yet clayton and other points of interest could easily be reached by skiff or steamboat. Taylor's promotions were heartfelt. He truly belleved that the Islands could bring anyone, as it did him, better physical 
and mental health. His broadsheets and pamphlets claimed "No Mosquitoes! No Malaria! No Asthma! No Hay Fever!, Unquestionably the healthiest and most sightly location on the st. Lawrence." After two summers on the island, Taylor wrote "It brought immunity from illness, a choice circle of new acquaintances, and capital of reserve strength with which to tide over the long Northern winter. It has too, given a new zest to life in recalling, through the winter, the pleasures past, and anticipating their repetition in the summer to come."71 No greater testimonial could be given. Taylor's Shady Ledge was a wonderful example of picturesque cottage architecture (Figs. $16 \& 17$ ). It was situated on the most easterly point of the island. The cottage and its owner were the subject of an article in the Gananoque Reporter on September $24,1887.72$ The anonymous writer noted that the cottage set at the top of "a round smooth bank with winding stairs which led to the boathouse and dock which is built on piers high above the water to prevent the floor being flooded in time of high water." The artist's wood engraving shows the enormous windmill that once pumped water to the cottage, and the vernacular stick style architecture is reminiscent of the "cottages" Richard Morris Hunt built for clients like J. N. A. Griswold of Newport, Rhode Island. ${ }^{73}$ While on a smaller scale, Shady Ledge retains the same asymmetrical characteristics of lts elaborate counterparts, designed to reflect the informal, relaxed atmosphere of resort living. Also typical was the 
utilization of a variety of surface textures, a roof line punctuated with dormers of various shapes, the knee braces of the porch frame, as well as the use of the porch to offset the density of the cottage itself. Leland Roth, in his $A$ Concise History of Amertaan Architecture, states that elaborate division of surfaces "in a fashion... attempts rationality" making it part of the emerging realism in art and literature. ${ }^{74}$

All these elements make for a visually attractive structure, one which would certainly have great appeal for an artist. Taylor himself was the architect, for he wrote that "within the airy confines of our tent a cottage was built, on paper. Before we left at the end of one month, a builder had the plans and we had accepted his figures."75 It was not necessarily unusual that someone would design his own house. What was extraordinary was that the design was based on the most curpent architectural trends. Through his travels, however, Taylor had undoubtedly seen a wide varlety of architectural styles, and had to look no further than his adopted city of Philadelphia to see the Second Empire Baroque of John MacArthur's City Hall or the Ruskin-inspired High Victorian Gothic of the Pennsylvania Academy of the Fine Arts designed by Philadelphia's own Frank Furness and George w. Hewitt. ${ }^{76}$ In fact, Ruskins' seven conditions of architecture, -sacrifice, truth, power, beauty, life, memory and obedience -- were, no doubt, a design consideration of Taylor's. In addition, Japanese and British exhibition bulldings at the 
Philadelphia Centennial Exposition which emphasized exposed framing members, whether or not structurally significant, were certainly familiar to Taylor. ${ }^{77}$

The interior of Shady Ledge with its etched glass door panels, imitation stained glass window appliques of naturalistic designs, plaster reliefs, exposed wood, and imitation tiles, all reflect a moderated adaptation of the texturally rich Victorian Gilded Age taste. Taylor's modest cottage was also "textually" rich due to his use of quotations as part of the wall decoration, such as the one from Longfellow on a panel over the fireplace:

$$
\begin{gathered}
\text { A man's chimney is his golden } \\
\text { mile-stone, is the central point from } \\
\text { which he measures every distance } \\
\text { through the gateways of the world } \\
\text { around hlm. }
\end{gathered}
$$

These sayings further contributed to the informality of the summer residence, a place to relax from a more structured urban life. The few pieces of extant Eastlake-inspired furniture further emphasized the trend toward realism. ${ }^{78}$ what is important to note here is that Shady Ledge was not just a building; it represented the principles of life which Taylor consciously incorporated into the design.

Like the main buflding, the two-story boat house also carried out the stick-style design elements. ${ }^{79}$ As the Gananaeque Reperter article continued, "Over the boat house is Mr. Taylor's studio in which he exhibits, from his own 
brush, paintings of every plcturesque resort from Maine to California." The windows of the boathouse, which looked out over the St. Lawrence, face north and east, providing the best and most consistent light for painting. There were no windows on the west side to capture the sunsets about which Taylor waxed poetic, but he no doubt enfoyed going out on the water at the end of the day to record the atmospheric phenomenon.80 Taylor worked on his guidebooks and articles in the studio during the summer. The "River Ripples" columnist for the daily newspaper on the St. Lawrence, noted in 1891 that Taylor was "working at hls 'Shady Ledge' studio upon a number of 1llustrated articles, one of which relates to Rafting Scenes Down the St Lawrence. An interesting topic which will appear in Erank Leslies."81

Taylor did not, however, spend all his time sequestered in his studio or painting in solitude on some isolated shore. On the contrary, he loved to entertain, and his Shady Ledge guestbook contains pages of signatures from friends who declared their reluctance to depart. Fellow special Artist, William A. Rogers, wrote on one occasion that he "Did not want to leave until winter," and included a caricature sketch of himself on ice skates pulling a canoe over the frozen water to reinforce his message. Taylor not only entertained small groups of friends at the cottage but also hosted large outdoor "campfires" where as many as 300 "friends" would gather in the evenings to sing songs and tell storles.82 
These campfires were legend in the Islands, and the newspaper reporter from Gananoque described in detall the festive event:

At the right of his cottage is the grounds where Taylor's celebrated campitres are held each year, around which the merry songsters cluster, filling the air with thelr evening carols. Near the spot of the campfire is a neatly constructed booth covered with evergreens and underlaid with birch bark, which was cut from the trees in the forests of Canada, in mid-winter, and shipped to the Island in the spring. . . On the bark walls of the booth are numerous mottos among which was quite noticeable, 'How shall we beguile the lazy time if not with some delight,' which seemed very appropriate as everything about the grounds was so arranged as to glve the pleasure seekers perfect delight.

On one occasion a boat was hired to bring over the Clayton band and guests.for the evening. The program as printed in the paper the following day, included army reminiscences, comic impersonations, harmonicon, recitation, solos, quartette, and chorus. The article also, noted that "it goes without saying that it was a success the like of which attends all of Mr. Taylor's undertakings."83 So popular were Taylor and his campfires that a poem "Ode To Tayler" was composed, (Appendix B) counting the memories of these Round Island gatherings. At the conclusion of his article, the reporter from Gananoque expressed the feelings of all who visited Taylor's abode, "Mr. Taylor is very proud of 'Shady Ledge' and may well be, for with this prelude the writer is ready to record his well-rooted belief that there is no finer 
spot on the river." It is as though Taylor's life-style were as artistically composed as his paintings; designed to be as welcoming and informal as his architecture and as spontaneous and fresh as his watercolors. One of the lines in "Ode te Taylor" asked appropriately if artistic intellect lay behind the creation of these "fiery" evening events. No doubt this was true, not only for the famed campfires, but also for his entire existence.

The most prominent structure on the island, and equally as famed as Taylor's campfires, was the grand hotel. First built by the Baptists as Round Island House in 1881, it was patterned after the Second Empire Baroque architecture of the Thousand Island House. Located on the highest ground on the island, it had an observatory 150 feet above the water, offering magnificent views of Clayton, Thousand Island Park, and Alexandria Bay, as well as "the immense pleasure and business activity which characterizes the summer navigation of the St. Lawrence." It had steam heat and was ent1rely lit by gas. It boasted of a wonderful culinary department, but sold no liquor at the hotel or on the island.84 Two wings were added in 1889 and it was renamed the Frontenac Hotel. It was "one of the largest and most elegantly equipped hotels -. second to none on the river." It was purchased by Charles G. Emery, tobacco multi-millionalre, in 1899 and ceased its tenuous connection with the Baptists. It was electrified and furnished electriclty and water to the entire island. 
During the Island resort's heyday, the Frontenac Yacht Club was host to some of the most spectacular yacht and motor boat races held each August including the Gold Cup Yacht Race in 1911. To accommodate the large numbers of yachts, 500 feet were added to the Club's main dock, "and frequently yachts were tied two abreast on both inside and outside docks." The sailing races and regattas were organized by the St. Lawrence River Squadron of the Corinthian Navy whose headquarters were in New York City. Taylor served as Commodore and later Vice Commodore of the Squadron, whose members included the most prominent yachtsman of the region. Emery's calumet was the Yacht Club's flagship. Two of Taylor's watercolors, completed in 1905, hung in the Yacht club, one of Indians in a war canoe, and one of a sleek motor launch -- the two encapsulating the evolution of boating on the River. ${ }^{85}$

Charles Emery may have owned the Frontenac Hotel and belonged to the local civic groups, but his own residence was Calumet Castle on Calumet Island, which Taylor painted on at least two occasions. ${ }^{86}$ Built in 1893-4, the three story castle contained over thirty family rooms, a mahoganypanelled ballroom, and a cyclone cellar with an outlet a few feet above the high water level. ${ }^{87}$ Emery's Castle and those of his wealthy neighbors, reflect the Imperial Classicism popularized by Beaux-Arts trained Richard Morris Hunt. It was the pervading style at the Columblan Exposition and the preferred style of the nouveau riche who wanted to emulate 
the aristocratic architecture of Europe as if to create an American Royalty. ${ }^{88}$ The Thousand Island palaces were every bit as grand as Hunt's designs for the Vanderblits in Newport and Ashville, and set the wealthy visually apart -- they were already physically separated as each owned his own private island thereby selectively restricting contact. Even so, the Thousand Islands never became the exclusive resort area which catered only to the wealthy. It retained a charm, that Taylor's watercolors so effectively capture, where everyone from the wealthy yacht owner to the skiff guide had free access to the beauty of the river.

In addition to Calumet Castle, there was George Pullman's Castle Rest, and Jorstadt Castle owned by Frederick G. Bourne, President of the Singer Sewing Machine Co., who called his forty-two room "Towers" built in 1896 "Just a shooting and fishing shack." Josiah G. Holland as a summer home in 1877, not long after Pullman's promotion of the region. Holland was founder and editor of Scribner's. Perhaps that is why Howard Pyle was commissioned to write and illustrate an article on the Thousand Islands for the monthly, which appeared in the April, 1878 issue. 90 Taylor, who also published in Scribner's, no doubt knew the wealthy editor although no known personal correspondence exists. Numerous wood engravings of Bonnie Castle appear in guidebooks and articles about the 1sland, some of which were probably based on Taylor's sketches. 
The most famous of all the palaces was Boldt Castle, built by George C. Boldt, the former kitchen worker who became president of the Waldorf-Astoria in New York City and owner of the Bellevue-Stratford in Philadelphia.91 He was a true rags to riches story and his mansion was a symbol of the American dream for all to see. Boldt purchased Hart Island following an 1894 summer visit to the islands.92 He had the original shape of the island altered to resemble a "heart" supposedly as a symbol of his undying devotion to his wife Louise for whom the castle was to be constructed. (An original summer house was removed.) In 1899 he hired the Philadelphia architectural firm of Hewitt, Stevens and Paist, and building of the 150 plus room Rineland-style Castle commenced in 1900.93

This was to be only one of eleven buildings planned as part of the estate. Taylor wrote and lllustrated an article about the "Palace on the St. Lawrence" for Leslie's Weekly, in which he noted that "Within the past few years 'Heart Island,' . . has been a hobby with Mr. Boldt. He devotes his holiday period in summer to a broad scheme for its embellishment, which has transformed the place into one of the loveliest of American country houses."94 There is just the hint of sarcasm, here as though Taylor did not approve of Boldt's flaunting his wealth. Still Taylor's detailed description and rendition of the completed Alster Tower, designed to appear in simulated ruin as if out of some Romantic painting, attests to the fact that he was well 
acquainted with the island and its proprietor. But perhaps more likely Taylor was stating a fact, for he seemed generally comfortable in the company of the nation's millionaires.

The mainland village of Clayton was the subject of many of Taylor's paintings. ${ }^{95}$ The railroad terminus for sixteen dally trains as well as headquarters for numerous steamboat lines, it was the starting point for American summer tourism in the Islands. Taylor's view of Clayton and Round Island was included as 4 in the Harper's Weekly wood engraving. In his 1893 guidebook, Estes' Standard Guide te the Theusand Islands, Taylor noted that "Clayton is an attractive village" with established hotel facilities and an excellent newspaper, and that "During the heated months, when thousands come hither from the cities, . . . [1t] wears a festive air. . . .96 His birdseye view of Clayton, (Fig. 18) "Where Travel Centres At The Thousand Islands" provides an excellent detailed portrait of the town and the busy rallroad and steamboat activity at the northwest corner of Riverside Drive between Franklin and Webb Streets.97

The Village itself was laid out in a grid pattern with a central park square, providing the citizens with a public recreational space. ${ }^{98}$ The real focus of the town was its waterfront. Many of the buildings shown on the map are still extant including the Thousand Island Inn, established in 1897 on the corner of Webb Street and Riverside Drive, conve- 
niently located to cater to arriving and departing passengers.

The birdseye view, is undated, but must have been completed sometime after 1909 as the Hubbard Annex (Fig. 19), at the corner of James and Hugunin Streets, one of Clayton's most famous landmarks, was not included. Taylor's wash drawing entitled Hubbard House, clayton. (Before the Eire) appeared in the June 12, 1896 1ssue of On the St_Lawrence, and shows the turreted Annex and original hotel (later rebuilt) facing James Street. ${ }^{99}$ Well dressed couples stroll down the sidewalks and ride on carriages, many, no doubt, patrons of the Hubbard. Guests in those days were met at the depot by horse and "carry-all" shown by Taylor, as the conveyance deposits its passengers at the Annex entrance. Taylor's inclusion of people and various forms of transportation offers fascinating clues to the historian about costuming and dally activities. Here also his architectural rendering of detalls such as lattice work, balustrade, and turrets with flags flying, gives the viewer an accurate glimpse of a scene that would soon be nonexistent. ${ }^{100}$ On July 11, 1895 the original hotel burned. The Annex, completed only one month earlier, miraculously survived as quick thinking citizens draped water-soaked carpets from window sills, porch railings, and rooftops. Flames, however, engulfed the Annex in 1909; some of the wicker porch furniture survives as collectors's items in the village. 
At the end of Theresa Street, Taylor included the Brooks Lumber Co., (now the Antique Boat Museum). He also painted an aerial view of that enterprise which hung for many years in the Company's office. ${ }^{101}$ Otis Brooks, Union Army veteran, bought an interest in a lumber yard and wood shop in clayton with partner George Strough. In 1903 the firm was incorporated as the Otis Brooks Lumber Co. Taylor's view shows the yard probably at the turn of the century when it was busy as a boat builder and lumber supplier.102 The artist often gave paintings to friends and may have presented this drawing as a gift to Brooks.

Many people had written about the splendor of the Thousand Islands even before Pullman's promotional coup. In 1804 Thomas Moore wrote his Canadian Boat Song while travelling through the islands to Montreal. In the $1840 \mathrm{~s}$ James Fennimore Cooper set his novel, Rathfinder, in the Thousand Islands, and in 1842 Charles Dickens wrote about the beauty of the area as he travelled by steamer from Kingston to Montreal, later published in his American Notes. ${ }^{103}$ But it was the guides and newspaper articles of the late nineteenth and early twentieth centuries that brought tourists to the area in large numbers, and many of these were written and/or 11lustrated by Taylor, one of the best known men in the region. One newspaper writer noted that "Everybody who frequents the Thousand Island region knows Erank T. [sic.] Taylor, the artist correspondent of Philadelphia.. . No man has done more to popularize the Thousand Island region. . ."104 
Many of the guidebooks Taylor produced or contributed to were commissioned by area businesses; examples include his pamphlets for the Crossmon Hotel and E. W. Estes, the latter

a hardware store owner and businessman with establishments in Clayton, Alexandria Bay and on Round Island. In addition, Taylor was employed by the many railroad companies servicing the Thousand Islands. ${ }^{105}$ An article entitled "The Elegant New Guide Book to the Thousand Islands Issued by the NYC \& HRRR," (New York Central and Hudson River Railroad) noted that "Scarcely a more artistic guidebook of any region has ever been issued than that which has just been prepared by the Giles Co. for the Central-Hudson. It is written and illustrated entirely by Mr. F. H. Taylor."106 This 1892 guidebook:

$$
\begin{aligned}
& \text { inaugurated a new chapter in the fortunes } \\
& \text { of the Thousand Islands, as the New York } \\
& \text { Central and Hudson River Rallroad Company } \\
& \text { assumed control of the lines connecting } \\
& \text { its main thoroughfare at Utica, Rome and } \\
& \text { Syracuse with the St. Lawrence River } \\
& \text { heretofore operated by the R. W. \& O. } \\
& \text { (Rome, Watertown Odgensburg Railroad)." }
\end{aligned}
$$

The parent Company, one article noted, felt that the Thousand Islands had the potential "Of becoming the largest and most important summer resort and tourist traffic route in America. . . . "107

The ability to reach the Islands easily and connect with steamers for sightseeing and travel to downriver destinations was critical to creating a prosperous tourist area. Most of Taylor's guidebooks and articles devote much attention to the 
details of travel -- the conven:ence of certain train lines, accommodations, meals, interesting sites along the route, steamboat connections, and the wonders of river travel.108 Taylor had to ride all of these routes and take all the steamers in order to provide accurate information. The railroad companies provided him, and even his family, with a private car and, of course, free passage. Because he would be writing and sketching while traveling, a separate car with space to work was more a necessity than a luxury. While Taylor wrote that he hoped to rest from his years of travel after building Shady Ledge, he obviously spent a great deal of time traveling around upstate New York and Canada. Most of the train travel, however, allowed him to return to clayton and Round Island within the day or at most with only one or two nights away from his family. He now avolded the long separations he had during trips to the West or South.

A good example of his travel writing for the railroads can be found in a series of articles he published and illustrated in 1884 entitled St_hawrence Summer Life. ${ }^{109}$ One section detailed the travel from Niagara Falls to Clayton via the train known as the "Steamboat Express," possibly because of its steamer connections on Lake Ontario and the St. Lawrence.110 As with each section, a short verse sets the stage:

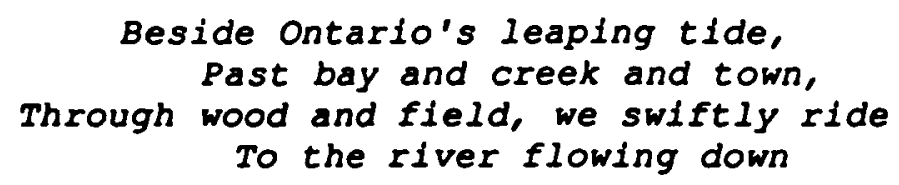


Taylor began by noting that this train "which is part of the through route via the St. Lawrence River to Montreal . . ." leaves Niagara Falls at 7:50 each evening except Saturday, bringing "travelers over the Lake Shore Division of the Rome, Watertown and Ogdensburg Railroad and a short section of the Utica and Black River Railroad from Philadelphia Junction to the thriving town of Clayton, at 6 a.m., making close and certain connections with the steamer Bothesay, of the 'American Line.'" He further noted that "The sleeping cars [Pullman's of course] used upon this line are exceptionally comfortable, having no upper berths."

Good travel writers tried to anticipate traveler's needs. In this instance Taylor noted that many people prefer to travel during the day in order that they may see the countryside. Therefore he would proffer a description of the route's outstanding features. "The morning express train passes down along Niagara River," travelling through Lewiston, "a historic little town," and then continues along the southern end of Lake Ontario where the passenger can see "pleasant glimpses of the comfortable and prosperous home life of the farming population of Western New York." As the train continued it traversed a "massive iron drawbridge," and a short time later crossed a sand bar at the entrance of Irondequoit Bay, a famous fishing resort. Here, Taylor noted, anyone wishing to stop over would find reasonable fare and boats, and fishing tackle could be purchased at either the "'Sea Breeze' or 'Newport." 
The train made a forty minute stop at Oswego where, Taylor wrote, an excellent dinner could be purchased at the Lake Shore Hotel located at the depot, or one could walk "uptown" to the Dolittle, famous for its "'deep rock'" water. Oswego had other attractions, he noted, if one chose to stay longer there, but he did not go into detall. A juncture was made with the train "upon the Syracuse Division" at Richland, and the next town described was Watertown, "one of the prettiest and most enterprising of the cities of northern New York." Here Taylor described the descent of the Black River as it cascaded into the city, providing it with "superb water power." The business district, he noted, fronted a large open space, reserved for public use. He described the avenues lined with stately houses and denoted the city's principle trades. As always, he provided the names of hotels, in this case commenting that the Kirby House provided carriage transportation from the depot at no charge.

The train connected in Philadelphia Junction, just outside Watertown, with the Clayton branch of the Rome, Watertown \& Ogdensburg Railroad. However, at this functure, Taylor took the reader by branch line to Cape Vincent connecting with the steamer St. Lawrence, which stopped at Clayton during its two dally round trips between Cape vincent and Alexandria Bay.111 His description of the arrival at "the Cape" would make any reader long to be his traveling compan1on. "We are" he wrote "after a short hour's ride over the Cape Vincent Branch, . . . set down upon the edge of the St. 
Lawrence, just where the lake pours its breeze-tossed waters into the lap of the great, 1sland-dotted channel." Taylor made travel seem like such a wonderful adventure, it is no wonder he was a sought after author of guidebooks. He tells the reader that even though the steamer is at the dock, "we must not go on board yet; let us wait over at least one boat and take a look at Cape vincent," because even though the town was visible from the train windows, there was more to see in this "curious and pleasant town." He described the wide, shady streets, the fine houses, churches and stores, finally arriving at two of the Cape's finest hotels, the Crevolin House and the Rathburn, the latter on the street leading to the river, at which point "we know we are in medias res." Some of the best fishing, he notes, can be found here along the river. An engraving showed one of the waterfront's most prominent features, the residence and great white warehouse of Mr. A. B. Cleveland, the "seedsman."

Taylor next provided a brief history of the founding of the Cape, and its French heritage. Now it was time to board the steamer for the final leg of the journey, the sixteen mile voyage to clayton. Taylor was not always praiseworthy in his descriptions, and he is particularly critical here of the image clayton presented to its arriving guests. "It presents its very worst front" he wrote:

to the stranger coming from up the river, who will, if allowed to go away upon the hurrying boat still influenced by his 
171

baleful first impression, hardly commend clayton as a summer resort. It would be money in Clayton's pocket if she would demolish a few of the rickety warehouses along her front and repair some of the ancient wharves, in short, if she would 'dress up for company.'

However, he goes on to say that the stranger would gain a far better view of the town if he would go ashore and explore the "neat and shady streets," sample the excellent fare at the hotels, and meet the charming citizens of the village.

The connection between the rallroads and the steamships, upon which Taylor always remarked in his travel guldes, was important. Once the trains dropped off their passengers, there needed to be some means to transport them to other island locations or downriver destinations, as well as a means to just tour the islands for a day's diversion, and it was helpful if the traveler knew whlch line and or specific steamer to take. For example the Rome, Watertown, \& Ogdensburg Railroad and the New York Central, for whom Taylor developed guidebooks, promoted the Thousand Island region extensively and worked with the Thousand Island Steamboat Company, started by Henry Folger of Cape Vincent. 112 The Folger "White Squadron," so named because all the boats were kept "gleaming white," consisted of the St. Iawrence, Emoire State, Islander, Maynard, and Jessie Bain. The ships connected with arriving trains at the Cape and clayton, providing service to Round Island, Grenell Island and other points. Taylor's Broadside for the rallroad and steamship 
companies (Fig. 20) shows the St. Lawrence with its detailed paddlebox scene painted by local painter John Keech.113 In the foreground is the ubiquitous river skiff, showing vacationers enjoying a pleasant day on the river, including watching the numerous steamers which made the waters their home.

Tourists could, however, continue down the river to Montreal and back, a twelve hour ride each way. They would "Shoot the Rapids" on the way down, returning to clayton on a calmer note via the canals that had been built to allow cargo ships to use the river. Taylor's engraving of the Prince Arthur (Fig. 21) shows the dramatic descent -- considerably exaggerating the danger, one might add.114 This aspect of the journey was described in many of the guidebooks as one of the thrills recommended as part of a Thousand Islands summer holiday. Taylor describes it thus:

An hour of placld streaming across the lake [Lake St. Francis] brings us to the head of the once dreaded and exciting run down the magniflcent la Chine Rapid, the Chinese Rapid, which takes its name from the early belief current among the Jesuit explorers that the river is a pathway westward to the Flowery Kingdom.115 IOnward forges our speedy craft, and ere long the troubled waters of the lachine are seen far ahead, a snowy breastwork across our path. . . A little while later and we are in the vortex. The current grows swlfter and swifter. All the bosom of the river is covered with reefs and rocks. All the mighty outpouring of the stream is pent up in a single channel. The boat heads this way and that, then the bottom of the river seems to fall out. Down we plunge! and onward, straight toward a rocky islet! What side? Just as destruction seems imminent, the vessel 
sweeps round to the right and shoots like an arrow between two sunken ledges. We are through and may look back up the watery hill we have descended, and admire the courage of the men who first navigated this wonderful channel.116

In addition to the thrill of rapids, another factor was added to heighten the tourlst's lelsure experience. An Indian pilot came aboard the steamer at the village of Lachine. The steamer's paddles were stopped and one or two Indian boatmen paddled out to the drifting steamer in a bateau. "Are the Indians really a necessity?" Taylor asked. "Quien sabe. It is the custom of the river, and the passenger remembers the incldent when every other feature of the trip is hazy and covered with the dust of forgetfulness that gathers over the events of bygone years."117

How could a tourist not seriously consider such an adventure with its historic overtones as he or she imagined how the explorers had felt while descending these same rapids in their search for the Northwest passage? The excursion also offered a dramatic change from the placid days spent at one of the Island hotels or cottages. The typical tourist might spend a month in tranquility, and this brief sojourn would be a pleasant diversion -- as well as money for tour boat companies. There was also, of course, the excitement of a few days in Montreal, "the brightest, busiest, and most metropolitan of Canadian cities."

A final Canadian destination mentioned in much of Taylor's Thousand Island Ilterature, was Lake St. John and 
the Saguenay River in northern Quebec province (Fig. 22). Lake St. John was the home of the famous "ouananiche" or fresh water salmon, while the river provided ideal camping sides for the hunter in search of bear, moose, caribou or beaver. Two of Taylor's Canadian watercolors, Vlew of Tadoussac Erom the Read and chicout Im Seen from the Bay, are from this region; they were probably completed during a research trip for the Rome, Watertown \& Ogdensburg 1893 guidebook.118 In that same year the Quebec and Lake St. John Railway had opened a new extension to Chicoutimi, allowing tourists to travel round trip from Quebec, by rall to Lake St. John, and "thence to Chicoutiml by rail,." transferring one of the steamers of the Richelieu and Ontarlo Navigation Co. for the trip down the Saguenay to Tadoussac, and then on to the St. Lawrence back to Quebec.

While the extension may have made travel more convenient, it was not the first time Taylor had been to the area. A French language newspaper clipping of July 1880 records Taylor's visit to the Saguenay one year prior to his Harper's Weekly assignment and indicates Taylor was a popular passenger on the steamers traveling down the picturesque provincial waterway. 119

For those tourists without the time or inclination for an extensive sojourn down the St. Lawrence, there were tours of the Thousand Islands area 1tself. E. W. Visger was the first tour boat owner/captain who saw the business potential of river excursions for the tourists who followed in the wake 
of Grant's 1872 visit. A consummate entrepreneur, he sold his passengers "the first souvenir island tour booklets" in order that they would possess a "constant reminder whenever describing their trip to friends."120 Visgar's family-owned business expanded until he formed the Alexander Bay Steamboat Company in 1888. The stock was controlled in large part by Watertown industrialists and disputes with the new owners led to Visgar's resignation. He remained on the river however, serving as pilot for his former competitor, the Thousand Island Steamboat Company. In 1895 Visgar's son, Walter, began a new family venture, the Captain Visger Line, and Les Corbin concludes, "Visger steam yachts became the transitIonal tour boats between the big passenger steamers of the past and the gasoline-powered boats of the next era."121 Walter continued the guidebook tradition, and the 1900 edition included a wash drawing by Frank Taylor on the cover, and a Taylor map outlining the routes of "the Excursion Yacht Captain Visger."122 Between 1879-1911, when the beautiful steamers and steam yachts traveled the river from Clayton to Alexandria Bay, the twelve mile lane was known as the "Fifth Avenue of the St. Lawrence."

It was truly a glorious age for travel. Tourism was popularized by Special Artists like Taylor, whose images of tranquil hours on the river offered the urban masses the promise of a brief respite from the structure of their daily lives. The Thousand Islands was within a day's train travel from the country's major metropolitan areas, so it is no 
wonder that the railway companies spent advertising dollars to promote the Islands' scenic beauty. The area also allowed the middle class to mingle comfortably with the extremely wealthy; the underlying idea was that the rags to riches story was achievable by all. Visitors might not own a private railcar, yacht, or island but could travel along the same rail lines, tour the islands on a steam yacht, stay in a magnificent hotel, and even own a small parcel of land. They could also fish in the same waters; and if desired, could easily make it an international visit with a short boat ride to Kingston or Gananoque or experience the French culture of Montreal and Quebec. They would breath the same clean fresh alr, as well as improve their mental and physical health. The Thousand Islands was, of course, not the only publicized travel destination. While Taylor's specific associations with the western rallroads remain to be determined, it Is clear that they formed part of his artistic life. A Philadelphia clipping entitled "As One Woman Sees It" for example notes that:

\footnotetext{
It is he [FHT] who has made the pictures and in some cases written the sketches on most of the railroad folders which make American timetables unique in the world. To do this he has had to live in many places as well as travel along the rallroad routes which have followed the Indian trails across deserts and mountain ranges from ocean to ocean and from the Gulf to the Great Lakes."123
} 
The writer, Sarah D. Lowrie, who wrote about Taylor more than once in her column, went on to note that it was Taylor's "ready pencil that lured us to try one by one of the Flagler hotels as they progressed to the [Florida] keys" and that Fred Harvey's masterpieces along the Sante Fe Rallway, "were his [Taylor's] to magnify for the benefit of the eastern traveler." In addition, she wrote that he sketched for the interested public cities and sites along Charles Crocker's Southern Pacific Railway.124

In short, Taylor, along with other illustrators, made the scenic attractions of an expanding America visually, and literally, available to everyone through guidebooks and newspaper articles. In the process he and his fellow Special Artists in many ways democratized America and American art. Not everyone could own or even get to see Thomas Moran's Grand Canyon of the Yellowstone, yet they could have access to his 1llustrations of the western frontier done for a Scribner's article.125 Remington's romantic yet accurate illustrations of life on the plains for Harper's Weekly allowed the reader in New England or Florida to have some understanding of, and appreciation for, the unique attributes of his or her country. And arouse his or her curiosity in contemplating a visit, now that the railways provided a relatively comfortable and speedy means to visit.

As Alfred Runte has noted, the illustrations provided by these artists complemented the nature writings of olmstead, Leopold, Mulr and Roosevelt. These in turn helped to encour- 
age the preservation of certain areas and the establishment of the National Park System. "The success of scenic protection," according to Runte, "depended on visual proof of the uniqueness of western landmarks."126 The exhibition of Moran's sketches and watercolors from the Hayden Survey, prominently displayed in the halls of the Capitol, influenced the decision by U. S. Grant to sign the Yellowstone Park Act on March 1, 1872.127 Not generally associated with preservation, Grant probably had elections, rather than conservation, in mind. But perhaps, after witnessing the destruction of the land during the Civil war, he really did appreciate the beauty of the country and the symbolic importance of preserving of some of its unique natural features. Winslow Homer's Adirondack paintings were executed during the debate over the creation of the Adirondack Forest Preserve in 1885, and while he never took an active part in the debate, "It is doubtful if proponents of the Adirondack wilderness then or now, have ever had a more eloquent or articulate spokesman."128 Taylor too wrote about the Adirondacks, his engravings and descriptions played their part in publicizing the beauty of the famous mountains.129 While Taylor might in some sense be considered a proponent of conservation, his views were not those of men who felt wilderness and natural marvels should remain cordoned off, forever pristine, as when first "discovered" by the White man. More in line with Gifford Pinchot and Theodore Roosevelt, Taylor believed in "conservation for use" 
and the progressive reform philosophy "that stressed the ability of the human mind and will to alter and improve the environment."130 Taylor saw nothing wrong with big hotels or with trains and steamshlps that permitted the average citizen to visit the country's natural areas, but he also understood the symbolic importance of these areas in developing a feeling of national pride and the formation of a national culture. He realized perhaps that there needed to be and could be a happy medium or compromise between the purist Ideals of John Muir's plan for Yosemite, and the commercial fiasco that had despoiled Niagara Falls.131

Special Artists contributed greatly to the feeling of national pride as they wrote about and illustrated the country. Their work encouraged the average citizen to experience the landscape with a respect for the nation's heritage, perhaps particularly critical after the Civil War when America needed to see itself as a single unified country. Taylor brought the reader from tobacco auctions in virginia to maple sugaring in New England, and out to the majestic mountains of Colorado. ${ }^{132}$ He made it a country for everyone to see and feel. As people ventured away from their urban homes they were able to find peace and re - creation in their own country without the need to go abroad. Perhaps no greater accolade can be given the Special Artist than the acknowledgement of this significant contribution. 
CHAPTER NOTES

Note: Three well-known Clayton/Taylor historians who shared information with the author have passed away within the last few years. Their widows have graciously made their flles avallable for continuing research. These men were Harold E. Herrick, Jr. of Cape Vincent and William $H$. Wells and Lester $\mathrm{J}$. Corbin of Clayton. Information from their files will be referred to in the notes as: From the collection of. . .

${ }^{1}$ American Tourist Gazette, n.d., p. 9, AKM scrapbook. Two clippings from this interesting publication were found in Taylor's materlals although its publication source and dates are as yet unknown. Th1s page also provides statistics on the number of locomotives in the United States $(18,000)$ of which Pennsylvania and New York had the most, 2700 and 2000 respectively. There is also the conclusion of an article on a French Canadian village which Taylor may have written, not only because he wrote and illustrated numerous newspaper articles and guidebooks about the St. Lawrence and the French Canadian towns along its border, but also because the next article, "Kennebunkport Rocks," is accompanied by his signed wood engraving. In a rather prophetic statement he notes (it would be assumed here that Taylor wrote the brief article), that "some day the masses of richly colored, rudely-carved rock that boarders the land along the sea to the southward of the Saco as far as the Kenneybunk River -- someday they will be famous."

${ }^{2}$ As a result of industrialization, for the first time Americans had a prescribed time frame for leisure activities rather than the more flexible work schedule of the artisans and craftsmen of Colonial America. Mary Beth Norton, David M. Katzman, Paul D. Escott, Howard P. Chudacoff, Thomas G. Patterson, and William M. Tuttle, Jr., A People and a Nation: A.History of the United States, 2nd ed., 2 vols. (Boston: Houghton Mifflin Company, 1986) 2:547.

${ }^{3}$ While this generally meant the United States, train travel to Canada, particularly along the St. Lawrence River, was equally accessible. Both the New York Central and the Grand Trunk Railway Systems connected U.S. cities such as New York, Portland, Detrolt, and Chlcago, with Toronto, Montreal, 
and Quebec. Travelers could also go south as Taylor did to New Orleans, where they could make rail and steamer connections to Mexico and South America to see the daily life of the countryside pictured by Taylor, or perhaps the grandeur captured in Frederic Church's views of the Andes.

"John Dewey, Ethics, pp. 52-57. Manual for "American Intellectual History," 622/822, University of New Hampshire, Spring 1986.

In the nineteenth century this often meant organized outdoor activities such as bicycling or sportfishing. However, the search for a cure for physical allments ratiner than merely an improvement of one's health had long been a catalyst for travel as the wealthy sought out spas for healing and made famous the resorts of Bath and Tunbridge Wells in England and later Saratoga Springs in the U.S. The curative powers of a Lourdes made travel destinations of many medieval cities, however, the pilgrims had little thought of enfoyment, unless cured of course.

${ }^{6}$ Aldo Leopold, "W1lderness," Sand County Almanac. For an excellent summary of American attitudes about wilderness from Cotton Mather to the present, see Frank Bergon, ed., The Wilderness Reader (New York: New American Library, 1980).

'In the past travel was generally a part of trade such as practiced by the Phoenicians or mllitary campaigns like those of the Romans. Roman conquests, in fact, notes George Young in his book Tourism Blessing or Blight?, led to some of the most extensive, safe, and convenlent means of travel in Western history up until the industrial revolution. A traveler could, he notes, "leave Hadrian's wall in the north and travel the 4500 miles to Ethlopia on first class roads." The Romans also built hotels along the route although many only accommodated officials with a diplona tractatorium. Most Romans, however, were unable to take advantage of the travel opportunities provided, and there would essentially be no change until eighteenth century England when "a change of mental attitude and 'the exlstence of places' for the accommodation and entertainment of pleasure seekers," produced the traveller who liked travel for its own sake or sought a strange place for rest and recreation. George Young, Teurism Blessing or Blight? (Middlesex, England: Penguin Books, 1973). 


\begin{abstract}
${ }^{8} \mathrm{FHT}$, Away Down Easti or My Unexpected Vacation (New York: Leve \& Alden, 1880).

${ }^{9}$ Victor Wolfgang von Hagen, ed., intro., Incidents of Travel in Egyot, Arabia, Retraea, and the Holy land by John Lloyd Stevens (Norman: University of Oklahoma Press, 1970), p. xxxvili.
\end{abstract}

${ }^{10}$ For the most comprehensive analysis of exploration and the maps produced which glorified new findings see J. B. Harley and David Woodward, The History of Cartegraphy (Chicago: University of Chicago Press, 1987), vol. 1. Also see Chapter 3, "From Traveler to Tour1st: The Lost Art of Travel," in Daniel J. Boorstin's The Image: A Guide to Rseudo-Events in America (New York: Harper \& Row, 1972).

${ }^{11}$ While they promoted travel, rallroads did not initially coordinate or cooperate in package tour programs like those developed by Thomas cook in England, except in the case of spectal events such as the Philadelphia Exposition and the Chicago World's Fair. This was largely because, unlike travel on the continent, travel in the United States did not involve Americans dealing with forelgn languages, currency, and strange customs. Everyone, for the most part, spoke English, and if a traveler wanted to experience a foreign flavor, without inconvenience, he could travel to Montreal or Quebec, both of which catered to U.S. tourists. These popular French Canadian cities were described in detall by Taylor and other guidebook writers, eliminating what little risk and frustration might be encountered. ICook deserves mention here, however, as the ploneer of the package tour whose primary U.S. competitor would be the American Express Company. Cook's innovations included, among others, "courteous and knowledgeable guldes, hotel coupons, room reservations, and protection and advice against disease and thlevery" notes Daniel Boorst in in his book The Image: A Guide to Pseude-Events in America. It was the conducted tour with its cost cutting dimension that would eventually allow the middle class to experience the Grand Tour of Europe even if not in as leisurely or as philosophical an approach. It was on such a tour that Mark Twain embarked in 1867, documented in The Innocents Abread. His way, like Taylors, was paid for -- in this case by the Daily Alta callfornda of San Francisco. One can only wonder how Taylor's artistry might have enhanced Twain's writings. See Boorstin, The Image, and Mark Twain, The Innocents Abroad or The New Pllarims Progress (New York: New American Llbrary, 1980). 
12 "The Centennial of 1876, Artist Frank H. Taylor recalls interesting facts of Great Exposition 50 years ago," clipping from the Taylor family scrapbook. The reporter notes that "Mr. Taylor prepared the entire copy for the booklet. . . probably one of the first of its kind. . . which was 1llustrated with pictures from plates which were the pioneers of the zinc plate halftone etching process of the present day."

13"A Flying Trip," newspaper clipping from 1879, AKM Scrapbook.

14 "As One Woman Sees It," Sarah D. Lowrie, HSP, Taylor Collection, Box 1, Folder 4. Lowrle notes in one of at least three columns she wrote about Taylor, that the artist explained to her that he eventually resigned from the staff of the Rublic Ledger because having to work "within fixed hours confined his soul and contalned his mind." However, she noted that for forty years he had chosen to spend the summer at the same location, but Taylor remarked "there was no 'have to' about that choice." Certainly indicated here is the artistic temperament that rejects confinement and scheduling, the need to be free to make choices and select projects. While never seemingly to have the freedom of a Homer or Remington, in part due to family obligations, Taylor was able to exercise some control over his destiny. The ablilty to write, 1llustrate and produce guidebooks and brochures helped in that liberation.

${ }^{15}$ The islands were formed when the North American Glacier receded and the ancient Laurentian River was forced to cut a new channel. The river now flowed over an area where the glacier had already scraped away some of the younger rock, leaving the older precambrian rocks exposed. These "hummocks of granite" eventually became vegetation complexes, and were called the Garden of the Great Spirit by the Iroquois. It was the Erench who named the region the Thousand Islands; but as Taylor noted, in the Treaty of Ghent "the islands are officially stated as numbering 1,692 ;" even though the actual number varles depending on the water level, a dry season "adding very materially to the count." Adrian G. Ten Cate, ed., 2nd ed., Pictortal histery of the Thousand Islands of the St. Lawrence River (Brockville, Ontario: Besancourt Publishers, 1982), p. 1 and FHT, Estes' Standard Guide to the Thousand Islands and Voyage Down the Bapids to Montreale Quebec. Lake St. John and the Saguenay River (Clayton, NY: E. W. Estes, 1893), P. 6. 
${ }^{16}$ Americans' continuing psychological dilemma of a love, almost reverence for the rural landscape, while living in an oft perceived hostile urban, industrial environment, has been the subject of many books and articles. Marx gives an excellent account of the "pastoral ideal," its origins and its unresolved place in the modern landscape. Marx, The Machlne in tie Garden. Kenneth Jackson also touches on the "landscape" in crabarass Erontier. He sees the lawns and open areas of the suburbs as the creation of hundreds of individual pastures, as people constructed their own miniature environments. Jackson, craborass frontier. Artists too have dealt with this seeming oxymoron. The most recent study is Sarah Burns' Rastoral Inventions: Bural life in Nineteenth-Century American Art and Culture (Philadelphia: Temple University Press, 1989). Also see Francis D. Klingender, Art and the Industrial Revolution (1947; rpt. New York: Augustus M. Kelley, 1968), and Art and Commerce:

American Prints of the Nineteenth Century (Boston: Museum of Fine Arts, 1978).

${ }^{17}$ While Captain François Pouchot was able to delay Amherst's attack on Montreal, it was not enough to turn the tide. Amberst and his men continued downriver to Montreal where the British forces converging from Quebec and Montreal had waited for his arrival, and the French surrendered the city without resistance on September 8, 1760. Ten Cate, Rictorial History of the Thousand Islands, p. 24. IFrench influence in the area south of the St. Lawrence, however, did not end at the close of the war. In the late 1700 s James LeRay de Chaumont and John LaFarge (father of the American artist), acquired large tracts of land in Jefferson County, New York, along the river, giving the area "virtually to the control of Frenchmen." The region became home to many refugees after the French revolution as well as emigres from New France. In addition, LeRay persuaded artisans from his homeland to assist in settlement. Around 1815 he also facilitated the emigration of many aristocratic families, including friends and relatives of Napoleon whom they planned to rescue from St. Helena, eventually bringing him to Cape Vincent (named for LeRay's second son). They had a house bullt for their fallen emperor; but when he died, their plans were for naught. While some of the group returned to France, many remained adding "not a little to that character of the population in that part of the country." In 1818 Napoleon's brother Joseph, purchased 15,000 acres for hunting from his old school frlend LeRay, where he bullt a chateau and hunting lodge. He eventually tired of his property and sold it to LaFarge. IJames LeRay built two homes, a mansion at 
LeRaysville and a snaller house at Chaumont (named for the old estate in Franc a where he was born). The stone house at Chaumont eventually became home to Watertown publisher and journalist Charles Congdon, a friend of Frank Taylor's. Taylor visited the Congdons on many occasions, and his watercolors and wash drawings of the house, the river and boatworks, the bridge with Mrs. Congdon's electric car, and even the family dog, are among his best works. p. 27 .

${ }^{18} \mathrm{Ten}$ Cate, Rictorial History of the Thousand Islands,

${ }^{19}$ Ibid.

200 e other lasting change was the creation of the Rideau Canal at the suggestion of the Duke of Wellington, to serve as a supply line for goods from Montreal in the event of another armed conflict with the United States. Completed in 1832, the canal was one of the greatest englneering feats of the nineteenth century. Its role as a commercial artery continued until the completion of the St. Lawrence canal system, and the introduction of the railroads in the $1850 \mathrm{~s}$. Its role then became one of host to luxury steamers and tourist hotels such as the previously mentioned Kenney at Jones Falls, palnted by Taylor in 1896. Interestingly, while canals played an important role in the history of U.S. transportation, opening up inland areas to commerce, they did not then evolve into centers for tourism as did the Rideau.

${ }^{21}$ Canada became a Dominion as a result of the British North American Act. Tensions in the area were inflamed in the $1830 \mathrm{~s}$ when secret societies called Hunters' Lodges were formed in the U.S. to aid Canadians who wanted freedom from Britain. Another secret soclety, the Fenian Brotherhood, again disturbed the peace, this time in 1866, when this Irish organization in the U.S. attacked Canada. For a more comprehensive analysis of this restive period see Ten Cate, Rictorial History of the Thousand Islands, pp. 107-117.

${ }^{22}$ Taylor notes that by 1800 the "bulk of the timber passing 'in the stick' down the St. Lawrence is brought to Kingston, at the foot of Lake Ontario, from Lake Superior in 'lakers,' as the big schooners are called, and there made up." FHT, "St. Lawrence Summer Life," 1884. IThe theme was apparently a popular one for Taylor. According to the newspaper on The St. Lawrence of August 4, 1891, he was that summer again preparing an 1llustrated article about timber 
rafting which was to appear in an upcoming issue of Erank Leslie's.

${ }^{23}$ Boorstin argues that eventually American tourlsts would want to experience pseudo-events, 1.e., ones that were created and/or modifled for the traveler so that they really had no relation to reality. Here Taylor partakes of and recommends that visitors experience the unfamiliar, which Boorstin says was the original intent of travel. There is no insulation here in the form of tour guide to arrange to take you out to the raft and on occasion act as interpreter as many of the rafters were French Canadians. And, the rafting was not staged for the tourist, it was part of the local economy whether tourists came or went. For Taylor, and the audience he sought to reach, travel was still "an athletic exercise, not what Boorstin laments it became -- "a spectator sport." Boorstin, The Image, pp. 77-117. p. 108 .

${ }^{24}$ Ten Cate, Rictorlal History of the Thousand Islands,

${ }^{25}$ John Gardner, The Saint Lawrence Biver Skiff (Clayton, NY: Thousand Islands Shipyard Museum, n.d.), p. 3 This article was reprinted by the museum from Buliding classic Small Craft (Camden, ME: International Marine Printing Co., 1977)

${ }^{26} \mathrm{FHT}$, The crossmon: Alexandria Bay, N.Y. (Philadelphia: Alfred M. Slocum Co., 1901), p. 26. Taylor prepared at least one other of the Crossmon's yearly guidebooks and probably many others. Full documentation has yet to be made. Because the hotel was eventually demolished, however, the task may prove difficult.

${ }^{27}$ The majority of Taylor's work consists of landscapes. The few occasions where action is predominant occur in sketches made during the Grant trip such as the one documenting the Volante ride in Cuba, and the Bulltailing in Mexico.

${ }^{28}$ Fredertc Remington was also in the Thousand Island area (he had a summer home on Chippewa Bay) and an engraving from his sketch appeared in the October 6, 1888 issue of Harper's Weekly on p. 745 entitled "Her First Muskallonge." The full page illustration shows a lady in a St. Lawrence skiff landing her prize catch. A note here that this was not an uncommon occurrence. Many women flshed and had their own skiffs -- the lady's version being 16 feet. Photographs at 
the Hawn Memorlal Library and the The Antique Boat Museum in clayton record prize catches by female fishermen.

${ }^{29}$ Lloyd Goodrich, "Winslow Homer in New York State," Art 10 America, no. 2 (1964), p 84.

30 "Home News," en the St_L_awrence, April 28, 1983.

31 G. M. Skinner catalog, c1900, p. 5, The Antique Boat Museum.

${ }^{32}$ The spoons were manufactured in clayton, and an example of industrialization on the local level, which allowed for the mass production of the sophisticated bait. Skinner's motto, which acknowledged the economic savings of mechanization, albeit limited, was "not how cheap, but how good; The best in the market." As many as thirty women worked in the small James street bullding during the winter months to fill orders from the previous summer from H. A. Whittemore of Boston, Skinner's U. S. Agent, and Sears and Roebuck where the bait was sold under the name Meadowbook. The patented spoon or blade was avallable in gold, silver, copper, nickel, brass, and white enamel, the inside partly painted red, in sizes from 0 , the smallest of "The Bass Killers," to 12 for the extra large muskellunge. The heavy brass wire onto which the essential elements of hook, spoon, and swivel were threaded, was made in the clayton factory on a machine specifically designed for that purpose by a man Skinner recruited from Germany. The machine was so unusual, sald Calumet Fitzgerald who worked in the factory for over forty years, that people would stop in just to admire it. Typed oral history interview with Calumet Fitzgerald, 1979, The Antique Boat Museum. IMrs. Fitzgerald managed the firm for over forty-four years, selling the company in 1968 to Arthur T. Freer of Gilbertsville, New York. She was born on Charles Emery's Calumet Island, hence her name. Her father was caretaker of the Emery estate and captain of the Emery Yacht also called the Calumet.

${ }^{33} \mathrm{Although}$ certainly not a precisionist artist in the manner of Charles Demuth and Charles Sheeler, Taylor clearly understood the artistry of the machine and its contribution to an American lifestyle.

${ }^{34}$ The term "angler" was used somewhat to elevate the catching of fish to a sport. The term originates from the need to keep the rod tip up to retain ari "angle" on the fish and prevent the fish from gaining slack. John Keates, The 
Sklff and the River, (Nantucket, MA: The Herrick Collection, 1988), p. 90 .

${ }^{35}$ Such a trophy was the muskie that, once landed, a white flag would be flown to alert everyone to the angler's prize. A reproduction of Taylor's watercolor documenting this tradition appeared in both the Estes and Crossmon guidebooks, and the tradition is still observed. The record muskie welghed one ounce short of seventy pounds. The largest, strongest and most active of the freshwater game fish, with a jaw full of double-edged teeth, it could tow a skiff against the current. No wonder the day's fishing was declared over once the mighty fish was aboard. Keates, The skiff and the Biver, pp. 23-24.

${ }^{36}$ For a more detailed analysis of the nautical properties of the skiff see Gardner, The Saint Lawrence River Skiff, and Garth S. Wilson, "The Great Lakes Historic Ships Research Project: Computers and the Analysis and Documentation of Small Craft," Eresh Water, A Jeurnal of Great Lakes Marine History, 2, no. 2 (1987), pp. 9-13. For an understanding of the importance both economically and psychologically of the skiff to the Thousand Islands see Keates, The Skiff and the River.

${ }^{37}$ Gardner, The Saint Lawrence Biver Skiff, p. 12.

${ }^{38}$ The Ant1que Boat Museum of Clayton, New York, reprinted the 1893 Illustrated Catalog of the St. Lawrence River Skiff, canoe, \& Steam Lawnch $c e$, and references to the company catalog refer to this 1893 reprint.

${ }^{39}$ Two could in fact stand in the boat as a historical photo from the les Corbin collection indicates. Pictured is a guide standing ready to net the fish as the angler reels him in, while the other fisherman sits, waiting for a bite. Keates, The Skiff and The River, p. 47.

${ }^{10}$ Ibid.

120ne of Taylor's watercolors now in private ownership in clayton, shows a gulde displaying a full fish box for the viewer.

12The boat did have a collapsible centerboard, invented In 1882 by Clayton plumber, Montraville Atwood, which folded out like a lady's fan. A permanent keel or centerboard would limit the skiff's ability to work in the shallows, the 
favorite hiding place for fish. A drop centerboard was available in the 1870s, but its high trunk hindered the fisherman who needed to "move around the boat while playing a large fish." The rudder too would have restricted movement beneath the boat, and anything that obstructed fishing was deemed superfluous. Keates, The skiff and The River,

pp. 112-113.

${ }^{43} \mathrm{FHT}$, "The St. Lawrence River Skiff," p. 11.

14Gardner, The Saint Lawrence River Skiff, p. 4. Gardner notes in his article that Eorest \& Stream should not be confused with field \& stream. The former began publication in the second half of the nineteenth century and was for many years the leading boating journal in this country until suspending publication.

${ }^{45}$ Harold E. Herrick, Jr., "Charles Estes - Skiff Bullder, Alexandria Bay, New York," The Herrick Collection, The Antique Boat Museum. Herrick outlined the characteristics of an Estes skiff and noted that a custom built skiff "The Commodore" was bullt for Frederick G. Bourne, president of the Singer Sewing Machine Co., who built one of the famed Thousand Island castles.

${ }^{46}$ Keats, The Skiff and The River, p. 31.

17Like Skinner's lures, the skiff was a beautiful machine, and no doubt appealed to Taylor for 1ts beauty as well as the pleasure it provided as a flshing and sailing craft. That the skiff appears in so many of his drawings attests to his love of the boat as art. IAn 1890 notice in en The St. Lawrence noted that the "Genie" of the St. Lawrence River Skiff, Canoe Steam Launch Co., the "finest skiff ever ordered" was exhibited at John Wanamakers in Philadelphia. Whether or not Taylor was instrumental in arranging for the skiff's exhibition, it is interesting to note the company's connection to one of the country's first large department stores along with Skinner's assoclation with Sears and Roebuck, the country's premiere mall-order firm. Indicated here is the rise of consumerism in America, and the democratization of goods as rural and urban families alike could easily acquire the same products. Special Artists like Taylor who did sketches for company catalogs made these goods attractive, contributing to the new materialism which would steadily increase in the twentieth century.

${ }^{48}$ Keats, The Skiff and the River, $p 52$. 
${ }^{19} \mathrm{FHT}$, The cressmon, p. 43.

${ }^{50}$ Ibid., p. 44.

${ }^{51}$ Two sheets of letterhead stationery were given to the author by Mr. Charles Dunham, of Chaumont, New York.

52Roth, A cencise History of American Architecture, p. 139. Pullman built perhaps the most famous nineteenth century company town on Lake Calumet just south of Chicago. Pullman's island in New York was also named Calumet. The idea behind good housing was part of the belief in reform, and reflects Ruskin's faith that morality inhered in architecture.

${ }^{53}$ Susan W. Smith, A History of Recreation in the Thousand Islands (Ottawa: Parks Canada, 1976), p. 11. A special skiff was built for Grant and is on display at The Antique Boat Museum.

54James Bayne, A Souvenic of the Thousand Islands (Grand Rapids, MI: The James Bayne Co., n.d.), The Antique Boat Museum Collection. This brochure is one of many published by Bayne who owned a commercial photography business in Michigan, later moving to clayton.

55 "Among the Thousand Islands," Harper's Weekly, 25, (1881), article p. 550, engravings p. 549.

${ }^{56} \mathrm{FHT}$, The crossmon, p. 7.

${ }^{57 I b i d ., ~ p . ~} 13$.

50The guide not only provided boat, bait, and tackle, for the price of $\$ 3.00$ per day, but also a noon meal -- the famous Thousand Island Shore Dinner. The guide would pull ashore on one of the islands "and there he would make a fire and clean the morning's catch. From the skiff he would produce the bacon, new potatoes, corn, steaks, and berry ples. . . " Coffee was boiled using eggshells to settle the grounds; bass was wrapped in wet newspapers for baking under the coals, and pike were fried in bacon grease. Preparation for the feast took about an hour during which time the sportsmen relaxed and would do so again while the guide subsequently cleaned the pots and pans. Then the party was ready to return to the river to fish again. FHT, The crossmon, p. 7 . 
${ }^{59}$ Charles and Mary Beard, The Bise of American civilization (New York: Macmillan, 1934), p. 400.

${ }^{60}$ The Presbyterians also had a camp on Wellsley Island called Westminister Park and the Baptists established Round Island Park. The resorts were noteworthy, writes Fryer, "for their lack of noise" -- another relief from the congested urban landscape. Ten Cate, Ricterial Histery of the Thousand Islands, P. 142 .

61 Ibld. and John de Visser and Patricia Fleming, 1000 Islands (Erin, Ontario: The Boston Mills Press, 1990), p. 85.

62Smith, A History of Becreation in the Thousand Islands, p. 20 .

${ }^{63}$ In nice weather the Sunday service might be held outdoors with parishioners arriving via skiff to hear the preacher.

64The hotel was destroyed by fire in 1890 and the 200 room Columbian Hotel was built to replace 1t, opening in 1892. In 1921 the Columbian was also destroyed by fire. While a few of the grand hotels like the Crossmon were eventually torn down as tourism waned in the later part of the twentieth century, fire was and still is the greatest threat to island structures. p. 142 .

${ }^{65}$ Ten Cate, Rictorial History of the Thousand Islands,

${ }^{66}$ The men would often travel up to the Islands on weekends, while wives and children spent the entire summer on the river.

${ }^{67}$ FHT, Summer Days at Round Island by one whe Has Been There (New York: Leve and Alden's Publication Dept., 1884), p. 1 .

${ }^{68}$ Taylor family scrapbook.

${ }^{69}$ Taylor wrote that "there is an entire absence of those cheap camp-meeting attributes which are found at many denominational resorts in other portions of the land. FHT, Bound Island, p. 4. 


\begin{abstract}
${ }^{70}$ The Park's Baptist connections were to be immortalized, however, because "The avenues were named after Baptist Colleges and Academies, after deceased College Presidents, after deceased Baptist missionaries, and after prominent cities of New York and Canada," (the latter, it would be presumed, which met church standards). Ibid., p. 7.

${ }^{71}$ Ibid., p. 2.

72Gananogue Reporter, Ontario, September 24, 1887, The collection of Les Corbin.

${ }^{73}$ The term stick style was coined by architectural historian vincent Scully, and had its origins in the works of A. J. Downing and Richard Upjohn as well as the Romantic "rustic architecture of Europe." Hunt's wooden cottages are seen as his most American works. Hunt was a classically trained architect and became the Gilded Age architect in a way, designing chateaux for the Vanderbilts in New York City, Newport, and Ashville, North Carolina.
\end{abstract} p. 155 .

${ }^{74}$ Roth, A Concise History of American Architecture.

${ }^{75} \mathrm{FHT}$, Bound Island, p. 1.

${ }^{76}$ Furness was a student of Rlchard Morris Hunt whose atelier was the first of its kind in the country.

77Taylor also undoubtedly had access to the most current architectural design books through the extensive library of the Philadelphia Sketch Club. Many architects were also Club members, and he perhaps discussed design considerations and phllosophical issues with them.

${ }^{78}$ Charles Eastlake published his book Hints on Heusebold Taste in England in 1868 (it was published in America in 1872). He maintained a preference for craftsmanship and simplicity. He gave furniture the morality that Ruskin attributed to architecture. Russell Lynes in his book the Art Makers, notes Eastlake's credo might have been "'I believe in the sincere, the artistic, and the healing gualities of honest design." His designs were on exhibit at the Centennial Exhibition where Taylor had ample opportunity to view them. Taylor too believed that good design was important, and his philosophy was in accord with Eastlake's. It is interesting to note here that James Bayne who published many Thousand Island's souventr booklets which included 
Taylor's drawings and probably writings as well, was from Grand Raplds, Michigan where Eastlake inspired furniture was mass produced.

${ }^{79}$ Notice the two St. Lawrence River skiffs (also shown in the engraving), Important both as a part of the Thousand Island's ambience and in some ways stick-style architecture in their own right.

${ }^{80}$ For Taylor the ever changing light made "Eventide. . . the grand, every-day-free landscape gallery of the world." FHT, Bound Island, p. 4.

81 "River Ripples," On the St. Lawrence, August 4, 1891, Hawn Memorial Library. Taylor also designed a "handsome" boat house for the Mason family and it was said "Round Island bids fair to present the finest array of handsome boat houses on the river." On the St_L_awrence, August 25, 1891. IMention should be made here of the engraved masthead for this Thousand Island newspaper which was a dally during the summer tourist season (Fig 23). The design can be attributed to Taylor.

82Taylor also entertalned members of the B1g Four Wheelman, a bicycling organization, and the American Canoe Association which had annual meetings in the Thousand Islands. 20,1891 .

83 "Shady Ledge Camp Fire," On the St. Lawrence, August

${ }^{84}$ The Frontenac Hotel became "one of the largest and most elegantly equipped hotels in the northern region, second to none on the river. Because the hotel's public landing was the first stop as steamboats left clayton, which was then the southern terminus of the Rome, Watertown, Ogdensburg Railroad, the hotel from its opening, became a favorite resort. Emery rebuilt the hotel, and it opened as the New Frontenac Hotel in 1901 with 300 rooms. It had, according to newspaper accounts, "everything necessary to the requirements of a fine hotel" which included "telegraph offices, stock brokers offices, express and railroad ticket offices, boat livery, tennis courts, baseball grounds," and a nine-hole golf course designed by champion golfer harry Varden. World famous cellist George Rogavoy, and his Russian orchestra, who played winters at the court of the Russian Czar, had replaced Professor Capp and his five plece orchestra from Syracuse. In 1905 a 100 room Annex was built, the final enlargement. The 
Gilded Age icon, however, was destroyed by a fire on the evening of August 23, 1911 with guests fleelng for their lives. The fire was so brilliant that residents on nearby Grindstone Island were able to read their evening paper by the blaze. Emery soon left for California never rebuilding the structure, and in 1918 the Annex was struck by lightening and completely destroyed leaving almost no trace of the opulence that was once there. The collection of William Wells, pp. 365-366, 380. IEmery was one of the organizers of the American Tobacco Company which manufactured cigarettes under the name Old Judge and the Canvas Back, the latter a two cent product made for the Australian trade. Captain Henry S. Johnston, A Tour of the 1000 Islands: The American Venlae of the St. Lawrence River with Map (Watertown, NY: A. W. Munk \& Co., n.d.), p. 6, The Antique Boat Museum.

${ }^{85}$ The watercolor A Motor Boat Spin Among The Islands was reproduced in the 1905 edition of The crossmon, but its whereabouts in now unknown. The Taylor family has a 1905 watercolor of Indians in a war canoe, but there is yet no way to determine if this painting was the one which hung in the Yacht Club.

${ }^{86}$ One watercolor signed but undated, is privately owned. A photograph of a watercolor dated 1895 was given to the author by Verda Corbin from her husband's collection.

87Mrs. Emery feared these storms even though they were unheard of in that part of the river.

${ }^{88}$ Mumford, The Brown Decades, p. 50.

${ }^{89}$ Smith, A Histery of Recreation in the Thousand Islands, p. 31. Ilike the Thousand Islands which provided opportunities for different classes to intermingle in an acceptable neutral ground, Bourne represented another socially leveling phenomena, the sewing machine. The mass production of garments allowed rich and poor alike to purchase their cloths 'off the rack.' Only the extremely poor made and repaired their own clothing.

${ }^{90}$ Howard Pyle, "Among The Thousand Islands," Saribner's Monthly, 15, no. 6, (1878) pp. 825-842.

${ }^{91}$ While most of the castles were elther destroyed or remain privately owned, Boldt Castle is now owned by the Thousand Island Bridge Authorlty and the area's most popular tourist attraction. Boldt is perhaps best remembered for his 
assoclation with 1000 Island salad dressing, often credited to Chef Oscar of the Waldorf, who supposedly created it while at the Islands. Another version attributes the famed dressing to Mrs. George LaLonde of the Harold House in clayton who is said to have shared her recipe with actress May Irwin, who had a home in the Islands. A friend of Boldts, Irwin then took it to the hotel owner who shared it with Oscar.

${ }^{92} \mathrm{He}$ also purchased a large parcel of land on Wellesley Island where he established a model farm which supplied eggs, butter, poultry, and meat for his hotels and the maple grove at the farm made syrup for the tables of his wealthy clientele.

${ }^{93}$ Hewitt was the former partner of Frank Furness. For further information on Hewitt's contribution both to the Thousand Islands and Philadelphia see John Harbeson, "Philadelphia's Victorian Architecture 1860-1890," Penosylvania Magazine of History and Biegraphy, 67, no. 3 (1943), pp. 254-271.

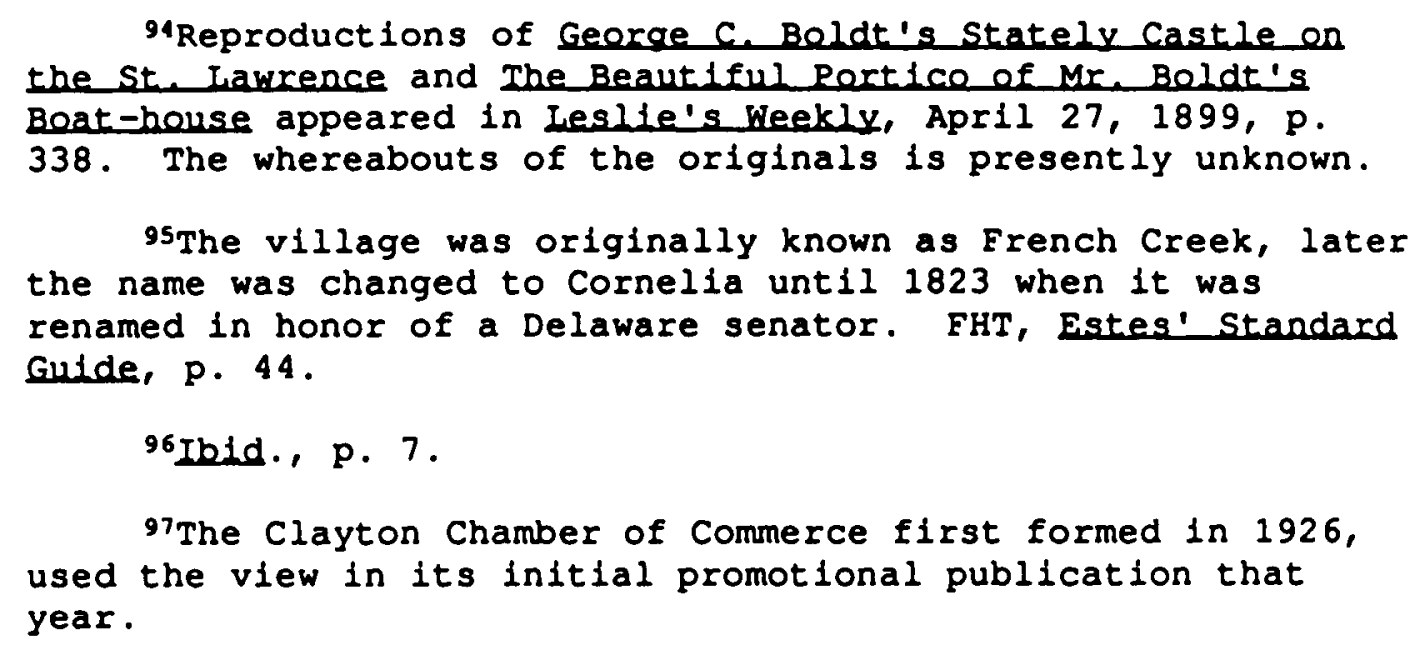

${ }^{94}$ Reproductions of George $C$. Boldt's Stately Castie on the St. Lawrence and The Beautiful Portico of Mr. Boldt's Boat-house appeared in Leslle's Weekly, April 27, 1899, p. 338. The whereabouts of the originals is presently unknown.

95The village was originally known as French Creek, later the name was changed to Cornelia until 1823 when it was renamed in honor of a Delaware senator. FHT, Estes' Standard Gutde, p. 44 .

96 Ibid., p. 7.

${ }^{97}$ The Clayton Chamber of Commerce first formed in 1926, used the view in its initial promotional publication that year.

98Perhaps part of this European design which incorporated a Renaissance love of open public spaces, stems from the region's French heritage.

${ }^{99}$ From the collection of Les Corbin, and an article "Meet Me at the Hubbard, from the collection of William Wells, p. 115 .

${ }^{100}$ Les Corbin wrote that "Due to the short time together, no photos were taken of the two bulldings, and I belleve this 
to be the only record," private correspondence with the author.

101During a fire prior to being acquired by The Antique Boat Museum, the painting was thoughtfully rescued by one of the employees, and remains a reminder of the village's manufacturing heritage.

${ }^{102}$ The Stone Shop at the lumber yard was the first electric plant in Clayton and power for the lights was furnished by the same steam power that operated the machinery in the yard during. the day. The lights were turned off around $11 \mathrm{p} . \mathrm{m}$. each evening. Collection of William Wells, p. 192 .

${ }^{103}$ Dickens wrote: "The beauty of this noble stream at almost any point but especially in the commencement of this journey, where it winds its way among the thousand islands, can hardly be imagined. The number and constant successions of these islands, all green and richly wooded; their fluctuating sizes, some so large that for half an hour together one among them will appear as the opposite bank of the river, and some so small, that they are mere dimples on its broad bosom; their infinite variety of shape; and the numberless combinations of beautiful forms which the trees growing on them present: all forms a picture fraught with uncommon interest and pleasure." "Smith, A Histery of Becreation in the Thousand Islands, pp. 4-5.

104"The Great Lakes in Time of War," October 22, 1918, newspaper clipping in the author's collection. The unidentified newspaper reporter noted that this article about the Great Lakes by $F H T$ was reprinted from a recent number of the Philadelohia Record and he thought it would be of interest to his [Taylor's] friends in Central and Northern New York.

${ }^{105}$ Those companies included the Utica and Black River Rallroad; the New York Central and Hudson River Railroad; the Rome, Watertown \& Ogdensburg Railroad, The Adirondack Railway, the Passumpsic Railroad Company; and the Lehigh Valley Railroad. He probably worked for other railroad companies in the northeast, but verification has not as yet been established.

106"Region of the Thousand Islands," On the St. Lawrence, June 24, 1892 . 
${ }^{107}$ 0n The Saint Lawrence, July 11, 1891. This was certainly a sign of the power of the railroads which prompted Theodore Roosevelt's trust busting measures and writers like Frank Norris to fictionalize the depredations of the large companies.

${ }^{108}$ This was very much like the descriptions provided in Baedeker's guides, albeit without the stars. Karl Baedeker (1801-1859) of Leipzig was the pioneer of the modern tourist guidebook. His first English language edition appeared in 1861 providing information on a modifled Grand Tour to the rising middle class in Europe and America who might strike out on their own rather than on one of Cook's tours.

Baedeker was known for scrupulous accuracy leading $A$. P. Herbert to write "For kings and governments may ere, But never Mr. Baedeker." Boorstin, The Image, pp. 104-105. ITaylor too strove for accuracy, and did not write about establishments or points of interest which he had not himself visited. He provided readers with all the details required to enfoy one's leisure experience.

${ }^{109} \mathrm{FHT}$, "Glimpses of St. Lawrence Summer Life," from the files of Ted Cornell, Shortsville, New York.

${ }^{110}$ Taylor included a thumbnail sketch of the train.

${ }^{111}$ Here he included an 1llustration of the depot and dock with awaiting steamer, thus familiarizing the traveler with the layout, and making approprlate connections less intimidating. While not the most plcturesque of scenes, it served a purpose in facilitating the traveler's journey.

1120 ther cooperating lines Included the New York, Ontario and Western Railway connecting in Oswego with the steamer entarle for Kingston, Clayton, and Alexandria Bay. This route Taylor noted would be good for the New York City businessman who "can only leave upon Saturday" because it allowed them the "opportunity to spend a part of Sunday and all of Monday at the lslands, thus only losing but one day from business." The Utica and Black River Railway route left New York from Grand Central Depot every evening except Saturday, terminating in Clayton during the summer months. Arriving in just over thirteen hours, it connected with the steamer Maynard. And, the Canadian Pacific Rallway had an agreement with the steamers of the Richelieu \& Ontario Navigation Co. to meet their trains. 
113 Keech made his living palnting decorative scenes on canoe paddle blades which are now highly prized collector's items. Ten Cate, Pictortal Histery of the Theusand Islands, p. 194 .

${ }^{114}$ The image was used on at least two occasions. In the guidebook Picturesque, n.d., from The Antique Boat Museum collection, the ship, so named, and flying the stars and Stripes descends the rapids. Taylor used the same lmage in his guidebook for Estes, p. 49, however this time the boat was unnamed and 1 flew the Union Jack. TThe Prince Arthur was operated by the Thousand Island and Montreal Steamboat Company. Known as the New American Iine, they operated the Bothesay and Prince Arthur dally from Clayton to Montreal.

115 FHT, Estes' Standard Guide, p. 49.

$116 \mathrm{FHT}$, The crossmon, pp. 38-39.

117 FHT, Estes' Standard Gutde, pp. 49-50.

${ }^{118}$ These two watercolors are now in the collection of the Royal Ontario Museum in Toronto, Canada.

119"Chronique Des Eaux," Malbaie, 31 julllet, 1880, AKM scrapbook. While Taylor did not speak Spanish, and sometimes had to relay on his artistry to express his needs when in Cuba and Mexico, he may well have been fluent or at least conversant in French. His guidebooks and articles often contained French phrases, and he was a friend and employee of a Montreal based railway executive who owned property on Stave Island, one of the Canadian owned Thousand Islands. In addition, in Taylor's brochure for $\mathrm{E}$. W. Estes, he included an engraving of a small sailboat pulled ashore next to an artist's easel and stool, on the banks of the Saguenay, as if to indicate that he went out alone on sketching trips in this somewhat isolated portion of the province where French would certainly be prevalent. IWhile in San Cristobel, Cuba documenting the earthquake damage, Taylor wrote: My Spanish was not equal to the demand, and I seemed in a fair way to fast. A Spanish officer came to prevent me from sketching the camp. I made a drawing of a skeleton reaching for a loaf of bread and bottle which dangled at a hopeless distance above his head, and dinner was forthcoming. During the balance of my stay my escort was ample." When the situation demanded, the Special Artist was inventive. Something like language would not be a deterrent to getting a good story. 
120Ies and Verda Corbin, The Visgers' Werld (Clayton, NY: Les and Verda Corbin, 1987), p. 16.

121Ibid., p. 18.

${ }^{122}$ Datly 1000 Island Tours of the Exaursion Yacht captain Visger, 1900, collection of Les and Verda Corbin.

${ }^{123}$ Sarah Lowrie, "As One Woman Sees It." FHT, Manuscript Collection, HSP, BOX 1, Folder 4.

124 Building overnight lodging facilities along transportation routes was certainly not new, inns along stage coach routes were already a fixture in the American landscape. What was different was the size and scope and that the transportation company itself, in this case the railroad, was the one doing the promotion and/or bullding. Travelers too were not fust staying overnight; but now could travel to destinations along the route and remain for days and even months. "Railroad owners . . . quickly realized that they could double their investment by providing hotel accommodations both along and at the termini of their railroads." Henry Flagler was an excellent example as he built a string of hotels along his Florida East Coast Railway including the Ponce de Leon and Alcazar in St. Augustine. Jeffrey Limerick, Nancy Ferguson, and Richard Oliver, America's Grand Besort Hotels (New York: Pantheon Books, 1979), p. 47.

125 Nathaniel P. Langford, "The Wonders of the Yellowstone," Scriboer's Monthly, 2, no. 1 (May 1871), pp. 1-17 and no. 2 (June 1871), pp. 113-128. Moran's 7' $x$ 12' oil painting was purchased by Congress in June 1872 for $\$ 10,000$ and it hung in the Senate lobby.

${ }^{126}$ Alfred Runte, National Parks: the American Experience (Lincoln: University of Nebraska Press, 1979), p. 14.

${ }^{127}$ In 1871 Congress appropriated $\$ 40,000$ for Dr. Ferdinand Vandiveer Hayden, professor of geology at the University of Pennsylvania, to lead a team, including Moran and photographer William Henry Jackson, to survey Yellowstone. IF inancier Jay Cooke and officials of the Northern Paciflc Rallroad may have suggested the blll to designate Yellowstone as the nation's first National Park as they realized that if Yellowstone became a park, their raliroad would be the sole beneflciary of the tourist traffic. Cooke even provided financial ald to Moran to allow 
the artist to accompany the Hayden Survey, no doubt realizing the impact the artist's sketches would have on the final park decision. Runte, National Parks, pp. 44-45.

128pleter W. Fosburgh, "Winslow Homer, Painter of Fishes and Fishermen, The conservationist, 26, no. 5, (1972), p. 4 .

${ }^{129}$ While Taylor concentrated on the Thousand Island region of the St. Lawrence, he did write about and lilustrate all the areas of the Northeast serviced by the railroads for whom he was employed, or more correctly it would seem, who employed the Giles Iithog. Co., Leve \& Aldens, and the American Bank Note Company to produce their guidebooks. For example, the 1891 Boutes and Rates for Summer Tours published for the $B W \& O R B$, probably written and partially illustrated Taylor, included a section on the Adirondacks (accessible by the Adirondack Rallway Line) with a wood engraving signed by Taylor entitled Geing te Church, Raquette Iake.

$130 \mathrm{John}$ M. Blum, William S. McFeely, Edmund S. Morgan, Arthur M. Schlesinger, Jr., Kenneth M. Stampp, and C. Vann Woodward, The Natienal Experience: A History of the United States Since 1865, 6th ed., 2 vols. (New York: Harcourt Brace Jovanovich, 1985) 2:564. ITheodore Roosevelt, in reaction to the exploitation of public lands by private developers, helped pass the Newlands Act, called a National Conservation Congress, and appointed the Inland Waterways and Public Life Commissions.

${ }^{131}$ Niagara Falls was regarded at home and abroad as the country's most spectacular natural landmark as early as 1830, due in large part to its having been the subject of many paintings and engravings. Without protection, however, by 1860 "gatehouses and fences rimmed the falls from every angle; a monument despoiled." For a more detailed account of the problems associated with development at Niagara Falls see Runte, National Parks, pp. 5-9, 57-59.

132 A watercolor of "Split Mountain," Colorado, now privately owned, is currently the only known painting or sketch of Taylor's western travels. 
CHAPTER IV

"EVER CHANGING PHILADELPHIA"

\begin{abstract}
I am filled with deep emotion in finding myself standing here in the place where were collected together the wisdom, the patriotism, the devotion, the principles, from which sprang the institutions under which we live
\end{abstract}

\author{
Abraham Lincoln \\ February 22, 1861
}

Long after I am forgotten [my sketches] will remain to tell other generations that $I$ once lived and added something to help future philadelphians to visualize our city of today.

Frank H. Taylor

February 27, $1926^{1}$

The city of Philadelphia which became Frank Taylor's adopted home, and which he loved and documented in a series of over four hundred watercolors and wash drawings as well as numerous pamphlets and books, symbolized as Lincoln sald, the very principles on which America was founded.2 The belief in the rights of the individual and freedom of expression upon which the new government was created were part of the city's heritage from its founding by William Penn, and were continually reinforced as the city grew and prospered. ${ }^{3}$ It was this pervasive democratic ideology that fostered independent 
thinkers in the arts and sciences, and provided an environment which produced the "realism" found in the works of Thomas Eakins and Walt Whitman, among others -- considered the most "American" of American art and literature." Taylor's drawings were part of this realistic Philadelphia outlook -straightforward scenes without romantic overtones or idealized subjects, the same way the city viewed itself.

In large part Taylor's approach to the subject matter was due, of course, to his fournalistic background; but in a subtle way, Philadelphia itself contributed to his appreciation of the value and power of recording what was actually before him, and the ldea that it was the responsibility of the artist to make good visual images available to every American. In addition to reflecting this prevailing democratic philosophy, Taylor's works were influenced by the physical geology and geography of the city as well as his association with the nation's premiere art1sts, 1llustrators, architects, and photographers, primarily through his long membership in the Philadelphia Sketch club. The close bond he formed with fellow artists was particularly 1mportant to a man who relished friendship, and the city again provided the right atmosphere -- for despite its size, Philadelphia retained a small town community closeness that made Taylor feel a part of a family, a feeling that was transferred to his art.

Philadelphia, sometimes referred to as the Athens of America, was from its conception founded on Greek principles 
of democracy and freedom.5 The city's classical heritage began in 1682 when Penn chose to name his new town after the ancient Palestine city which honored Ptolemy Philadelphus. The name meant brotherly love, an appropriate designation for Penn's Holy Experiment, a city where the Inhabitants were to have "a sanctuary, a place of refuge, not for one's own particular church as in the case of New England, but for all God-fearing men and women everywhere." 6 As a result, Philadelphia more than any other colony, welcomed settlers from all over northern Europe and the British Isles. This mix was not unlike the Athenian's heterogeneous heritage which scholars suggest was one of the "causes of the peculiarly high competitive and creative energy of the Greek peoples." 7

Philadelphia had additional characteristics that paralleled Periclean Athens and which contributed to its greatness. Its late founding (in comparison to other Atlantic coast colonies) allowed it to observe and learn from the growth of surrounding communities, and its agrarian hinterlands contributed significantly to the city's economic prosperity. In addition, its role as a vibrant port city with ships sailing regularly to Spain, Portugal, China, and Italy, led it to become one of the country's most cosmopolitan cities. 8

Early on Philadelphia developed an extensive system of roads, called Pikes, to transport goods from its remote hinterlands which laid the groundwork for Philadelphia's 
initial economic success. By 1832 there were 220 turnpike companies chartered by the state and over 3,000 miles of roads had been built leading to New York City, Reading, Harrisburg, Lancaster, Baltimore, and into New Jersey. Taylor acknowledged the city's early transportation history in his paintings of toll houses and inns, some still extant, that were part of this first important highway system. His watercolor Rerkiomen Bridge Hotel 238 for example shows the terminus of the Ridge Pike (an extension of the Germantown Pike) built in 1801 as it appeared in the early twentieth century when automoblles and trolleys shared the roadway. He also recorded Blstag Sun Tavern \$181 and Bed Lion Hotel \$178, the beginning and end of the Bristol Pike along the old York Road built by the Cheltenbam and Willow Grove Turnpike Company incorporated in $1803 .{ }^{9}$

To become a great city, however, there often needs to be a crisis which serves as catalyst for the evolution from the embryonic or developmental stage, such as Athens' defeat of the Persians for example or the repulsion of the Dukes of Milan from Florence. ${ }^{10}$ Philadelphia's metamorphosis was the result of the Revolutionary War when it became the country's symbol for independence from Great Britain, and as the nation's early capital, retained that position. Even after the government seat was removed to Washington, D.C.in 1800, Philadelphia would remain the emblematic heart of the country with Independence Hall, Old City Hall, Congress Hall, the 
Liberty Bell, and the flag, visual reminders of the historic events which created the new nation.11

Philadelphia also retained control of some of the fledgling nation's primary institutions thereby maintaining a place in the country's economic if not political future. Two of the most important were the Navy Yard and the United States Mint, both of which were portrayed in Taylor's series. Taylor documented the Navy Yard more than once. Originally located on the Delaware River at Southwark, it was important for the development of American Naval technology as well as the city's economy. ${ }^{12}$ Taylor's watercolor eld Nayy Yard, 1864 \$51, shows the Yard's two shiphouses which Edgar Richardson noted "were erected in 1821-1822 to protect. . . against the weather, [and] were for half a century the largest, most consp'.cuous objects in and around the city."13 Taylor's view shows the construction of one of the eleven warships which were built in the shlp houses during the Civil War, when as many as 3,000 men were employed. In his book Philadelphia in the civil War, Taylor noted that the Yard "occupied the site of the pre-Revolutionary Association Battery" which later became the shipyard of naval architect Joshua Humphries, appointed First Chief Naval Constructor. ${ }^{14}$ The yard eventually became too small, and in 1862 the city presented the government League Island at the mouth of the Schuylkill for a new Navy Yard. The old yard was sold at auction on December 2, 1875.15 
Also important in retalning and enhancing Philadelphia's role in America's industrial age was the federal government's decision not to move the United States Mint to Washington, D.C. This was particularly important, notes Richardson, because the new technology needed men "able to invent, build, and use precision tools and precision machines," the very skills successfully solved both by the Navy Yard and the U. S. Mint. ${ }^{16}$ Many men employed at these places were clock and watchmakers who turned their skills to other channels. These included David Rittenhouse who became first director of the Mint, and Joseph Saxon, the Mint's constructor and curator of the standard weighing apparatus.

Taylor's drawing of the U. S. Mint on Chestnut Street, where it was located from 1829-1833, 1s number 68 is his series.17 The bullding itself was a tribute to the city's evolution as its marble facade, courtesy of architect william Strickland was changing Philadelphia from a city of brick to a city of marble.18 Here is a testament to the city's historic dedication to the finest detail of workmanship which would be reflected in the art produced there. It also reflected the city's rich architectural heritage. This was a city built on realistic, not flamboyant dreams.19

A great crisis also creates heroes, and Philadelphia historian E. Digby Baltzell, noted that between the signing of the Declaration of Independence and the Adamses' departure to the White House, "the greatest generation of American statesmen and leaders walked the streets of Philadelphia."20 
Some were Philadelphian's by birth, others like Benjamin Franklin adopted the city as a permanent home, while still others like George Washington, John Adams, and Thomas Jefferson were embraced by the city when their extended residences made them honorary citizens.

Philadelphia also produced heros in the arts and sciences who, unlike the politiclans, would not leave for Washington, D.C., but remained to provide a foundation for future generations, thus keeping Philadelphia at the forefront of American cultural development into the twentleth century. ${ }^{21}$ Colonial Philadelphia's receptive intellectual atmosphere provided an entrée for palnting, seen as idolatrous (except for the portrait), by Quakers and Calvinists. The wealthy inhabitants of Penn's city, however, were for the most part not Friends. ${ }^{22}$ Rather they were families with European tastes able to support an artistic community, and with a desire for paintings for their estates. Evidence of this support for the arts is provided by Carl and Jessica Bridenbaugh in their book Rebels and Gentlemen who note that "sometime or other all the painters of the Middle Colonies visited the city to purchase materials from the shops of Claypoole or Marshall." Colonial demand for artistic supplies was sufficient for Christoper Marshall to open the oil and Colour Shop at the Sign of the Golden Ball, and for James Claypool, one of the members of the informal "Philadelphia School" to also open a business which sold "most Sorts of Palnters Colours, ready prepar'd for Use and neatly put up in 
Bladders."23 In addition, bookstores such as Revington and Brown's stocked art reference books like The Handmaid of the Arts.

The city's most famous and influential painter prior to the Revolution was expatriate Benjamin West. 24 After attending the College of Philadelphia the young painter, financed by local connoisseurs, went abroad to study in 1759 , eventually becoming court painter to King George III and president of the Royal Academy of Fine Arts. West became the "'Father of American Painting'" because, note Klein and Hoogenboon, he "welcomed . . housed, fed, financed, and taught . . " such aspiring artists as Philadelphians Matthew Pratt, Charles Willson Peale, and Gilbert Stuart, as well as John Singleton Copley, Ralph Earl, Washington Allston, John Trumbull, and Samuel F. B. Morse. ${ }^{25}$ what he taught was a love of history painting, and devotion to realism. His defiance of accepted Academy standards, for example, by placing his figures in contemporary dress in Death of General Wolfe, was a first step in the elevation of historical realism, and North American subjects to academic levels. Further, he saw himself as an historian with a moral obligation to accurately depict events and "restore painting's true dignity."26 A century later Frank Taylor would also view himself as a recorder of history with the same moral convictions. Philadelphia emerged as a great city on the eve of the Revolution, and one of West's prodigies, Charles Willson Peale, who permanently settled in the clty with his family as 
the Declaration of Independence was being drafted, expressed his mentor's approach in new ways. Peale championed an interest in science and archeology that reinforced Philadelphia's role as the leader in the arts and sciences. Many of his portraits of George Washington such as George Washlnaton at Rrinceton were done from life, and presented the general with candor and clarity, not a god-like figure that might have led Washington to be seen more as monarch than patriot. The paintings were, notes Nell Harris, part of the creation of American history.27 A history that began in Philadelphia.

A favorite of Washington's with entree to the innercircle of the powerful, Peale painted portralts of all the Revolutionary heroes including Lighthorse Harry Lee, William Washington, Lafayette, and Rochambeau. These were displayed in his gallery which was open to the public -- the origins of the nation's first museum. Peale was aware that a new nation needed heroes, and was an important chronicler of the country's history just as Herodotus was to the Greeks, except in this instance the record was primarily visual. ${ }^{28}$ Also like West, Peale saw a moral responsibility to his work. His museum for example was an educational institution not fust a collection of artifacts. He provided public lectures, published a visitor's guide, and sponsored, in conjunction with the Philosophical Society and the federal government, the nation's first organized scientific expedition. His carefully documented natural history displays were arranged 
in realistic groupings often in front of painted landscape backgrounds to evoke the animal's habitat and to foster further research.

Realism and accuracy were Peale's hallmarks in all his endeavors, continuing and expanding on the tradition begun by West. Also like West, Peale generously passed his knowledge on to others, part of the cooperative spirit of the Quaker city. He encouraged his own children, Rubens, Rembrant, Raphael, and Titian, as well as all the artists, including Taylor, who would study at the Pennsylvania Academy of the Fine Arts, which he helped establish in 1805.29 Now young artists could receive the kind of training in their own country once only available overseas in such ateliers as Benjamin West's or in other art centers in Europe. It was the American beginning of a professional approach to art.

The man often considered the greatest "American" artist, Thomas Eakins, came on the scene as Philadelphia celebrated its role as the birthplace of the nation at the Centennial Exposition in 1876. The legacy of realism and attention to detail, inherited from West and Peale, now became more aesthetically solid and artistically conveyed. In fact, Eakins' graphic realism was so intense, it sometimes made viewers uncomfortable, just as West's had done earlier. In its well known attempt at discretion, the Centennial's art comittee refused to hang The Grossclinic in Memorial Hall, later the Philadelphia Museum of Art, exhlbiting it instead In the Army Post Hospital. 
Iike the Exposition which celebrated the industrial age brought on by scientific inventions, Eakins' painting was a commemoration of the contribution science made to art, in this case medical science. His other palntings were also tributes to the symbiotic relationship of art and science as he utilized mathematical principles to determine perspective, and had, as subjects, some of the nation's leading minds. Like West and Peale before him, Eakins too was a teacher, instilling in his students these American values of not only precision but boldness to push the limits of what was considered acceptable by the majority. He taught at the Academy of Fine Arts, and was its director during the Centennial year when Taylor was covering the event for the Daily Graphic. While never studying with Eakins, Taylor was also concerned with accuracy, and saw beauty in his surroundings. The city was as compelling a subject as the Thousand Islands.

Taylor entered this artistic tradition when he arrived as a lithographer's apprentice in 1867. Philadelphia would soon be at its cultural zenith. Although eventually overshadowed by New York in art and publishing, and Washington D.C. In politics, it would never be forgotten and would continue to prepare creative thinkers who would take their values with them as they ventured forth. No wonder that this young sensitive artist, Frank Taylor, would be impressed by the city's accomplishments and contributions to society, and embrace it as his home. 
The city's friendly atmosphere was as important to Taylor's professional and personal development as its artistic and scientific tradition. Taylor, as has been demonstrated, was an outgoing, fun loving person, who seemed to thrive on, and almost require, interaction with his peers. While belonging to other clubs, it was the Philadelphia Sketch Club, a men's club, which best satisfied his need for the camaraderie of other artists. The Archives of American Art which microfilmed the Club's historical documents, prefaced the profect with this description of the organization:

\begin{abstract}
Founded in 1860, the Philadelphia Sketch Club is among the oldest continually active artist's organizations in the country. During the nineteenth century and early twentieth centuries, it was an influential cultural force in the city, sponsoring numerous important exhibitions. Its active and honorary members included many leading artists of the period. ${ }^{30}$
\end{abstract}

The History of the Philadelphia Sketch Club notes that at the invitation of President E. B. Bensell, Taylor was voted in as a member in 1869, fust four years after moving to the Philadelphia. ${ }^{31}$ Sidney C. Lomas, Club historian and author of the Histery, as well as a contemporary of Taylor's, wrote that the artist was "Genial, witty, [and] a tireless worker [who]. . . started immediately after his arrival in Philadelphia to make himself at home in the Sketch Club, and when not away from the city on business, found his relaxation at the club gatherings."32 on the night Taylor was elected to 
membership, the secretary's notes state that the club resolved it was to be "both a working and social organization, but always an art club."33 The main purpose of the weekly meetings was sketching, art discussion, and the spending of a pleasant evening -- just the right mix for Taylor.

This Club, with the central purpose of sketching "illustrations to stories," was formed by six Academy students, George F. Bensell and his brother Edmund, Edward J. McIlhenny, Henry C. Bespham, John L. Gihon, and Robert Wylie, who sought more opportunities to draw than provided at the Academy. Taylor remembered the Academy as "somewhat depressing . . [without] the friendly spirit of comradeship and mutual encouragement as you have today."34 The club met on Thursday evenings, initially at Bensell's studio at 520 Walnut street, where their first sketching subject was "Hope." Thereafter a different topic was selected at each evening meeting as well as one for a sketch due in a fortnight. Members were fined for fallure to produce the required sketch (as well as for sloppy technique and using obscenities). Other selected subjects included "The Wandering Jew," and "Lady Macbeth" as well as more specific topics, such as "The Executioner Grinding His Axe Prior to the Beheading of Lady Jane Grey." Sketches were made in lead pencil, charcoal or watercolor with the members usually seated around a large table. Critiques led by the more advanced artists present were held after the session. Here 
Taylor would benefit from the experience of Club members, supplementing his limited formal training:

The Club was also formed with the expressed desire to promote the advancement of American talent and in "having Philadelphia maintain itself as a centre of the Fine Arts."35 To that end the members staged their most ambitious exhibition in December, 1865 just prior to Taylor's joining, although he no doubt attended, and was probably impressed with their resourcefulness. Hailed as "'the most important showing of distinctive American art ever held in the city," " and the only serious attempt ever made to hold a large exhibit of American art works in Philadelphia, the exhibition was hung at the once shunned Pennsylvania Academy. ${ }^{36}$ A first prize of $\$ 2,000$ offered by the club attracted entrants from across the country. Unfortunately, the expenses of the exhibition nearly broke the club. The members were forced to relinquish their newly rented quarters on Chestnut Street, and were for a year homeless, finally settling in inexpensive rooms at $209 \mathrm{~S}$. 6th street. Things finally began to improve In the late 1860 s when Ridgeway Knight and Thomas Moran became members adding considerable prestige to the organization. With the war over life began to return to normal, and artists and illustrators were in increasing demand particularly for the numerous newspapers and magazines produced in Philadelphia.

In the $1870 \mathrm{~s}$ and $80 \mathrm{~s}$ almost every distinguished American artist came from or through Phlladelphia, and most were Club 
members. The list included Thomas Anshutz, Thomas Eakins, A. B. Frost, Howard Chandler Christy, N. C. Wyeth, Rockwell Kent, W. A. Rogers, F. O. C. Darley, F. Cresson Schell, Fred B. Schell, and Joseph Pennell. Many of these artists were closely associated with American Realism such as Eakins and Anshutz, and others like Taylor, Christy, and the Schells, were Special Artists responsible for documenting the nation's vibrant life. Christy and F. C. Schell would later report on the country's participation in the Spanish-American War.

In 1874 the Club began its life classes which were initiated with a series of four lectures on "Artistic Anatomy" by Dr. Harrison Allen. ${ }^{37}$ A newspaper clipping announcing the lectures noted that the city's art students recently had little opportunity to draw from the living model as the old Academy of Fine Arts was being torn down, and the new building was not yet finished, making the Club's life classes an important contribution to the city's art education. ${ }^{38}$ It also demonstrates the city's continuing artistic and scientific connections, and concern for finding truth and accuracy.

The 1870's were a particularly active time for Taylor in the life of the club. He served as treasurer from 1870 to 1875, on the mistaken estimate, Taylor commented, of his financial abilities. ${ }^{39}$ with the increase in club membership and prestige, the Club was once again solvent. In 1874 when F. Walter was born, the Club presented the new father, as proxy of the young member -- the Club Baby -- with a silver 
cup at a cost of $\$ 62$, no small sum. ${ }^{10}$ The same year also saw the initiation of the Rortfolio, organized by Taylor and published by his firm of Taylor Smith." 1 The next years saw Taylor busy "with 'Centennial Affairs'" as head of the New York Graphic 1llustrators, and his meeting on the exposition grounds with Joseph Pennell is noted in the Sketch Club Histery as one of Taylor's favorite stories of this heady period of his life.

Shortly after the Centennial closed, the Sketch club held its flrst of what became many outings; this one a shad supper at Ringsetten, Falls of Schuylkill with the members of the Undine Barge Club. This and later outings were often quite elaborate affairs. For this initial event club members traveled by chartered steam yacht up the river where dinner was prepared followed by "songs, storles, and dancing, and a jolly good time generally." Thomas Eakins was a guest at this initial adventure. 12 Taylor was also present and attended most functions when he was in town. His Shady Ledge camp fires may well have had their inspiration in these Sketch Club outings.

The Club's most lavish event was held in 1892 when millionaire Club member James P. Simpson sponsored a cricket match at his estate in Merion between the "Gentlemen of the Grub Club and The Gentlemen of the Sketch Club."43 Each team member was supplied with custom-made old English cricket clothes and wore a tall silk hat. The game, however, it was noted, was "played with more attention to enfoyment than to 
form."44 Plenty of food and refreshments were made available at various tents and buildings on the grounds, and a band played "martial airs" throughout the day. These outings became yearly events accompanied by elaborate invitations designed by Club members, many preserved in the club files. 45 For a time in the 1870 s the sketch Club also had its own country estate in Lafayette, a headquarters for plein-air sketching and outings, instituted by William Moyland Landsdale. Unfortunately the house burned and efforts to secure a new site, which Taylor was in favor of, were unsuccessful.

Taylor was placed on the Club's inactive list in 1879 and did not reappear as a permanent active member until after 1903. During this time he was listed as being in "New York?" This colncides with his Harper's Weekly assignments and his association with the nation's burgeoning railway system all of which kept the artist constantly on the road -- or tracks so to speak. He appears to have malntained his Philadelphia residence as Clayton's on the st. Lawrence listed him as arriving from Philadelphia each summer; but work obviously kept him away from the city much of the time. 16

In 1903 the club moved to its own quarters at $235 \mathrm{~s}$. Camac Street where two buildings had been purchased. One of Philadelphia's narrow, picturesque streets, South Camac Street between St. James and Spruce was known as "The Little Street of Clubs" and the Greenwich Village of Philadelphia." Neighboring clubs included the Charlotte Cushman Club, named 
for the nineteenth century American actress. Initiated at a time when the profession was not considered all that appropriate for young ladies, it offered accommodations and a place to relax. The Plastic Club, founded in 1895 for women painters and sculptors, was the nation's oldest women's art club. Taylor lectured there in 1915. The Franklin Inn Club, a male writer's club, was founded by historical novelist and psychiatrist, S. Weir Mitchell in 1902.48 Christopher Morley, one of Philadelphia's most famous writers and close friend of Taylor's was a member. And finally there was the Poor Richard Club, a men's club founded in 1906 for advertising professionals for whom Taylor wrote a Dictionary of Pbiladelphia in 1916.

Philadelphia itself was called the "City of Clubs," a haven for those of artistic bent. In discussing the city's "Iron Age 1876-1905," Burt and Davies note the "proliferation of clubs, old and new, city and country, male and female, was one visible evidence of the cohesive group consciousness the basically conformist atmosphere that pervaded the city."49 There was a club for everyone they note, and this allowed everyone to fit in.50 It was one of the reasons for Philadelphia's initial success as an urban center -- its ability to make everyone feel as if he or she belonged to part of the city. It created the kind of loyalty Taylor expressed in his paintings, the feeling of being an important part of something bigger than oneself or one's group. 
As mentioned, Taylor's later years were spent recording the sights of Philadelphia, both old and new, that he thought were important in retaining the city's understanding of itself -- from whence it came, and the direction in which it was headed. Although the series could be regarded as the work of a old man whose life revolved around the past, it was not the first, nor would it be the last time artists had documented the city or analyzed its historical importance. Nicholas Wainwright notes that it was in the nineteenth century that the city "began to identify its historical image," beginning with Lafayette's visit in 1824.51 The occasion prompted civic leaders to recall the city's founding, and a dinner that year to commemorate Penn's landing in 1682 resulted in the creation of the Historical Soclety of Pennsylvania. Soon sites were honored such as the great Elm where Penn made his treaty with the Indians in 1682; documents like James Logan's correspondence were preserved; and historles were published including Thomas Gordon's history of the state, and John Fanning Watson's history of the city.

The visit by Lafayette on his farewell tour also renewed interest in the State House, (Independence Hall) which had been the culmination of the general's entering procession and site of daily receptions held in his honor. Little acclaimed until then, its wooden steeple having been removed in 1781, it was refurbished for the general. 52 Thomas sully made a full-length portralt of Lafayette for the Hall, paid for by 
private subscriptions which, Marc H. Miller notes, was "consonant with their [Philadelphian's] feeling that pageantry and commemoration should stem not from the government but directly from the people."53 As a symbol of liberty, Lafayette inspired Philadelphia (and Americans in general) to reevaluate the importance of material culture which was close to being lost.

One of the artists who saw the need to record the city's buildings in hundreds of sketches, was a skilled amateur palnter named David J. Kennedy. ${ }^{54}$ He was following the tradition of William Russell Birch who published a volume of engraved plates in 1800 highlighting the beauty of the city. Birch's views are most often used as lllustrations of Philadelphia's federal facade by modern documenters of the city. Kennedy is used to record Philadelphia in the mid1800s. Later works like Taylor's, however, are overlooked, even though he included colonial and federal era architecture no longer extant or not previously documented. An example would be his watercolor of the home of Thomas I. Wharton, at 103 South Sixth Street as it appeared in 1824 when it became the birthplace of the Historical Society of Pennsylvania. 55 Taylor's drawings were, however, used to lllustrate contemporary records of Philadelphia. His friend Christopher Morley for example, used Taylor's sketches in his 1920 Travels in Phtladelphta, and Francis Burke Brandt and Henry Volkmar Gummere used "five original drawings by Frank $H$. 
Taylor" to illustrate their Byways and Bowlevards in and about Histeric Philadelohia, published in 1925. While understandable that authors may prefer the drawings of Birch and Kennedy to illustrate the Philadelphia of the artists' time, less clear is a seeming reluctance to use Taylor's watercolors and wash drawings when analyzing the city as it emerged into the twentieth century. Part of the reason for the neglect may be the result of Taylor's relative anonymity up until now, and the fact that photographs of the city were available from the mid-1800s on, and are perhaps seen as more representative. Weigley's comprehensive edited history of the city for example contains none of Taylor's work. Even Taylor's early engravings, particularly the ones of the Centennial, have often been overlooked because of the obscurity of the Daily Graphle. Writers use the wood engravings of the better known Harper's Weekly and Erank Leslie's to 1llustrate the 1876 Exposition, and on occasion even fail to document the source, further obscuring the contributions of the nation's Special Artists.56 An interest in the history of the Dafly Graphic might generate a curlosity in its contribution to pictorlal journalism, as well as American art, thereby reintroducing Taylor and other Special Artists to American historians.

It is also possible that while Philadelphia at the turn of the century has been the subject of scholarly attention, for example in Sam Bass Warner's The Private city, it has not been viewed as being the picturesque city it was in its 
federal glory, and therefore, the inclusion of guidebook-type views have not been considered germane. Art historians find much to study about American art, but not necessarily Philadelphia, in the works of Eakins and Anshutz. But these and the paintings of The Eight, look at a reality that focuses not always on the beauty of the surroundings but a rather forceful realism that confronts the viewer. Certainly Eakins for example, did paint the city in Max Schmidt and the single sauld, but without the focus on historical documentation seen in Taylor's sketches and watercolors. In some ways it was as if Eakins took a sketch, one which could be similar to raylor's, and took it one step further into a finished academic painting. Whether Taylor did not want or could not create a more "serious" work is not clear; however, he may well have felt that all he wanted to say was conveyed in his drawings without the need for elaboration.

In addition, Taylor would have perhaps better served his future reputation had he published his sketches as a book with commentary. While he did publish a set of twenty-four lithographs in a limited edition in 1915 as Ever changing Rhiladelphia, it was more a group of prints for framing or a large coffee-table book, but not a publication for the general population. He did write and illustrate guidebooks such as The Philadelphla Electrical Handbook for the Institute of Electrical Engineers, Roor Rlchard's Dictionary of Philadelphia for the Associated Advertising Clubs of the World, and The Port and city of Pbiladelphia for the Twelfth 
International Congress of Navigation, but these were for a selected clientele. He failed to produce a book like Brandt's and Gummere's for the population in general -- one that would truly showcase his talent. We cannot say why this is so. No doubt, he thought the lithographs themselves would secure his name in Philadelphia's history. Also, had he bequeathed his four hundred plus sketches to the Historical Society of Pennsylvania rather than stipulating in his will that, if not purchased by the Society, they would be sold at auction -- which they were -- perhaps such an extensive collection would have generated scholarly research at an earlier date. As it was, the works were dispersed throughout the city, and have only recently been received as gifts by the city's museums. 57

Perhaps now is the time to take a new look at the city at the turn of the century to appreciate the beauty that was there, and understand why Taylor thought the preservation of its material culture was important for the city's and nation's heritage. What is interesting is that Taylor did not just choose the historic landmarks to capture for future generations, although many were among his city views; but equally, if not more important, he included everyday vistas which might have forever passed from the scene had he not the foresight to realize the cultural value of preservation.58 It is unfortunate that his works were sold as "historical" prints when over than half were of contemporary subjects. 
Before analyzing his Philadelphia works, however, mention needs to be made of his two most important historical written works, the guidebook for Valley Forge, and his history of Philadelphia's participation in the Civil War. Both speak to Taylor's appreciation of history passed down from West and Peale to artists who settled in Philadelphia, as well as the interest spawned by the Centennial. The city's account of itself in these two wars, and the importance that was placed on the creation and maintenance of freedom and democracy, were stories Taylor felt needed to be remembered in words as well as illustrations. They were part of the city's ethos.

Valley Forge represented a turning point for the Continental Army and for the city of Philadelphia. Washington positioned his troops that winter where he could maintain surveillance on General Howe whose forces occupled the city. Had Washington's army crumbled under the oppressive conditions, the struggle for freedom might have been lost. As it was, the men persevered, and "a victory not of weapons but of will" was won. Taylor was undoubtedly proud to be selected to prepare the text and illustrations for the Valley Forge Park Commission's first guidebook in 1905, and its four subsequent revisions. 59

The Civil War was, of course, also Taylor's war, and while he did not serve in a Philadelphia regiment, his association with the conflict made the compilation of this book a true labor of love. The book was exhaustively 
researched. The special committee, appointed by Major Rudolph Blankenburg to oversee its publication, noted that "The Book is the result of the author's conscientious, resourceful, intelligent, and untiring industry."60 They further noted that "Original research has uncovered facts not heretofore disclosed; official records appealed to, and personal recollection sought for to supply matter not previously available."61 The book includes details of all the city's military organizations as well as accounts of specific battles; Philadelphia hospitals, and other war related organizations; financial data, veterans' activities, and a war chronology as well as a military map of Philadelphia. ${ }^{62}$ Taylor also included numerous illustrations. His regimental sketches, the committee noted, had been "verifled or revised by leading members of the associations" that were still active, and "personal recollections of survivors." Other illustrations were "from. . original drawings by the author . . selected with discriminating fudgement. . [and] give to the text a sentiment that invites the readers' close attention." 63

That Taylor was selected by the city to write the Civil? War history and by the Valley Forge Park Commission to write the first important guidebook attests to the high regard in which he was held by his contemporaries. He was seen as much as historian as illustrator. This probably explains why his sketches of Philadelphia have heretofore been viewed more as historical than contemporary documentation. As his Philadel- 
phia series is reevaluated, however, its true contribution to the city's history will be reallzed. Perhaps he will again be appreciated as both author and artist.

A closer look at some specific drawings will demonstrate Taylor's ability to record a city in transition as it began to lose some of its industrial age prestige and settled into a comfortable, if uninspired, middle age. Penn's surveyor Thomas Holme laid out the "greene countrie towne" on a grid with five public park squares.64 (Figs. $24 \& 25$ ) While Taylor included all of them in his series, two with their surrounding structures particularly reflect the changing city as it entered the twentieth century. South Washinaton Square \$18 (Fig. 26), originally known as Southeast Public Square, shows the southwest portion of a square at the center of Philadelphia's publishing industry, which was at its zenith when this view appeared in George Barton's Ifttle Journeys Around ald Philadelphia in 1925.65 In the southwest corner, facing the viewer, Taylor shows the small, still extant Farm Journal Building. On the opposite southeast corner, fust out of view was the publishing house of Lea and Febiger, founded in 1785 by Matthew Cary, the oldest publishing house in America. Also on the eastern side of the square is the J.B. Lippincott Company, founded in 1782, publisher of Taylor's book for the Poor Richard Club, two of the editions of the Valley Forge guldebook, as well as an article on New York lakes for the firm's monthly magazine.66 
Just to the north of the square was the Curtis Building, a name synonymous with the city's role as the leading popular magazine publishing center, home of the Ladies' Home Journal (1883) and the Saturday Exentag Post (1897). Both these magazines, but particularly the Ladies'Home Journal, Influenced the middle class female population of the United States. The Jewral followed in the tradition of Godey's Ladies Beok which first gave advice on clothes, food, house decoration, manners and morals to its readers. ${ }^{67}$ The white marble building contained a glass mosalc mural, The Dream Garden, designed by magazine illustrator Maxfield Parrish, and executed by the Louis C. Tiffany Studios in 1916 incorporating the ideals of the craftsman movement. Just off the square was the Public Ledger Building, home to one of the city's leading newspapers, and for many years Taylor's place of work.

The square itself had modest beginnings, and the park space was used as a burial grounds first for American and British soldiers of the Revolution, and later, in 1793, for victims of the yellow fever epidemic. The Walnut street prison was located at the northeast corner at that time. The square's character began to change in 1825 "and gradualiy began to acquire a more residential character."68 In Taylor's watercolor, the row of bulldings on the left (south) facing the square, gives a good idea of how Colonial and early federal Philadelphia must have looked with its prevalent red brick. The Meredith-Penrose House, on the western end of the 
row, closest to the viewer, with the cast iron railings above the basement, wis built by prominent merchant Asaph Stone in 1823. Writer Christopher Morley lived fust two houses west. The Greek Revival First Presbyterian Church shown in the left foreground was designed by John Haviland and built in 1822. The church, which Hogarth called "one of the finest Greek Revival churches in the city," was razed in 1939.69 Whether or not Taylor had any insight into the church's eminent demise, he was aware in looking around his city that architectural treasurers were disappearing. He was also aware that as important as a building such as this was individually, its relationship to its surroundings, tts influence on the character of the city, in this case, washington square in particular, was equally significant. Even though the topography of the city was destined to change, and Taylor certainly appreciated the need for that change, he also knew 1t was important to understand what preceded, which is why this series was so important for him and to us.

A reconstructed colonial residence is on the east side of the Square as is the Italianate Phlladelphia Athenaeum, symbol of the city's dedication to learning and architectural progress, and where this work now resides. The Athenaeum was designed by John Notman, and built between 1845-1847. It was, wrote Leland Roth, "One of the earliest instances of the more correct use of the palazzo mode.. . at a time when such bulldings were usually designed as Greek Temples."70 Here in the Square was the successful blending of colonial, 
federal, Greek, and Italian architectural styles. It represents the city's encouragement of architectural experimentation as well as the city's continued cultural literacy and social tolerance as different styles, religions, and social classes co-existed in harmony. ${ }^{71}$

Taylor chose to record this view of the square on a rainy day, and thus we should consider the "color" of paintings of Philadelphia which often have a subdued tone or feel. This look can be attributed in part to the city's physical attributes as well as its conservative heritage. Philadelphia was described by Carl and Jessica Bridenbaugh in Rebels and Gentlemen as a city and countryside of soft browns and grays and deep reds, due to the native fleldstone, and the use of red bricks as the primary building material in the city. ${ }^{72}$ Louis Mumford in The Brown Decades attributes the city's overall muted atmosphere to Eakin's pallete of "yellow brown and dark sienna"73 Philadelphia historian Struthers Burt also commented on the soft gray, yet luminous atmosphere which remains a consideration of artists. 74 Bright colors might certainly appear as interior decoration, but the prevaling exterior impression was one of subtle gradations in color.75 Taylor's use of black and white wash, and watercolors that often only suggest the values, fittingly reflect the city's atmospheric subtleties.

Taylor's fine perspective drawing also includes the local citizenry as well as contemporary modes of transportation, including the electrlc trolly car, here in 
juxtaposition with the then still prominent horse-drawn carriage. In 1925, washington Square, as was much of older Philadelphia, was st 11 a place where businesses and residences co-existed. Even in the mid-twentieth century Christopher Morley could walk from his home to the Public Ledger Building where he worked. But the trolly as well as other factors permitted a decentralization of the urban population as the newer houses on larger, less expensive parcels away from inner city congestion built or were made accessible. ${ }^{76}$ Warner notes in The Private city that "BY 1900 every major street in Philadelphia carried an electric streetcar line. . . ."77

Taylor no doubt visited often with his friend "Kit" Morley, submitted articles to Lippincott's, and regularly dropped by the Sketch Club, a few blocks away. He had a particularly close attachment to Washington Square. To him it represented the successful blending of public and private interests that made the city a vibrant place. Its publishing houses and newspaper buildings provided the opportunities for Special Artists and illustrators to disseminate through plctures and words what the country was all about, documenting and influencing American cultural development. Philadelphia in fact had always been a literate city hungry for information and appreciated its illustrators even perhaps more than 1ts other artists because these men and women, through the press, were part of their daily 11 ves. ${ }^{78}$ 
Taylor's black and white wash Bittenhouse square 8 (Fig. 27), the former Southwest Public Square, symbolizes the city's move westward as he shows this upper class meeting area with John Notman's Holy Trinity Episcopal Church (185759) In the background. ${ }^{79}$ There were no burial grounds or prison here, and, as Bobbye Burke writes in H1storic Rittenhouse, "By the end of the Civil War, Rittenhouse square was completely surrounded by private homes." 80 These were not just the homes of wealthy merchants, but also the residences of the city's elite including Joshua B. Lippincott and Joseph and Sarah Harrison. The Harrison home was "the most opulent residence of the city" with an entire wing serving as a plcture gallery. ${ }^{\circ 1}$ when property directly on the square was no longer available, the surrounding streets became the first choice for those wanting to live in close proximity to Philadelphia's first familles. These new residents, many related by birth or through marriage to the city's old families, could afford the services of an architect. And the section west of the square, notes Burke, is the finest "concentration of the work of Philadelphia's most important nineteenth century architects," including homes and churches by Erank Furness, Theophilus P. Chandler, G. W. and W. D. Hewitt, Henry Sims, Walter Cope and John Stewardson, and John McArthur.82 On the square they practiced generally in the Beaux-Arts style following Chandler's emphasis on "correctness" of design which set the standard there.83 


\begin{abstract}
Taylor's view of Rittenhouse Square shows it prior to its decline in the late $1920 \mathrm{~s}$, and after the redesign of its landscape by Paul Cret in 1913-14, when "Its Shady tree-1ined paths, inviting greensward, and comfortable benches created a focus for families. . and generations of toddlers with their nurses considered the square their playground." 84 As economic and social patterns shifted after World war I, however, the large (3,000-5,000 square feet) homes became "difficult to maintain as single-family resldences." Not only were substantial domestic staffs no longer available, but repairs to heating and electrical systems, as well as plumbing and roof improvements and/or replacements, led owners to seriously consider the financial benefits of demolition and the construction of apartment and office buildings. ${ }^{85}$ While the Square and its surrounding area remains residential, with some of the city's finest apartment buildings still providing the area with an air of refinement, gone is Taylor's view of the reserved opulence that the Square once personified. What remains, however, is the sense of community founded on diversity that, just as on Washington Square, was what made Rittenhouse Square initially successful; and what Taylor recognized as an important contribution to the urban environment.

What both these scenes also show is the importance not just of the buildings but of the outdoor space. Philadelphians treated the street as an important part of everyday life beginning in colonial times. Much of the community
\end{abstract}


activity occurred outside, and the streetscapes of the city "affected and reflected" the attitudes the city's residents had toward themselves and the city. From the beginning Philadelphia was designed to promote citizen interaction. Its grid layout of public squares provided a uniformity of design that encouraged neighborhood cohesiveness, and Independence Square offered a large public gathering place for mafor events such as the reading of the newly written Declaration of Independence, and later, celebrations of the Fourth of July. Inns and coffeehouses were gathering places for the exchange of information as most business was conducted face to face.

The nineteenth century landscape was a changing one for Philadelphia as the city expanded westward past Broad to Rittenhouse Square and ultimately across the Schuylkill where Taylor himself would reside. Downtown or "Center City," however, remained an active area both culturally and economically, although increasingly dominated by banks, insurance buildings, and the imposing city hall, a thirty year construction project that climaxed in 1901. Some of Taylor's best drawings show a blending of old and new, commercial and residential in this urban core, such as Sansom Street East of 8th $\$ 21$ (Fig. 28) dated 1914. Here Taylor captured a typical day on the street just a block northwest of Washington Square. Not one of Philadelphia's small alleyways, Sansom had ample room for horsedrawn carts, motor cars, and the ever-present trolly. The shops whlch lined 
both sides of the street include a variety of architectural styles all blended together with business owners and/or renters living above the establishments. Taylor chose an interesting vantage point, for as the street heads east, it narrows or jogs due to the large imposing nine-story building in its path. This "skyscrapez" is indicative of the architectural search for a modern approach to dealing with structural and scale differences. Like Adler and Sullivan's Walnwright Bullding in St. Louls, this Sansom street edifice uses a columnar form to express function with a base, shaft and capital, emphasizing the different operations occurring within each section without sacrificing the feeling of vertical thrust. ${ }^{86}$

A different viewpoint on the changing skyline is seen in Taylor's 1911 wash Where old Philadelphta still clings to the Soil. ${ }^{87}$ Here Taylor recorded the undulating rooftops of the city as the sloping, snow-covered(?) roofs of the middle ground catch and reflect the bright sunlight while the ever expanding city skyline continues into the distance. Rather than appearing misplaced, the modern building in the background adds a new architectural dimension to the view, finding its niche in the city's great building tradition. Taylor's ground level view Broad and fllbert Streets \#2 again shows that architectural and social harmony can be achleved as change occurs. Here the rear of the smaller scale residential structures and foreground park area records the human side of the city where citizens could st1ll find 
places to enfoy the out-of-doors and chat with their neighbor or the local foot patrolman. This amiable scene at the intersection of the heart of the city, is set against an imposing backdrop of large scale office bulldings and the Gothic inspired Broad Street Station which dwarf the almost eighteenth century setting below.

There are many messages to be read here, but not one which would eliminate all modern structures and return the city to the days of Benfamin Franklin. What Taylor is saying and demonstrating throughout this entire series, is that there could be room for past, present, and future; that each have values that should be appreciated. ${ }^{88}$ He understood that what made Philadelphia great was the variety of ideas it originally encouraged. There was danger in a conformity that refused to acknowledge new contributions. The city needed to change to preserve its vitality, and that was part of Taylor's message. Also, that bulldings communicate the city's evolution and symbolize what made and makes it great. To eliminate every trace of the past Taylor knew would Jeopardize the cultural traditions that brought philadelphia to its turn of the century prominence. Preservation in some form was imperative.

Taylor also captured in his series the humanity of the city he so highly regarded -- the small community atmosphere such as that generated around its squares with a concerned citizenry, which he felt should not be sacrificed at the expense of new development. He certainly welcomed change, 
and saw a Darwinian progress to be made in making the city a continually better place to live and work, but he also thought it should be carefully planned. Unfortunately Taylor, in his declining years, was often thought of as a man who concentrated on capturing "Old Philadelphia" (or should it be Olde Philadelphia) on paper. And perhaps that is what people wanted to read in his drawings. Maybe the changes were too uncomfortable and like the works of West and Eakins, revealed a reality no one wanted to admit to. But in fact Taylor was a man recording the contemporary city which was destined to change. The city could not remain trapped in the past if it was to have a viable future, but it had to learn how to benefit from 1 t. 89

Taylor's industrial views of the city, mostly in black and white wash, are some of his most striking. Philadelphia At work - Eive O'clock In winter I1me (F1g. 29) which was used by Brandt and Gummere in their guidebook, shows an 1lluminated evening view of the city's commercial center, Broad Street.90 Taylor sketched this scene across the Pennsylvania Rallroad's elevated tracks (what became known as the city's "Chinese Wall") which led into Broad street Station, the lighted city hall clock tower serving as beacon. This sketch, as many in the series, owes part of its interest to the skill of the Special Artist to seek interesting vantage points.

Broad Street Station was the temple of Philadelphia's Iron Age symbol, the steam locomotive, write Burt and 
Davies.91 Taylor's view does not show the red brick medieval castle designed by wilson Brothers \& Co., enlarged and embellished by Erank Furness in 1892-93. What he does record from his aerial vantage point is, in the immediate foreground, the stone viaduct which connected the bullding to the former West Philadelphia terminal, the so-called Wall. Just above is the arched glass shed, "the largest in the world," where "By 1894, 530 trains carrying 60,000 people" arrived and departed daily. ${ }^{92}$ Not only did the city depend on the powerful Pennsylvania rallroad (among others) for its prosperity, but railroads brought this and other special Artist financial rewards, and their inclusion in Taylor's depiction of the contemporary city was inevitable. ${ }^{93}$ Here he shows the power and beauty they provided to Philadelphia before the New York Central came in to bankroll the failing empire just as New York City would usurp Philadelphia's leadership role as America's premiere city. 94

Taylor successfully depicts a strictly industrial view in his watercolor The hower schuylkild $\$ 373$ (Eig. 30). This shows not a romanticized look at industry but the root of Philadelphia's Iron Age success, "the basic trinity of iron and steel, rallroads and coal." This was the "tripod on which the city's nineteenth century industrial reputation and a large share of its prosperity rested."95 Taylor included all the elements here as numerous smokestacks puff away while ships and trains provide the important transportation link to the hinterlands and beyond. Artistically this well-balanced 
composition, completed when he was 80 , creates the feeling of quiet strength, typical of Philadelphia's image of itself.

Taylor records what might be considered a more dynamic scene further up the schuylkill in View of columbla Aveaue (Fig. 31) cl915. The arching white Philadelphia and Columbia Rallroad bridge originally linking the city with the "West," dominates the scene, dwarfing the spectators, and rowers. The train is again seen here as the all powerful element which ties together the threads of industrial progress, but in a graceful, accommodating way as the bridge permits both man and machine to occupy space on its roadbed.

When Taylor made this sketch the bridge linked the two sides of Fairmont Park, the city long ago having settled the river's western shores.96 The park, which "was a place of recreation for all" was governed by a separate Fairmont Park Commission founded in 1867.97 At this time, much of the land west of the Schuylkill was added including the portion on which Taylor was standing when he made this sketch, and which had become the thirty-three acre site of the zoological Gardens in $1874 .{ }^{98}$ The popularity of the park was such that by 1872 it was accommodating 750,000 pedestrians, close to 400,000 horse-drawn vehicles, as well as 26,500 equestrians. ${ }^{99}$ Taylor's tinted wash shows these activities as cars, horses, and spectators line the west bank of the river and pedestrians lean over the brldge to watch the rowers as they head toward the Fairmont Dam. Just above the dam were the numerous boat houses that were home to various rowling clubs, 
collectively known as the Schuylkill Navy and which Taylor included in an earlier vignette for the Dafly Graphic as noted in Chapter II. Taylor also shows along side the rowers one of the many excursion boats that offered a pleasant afternoon on the river for those not inclined to physical exertion.

It is interesting to compare this twentieth century view with Taylor's previously mentioned account of the boat races of the Schuylkill Navy for the Daldy Graphic in 1874. In the nineteenth century 1llustration there was no bridge across the river as the western side was then undeveloped. The crowds of race viewers all on foot, then lined the eastern side of the bank. The "crowd" rather than represented by small, impersonal brush stokes as they would be later, is shown as individual people with unique clothing and facial features. The human scale was what was important here, as is also shown in Taylor's closeup of the pre-race activities, and start of the race. A. B. Frost contributed detailed "character sketches." Just as Philadelphia was becoming larger and somewhat more lmpersonal, as well as controlled by technological advances, Taylor's two views reflect an identical perspective.

Fairmont Park was only two miles from Taylor's Springfield Avenue home and afforded the artist a respite from hectic days in the city while providing him ample opportunities for sketching. 100 His lovely watercolor Eirst Horseless Carriage in Falrmont Park, (Fig. 32) shows again 
his interest in the park as one of the city's important landmarks. Taylor here continues his theme of the city's ability to accommodate the new while preserving the old in this picture of turn of the century recreational activities. The setting is the courtyard of Mt. Pleasant, the High Georgian home built by privateer and sea captain John MacPherson (1761-62). Unfortunately, in Taylor's watercolor the elaborate Palladian window is obliterated by a tree, and the Doric frame and pediment outlining the main entrance are concealed by the addition of an awning. Still the beauty of the Gibbs inspired structure which John Adams called "the most elegant seat in Pennsylvania" is evident; and it makes a wonderful backdrop for the activities it frames.101 Reminiscent of Eakins' painting The Fairman Bogers Four-in-Hand, in Taylor's setting it is the horseless carriage that commands center stage as its red, black and gold body turns the circle and heads straight for the viewer as if to say this is the transportation vehicle of the future. The horse-drawn carriage, however, was still a park fixture as ladies with parasols all in white, enfoy a Sunday afternoon outing. Each element -- the private colonial residence, the eighteenth/ nineteenth century equestrian pleasures, and the early twentieth century automobile that provided ever increasing mobility -- has a place in this landscape. Mt. Pleasant stands firm as a symbol of Penn's designs for the city and enfolds the changes that naturally occur. And even though Taylor places the motorcar in the center of the composition, 
it does not detract from the beauty and grace of what preceded it, but adds new variety to the landscape.

Fairmont Park was not the city's first public green space. As already discussed, Philadelphia was originally planned with five open spaces to relieve congestion and offer some discontinuity to the structured grid layout. These were, note Goldfield and Brownell in Urban Ameriaa, "the first dedicated public parks in America."102 But, as the city landscape became ever more congested, these urban squares did not satiate a need for larger public spaces that could accommodate a variety of recreational needs.

Nationally, the first such large public landscapes were cemeteries, and were planned recreational spaces. One of the earliest was Philadelphia's Laurel Hill with its ninety-five acres of "winding paths and carefully designed terraces laid out in 1836 by John Notman whose buildings it should be remembered graced Washington and R1ttenhouse squares.103 Cemeteries like Laurel Hill were usually on the edge of the city, offering a true rest from the crowded urban environment -- for its residents and visitors -- and were quite popular. In 184830,000 people had visited Laurel Hill, a number which rose to 140,000 in 1861 . Here city residents could picnic under the shade trees or walk along wooded paths and breathe the fresh air.

As the population grew, and interest in recreational activities for health exceeded the abilities of the cemetery to accommodate these new pastimes, a larger area was 
eventually called for. This resulted in Philadelphia's interest in establishing an extensive park system along the Schuylkill. In 1855 the old Robert Morrls estate at Lemon Hill was transferred to direct city management and Fairmont Park was born. Later other estates were added, particularly after the completion of the Fairmont Dam which created swamp like conditions and a breading ground for typhoid carrying mosquitoes. The park eventually abutted Laurel Hill and really seemed an extension of the original Notman design. From the beginning Fairmont Park (following Penn's creed), was egalitarian in nature with both public and private funds used to provide beneflts for all. That so much of the park consisted of estates bequeathed to the city, is again a testament to the Philadelphia philosophy of private support for the public good be it funds for improvement of the State House, Rittenhouse Square, or a 2200 foot toboggan run for Fairmont Park. Taylor's watercolors show the park remained an important gathering place for all citizens into the twentieth century when the Ben Eranklin Parkway brought it "to the center of the c1ty."104

The eastern side of Philadelphia along the Delaware remained the active port it had been since the days of William Penn when the city's location was selected. This river connected Philadelphia with the outside world while the schuylkill, its western boarder, was the "highway to the Interior."105 Taylor chose an interesting composition for his wash it the Foot of South Street $\$ 35$ (Fig. 33) to document 
the commercial activity along the Delaware. Here in black and white, color would seem inappropriate, he examined the docks at close range rather than the distant wide angle vantage point he used in recording the industrial complex on the lower schuylkill. The viewer is now not a remote observer, but an active participant in the dark environment which seems more like the city's true pulse. Nineteenth and twentleth century transportation modes again meet under the elevated tracks to transport incoming wool, glass, iron, and molasses from England, Germany, Scandinavia and the West Indies and outgoing coal and grain. The trans-Atlantic ship In the right middle ground was probably part of the International Navigation Company on its way to Liverpool and Antwerp. Motorcars, horsedrawn vehicles, and steam engines bustle in the foreground as the day's activity commences. The strong patterned shapes of this composition along with the effective use of light and shadow, create a dramatic quality. The only true vertical is the powerful bridge support that maintalns the elevated railroad tracks. The remalning dominant lines -- the rallroad bed with its tracks and ties, the steamship's smokestack, the masts and rigging on the windjammer and its prominent bow, as well as the architecture of the dock building in the left middle ground - are all angled, creating a feeling of tension appropriate to the scene. The only softening curved lines occur in the more human scale of the foreground as a set of rails takes the viewer's eye off into the inner operations of the wharf. 
Philadelphia had the smallest immigrant population of any of the colonial seacoast cities and the immigrants who did arrive were largely English, Irish, and Germans, later to be supplemented by European Jews and Italians. There was also a small Chinese population in the city and Taylor chose to record that segment of the city's ethnic heritage in his 1923 watercolor Ear East Restaurant (Fig. 34). Of course Philadelphia had been an initial participant in the China Trade, and Taylor no doubt wanted to underscore this aspect of the city's early trade history. In addition it should be remembered, he had visited and painted Chinese establishments on his travels to Cuba, recording Havana's Chinese Theater on the 1880 Grant Trip. Always seemingly aware of the importance of an appreciation of cultural diversity in one's own personal development and of Philadelphia's as well, Taylor saw this subject as appropriate for his series of city drawings which were designed to capture all aspects of the city's history. He chose a magnificent architectural facade to represent the city's Chinese ties. The bullding directly abuts a Mansard roofed structure whose plain exterior, along with that of its neighbor, is in sharp contrast to the multifaceted restaurant that projects outward into the sidewalk area. Neither the awnings on the small building to the right, nor the interesting roof lines of the tall adjoining structures to the left can compete with the varied roof lines, porches, and decorations of the Far East establishment. 
While demonstrating Taylor's architectural artistic ability, this watercolor also displays a somewhat fumbled delineation of human figures. His skill at rendering people was, occasionally, inconsistent and sometimes even a detriment to the composition. 106 and yet, he knew the figures added an important aspect to the overall theme of the work just as the human element was important to his own life. Here the figures not only add scale, but indicate the integration of the Chinese into city life as Taylor shows two well-dressed women descending the stairs as they leave the restaurant while a Chinese host looks on. The woman approaching from the left shows no hesitation as she walks toward the two Chinese gentlemen conversing on the sidewalk, while a third leans against a supporting porch post. Without these figures this painting might have been more successful artistically, but Taylor generally attempted to humanize his work, making it more personal and thereby perhaps more valuable to the potential buyer. And, as mentioned previously, Philadelphia was a city where people interacted on the streets. If Taylor wanted to record the city on any given day, lifeless streets would be an anomaly. Here he has documented a part of turn of the century Philadelphia life, not merely preserved a building on paper.

What is important to realize here and in all Taylor's drawings is that even though his main purpose was to record an aspect of urban life, Taylor "composed" his pictures to obtain the desired effect. He wanted the average Philadel- 
phia householder to purchase his photolithographs for their walls and in portfolios to display on thelr coffee tables. He felt it was the responsibility of the artist to assist these middle-class Americans to "know the good in art from the bad."107 It would be unconscionable to record a scene without trying to also make it a good composition, and in his lectures on art he constantly reiterated the need for all young artists to heed this directive. ${ }^{108}$ While he may have been basically self-taught, his work with the country's top artists made him aware of the elements of an effective and pleasing composition. And his inheritance of the moral responsibility of the artist from West, Peale, and Philadelphia itself, made it imperative that his work be well executed.

Taylor recorded a time when Philadelphia was changing. Not the great city it once was where everyone looked outward and cared for their neighbor, but one where privatization had created an atmosphere where people began to look inward and were basically concerned with themselves. Rather than being receptive to new ideas the city seemed content to retain its status quo, to rest on its laurels so to speak. While great artists got their start at the Academy, they had to leave to find acceptance. John Sloan, Henry Glackens, Everett Shinn, and Mary Cassatt left for New York and Europe, and even Joseph Pennell who retained the closest ties to the clty, spent much of his artistic life abroad. Taylor was certainly aware of the changing climate of the clty he loved, and by 
recording what he considered the best aspects of the city's cultural heritage and its new urban landscape, he tried to visually reinforce the ldeals of civic pride, brotherly love, and historical commitment. He saw the city fall to solidly support the Sesqui-Centennial in 1926 which must have caused him great concern in the year prior to his death. Fewer people attended the nation's 150 anniversary party than the 1876 Centennial which had launched his career, providing a sad ending note to his life, but he always held out hope for the future.

Philadelphia's role in the founding of the nation held moral implications for Taylor who saw the preservation and continuation of the ideals of the Constitution an important part of the city's responsibility to the nation. His two major written works, the guidebook for Valley Forge and the city's civil War history, reinforce his theme of the importance of the preservation of these early values, and they have kept his memory alive. He embraced the city's and nation's concern for history in part due to his coverage of the Centennial when self-examination created a new civic pride. He also Inherited an artistic tradition from West, Peale, and Eakins which saw realistic visual representation of contemporary life a worthy goal, and as history, accurately depicted, a valid part of that realism. As a journalist in a city with a rich publishing tradition, factual reporting was instilled from early on, and he seemed to enjoy the telling of an interesting story. Had Taylor 
taken up residence in another city his skill at reporting may have remained constant, but it is doubtful if he would have found the encouragement to expand his career or the philosophical base that gave meaning to his work.

Even though Philadelphia suffered a loss of prestige as it moved into the twentieth century, its influences on all aspects of American life remained. The grid street plan was adopted by cities, including clayton, New York, as the country expanded westward; the Ladies' Home Jowrnal and Saturday Evening pest continued to influence family values far outside the city boundaries; Owen Wister gave America the quintessential cowboy and John B. Stetson provided his most recognized accoutrement; the Liberty Bell and the flag continued to symbolize American values; and Thomas Eakins and Walt Whitman prövided visual and written testament to individual pride. Taylor was an important part of that influence as his writings and illustrations preserved the best aspects of Phlladelphia's transformation from colonial seaport to nineteenth century industrial giant, to twentieth century urban center. He hoped future generations would appreciate the values Philadelphia embodied, and carefully venture forward without disregard for the past.

It is fitting that he is buried in Laurel Hill cemetery, now almost at the heart of the city, where forever he remains simultaneously a part of the urban and rural environment. There he sleeps in the city's early greenspace as a keeper of the flame of the city's most 1mportant citizens. 


\begin{abstract}
1Letter from Frank H. Taylor to the Philadelphia Sketch Club addressed "Friend Creighton." Reprinted in the H1stery of the Philladelphia Sketch club by Sidney C. Lomas, 1936, p. 824. Mr. Lomas was appointed Club Historian in 1933 as the Club approached its seventy-fifth birthday and the need was felt for a comprehensive history of the organization. Mr. Lomas also served as Club secretary, a position to which he was elected in 1921 the year following Taylor's presidency. Taylor's letter was written to thank Club members who had visited him while he was confined to his home because of "grippe." He was feeling better when he wrote the letter, but said he was "a prey to mental loneliness." He never returned to the club.
\end{abstract}

${ }^{2}$ Reproductions of Taylor's drawings were sold in the 1920 s at the Charles Sessler Gallery at 1314 walnut Street and J. E. Barr and Company, 1109 Walnut Street. A list of available prints and prices for the two galleries have survived. Both advertised Taylor's work as drawings of "old Philadelphia." A quote from Philadelphia writer, newspaperman, and friend, Christopher Morley, reproduced on both lists stated that "'Frank $H$. Taylor has certainly done more than any other living man to keep alive Phlladelphia's appreclation of her historic past through hundreds of charming drawings of old beauty spots and old-time vistas." The prints were $12 \times 15$ (J.E. Barr lists them at $8 \times 10$ ) and sold for $\$ 2.50$ each, or $\$ 2$ each for flve or more. A portfolio of forty-eight selected prints was available for $\$ 48$. The more extensive Barr list also noted that the artist would make "special drawings. . . of old structures for those interested." Each drawing had a number, and these numbers often appear on the original wash drawings and watercolors. Where known, they will be provided when discussing Taylor's work. The Barr list of 406 prints plus six New Jersey subjects is at the Library Company of philadelphia. The Sessler list of 266 prints plus the six New Jersey views is from the HSP.

${ }^{3}$ For a comprehensive background on Philadelphia's founding see Struther's Burt, Bhlladelphia: Holy Experiment (Garden City, NJ: Doubleday, Doran \& Company, Inc., 1945); Carl and Jessica Bridenbaugh, Rebels and Gentlemen; Welgley, ed., Philadelphia; Warner, The Private City; and Sylvia 
Doughty Fries Chapter 3, "William Penn's 'Greene Country Towne," in The Urban Idea in colenlal America (Philadelphia: Temple University Press, 1977).

IIt is logical that what has been termed American Art should emerge from a city which called itself "the most American of American Cities." (Weigley, p. 530). Besides being the birthplace of the nation, it was physically at the center as "all maps made in the colonies" from before the Revolutionary War and well after, "calculated their longitude from the Meridian of Philadelphia." This line, set in 1769, was 75 degrees, 8 minutes, 45 seconds west of Greenwich -running through Independence Hall. G. Don Fairbairn, Philadelohia: Fabulous city for 'Eirsts' (Wyncote, PA: Kirsh Publishing Co., 1976) p. 7. IAmerican Realism began in part, wrote Marianne Doezema in American Realism and the Industrial Age, because "the pragmatic merchants and farmers of the New World developed a taste for the straightforward, honest depiction of real life in actual places. An identifiably nat ive imagery and style began to emerge, derived from a predilection for real subjects presented with as much clarity, precision and honesty as the artist's skills permitted." Doezma, American Bealism (Cleveland: The Cleveland Museum of Art, 1980), p. 12.

${ }^{5}$ The phrase, while often used to describe the clty in the early nineteenth century as did Edgar P. Richardson in his chapter, "The Athens of America 1800-1825" in Welgley's Rblladelobia, is not attributed to contemporary sources except for Gilbert Stuart who once said he resided in the Athens of America when discussing his tenure in Philadelphia. Philadelphia and Periclean Athens shared similar characteristics that influenced their urban excellence, some of which will be discussed in this chapter. But whether philadelphian's consclously viewed themselves as Athenian counterparts has not been firmly established.

6Burt, Rhiladelohia: Holy Experiment, p. 7.

'Ibid., p. 59. In both cases the permanent citizenship eventually assumed an orthogenetic character.

${ }^{8}$ For additional information on Philadelphia's lucrative maritime trade see Bridenbaughs' Rebels and Gentlemen and Jonathan Goldstein, Philadelohia and the China Trade 16821846 (University Park: The Pennsylvania State University Press, 1978). 
9Richardson, "The Athens of America," Rhiladelobia, Weigley, ed., p. 230. The Bristol p1ke was the oldest road to New York originally designated as the King's Highway in 1675. William Penn traveled this road to his Pennsbury Manor, and John Adams as well as other delegates used it to arrive at the Continental Congress in 1775. In 1781 Washington and his army marched along the road to their Yorktown victory. Francis Burke Brandt and Henry Volkmar Gummere, Byways and Boulevards In and About Histeric Rhiladelphia (Philadelphia: Corn Exchange National Bank, 1925), p. 308 .

${ }^{10}$ For more information on city development see Lewis Mumford, The city in History. Its oriains. Its Iransformations, and Its Prespects (New York: Harcourt Brace Jovanovich, 1961).

11Harry M. Tinkcom writes in his chapter "The Revolutionary City 1765-1783," that the "veneration of the bell as the 'Liberty Bell' was a nineteenth century development courtesy of the George Lippard one of the city's popular writers." The connection of Betsy Ross and the creation of the flag was also an embellished historical fact aided by Mrs. Ross' grandson. Whatever their true origins, that the bell and flag became national symbols for independence and assoclated with Philadelphla remalns a fact. Tinkcom, "The Revolutionary City," Philadelohia, Weigley, ed., pp. 124-225.

12Richardson, "The Athens of America," Rhiladelohia, Weigley, ed., p 241.

13Ibid. Richardson goes on to note that Philadelphia would retain its maritime economy, adjusting to industrial change, even when "older seaport cities faded away before the thrust of machines."

${ }^{14}$ Taylor, Philadelphia in the civil War, p. 202.

${ }^{15}$ Russell $F$. Weigley, "The Border City in Civil War 18541865," Philadelphia, Welgley, ed., p. 398

${ }^{16}$ Richardson, "The Athens of America," Rhiladelphla, Welgley, ed., p. 240.

${ }^{17}$ A photolithograph of this sketch is in the collection of the Iibrary Company of Philadelphia, the location of the original is unknown. The original Mint, established by an 
act of Congress in 1792, stood on Seventh street from 17931833, and was "the first building erected in any part of the United States under the authority of the National Government." Brandt and Gummere, Byways and Boulevards, p. 260.

${ }^{38}$ Strickland had a great interest in archeology, not surprising in a city that was instrumental in the development of the discipline through West and at the University of Pennsylvania. Strickland's most famous classical Philadelphia building was his Second National Bank of the United States in which he utilized the measured drawings of Stuart and Revett for his "copy" of the Parthenon. Roth, $A$ concise Histery of American Architecture, pp. 86-87.

${ }^{19}$ Equally important was the symbolic connection of the Mint as unifier of America as it developed a standardized coinage system for the nation. The Philadelphia Mint remains the nation's largest.

${ }^{20}$ Paul Hogarth, Walking Tours of Old Philadelphia, p. 1x.

${ }^{21 E v e n t u a l l y ~ t h e ~ g r e a t ~ p u b l i s h i n g ~ h o u s e s ~ a n d ~ t h e ~ l e a d e r s ~}$ in the art world moved to New York.

22By 1750 less than one-quarter of the city's inhabitants were Friends. As their fortunes grew and social position became of greater concern, many Quakers folned the upperclass Anglican (Protestant Episcopal) church. Baltzell, Rhiladelohia Gentlemen, p. 238.

${ }^{23}$ This "school" included besides Claypool, a member of one of Philadelphia's most prominent families, John Meng, Matthew Pratt, Benjamin West, William Williams, and Eugene dusmitiere. For a more comprehensive look at this period of Phlladelphia Art see Chapter V, "The Arts Move Westward, in Bridenbaughs' Bebels and Gentlemen, pp. 135-178. IClaypool's brother ran James' Coffee House, "a favorite meeting place for these artists." Ibid., p. 165.

2'Even though West would leave Philadelphia, his Quaker out look would influence all American artists, many from Philadelphia, who would travel to England to study with him. These artists then returned home incorporating West's philosophies into their own work. America's other outstanding Colonial painter was Bostonian John Singleton Copley. Unfortunately when he left Boston for England, Copley's ties to his native country were severed. West remained a Philadelphian but Copley became a Londoner. 
25philip S. Klein and Ari Hoogenboom, A History of Rennsylyania (1973; rpt. University Park: The Pennsylvania State University Press, 1980), p. 265.

${ }^{26}$ Kenneth S1lverman, A cultural History of the American Revolution (New York: Thomas Y. Crowell Co., 1976), p. 172.

${ }^{27}$ Harris writes that "the [American] Revolution proved a godsend to art and the artist life... . [it] created a History, marked with a great event the beginning of an epoch, and introduced the factors of time and specific creation into the consciousness of a people." He further notes that art now had a mission in reassuring the people of unity and harmony. Nell Harris, The Art ist in American Society: The Eormat Ive Years 1790-1860 (New York: George Braz1ller, 1966), pp. 15-17.

${ }^{28} \mathrm{His}$ innovative labeling techniques, however, did provide important and accurate written documentation.

${ }^{29}$ This was the first school of 1 ts $k$ ind in the United States. Peale's first attempt came in 1791 when he tried forming a drawing school for promising young artists. This was unsuccessful and in 1794 in cooperation with Phlladelphia carver William Rush and Italian Sculptor Gluseppe Cerracchi and others, he formed the Columblanum, an association designed to promote the arts in America. This attempt also falled. Finally on December 6, 1805, Philadelphia's most progressive citizens subscribed to articles of agreement providing for the creation of the Pennsylvania Academy of the Fine Arts which antedated by nineteen years the founding of the National Gallery in London. The meeting took place in the State House in the room then used by the Continental Congress, an appropriate location for the birth of American art.

30"Secretary's notes, October 2, 1869," Archives of American Art, Roll 3665.

${ }^{31}$ Lomas, History of the ehiladelohia sketch club, p. 59. In addition to the Histery, information about the Philadelphla Sketch Club has been preserved by the Archlves of American Art who microfilmed the club's records in 1985 as part of their Phlladelphia Collecting Profect; rolls 3665, 3666,3919 , and 3920. Information is also found in The Sketch club in its Ninetieth Year, published by the Club in 1950, N. pag., and The Club's 100th Anniversary calendar 
published in 1960, N. pag. Both 1tems are on file at the HSP.

32Lomas, H1stery of the Phlladelohla Sketch club, p. 59.

${ }^{33}$ Archives of American Art, Roll 3665.

${ }^{34} \mathrm{FHT}$, Manuscript Collection, HSP, Box 2, Folder 3.

35100th Anniversary calendar. It is interesting to note that while the Sketch Club was focused on promoting American talent, that did not mean they were unaware of or uninterested in what was occurring in Europe. Many of the PSC members traveled to Paris, and a gift of sketches was presented to the Club by the Paris Sketch Club who requested samples in return.

${ }^{36}$ The Sketch club in its Ninetieth Year, and Clipping from the Evening Telegraph, May 10, 1873, Archives of American Art, Roll 3665.

37 "Secretary's notes September 11, 1875 - December 26, 1885," Archives of American Art, Roll 3665. Here again the concern with scientific accuracy. Phlladelphia was a city with a strong medical tradition and the influence of the profession permeated all aspects of cultural development. The connection between science and the arts is a historic one, and the desire for a thorough understanding of the human body in order to represent it whether on canvas or stone has long been the concern of the artist. That Philadelphia artists had immediate access to excellent medical facllities and practitioners made a systematic, precise study of human anatomy easily accessible to all. It also exposed them to a logical, rational approach to rendering the human form -- a thought process that might be adapted to thelr own work, particularly in the case of Special Artists who needed to approach the coverage of a story in a straightforward manner.

${ }^{38}$ Ibid. From 1870 to 1876 the Academy was in rented quarters while the present building was under construction and classes were limited. IOne time a fire broke out during the Life Class when the Club was headquartered at 11 th and Walnut Streets. Although in another section of the building, and with fortunately no major damage occurring to the Club's rooms, stories of how the model was hastily dressed with the help of Club members and discreetly taken out to the street without causing comment, are a lively part of the club's history. 

1924 ."

39Ibid., "Secretary's notes January, 1918 to April,

10Ibid. In 1907 when Taylor presented a silver cup to Covington Few "Fewey" Seiss for twenty-two years service as Club secretary (he would continue in that position until his death in 1915), Taylor reminisced about the cup presented to him for his new son "now older than his father was at that time." He said he met Fewey's father, a popular minister, on his first day in philadelphia when his new employer insisted he attend Sunday church services.

${ }^{11}$ This was a follow-up on the enthuslastic response the Club had to an earlier publication of caricature sketches originally intended for Club members, but which attracted much attention. 1879.

${ }^{12}$ Eakins was elected an honorary member of the club in

${ }^{43}$ Burt and Davies note that in the 1890 s cricket was extremely popular in Philadelphia drawing as many as 20,000 spectators. The city even sent teams to compete in England and vise versa. . Nathaniel Burt and Wallace E. Davies, "The Iron Age 1876-1905," Philadelphia, Weigley, ed., p. 519. IThe Grub Club was organized in 1888 by Taylor's long time friend F. C. Schell, and then president Walter Dunk. Because a number of Club members would meet at noon at a local lunchroom "to eat, relax, and keep each other up-to-date with anecdotes and local gossip" (all had studios in the vicinity of the establishment on 8th Street below Walnut), it was reasoned that they could relax fust as well at the club which was only three blocks away. At first the group brought their lunches from home. Gradually as the popularity of the noon group grew, officially christened the Grub Club, the lunch was catered. The group still meets once a week on Thursdays and $1 \mathrm{~s}$ responsible for organizing the Christmas Gala where the famous "fish house punch" is served. PSC Rortfolio, November 1986. Note: This later Portfolio is a newsletter and not the same publication that Taylor first initiated in 1874 .

14The Sketch club in its Ninetieth Year.

15Invitations for special dinners and other events have also been preserved as well as Christmas Cards designed by the members and contributed to the Club's scrapbook. During 
an outing held at Dunk's Ferry on Saturday, June 10, 1905, Taylor received first mention for his sketch made during that day.

${ }^{16}$ City directories do not always have Taylor listed during these years, and his address appears intermittentiy in Club files as $1303 \mathrm{~N}$. 6th Street, and 718-724 Arch Street. The 6th street location was his first home, and it may have been when away from the city Mrs. Taylor and Walter stayed with her mother. The Arch Street address, a seven story cast Iron building, was a business address he used for a number of years, apparently when he was no longer a partner with Ferdinand Smith.

17Originally laid out as Dean Street c.1756, it was renamed Camac in the 1900 s for the family of Captain Turner Camac who came to the city from Ireland in 1804. A grandson, Dr. William Camac was a founder of the Phlladelphia Zoo. Paul Hogarth, Walking Tours of eld Philadelphia, p. 137.

${ }^{48}$ This club was originally two properties erected in 1795, one of them for Richard Wister, a pioneer merchant and member of the Board of Directors of the Library Company of Philadelphia.

49urt and Davies, "Iron Age," Rhiladelphia, Weigley, ed., p. 520 .

50Ibid., p. 523. This blending of rich and poor was also made possible by the fact that "discretion" was the key; ostentatious or the flaunting of one's position were unacceptable. Everyone, wrote Burt and Davies, seemed to be "striving toward the same ends; a respectable family, nestled in a respectable house at least as decorously comfortable as the neighbors', whether the house had three or thirty rooms."

${ }^{51}$ Nicholas B. Wainwright, "The Age of Nicholas Biddle 1825-1841," Pbiladelphia, Weigley, ed., p. 301.

52Up until then the Hall had been maintained by Charles willson Peale whose museum, with portralts of American heroes including Lafayette, was on the second floor. In 1828 the steeple was restored by William. Strickland. John Haviland was commissioned in 1831 to restore to its eighteenth century form the Assembly Room where the Declaration of Independence was signed. The bullding was permanently opened in 1836 . 
${ }^{53}$ Mark H. Miller, "The Farewell Tour and Amerlcan Art, in Lafayette, Hero of Two Worlds. The Art and Pageantry of $\mathrm{H}$ is Earewell Tour of Amer1ca, 1824-1825, (Hanover, NH: University Press of New England, 1989), p. 131.

54Kennedy came to Philadelphia in 1836. In addition to contemporary paintings of the city he made lithographs after earlier artists of bulldings and situations no longer extant. Wainwright, "The Age of Nicholas Biddle," Rhiladelohia, Weigley, ed., p. 301. Many of Kennedy's watercolors are in the collection of the HSP, and his lithographs done with William Lucas after $W$. $L$. Breton are in the collection of the Library Company of Philadelphia.

55In some instances Taylor based his drawings on old photographs or sketches with a note so indicating. His wash drawing of Eort Mifflin. A Prison For Deserters, used in his Civil War book was, he notes, "Redrawn from a sketch by $T$. H. wilkinson."

56In Dee Brown's The Year of the century. 1876 (New York: Charles Scribner's Sons, 1966) for example the 1llustration's sources are provided, but not the dates the engravings appeared in Harper's Weekly, Erank Jeslle's or the Daily Graphic. Further, the Special Artist who was probably credited on many of the engravings for these papers was not named, nor the engraver. Of course the engraver might only be discerned by his initials, but more credit needs to be given to both Special Artists and engravers.

57There has been no order to these gifts of Taylor's work to the various instltutions of the city. It appears as if the watercolors were bought in small or individual lots when auctioned off and remalned family heirlooms until perhaps no helrs were left to receive them, whereupon they were donated to one of the museums. Many more are undoubtedly hanging on walls or stashed in closets in the city -- their importance being their reminder to the viewer of the city's history, the artist being generally unknown. Taylor would be pleased that his work invokes a civic pride, but he would also have undoubtedly liked to be remembered for his contribution.

${ }^{58}$ Taylor was concerned not fust with the preservation of buildings, whether in three or two dimensional form. He was also concerned about the instability of the paper that his words and drawlings (and those of others) were recorded on. In h1s 1915 lecture he noted that "We have lost, too, the old enduring hand-made paper made to withstand the tooth of time. 
Nearly all the machine made papers of today [are] chemically treated and clay surfaced are destined to discolor and rot. Somewhere I have read a statement that with in some 300 years all our present literature wherever preserved, will disappear." He further noted that future researchers would have difficulty and need to depend on what is left engraved in stone or bronze to study the past. FHT, Manuscript Collection, HSP, Box 2, Folder 3 .

${ }^{59}$ Harlan D. Unrau, Administrative History: Valley Forge National Historical Park, PA (Washington, DC: U. S. Department of the Interior, 1984), p. 109. Frank H. Taylor, Valley Eorge: A Chronicle of American Herolsm (Philadelphia: J. W. Nagle, 1905). Nagle was publisher of the 1905 and 1911 editions. Lippincott's published the 1916 and 1920 editions. These first four editions all carried a copyright by FHT. The last edition, 1922, was published and copyrighted by Danlel J. Voorhees, proprietor of the Washington Inn located on the park property. Originally known as the "Bake-House," because it was used as a bread bakery for Washington's Army, Voorhees ran it as a lodging/dining facility. In the preface to the 1911 edition Taylor noted that the illustrations were mainly comprised of photographs by the author unless otherwise noted. This is the only documentation that he supplemented his sketches with his own photos, but it is a logical progression for a man who knew the advantages of keeping pace with changing technology. Rather than lament the replacement of photographs with illustrations and suffer loss of income, Taylor galned proficiency in the new art form. Many photographers were members of the Philadelphia Sketch Club to whom he turned to for assistance in perfecting this new documentary tool. Ironically a preference for photographs may have been one of the reasons his illustrations of Philadelphia did not sell. What percentage of his later work was photography is, as yet, difficult to ascertain because the photographs in articles and guidebooks are often uncredited. His real love, however, remained drawing, where he could truly express his feelings.

${ }^{60} \mathrm{FHT}$, Philadelohia in the clvil War, p. 3. In a preface entitled "Concerning this Book" it was noted that $\$ 10,000$ was provided as part of a 1911 loan bill for the publication of this book and the "erection of a monument in honor of the Soldiers and Sallors of Philadelphia in the Civil War." The impetus came from the Grand Army Association along with cooperation from the Military Order of the Loyal Legion and the Sons of Veterans. Members of each group were chosen for a Jolnt Committee which met on October 26, 1911 and by 
resolution, recommended an official historian, Frank H. Taylor. The direction and scope of the book was entrusted by Mayor Blankenburg to a Special Advisory Committee composed of Col. Robert B. Beath, Lieut. Col. John P. Nicholson, and Maf. Gen. James $w$. Latta.

${ }^{61}$ Ibid.

62 This was not Taylor's first map of course. He often included maps as part of his railroad guidebooks, and one was included in his Valley Forge pamphlet as part of an advertisement for the Philadelphia and Reading Railroad and the Norris City Company's Automobile Iine which would take visitors from Center City Philadelphia to the park. He also, it should be remembered, would prepare the birdseye view of clayton.

${ }^{63} \mathrm{FHT}$, Rhiladelphia in the civil War, p. 3.

${ }^{64}$ Roth, A Concise History of American Architecture, P. 19 .

${ }^{65}$ George Barton, Little Journeys Around old Philadelphia (Philadelphia: The Peter Reilly Co., 1925).

${ }^{66} \mathrm{FHT}$, "Three Lakes of Central New York." Lipplncott's Magazine of Popular Literature and Science, 25 (1880), pp. 410-423. Ilea and Febiger's, and Ilppincott's later became the nation's leading publishers of medical books. For more information on the city's medical publishing background and medical history in general see John Francis Marion's Philadelphia Medica: Being a Gulde to the City's Histeriaal Places of Health Interest (Philadelphia: SmithKlein Corp., 1975).

${ }^{67}$ Burt and Davies, "The Iron Age," Rhiladelphia, Weigley, ed., p. 514 .

p. 105 .

${ }^{60}$ Paul Hogarth, Walking Tours of old Philadelphia,

${ }^{69}$ Inid. p. 118 .

${ }^{70}$ Roth, A concise History of American Architecture, 
11Just off this square on Walnut Street are a group of row houses designed by Benjamin Latrobe. Hogarth, Walking Tours of eld Philadelphia, p. 102.

72Bridenbaughs, Rebels and Gentlemen, p. 161.

${ }^{73}$ Mumford, The Brown Decades, p. 8.

74Struthers Burt, 2hiladelohia: Hely Experiment, p. 234. Also see Ann Jarmusch, "If Vermeer Were Alive Today, Would He Be Painting in Philadelphia?" Art News, 80, No. 3 (1981), p. 156 .

${ }^{75}$ An example of colorful interior design can still be seen in the restored interior of the Pennsylvania Academy of the Fine Arts by Furness and Hewitt. The new bullding opened in 1876. A tribute to Philadelphia's architectural vitality both in its exterior and interior design. Its High Victorian Gothic facade is texturally rich although the buliding committee stipulated the use of brick and dark stone. The result is that the Academy building becomes a complimentary part of the streetscape while still providing a visual comment on change. The interior, however, is extremely colorful, as if the proper Phlladelphian was allowed to let loose once away from public scrutiny. This freedom, appearing at the same time Eakins was challenging viewers with his realistic portraits, was short lived. "Soon the elaborate, brightly painted columns were encased in plain piers, the skylights and colorful stairhall were painted over, and the floor tiles were replaced. . . " Philadelphia seemed to be able to produce innovative artists but the city did not always appreciate that genius if it overstepped acceptable bounds. Kathleen James, A National Histeric Landmark: Penosylyania Academy of Fine Arts, Academy brochure, n.d., N. pag.

${ }^{76}$ Goldfield and Brownell discuss this changing aspect of the city in their section entitled "Radial Center" where they note "an era of vibrancy for both the [city] center and the periphery." David R. Goldfield and Blaine A. Brownell, Urban American: Erom Downtown to No Town (Boston: Houghton Mifflin Co., 1979), pp. 288-295.

77Warner, The Private city, p. 192.

${ }^{78}$ By 1876 the city had over a dozen newspapers led by the Rublic ledger and the Ilmes. Its outstanding journalists included "George $w$. Childes at the Ledger, Alexander $K$. 
McClure at the Times, John $W$. Forney at the Rress, Morton McMichael at the Nerth American, [and] Gibson Peacock at the Buldetin." Beers, "The Centennial City," Rhiladelobia, Weigley, ed., p. 455.

${ }^{79}$ Taylor's other drawings of the square and its surroundings include East Rittenhouse Square 14 , Colonnade Bow, 1834 107, and Besidences, South Rittenhouse Square \$303. Lithographs of these three works are at the Library Company of Ph1ladelphia, and $\$ 107$ was reproduced in the book Historic Rittenhouse: A Philadelohia Neighborbeod, Trina Vaux, ed., (Philadelphia: University of Pennsylvania Press, 1985), p. 9. The locations of the originals are yet unknown.

${ }^{80}$ The development of this square represents the city's continual expansion to the west. For a comprehensive history see Historic Rittenhouse, Trina Vaux, ed.

${ }^{81}$ The Harrisons were board members of the Pennsylvania Academy of the Fine Arts and often invited friends and fellow board members to see their collection which included Benjamin West's William Penn's Treaty with the Indians, Charles Willson Peale's The Artist in his Museum, a portrait of George Washington by Gilbert Stuart, and John Vanderlyn's Artadne Asleep in the Island of Naxes. They also owned many of Pennsylvanian George Catlin's canvases of American Indians. They had, in fact, paintings which were Phlladelphia's initial contribution to American Realism in the works of West and Peale, and the gloriflcation of the country and preservation of its heritage in the works of Stuart and Catlin. And in Vanderlyn they had a successful attempt at realistically depicting the human form "executed with a faithfulness and capacity unknown in . . America." Vanderlyn, who studied in Philadelphia with Gilbert Stuart, was also testing the country's acceptance of realism by including a nude.

${ }^{82}$ Bobbie Burke, "History and Development," Historic Bittenhouse, Trina Vaux, ed., p. 23. Chandler, notes Burke, served as president of the local chapter of the American Institute of Architects from 1888 to 1899 and was the profession's "acknowledged leader." From a prominent Boston family, he moved to Philadelphia in 1872, married Sophle Madeline dupont (making him a part of the city's old elite), and settled in Rittenhouse Square. Educated at Harvard, he became head of the University of Pennsylvania's school of architecture when $1 t$ was established in 1890 . He was succeeded by Paul Philippe Cret, a graduate of the Ecole des 
Beaux-Arts, who redesigned the Rittenhouse Square landscape in 1913-14. Chandler was influenced by the interest in indigenous American architecture resulting from the nation's interest in history spawned by Lafayette's tour and the centennial. The city's Georgian architecture was seen as "native examples of order, geometric simplicity, and logical planning, basic concepts of current training at the Ecole des Beaux Arts in Paris." Chandler, noted Burke, "put the stamp of approval on the Colonial Revival in Rittenhouse when, in 1899, he chose a Neo-Georgian mode for iron merchant Frank Samuel's house at 2136 Locust Street" (p. 26).

${ }^{83}$ Ibid.

${ }^{84}$ Ibid., p. 30.

${ }^{85}$ Ibid.

86 In this case the shaft appears to be of a different material or color, further accentuating the difference in function. It is interesting to note that Sullivan's theories which were expressed in his essay "The Tall Office Bullding," were published by Lippincott's of Philadelphia in 1896.

${ }^{87}$ This wash also carries a copyright logo dated 1915. Only some of Taylor's extant Philadelphia series were copyrighted.

${ }^{88}$ The same message is given by Sam Bass Warner and other urban historians who realize that complete obliteration of the past -- urban renewal -- destroys the city's philosophical base.

${ }^{89}$ Taylor's obituary notices and articles written about him after his death were put in the PSC scrapbook and subsequently filmed by the Archives of American Art. Most of the writers refer to Taylor's Philadelphia work as a record of "Old Philadelphia." One noted that he preserved on paper "a record of the historic spots of Philadelphia," while another called him "The Man Who Visualized Old Philadelphia." An editorial in the Bulletin dated July 27, 1927, however, more correctly noted that the artist was "a chronicler who tried to visualize the past and present true to fact. . . ." The writer, who appropriately called raylor a historian, noted that "for years [he] had been one of those who have helped cultivate and preserve the city's history." Archives of American Art, Roll 3921. 
${ }^{90}$ Brandt and Gummere, Byways and Boulevards, p. 245.

92Burt and Davies, "Iron Age," Rhiladelobla, Welgley, ed., p. 474. The Station was on the site where the Philadelphia Sketch Club had once rented rooms.

92 This glass shed itself was an expression of iron age architectural innovation. Cast iron construction allowed architects and builders to meet the growing demand for retail stores and warehouses as "Whole stores could be bullt of prefabricated cast iron panels and sheets of glass in as short a time as two months." James Bogardus is credited with the development of the bullding type in America. Among his projects was the frame for the Harper's bullding in New York City. Examples of this construction type are also seen in the nation's bridges of which the Brooklyn Bridge is the finest. Roth, A concise History of American Architecture, p. 120 .

${ }^{93}$ The other major railroad and the one for whom Taylor wrote and illustrated brochures, was the Reading. Its history, noted Burt and Davies, "was less fortunate than that of the Pennsylvania," and it eventually was controlled by a syndicate which included J. P. Morgan.

94Burt and Davies, "Iron Age," Philadelohia, Weigley, ed., p. 659. The authors also note that not only was the Pennsylvania Railroad the "keystone of the Keystone State" but it was the keystone of the nation as "the country's single largest corporation, and its headquarters were in Philadelphia. (p. 475). In 1910 when the Pennsylvania Rallroad built "the great Baths of Calcutta" on Seventh Avenue in New York City, under the leadership of Alexander $\mathrm{J}$. Cassatt, it was Philadelphia's statement of national prominence, though New York had the leadershlp role by then and Chicago was second. The rallroad could not retain its position, however. Burt and Davies note the decline was continuous thereafter until in 1958 the Pennsylvania was forced to merge with the New York Central.

95 Ibld., p. 474.

96Beers, "The Centennial City," Philadelohia, Weigley, ed., p. 451. This same bridge was used by Eakins as a backdrop for his Max Schmldt in a single Scull.

97Ibid., p. 426. 
98Ibld., p. 448. Taylor wrote in pencil on the foreground that this was the site of the Zoological Gardens. Frank Furness and George $w$. Hewitt designed the entrance pavilions at Thirty-Forth Street and Girard Avenue. Furness also designed the elephant house, and Hewitt the antelope house.

${ }^{99}$ Motorcars were not allowed in the park until 1899. Taylor's inclusion so many vehicles dates this sketch to at least 1900, but probably closer to 1915..

${ }^{100}$ Parks and outdoor spaces were important to Taylor. He knew the value of a respite from the urban environment which was why he spent his summers in the Thousand Islands. He also realized that relief could be provided within the city be it small parcels like Washington and Rittenhouse Squares, or the larger Fairmont Park. After moving to West Philadelphia he was instrumental in the creation of Clark Park between $43 \mathrm{rd}$ and $45 \mathrm{th}$ Streets and Baltimore and Woodland Avenues. He raised the money to purchase and move a granite stone from the Gettysburg Battlefield to commemorate the soldiers treated at the Civil War hospital formerly on the site. He also was an active member of the 49 th Street Station Improvement Association. M. Marshall Smith, letter to the editor of the Public Ledger, May 30, 1927, Archives of American Art, Roll 3921.

101Brandt and Gummere, Byways and Bouleyards, p. 118. In 1779 the house was purchased by Benedict Arnold as a gift for his intended, Peggy Shippen. The property was confiscated after his treason was uncovered. It became part of Falrmont Park in 1868 .

102Goldfield and Brownell, Urban Ameriaa, p. 33.

${ }^{103}$ Laurel Hill was originally the country seat of John sims. In 1836 it was purchased by a stock company and converted into a cemetery beginning the tradition of turning former estates into park lands. Wainwright, "The Age of Nicholas Biddle," Rhiladelphia, Weigley, ed., p. 286.

104Lloyd M. Abernethy, "Progressivism 1905-1919," Rhiladelphia, Weighly, ed., p. 525.

105"By the end of the nineteenth century there were five miles of continuous wharfs along the Delaware and four along the Schuylkill. Burt and Davies, "The Iron Age," Phlladelphia, Welgley, ed., p. 483. 
${ }^{106}$ Taylor was aware that he lacked certaln skills. While not speciflc, he did write in his speech to art students that he wished he had had the benefit of more formal training. "I have always been handicapped by the want of that thorough training which is here offered to you. Whatever I may have learned and applied has been rescued from the vicissitudes of life. In whatever particular I have falled to realize early ambitions, I attribute that fallure to that training which might have subordinated a facility to do several things fairly well rather than one more thoroughly." FHT, Manuscript Collection, HSP, Box 2, Folder 3.

${ }^{107} \mathrm{FHT}$, Plastic Club Lecture, November 17, 1915. FHT, Manuscript Collection, HSP, Box 1, Folder 4.

${ }^{108 \mathrm{He}}$ might also have seen a need for Improvement and hoped that by choosing this urban industrial scene he could influence Philadelphia to again take pride in her port. Badly neglected by an uninterested political machine, all but one pier was privately operated and many could not accommodate ships of sizeable draft causing the city's inboard tonnage rank to fall from 83 in 1900 to 51 in 1907. Abernethy, "Progressivism," Rhiladelohia, Weigley, ed., p. 546 . 
CONCLUSION

As a Special Artist, Frank Taylor was conditioned to record the essence of a scene -- not "just the facts" but a realism blended with human understanding. As a result, he has left historians an important legacy of visual images and written documents about late nineteenth century cultural development. His work and his life offer clues to how the expanding middle class dealt with technological change, an increasingly urban existence, leisure, and a new national image of America, as it recovered from war, and headed toward a new world presence. As a Special Artist for the country's premiere illustrated newspapers, Taylor covered a myriad of stories that helped readers feel less threatened by those changes. The Spectal was the eyes and ears for the public who were unable to participate directly in many of those events, but who eagerly awaited each issue to learn all they could.

Perhaps, because Taylor was such an acute observer of change, he was also aware that that change should not come at the expense of all that came before it. Particularly evident in his Philadelphia series, he saw benefits in the blending of old and new to create what Warner refers to as a "humane environment." Taylor understood that people need a foundation upon which change could be built -- not only in the city 
but everywhere. He did not, however, belleve in denying change. He embraced new inventions such as photography, even though it meant the elimination of the Special Artist in the fleld of news reporting. Taylor realized, and lectured to art students, that changes brought about new avenues of opportunity -- one just needed to be receptive. His images of Phlladelphia dealt with foundations and change for one of America's most important cities. A city that represented America's independence, a city which had given the country a sense of itself, and championed science, and realism in art. His works offer a wealth of both factual and philosophical data for new research.

Taylor's tourist guidebooks provided material concerning leisure, an activity Americans by and large experienced for the first time after the Civil war. Where did they go? What did they do? Why did they do it? Taylor took us on fascinating excursions by rail and steamer to those destinations, but in particular to his own "retreat" the Thousand Islands. While tourist publications were designed to be promotional, part of the consumer culture discussed by Fox and Lears, Taylor's views of the Thousand Islands were much more than just part of an assignment. He was a participant in this environment, giving a unique "insider's" view. We know he saw the area as a place for an individual to rest and strengthen family ties, to gain a release from the strains of urban pressures. He takes us on his muskie fishing expeditions, in his own skiff, using his Skinner Spoons for 
tackle. He invites the reader to his campfires and into Shady Ledge. And he shows us the homes of millionaires but he does not stand in awe of these elite summer residents. They are 1llustrated more as examples of achievement by the wealthy who also enfoyed the same recreational pleasures as the general population.

As a Special Artist Taylor was trained by his experience to search for interesting views, and human interest stories. His Philadelphia rooftop vistas provide an alternative perspective on the city as he looked down on the landscape. Better able to judge or provide insight from above perhaps. His feisty watercolors of fish suggest the thrill of sportfishing, and his band of black children who played for general Grant detail local color. Taylor never settled for the obvious. He wanted his sketches to pique the viewer's interest -- and they still do.

Taylor's journalistic approach to art, a narrative realism, was indicative of changes in the American art scene. Philadelphia's artistic heritage of morality, history, and real1sm had begun with Benjamin West and was passed down through Peale and Eakins. Taylor inherited that philosophy, and his sketches portray a realistic view of American life. The storytelling talents and experiences of Special Artists did, of necessity, directly influence men like Homer and Remington who adapted it to their later works.

Taylor concentrated his labors toward the general population, whom he saw as worthy of good art even if they 
could not afford the canvases of his "fine art" contemporaries. He saw beauty in the everyday, and sought to help the public appreciate what was around them. While Niagara Falls and Yosemite were spectacular, few people had the opportunity to see them first-hand. Taylor's works focused on the simple beauties of dafly life, and assisted the midale class in finding enjoyment and interest in their surroundings, thus helping them fit into a changing world. Taylor is just one of the hundreds of Special Artists who were documenting America during the late nineteenth century. These men and women, well known and respected artists of their day, have since faded from the scene; their lives were as fugitive as the medium they used. This is partly due to the fact that much of their original work submitted to the 1llustrated press has not survived. Often only the engravings remaln, and these have had little credit beyond being quaint newspaper images of another day. Taylor's extant work shows the skill of the Special in documentation, and the care and talent of the engravers who translated the scenes to wood. New attention directed toward Special Artists' works may uncover sketches previously disregarded. And even if only their engravings survive, they need to be viewed anew and appreciated as cultural records. Renewed research into the work of nineteenth century artists and engravers can add to and enrich scholarship in American history, journalism, and art. Special Artists need a 
twentieth-century Vasari to bring them to the nation's attention.

Such research should also focus attention on the lllustrated press which has from the Boston Massacre, served to set a national agenda. Whether inflaming resentment for British authority, debunking Tammany Hall, or encouraging national travel, pictorial fournalism has influenced decision making and brought about change. The ability to read was not a criteria for understanding. The illiterate colonial resident or the urban immigrant could comprehend the meaning of death or greed which Revere and Nast so cleverly portrayed. They felt a part of their environment and equal to those who were blessed with more education or economic advantages than they commanded. For a few pennies they were part of the "big picture."

Taylor's life and works illustrate the many facets that made up the middle-class environment in the Gilded Age. He reveals everyday life experiences with a trained eye, aware of what constitutes the important and significant elements. It is not often the historian is offered so complete a visual record; usually diaries and correspondence, and perhaps a few photographs, must suffice to supply the core for placing a person in time. Taylor's diary is his sketches and guidebooks, and they provide a unique look at American life. Since these documents are so rich they should encourage historians to search out the materials left by other Special Artists. Obviously, such fertile, untapped resources can, 
like raylor's, further help to enhance the reconstruction of American cultural history. 
BIBLIOGRAP HY

Werks by Erank H. Taylor

Butomobile Road Book of New Jersey. Philadelphia, 1901.

Autumn Leaves Upon the Lehich: Picturesoue and Industrial Scenes Along the Iine of the Lehigh Valley Batlroad. Philadelphia: J. W. Nage 1, 1878.

Away Down East: Or My Unexpected Vacation. New York: Leve \& Alden, 1880 .

Birch Bark From the Adirondacks: Or. Erom City to Tratl. New York: The Adirondack Railway Co., 1888.

"A Canadian Pilgrimage." Haxper's New Monthly Magazine 64 (1882): 501-505.

The City of Philadelobia as it Appears in the Year 1893. Philadelphia: G. S. Harris Sons, 1893.

The City of Roanoke, Viroinia as it Appears in the Year 1890. New York: Giles Company, 1890.

The crossmon. Alexandria Bay, NY: Charles W. Crossmon, 1901, 1905.

"A Crulse in the Buffalo." New York Dally Graphic 20 July $1975: 138$.

Daily 1000 Island Tours of the Excursion Yacht Captain Visger. Map. Alexandria Bay, NY: Visger Tours, c1900.

The Derrick's Hand-Book of Petreleum. Oll City, PA: Derrick Publishing Company, 1884 .

Estes' Standard Guide to the Thousand Islands and Voyage Down the Rapids to Montreal, Quebec, lake St. John and the Saquenay River. Clayton, NY: E. W. Estes, 1893.

Ever-Changing Philadelohia. Philadelphia, 1915. 
The Eavorite Rolite to All points Southwest. St. Louis, Iron Mountain and Southern Rallway Company, n.d.

Erom the Apalachicola to the St. Johns: or Fhrough the Uplands of Elorida. 2 ed. New York: Florida Central Western Railroad, 1883.

Erom the Mountalos to the Gulf. New York: Giles Co., c1890.

Geneva on Seneca Lake. Geneva, NY: Geneva Chamber of Commerce, 1902.

Glimpses of St Lawrence Summer Iife. New York: Leve \& Alden, 1884 .

Guldebook of the Watkins Glen. Watkins, NY: W. E. Robinson, 1901 .

The Hand Book of the Lower Delaware Rlver. Philadelphia: G. S. Harris \& sons, 1895.

Henry A, Dreer, Philadelphia, 60th Anniversary. Philadelphia: Frank H. Taylor, 1898.

History of the Alan Wood Iron and Steel Company 1792-1920. Philadelphia, c1920.

Ildustrated Record of the Southern Excursion of the American Society of civil Engineers. Phlladelphia, 1877.

International Conoress of Navigation. n.p.: n.p., 1912.

Key to the Reports of the General Hespltals: United States Army at Philadelohia, 1860-1865. Philadelphia, 1913.

Lake, Blyer, and Mountaln. New York: Leve \& Alden, 1882.

A Lake Tour to Picturesque Macklnac via the D. \& $C$. (Detroit and Cleveland Steam Navigation Company.) New York: Giles Litho. Liberty Printing Co., 1889.

The Middle South Wool Book. Leaksville, NC: Leaksville Woolen Mills, 1900.

Military Map of Philadelphia; 1861-1865. New Jersey. 1p.

My Vacation in Vermont. Philadelphia: Jas. W. Nagel for the Passumpsic Railroad Co., 1879. 
A New and Acaurate Detail Map of the St. Jobns Biver, Elarida. Ne'w York: Leve Alden's Tourist Publication Dept., c1881.

"Navigating the Air: A Review of Recent Aeronautic Progress." Beokleyers Magazine 5 (1905): 227-238.

Qld Places \& New People: or Our Pilorimage, and what We Saw. Boston: Rand Avery Supply Co., 1883.

Officlal Roadbeok of Penosylvania. n.p.: Pennsylvania Division, League of American Wheelman, 1897.

"A Palace on the St. Lawrence." Leslie's Weekly 27 April 1899: 338 .

The Philadelphia Electrical Handbook: A Sketch of the city and Some of its Great Enterprises for the Information of Visitors From Abroad Attending the International Electrical congress, St Louls, Missouri, September, 1904. Philadelphia: American Institute of Electrical Engineers, 1904 .

Philadelphia in the civil War 1860-1865. Philadelphia: The City of Philadelphia, 1913.

Roer Blchard's Dictionary of Philadelphia. Philadelphia: J. B. Lippincott, 1916.

The Pilarims of 76 , or our Late Vislters. Phlladelphia: E. H. Taylor, 1876 .

The Port and city of Philadelohia. Prepared with Wilfred $H$. Schoff. Philadelphia: Congress of Navigation, 1912.

"President Porfirio Diaz: The Benevolent Despot of Mexico." Book lovers Magazine 3 (1904): 763-773.

"Recollections of a Cuban Earthquake." The Mechanical_News: An Illustrated Jeurnal of Manufacturing, Englneeringe, Milling \& Mining 15 Oct. 1886: 1+

Becuerdos de un Viaje: En Honor de le Visita, a Los Estados Unides, del General Porfirie Dlaz con sus companeres en marze y abril 1883. New York: Leve \& Alden, 1883.

"St. Lawrence Skiff-Salling." The Mechanical News: An Illustrated Journal of Manufacturing, Enaineering. Milling Mining 1 Oct. 1882: 1+. The same article also 
appeared in The American Canoeist. November (1882):

153-154, and in the St. Lawrence River Skiff, Canee, and Steam Launch cempany Iflustrated cataleg. 1893.

Clayton, NY: The Antique Boat Museum, 1983, 11-12; and in Haddock's The Growth of A century, as "Skiff Sailing and Building," 166-167.

Souvenir 12the i e. $13 t \mathrm{~h}$, Anowal Convention of the National Association of Master Plumbers. Philadelphia: G. S. Harris Sons, 1895.

"Street Scenes in Havana." Harper's New Montbly Magazine 58 (1879) 682-686.

Summer Days at Round Is land By one who has Been There. New York: Leve \& Alden, cl884.

Summer Drifting Among the Lakes of Central and Western New York: A Guide for Tourist Travel. Philadelphia: J. W. Nagle, 1880.

"Three Lakes of Central New York." Lippincott's Magazine of Repular hiterature and Science 25 (1880): 410-423.

"Through Texas." Harper's_New Monthly Magazine 59 (1879): 703-718.

Through to St. Paul and Mlnneapelis in 2882. Including the Experiences of our Triumvirate in Wisconsin and Along the Upper Mississippi. Philadelphia: Craig, Finley \& Co., for the Chicago, Milwaukee \& St. Paul Railway, 1881 .

Valley Forge: A chronicle of American Herolsm. Philadelphia: J. W. Nagle, 1905, 1911, 1916; J. B. Lippincott, 1920; Daniel J. Voorhees, 1922.

The valley of the Schuylkill and its Attractions. Philadelphia: J. W. Nagle, 1879.

The Visiter in Philadelohia. Philadelphia: Trades League of Philadelphia, 1901.

The Visitor's Beference Book to Philadelobia. Philadelphia, 1895 .

"What We Are Buying at Panama." Booklovers Magazine 3 (1904): 228-233. 


\section{Additlonal Primary sources}

Autograph Collection, Historical Society of Pennsylvania. Frank H. Taylor, 10 November 1923.

Jack Brown. Letter to author. 12 August 1984. Personal interview. 31 August 1989.

Les Corbin. Personal interview. 16 October, 1986. Letter to the author. December 1987.

Timothy Decker. Letter to the author. May 1. 1990.

Charles Dunham. Personal interview. 10 August 1989.

Kurt Hasselbalch. Personal interview. 16 October 1986.

Bolling Haxall. Personal interview. 11 August 1989.

The Harold Herrick Collection. The Antique Boat Museum, Clayton, New York.

Mary Herrick. Personal interview. 1 August 1989.

Marshall Jackel. Telephone interview. 15 May 1990.

Cheryl Leibold.. Letter to the author. $16 \mathrm{July} 1990$.

The Paul Malo Collection. The Antique Boat Museum, Clayton, New York.

Manuscript Collection, Historical Society of Pennsylvania. Two boxes of materials labeled Frank H. Taylor.

Barbara E. McIlvain. Letter to the author. 16 August 1990.

New York Daily Graphic Collection. American Antiquarian Soclety, Worcester, Massachusetts.

On The St Lawrence 1890-1893. Hawn Memorial Library, Clayton, New York.

Records of the Philadelphia Sketch Club. Archives of American Art, Philadelphia Collecting Project. Microfilm reels 3665, 3666, 3919, and 3920 .

St. Lawrence River Skiff collection. The Antique Boat Museum, Clayton New York. 
Scrapbook attributed to F. H. Taylor. Atwater Kent Museum, Philadelphia, Pennsylvania.

Gardner F. Skinner Collection. The Antique Boat Museum, Clayton, New York.

Ezra Taylor. U. S. Census Records, Rochester, NY. 1840, $1850,1860,1870,1880$.

Marsha Taylor. Personal interview. 10 August 1990.

Frank H. Taylor, Certificate of Death. Dept. of Health, Bureau of Vital Statistics, Philadelphia, Pennsylvania, 1927.

Frank H. Taylor family records. Access provided to the author by Robert Taylor, 10 August 1990 .

Frank H. Taylor. Military Sesvice Record and Pension Application Files. Military Service Branch, National Archives and Records Administration, Washington, DC.

Frank H. Taylor photograph collection. Hawn Memorial Library, Clayton, New York.

Frank H. Taylor Portfolio. The Samuel P. Harn Museum of Art, University of Florida, Gainesville, Florida.

Frank H. Taylor. U. S. Census Records, Philadelphia, PA. 1880,1890 .

Frank H. Taylor, Will 1915. Register of wills, County of Philadelphia, Pennsylvania, 1927.

Robert H. Taylor. Personal interview. 25 July 1989.

Uncataloged folder of material on $F$. Walter Taylor. Historical Society of Pennsylvania.

Willlam Wells. Clayton historical records.

Secondary sources

*Denotes that the publication contains an illustration(s) by FHT 
*Allodi, Mary. Canadian Watercolors and Drawings in the Royal ontario Museum. Vol. 1. Toronto: The Royal Ontario Museum, 1974.

The Americar Personality: The Artist-Illustrator of Life in the United States, 1860-1930. Los Angeles, The Grunwald Center for the Graphic Arts, UCLA, 1976.

Adams, Henry. "Mortal Themes: Winslow Homer." Art in America 71 (1983): 113-126.

Art and commerce: American Priats of the Nineteenth Century. Proc. of a Conference on American Prints. 8-10 May 1975. Boston: Museum of Eine Arts, 1978.

Ashmead, Henry Graham. History of Delaware County, Upper Darby Townshie. Philadelphia: L. H. Everts \& Co., 1884.

Atlas, James. "Choosing a Life." New York Times Beok Review 13 January 1991: 1+.

Baltzell, E. Digby. Rhiladelphia Gentlemen: The Making of a National Upeerclass. Glencoe, IL: The Free Press, 1958.

Barber, W. Charles. "Elmira as Civil War Depot and Prison Camp." 1960. The Chemung Histerical Journal: A Civit War Anthology. August (1985): 753-756.

Barnett, Harry V. "The Special Artist." Cassells', The Magazine of Art 6 (1883): 163-170.

Barth, Gunther. Clty People: The Bise of Modern city Culture in Nineteenth Century America. New York: Oxford University Press, 1980.

*Barton, George. Little Jowrneys Around Old Philadelohia. Philadelphia: The Peter Rellly Co., 1925.

Bayne, James. A Souvenir of the Thousand Islands. Grand Rapids, MI: The James Bayne Co., n.d.

Beam, Philip C. Winslow Homer's Magazine Engravings. New York: Harper \& Row, 1979.

Beard, Charles and Mary. The Rise of American Civilization. New York: Macmillan, 1934.

Bergon, Frank, ed. The Wilderness Reader. New York: New American Library, 1980. 
Berman, Bruce D. Encyclopedia of Amertaan Shipwrecks.

Boston: Mariners Press, 1972.

Blumin, Stuart $M$. The Emergence of the Middle class: Social Experience in the American City, 1760-1900. Cambridge: Cambridge University Press, 1989.

Boorstin, Daniel J. The Image: A Guide to Pseudo-Eyents in America. New York: Atheneum, 1975.

*Brandt, Francis Burke and Henry Volkmar Gummere. Byways and Boulevards In and About Historic Philadelphia.

Philadelphia: Corn Exchange National Bank, 1925.

Bridenbaugh, Carl and Jessica. Bebels and Gentlemen: Rhiladelohia in the Age of Eranklin. New York: Oxford University Press, 1962 .

Brooks, Van Wyck. John Sloan: A Painter's Life. New York: E. P. Dutton \& Co., 1955.

Brown, Dee. The Year of the Century, 1876. New York: Charles Scribner's Sons, 1966.

Burns, E. Bradford. Eadweard Muybridge in Guatemala, 1875: The Photegrapher as Social Recorder. Berkley: University of California Press, 1986.

Burns, Sarah. Rasteral Inventions: Bural Iffe in NineteenthCentury American Art and culture. Philadelphia: Temple University Press, 1989.

Burt, Nathaniel. The Perenntal Philadelohians: The Anatomy of An American Aristecracy. Boston: Little, Brown and Company, 1963.

Burt, Struthers. Phlladelphia: Holy Experiment. Garden City, NJ: Doubleday, Doran \& Company, 1945.

Byrne, Thomas E. "Elmira's Civil War Prison Camp: 1864-65." The chemung Historical Journal 10 (1964): 1282+.

---. "Elmira 1861-1865; Civil war Rendezvous." 1964. The Chemung Historical Journal: A civil war Anthelegy. August (1985): 1247-1252.

Calhoun, Daniel. The Intelligence of the People. Princeton: Princeton University Press, 1973. 
Charles Parsons and His Doma1n: An Exhibition of 19th Century American Illustration. Montclair, NJ: Montclair Art Museum, 1958.

*Corbin, Les and Verda. The Visgers' World. Clayton, NY: Les and Verda Corbin, 1987.

Cresswell, Donald H. Comp. The American Revolution in Drawings and Prints: A Checkl1st of 1785-1790 Graphics in the Iibrary of congress. Washington, DC: Library of Congress, 1975.

Crouch, Tom D. The sagle Aloft: Twe centuries of the Badleon in America. Washington, DC: Smithsonian Institution Press, 1983.

Currier, William T. Eurrier's Price Gulde to American Artists 1645-1245 at Auction. Brockton, MA: Currier Publications, 1987.

*Datly 1000 Island Tours of the Excurston Yacht Captain Visger. Alexandria Bay, NY: n.P., 1900.

Dawdy, Doris O'Strander. Artists of the American West: A Blographical Diationary. v. 1. Chicago: The Swallow Press, 1974 .

Dehejia, Vidya and Allen Staley. Impossible Picturesqueness: Edward Lear's Indian Watercelours, 1873-1875. New York: Columbia University Press, 1989.

Dewey, John and James H. Tufts. Ethics. New York: Henry Holt and Co., 1932.

Doezema, Marianne. Amertcan Realism and the Industrial Age. Cleveland: Cleveland Museum of Art, 1980.

Driver, Clive E., ed. Passing Through: Letters and Documents Written in Philadelohia by Famous Visitors.

Philadelphia: Rosenbach Museum, 1982.

Edel, Leon. Writing Lives: Principla Biographlaa. New York: w. พ. Norton, 1984 .

Ellis, C. Hamilton. Bailway Art. Boston: New York Graphic Society, 1977. 
Exman, Eugene. House of Harper: One Hundred and Fifty Years ef Publishing. New York: Harper \& Row, 1967.

*Fairbairn, G. Don. Rhiladelohiai Eabulous City for 'Elrsts.' Wyncote, PA: Kirsh Publishing Co., 1976.

Falk, Peter Hastings, ed. Who has tho in American Art. Madison, CT: Sound View Press, 1985.

*Elorida. Insight Guides. Hong Kong: Apa Productions, 1982.

*Elorida Sulte Dance Rapsedy, Ne, l lover the Hills and Far Away. Sir Thomas Beecham conducting the Royal Philharmonic Orchestra. Seraphim Record S-60212 "Music of Deluis," Album 2.

*"F. H. Taylor Watercolors: Four Southern Views." The eld Priat Shop Pertfolio 10 (1951): 206-207.

Forbes, Esther. Paul Revere and The World He hived In. Boston: Houghton Mifflin, 1942.

"Foremost American Illustrators: Vital Significance of Their Work." The Craftsman 17 (1909): 266-280.

Fosburgh, Pleter $w$. "Winslow Homer, Palnter of Fishes and Fishermen. The conservatienist 26 (1972): 4.

Fox, Rlchard Wightmann, and T. J. Jackson Lears. The Culture of consumption: Critical Essays in American History, 1880-1980. New York: Pantheon, 1983.

Fredrickson, George M. The Inner Clyil Wari Nerthern Intellectuals and the crisis of the Union. New York: Harpex \& Row, 1965.

Fries, Sylvia Doughty. The Urban Idea in Colonial America. Philadelphia: Temple University Press, 1977.

Furst, Herbert. The Modern Woodcut. New York: Dodd, Mead \& Company, 1924.

Gardner, John. The Salnt Lawrence River Skiff. Clayton, NY: The Antique Boat Museum, n.d.

Gelman, Barbara, ed. The Wood Engravings of Winslow Homer. New York: Bounty Books, 1969. 
General Grant's Letters to a Eriend 1861-1880. New York: T. Y. Crowell, 1879 .

Goldfield, David R. and Blaine A. Brownell. Urban America: Eren Downtown to Ne Town. Boston: Houghton Mifflin Co., 1979.

Goldstein, Jonathan. Philadelphia and the China Trade 1682= 1846. University Park: The Pennsylvania State University Press, 1978.

Goodrich, Lloyd. The Graphic Art of winslow Homer. New York: Museum of Graphic Art, 1968.

--. John Sloan 1871-1951. New York: The Whitney Museum of American Art, 1952.

--. "Winslow Homer in New York State." Art in America. No. 2 (1964): 78-87.

Grant, Julia Dent. The Personal Memoirs of Julia Dent Grant. New York: G. P. Putnam's Sons, [1975].

* "Grant Visits St. Augustine." The East-Elerida Gazette 8 $(1984): 3$.

Groene, Bertram Hawthorne. Iracing Your Civil War Ancestor. Winston-Salem, NC: John F. Blalr, 1987.

Grossman, Julian. Echo of a Distant Drum: Winslow Homer and the civil War. New York: Harry N. Abrams, Inc., 1974.

*Gustke, Nancy I. "A Stately Picturesque Dream,.." Scenes of Elorida, cuba, and Mexice in 1880. Galnesville: University Presses of Florida, 1984.

*---. "Frank Hamilton Taylor, Nineteenth Century ArtJournalist: As Seen Through His Sketches of a Trip with General Ulysses S. Grant in 1880." Thesis. University of Florida, 1984.

Haddock, John A. The Growth of A Century: As Illustrated in the Histery of Jefferson county. New York, from 1793 to 1894. Albany, NY: Weed-Parsons Printing Co., 1895.

Harbeson. "Philadelphia's Victorian Architecture 1860-1690." Pennsylyania Magazine of History and Biography 67 (1943) : 254-271. 
Harley, J. B. and David Woodward. The Histery of Cartography. Chicago: University of Chicago Press, 1987 .

Harper, J. Russell. Early Painters and Engravers in Canada. Toronto: University of Toronto, 1970.

Harr1s, Elizabeth. Sut on Wood. The Art of American Wood Engraving 1790-1900. Washington, DC: National Museum of History and Technology, n.d.

Harris, Ne1l. The Artist in Amertcan Society: The Eermat tve Years 1790-1860. New York: George Braz111er, 1966.

--. The Land of Contrasts 1880-1901. New York: George Braziller, 1970 .

Hesseltine, William B. Ulysses S. Grant, Politician. New York: Dodd, Mead \& Company, 1935.

Hogarth, Paul. The Artist as Reperter. London: Studio Vista, 1967.

Hogarth, Paul. Walking Teurs of eld Phtladelphia: Through Independence square, Seciety Hill, Southwark, and Washlogton square. Barre, MA: Barre Publishing, 1976.

Holmes, Clay $w$. The Elmira Prison Came: A History of the Miltary Pirison at Elmira, New York July 6 e 1864 to July 10. 1865. New York: G. P. Putnam's Sons, 1912.

Horigan, J. Michael. "Elmira Prison Camp - A Second Opinion." The Chemung Historical Journal 30 (1985): 3449-3457.

Hornung, Clarence D. The Way it Was: New Yock, 1850-1890. New York: Schocken Books, 1977.

Houghton, Walter E. The Viatorian Erame of Mind 1830-1870. New Haven: Yale University Press, 1957.

*Il lustrated catalog of the St. Iawrence River Skiff, canoe, steam Lawnch co. 1893. Clayton, NY: Thousand Islands Shipyard Museum, n.d.

Jackson, Kenneth T. Crabarass Frontier: The Suburbanization of the United States. New York: Oxford University Press, 1985. 
Jackson, Mason. The Pictorial Press: Its erigla and

Rroaress. London: Hurst and Blackett, 1885. Detroit:

Gale Research Company, 1968.

James, Kathleen. A Natienal Histerte Landmark: Renosylvania

academy of Fine Arts. Philadelphia: Pennsylvania

Academy of Fine Arts, n.d.

Jarmusch, Ann. "If Vermeer Were Alive Today, Would He Be Palnting in Philadelphia?" Art News 80 (1981): 156.

Johnston, Captain Henry S. A Tour of the 1000 Islands: The american Venice of the St, Lawrence River with Map.

Watertown, NY: A. W. Munk \& Co., n.d.

Jones, James P., ed. "Grant Forecasts the Future of Florida." The Florida Histerical Ouarterly 29 (1960): 52-54.

Keates, John. The Skiff and the River. Nantucket, MA: The Herrick Collection, 1988.

Klein, Philip S. and Arl Hoogenboom. A Histery of Rennsylvania. 1973. University Park: The Pennsylvania State University, 1980.

Klingender, Francis D. Art and the Industrial Revolution. 1947. Ed. and revised Arthur Elton. New York: Augustus M. Kelley, 1968 .

Langford, Nathaniel P. "The Wonders of the Yellowstone." Saribner's Monthly 2.1 (1871): 1-17 and 2.2 (1871): 113128.

Lindley, Kenneth. The Woodblock Engravers. New York: Drake Publ1shers, 1970.

Linton, william J. American Woed Enaraving. A Victorian History. Watkins Glenn, NY: American Iife Foundation Study Institute, 1976.

*Lippincott, Horace Mather. Early Philadelphiai Its People, Life and Progress. Philadelphia: J. B. Lippincott, 1917.

Lomas, Sidney C. History of the Philadelphia Sketch club. Philadelphia: Philadelphia Sketch Club, 1936. 
Lynes, Russell. The Art-Makers: An Informal History of Raloting, Sculoture and Architecture in the NineteenthCentury America. 1970. New York: Dover Publications, 1970 .

* Maple Sugaring: Four Original Drawings By Frank Hamilton Taylor." The old Print Shop Portfolio 11 (1952): 166167.

Marion, John Francis. Philadelphia Medicai Being a Guide to the City's Historical places of Health Interest. Philadelphia: SmithKlein Corp. 1975.

Marquis, Albert Nelson, ed. Who's who in American Art.

v. 7. Chicago: A. N. Marquis, 1913.

Marx, Leo. The Machine in the Garden: Technology and the Pastoral Ideal in America. New York: Oxford University Press, 1964.

Marzio, Peter C. The Democratic Art: Pictures for a 19thCentury America. Boston: David R. Godine, 1979.

Mass, John. The Glorious Enterortse: The Centennial Exhibition of 1876 and $\mathrm{H}$. I Schwarzmano, Architect-in= chlef. Watkins Glenn, NY: American Life Foundation, 1973.

McFeeley, William S. Grant:A_Biography. New York: W. W. Norton, 1981.

McKay, George L. "American Artists As Reporters (1851-1900." American collector. November (1947): 6+

Miller, Frederic M., Morris J. Vogel and Allen F. Davis. St 111 Philadelphta: A Photographic History, 1890-1940. Philadelphia: Temple University Press, 1983.

Miller, Mark H. ed. Lafayette, Here of Two Worlds: The Art and Pageantry of his Fareweld Tour of Amertac 18241825. Hanover, NH: University Press of New England, 1989.

Moritz, Albert F. America the Picturesque in Nineteenth century Engraving. New York: New Trend, 1983.

*Morley, Christopher. Travels in Philadelphia. Philadelphia: David McKay Company, 1921. 
Mumford, Lewis. The Brown Decades: A study of the Arts in America 1865-1895. 1931. New York: Dover Publications, 1971 .

--. The City in History: Its origins, Its Transformations, and Its Prospects. New York: Harcourt Brace Jovanovich, 1961.

Mugridge, Donald H. and Helen F. Conover. An Album of American Battle Art 1755-1918. 1947. New York: DaCapo Press, 1972 .

Myron, Robert and Abner Sundell. Art in Amertca: Erom celonial Days Through the Nineteenth Century. London: Crowell-Collier Press, 1969.

Nevins, Allan. The Price of Survival. New York: Harper \& Row, 1967 .

100th Anniversary Calendar. Philadelphia: The Philadelphia Sketch Club, 1960.

*The eld Print Shop Portfollo 27 (1968): 164-165.

Pachter, Marc, ed. Telling Ifves: The Biographer's Art. Washington, DC: New Republic Books, 1979.

Parnes, Stuart. The Art of Ered.S. Cozzens. Mystic, CT: Myst1c Seaport Museum, 1983.

Pearlman, Bennard B. The Gelden Age of American Illustration: $F$. B. Gruger and His clrcle. Westport, CT: North Light, 1978.

--- The Immertal Eight: Amertaan Painting Erom Eakins to the Armory Show 1870-1913. New York: Exposition Press, 1962 .

Pennell, Joseph. The Adventures of An American Illustrater. Boston: Little, Brown and Company, 1925.

* "A Philadelphia Artist in Texas." The eld Print Shep Rertfolio 10 (1951): 161-165.

Phisterer, Frederick. New York in the War of the Rebellion 1860-1865. 3rd ed. Albany: J. B. Lion, 1912. 
Pletcher, David M. Rails, Mines and Progressi Seven American eromoters in Mexice, 1867-1211. Ithaca: Corne I1 University Press, 1958.

Pyle, Howard. "Among The Thousand Islands." Saribner's Monthly 15 (1878): 825-842.

Reed, Henry M. The A. B. Erost Book. Rutland, VT: Charles E. Tuttle, 1967 .

Reed, Walt. Great American Ildustrators. New York: Abbeville Press, 1969.

Bepert of the Twenty-Seventh Exhibition of American Manufacturers, Held in the City of Philadelohia From Qctober 6 to November 12,1874 by the Eranklin Institute. Philadelphia: The Franklin Institute, 1874.

Rogers, W. A. A World Worth while: A Recerd of "Auld Acquatntance." New York: Harper \& Brothers, 1922.

Bome, Watertown and Ogdensburg Raflroad: Boutes \& Bates for Summer Tours. New York: American Banknote Co., 1891.

Roth, Leland M. A concise History of American Architecture. New York: Harper \& Row, 1979.

Runte, Alfred. National Parks: The American Experience. Incoln: University of Nebraska Press, 1979.

Ruskin, John. Works of John_Buskin. New York: John Wiley \& Sons, 1886.

St. Lawrence River Skiff, Canoe, and Steam Launch company Cataleg. 1893. Clayton, NY: The Antlque Boat Museum, 1983.

Sander, David M. Woed Engraving: An Adyenture in Printmaking. New York: The Viking Press, 1978.

Siegel, Adrienne. Philadelohta: A Chronological and Decumentary History 1615-1970. Dobbs Ferry, NY: Oceana Publications, 1975.

Simpson, Marc, ed. Winslow Homer Paintings of the Civil War. San Francisco: The Fine Arts Museum of San Francisco, 1988 . 
The Sketch club in its Ninetieth Year. Philadelphia: Philadelphia Sketch Club, 1950.

Smith, Katherine I. "Newspaper Art." The Art Interchange 3 March 1900: 52-53.

Smith, Susan W. A History of Recreation in the Thousand Islands. Ottawa: Parks Canada, 1976.

Snow, Edward Rowe. Eamous Ilahthouses of America. New York: Dodd, Mead \& Company, 1955.

* Seuvenir of the Theusand Islands and River St, Lawrince. Grand Rapids, MI: The James Bayne Company, n.d.

Stebbins, Theodore E., Jr. Martin Johnson Heade 1819-1924. College Park: University of Maryland, 1969.

Stein, Roger B. John Buskin and Aesthetic Thought in America, 1840-1900. Cambridge: Harvard University Press, 1967 .

Stevens, John Lloyd. Incidents of Travel in Egypt, Arabia Retraea, and the Hely hand. Ed. and intro. Victor Wolfgang von Hagen. Norman: University of Oklahoma Press, 1970 .

Taft, Robert. Artists and Illustrators of the 01d West 18501900. New York: Bonanza Books, 1953.

Taylor, James E. Leaves Erom a Special Art 1st's Sketch_Boek and Diary. Dayton, $\mathrm{OH}$ : Morningside House, 1989.

Tebbel, John William. The Amerlcan Magazine: A compact Histery. New York: Hawthorn Books, 1969.

Ten Cate, Adrian G. Rictorial History of the Thousand Islands of the St. Lawrence River. 2nd ed. Brockville, Ontario: Besancourt Publishers, 1982.

Thorpe, James. English Illustration: The Nlneties. New York: Hacker Art Books, 1975.

Toffler, Alvin. The Culture Consumers: A Study of Art and Affluence in America. New York: St. Martin's Press, 1964 . 
Turner, Louis. The Golden Hordes: International Tourism and the Pleasure Periphery. New York: St. Martin's Press, c1976.

Unrau, Harlan D. Admlaistrative History, Valley Eorge National Historical Park. Washington, DC: U. S. Department of the Interior, 1984 .

*Vaux, Trina, ed. Historic Rittenhouse: A Philadelobla Nelghborhood. Philadelphia: University of Pennsylvania Press, 1985 .

Visser, John de and Patricia Fleming. 1000 Islands. Erin, ontario: The Boston Mills Press, 1990.

Wainwright, Nicholas. Philadelobla in the Romantic Age of Lithography. Philadelphia: Historical Society of Pennsylvania, 1982 .

Warner, Sam Bass, Jr. The Prtvate Clty: Philadelphia in Three Periods of It's Growth. Philadelphia: University of Pennsylvania Press, 1968.

--. Street car Suburbs: The Process of Growth in Boston. 1870-1900. New York: Atheneum, 1974.

Weigley, Russell F., ed. Rhiladelohlai A 300-Year History. New York: W. W. Norton, 1982.

Williams, Raymond. Culture and Soclety 1780-1250. New York: Columbia University Press, 1958.

Wilson, Garth S. "The Great Lakes Historlc Ships Research Project: Computers and the Analysis and Documentation of Small Craft." Eresh Water, A Journal of Great Lakes Marine History 2 (1987): 9-13.

Wurman, Richard Saul, and John Andrew Gallery. Man Made Rhiladelphia: A Guide to Its Phystcal and Cultural Environment. Cambridge, MA: MIT Press, 1972.

Young, George. Tourism Blessing or Blight? Middelsex, England: Penguin Books, 1973.

Zinsser, William. Extraordinary Lives: The Art and Craft of American Biography. New York: American Heritage, 1986. 
APPENDICES 


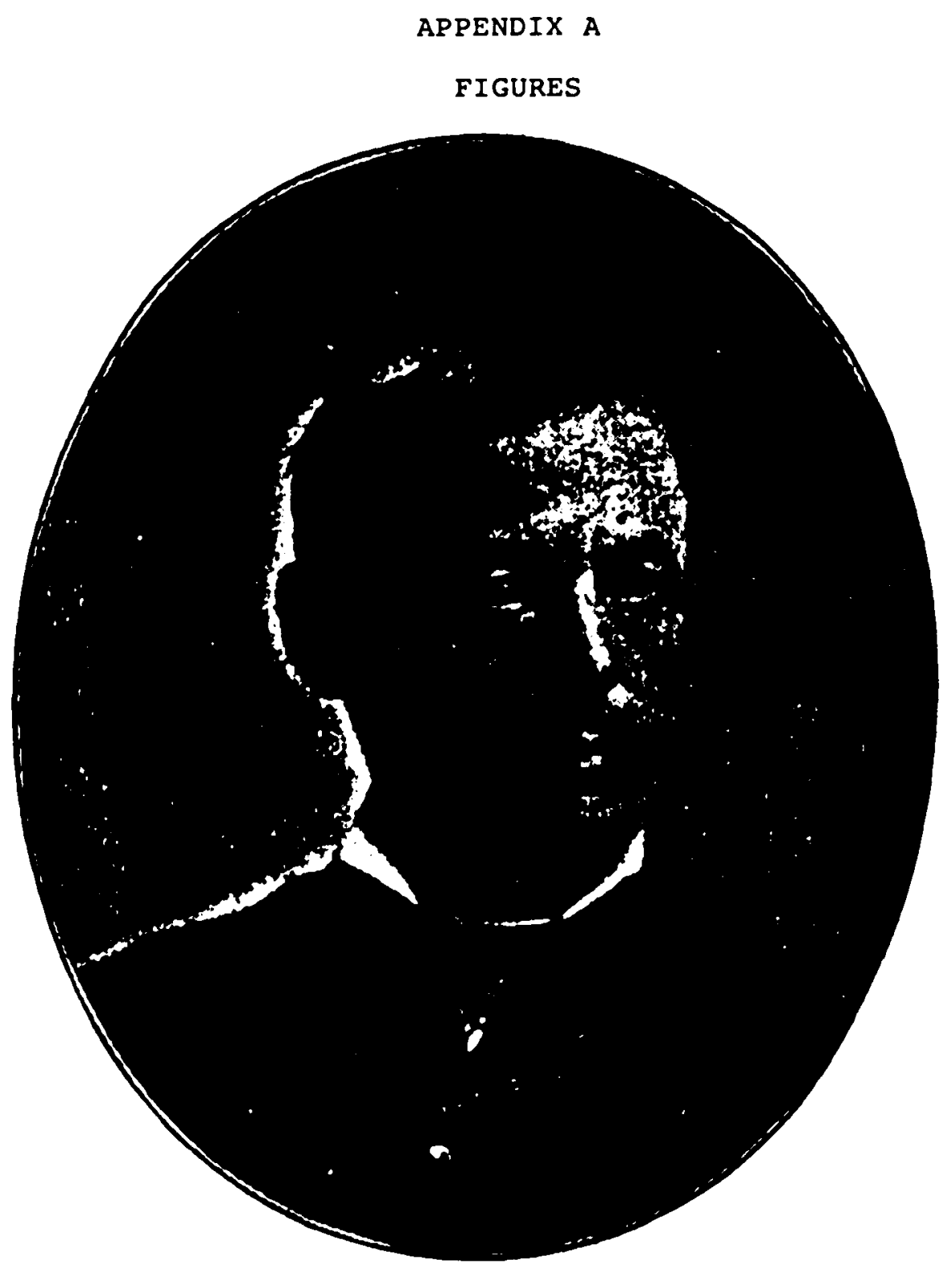

FRANK H. TAYIOR. THE ARTIST. C1896

Figure 1

Hawn Memorial Library, Clayton, NY 


\section{CONCERT AND LECTURE.}

BIRCE'S OPERA HOUSE, BURIINGTON,

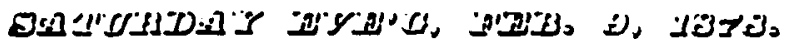
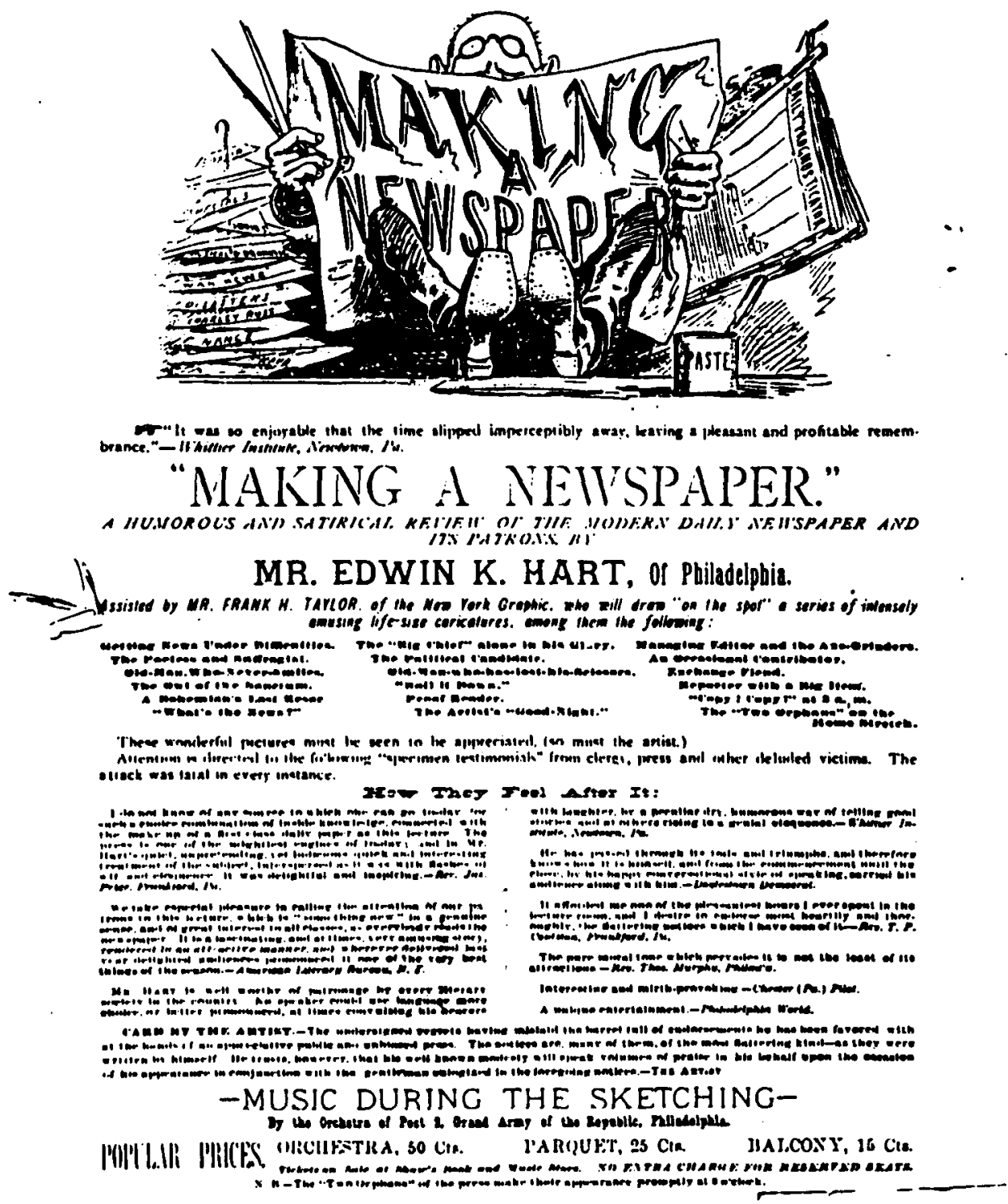

Figure 2

Annotated Broadside(?) c1877. Taylor Scrapbook Atwater Kent Museum, Philadelphia, PA 


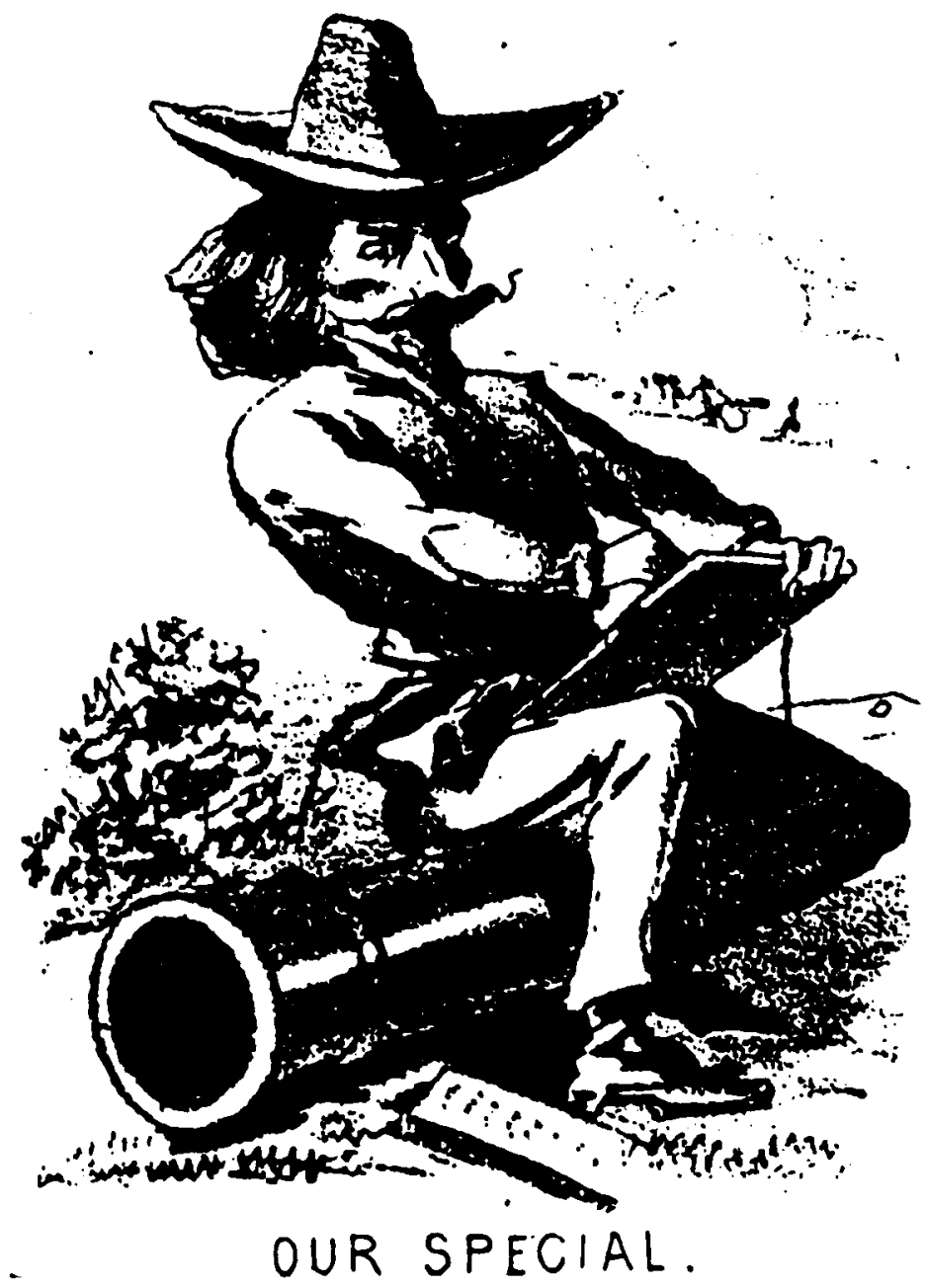

Elgure 3

Winslow Homer OUR SPECIAL Itthograph, 1864

The Butler Institute of American Art, Youngstown, $O H$ 


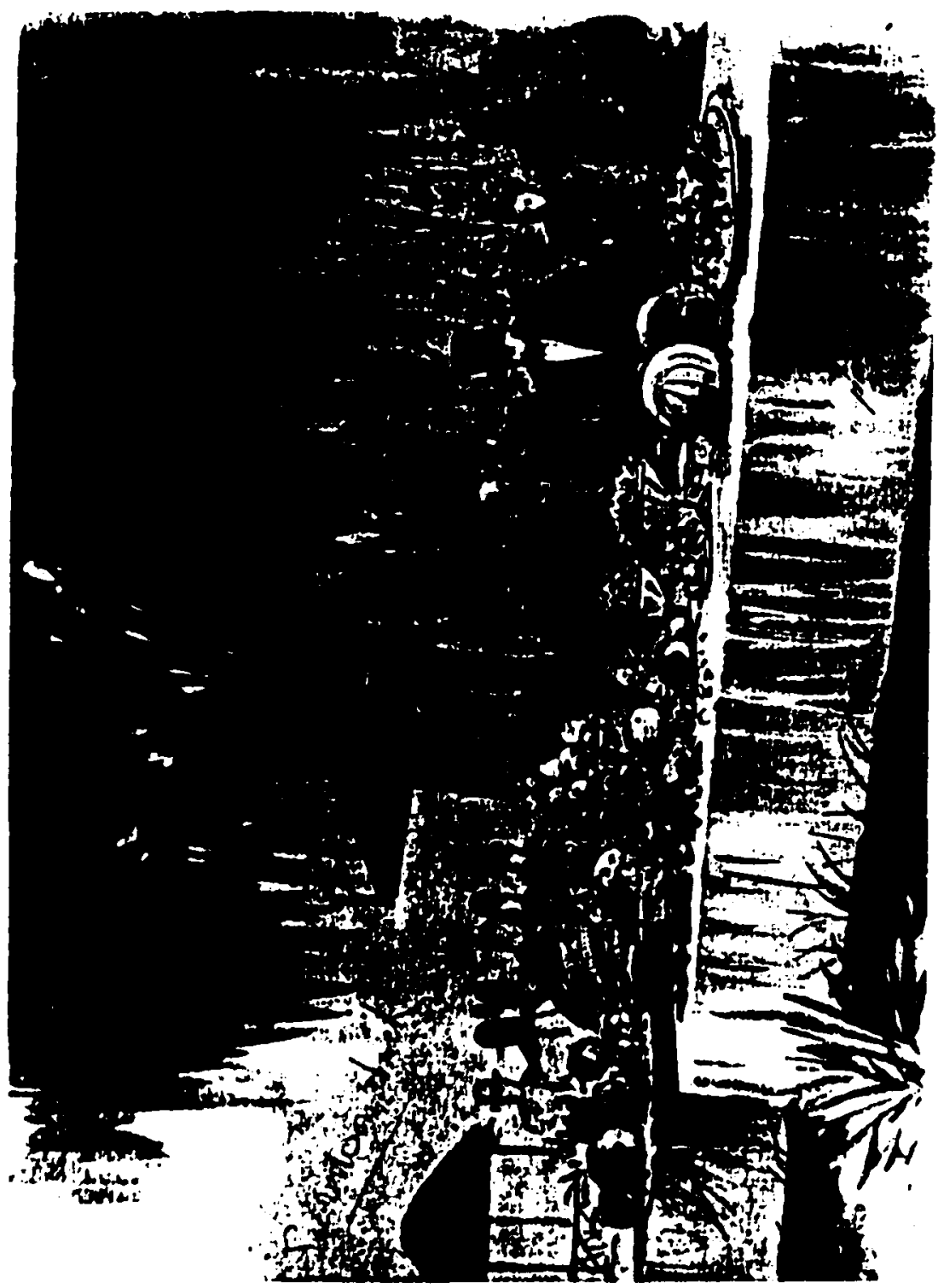

Figure 4

GENERAI GRANT AND PARTY ARE SHOWN SOME FLORIDA PRODUCTS Frank H. Taylor. Black and White Wash, 1880 Samuel P. Harn Museum, Gainesville, FL 


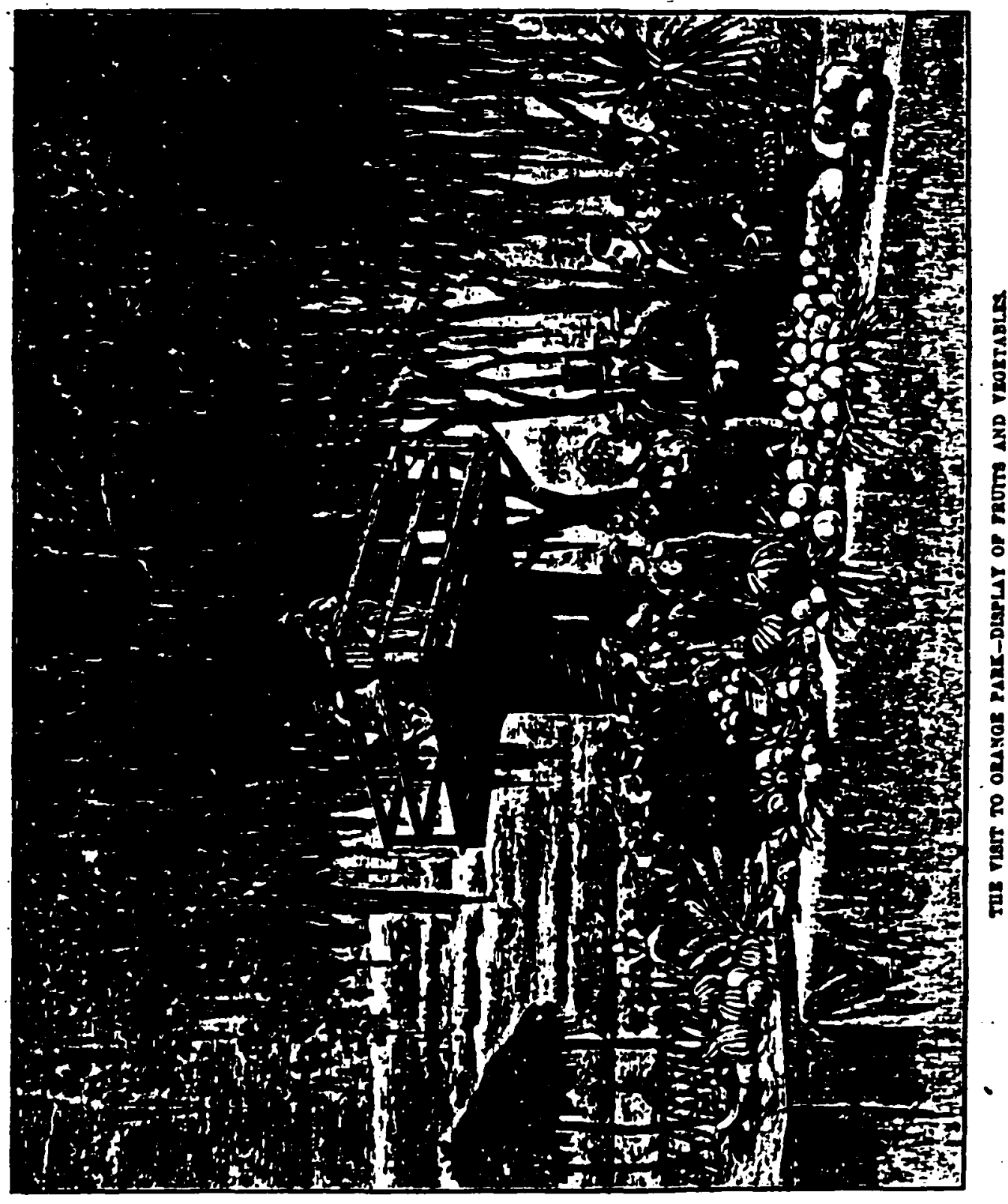

Figure 5

THE VISIT TO ORANGE PARK - DISPLAY OF FRUITS AND VEGETABLES Wood Engraving after sketch by Frank $H$. Taylor

Hagper's Heekly. 21 February, 1880, p. 117

Samuel P. Harn Museum, Gainesville, FL 


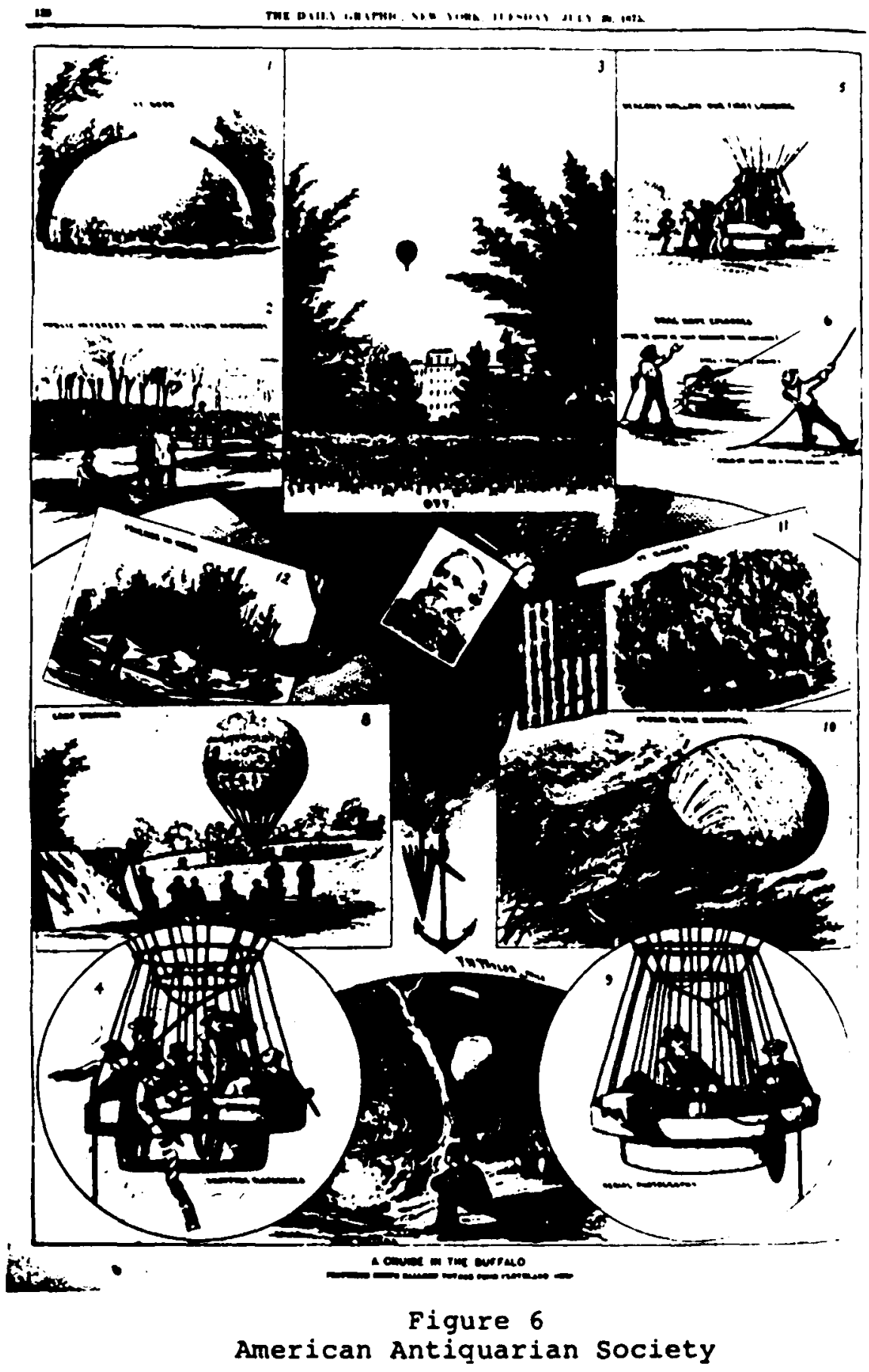




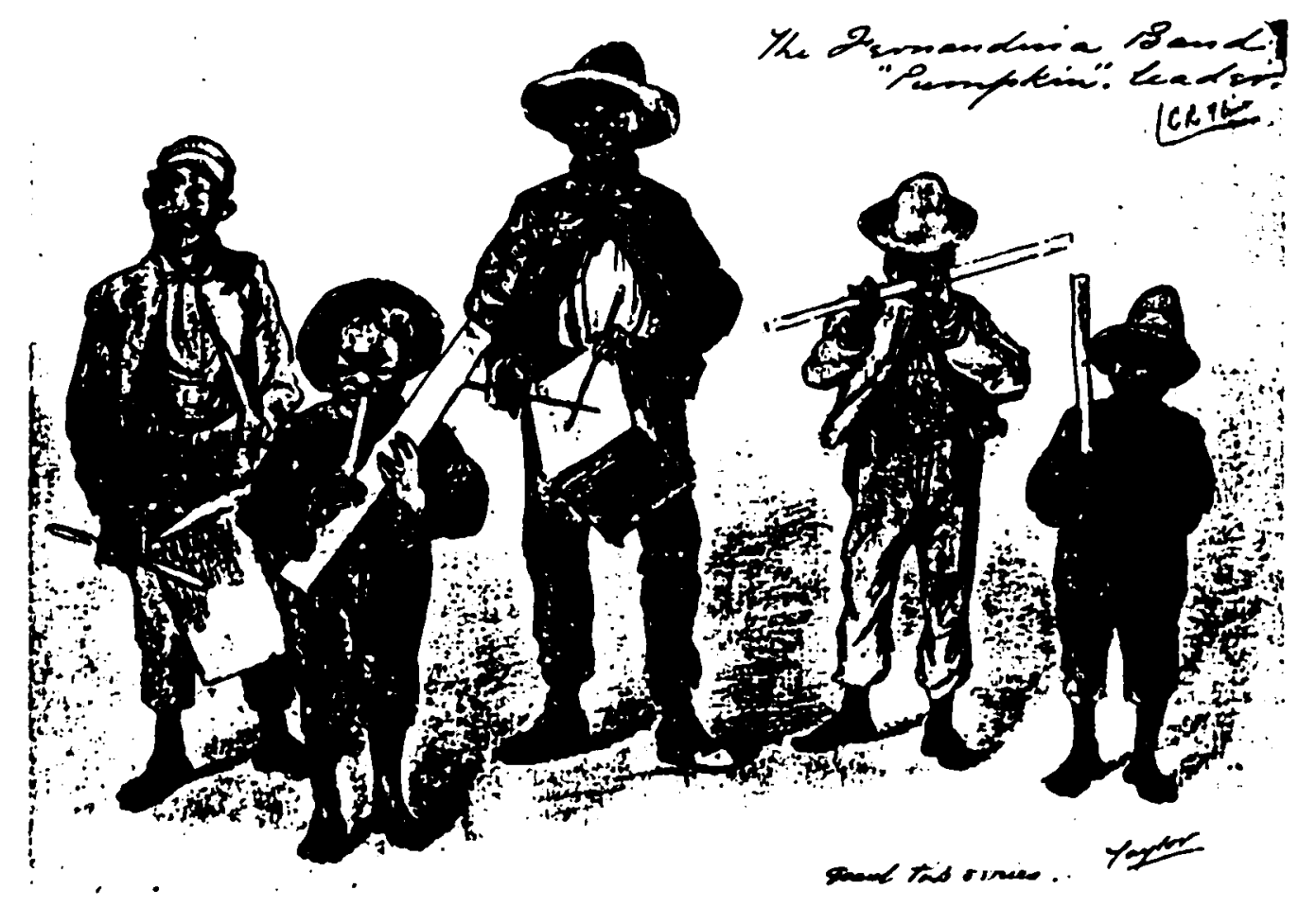

Eigure 7

THE FERNANDINA BAND "PUMPKIN" LEADER

Frank H. Taylor. Watercolor, 1880

Samuel P. Harn Museum, Galnesville, FI 


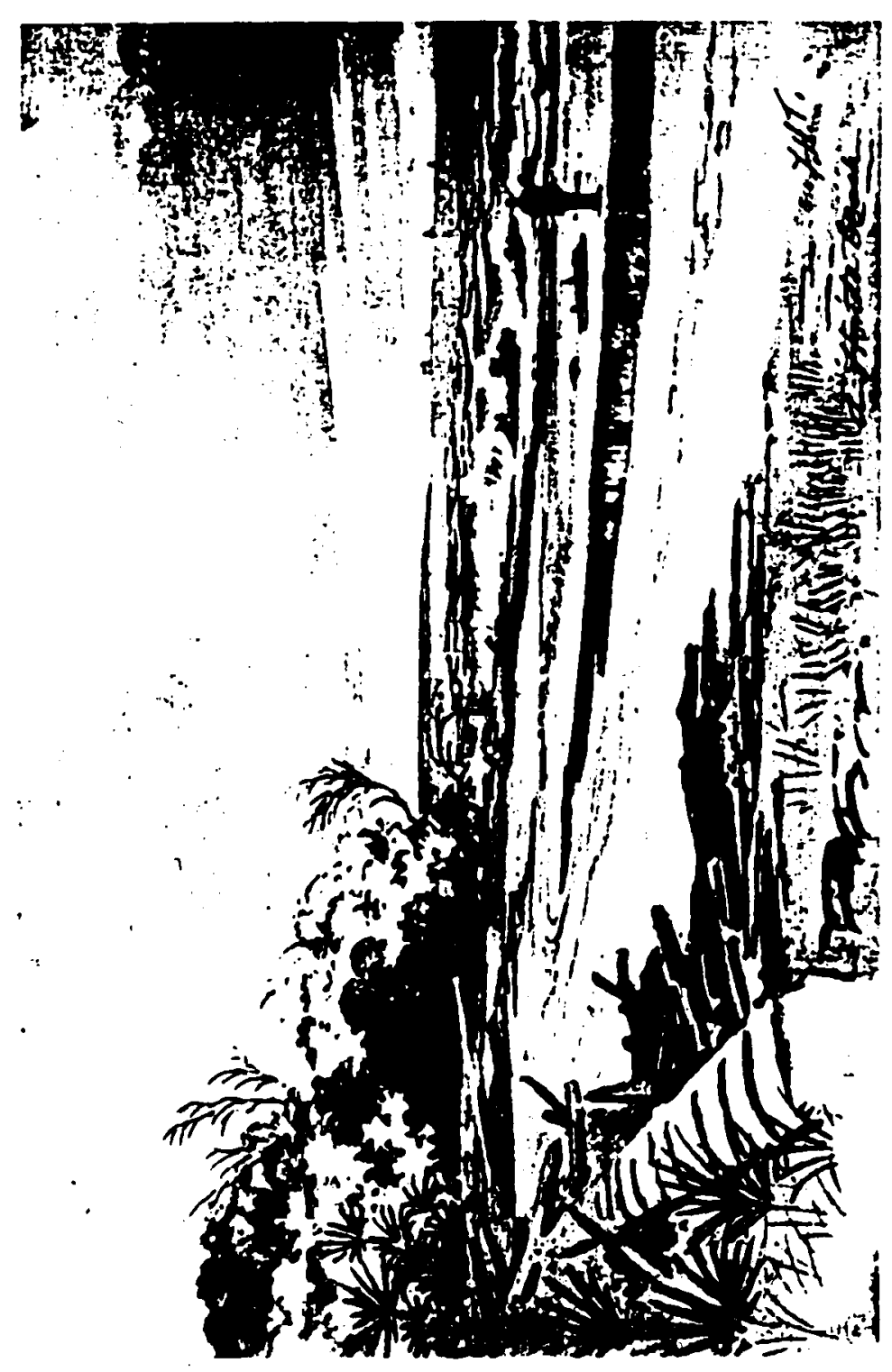

Figure 8

A ELORIDA BEACH (EERNANDINA?)

Frank H. Taylor. Black and White Wash, 1880 Samuel P. Harn Museum, Gainesville, FI 


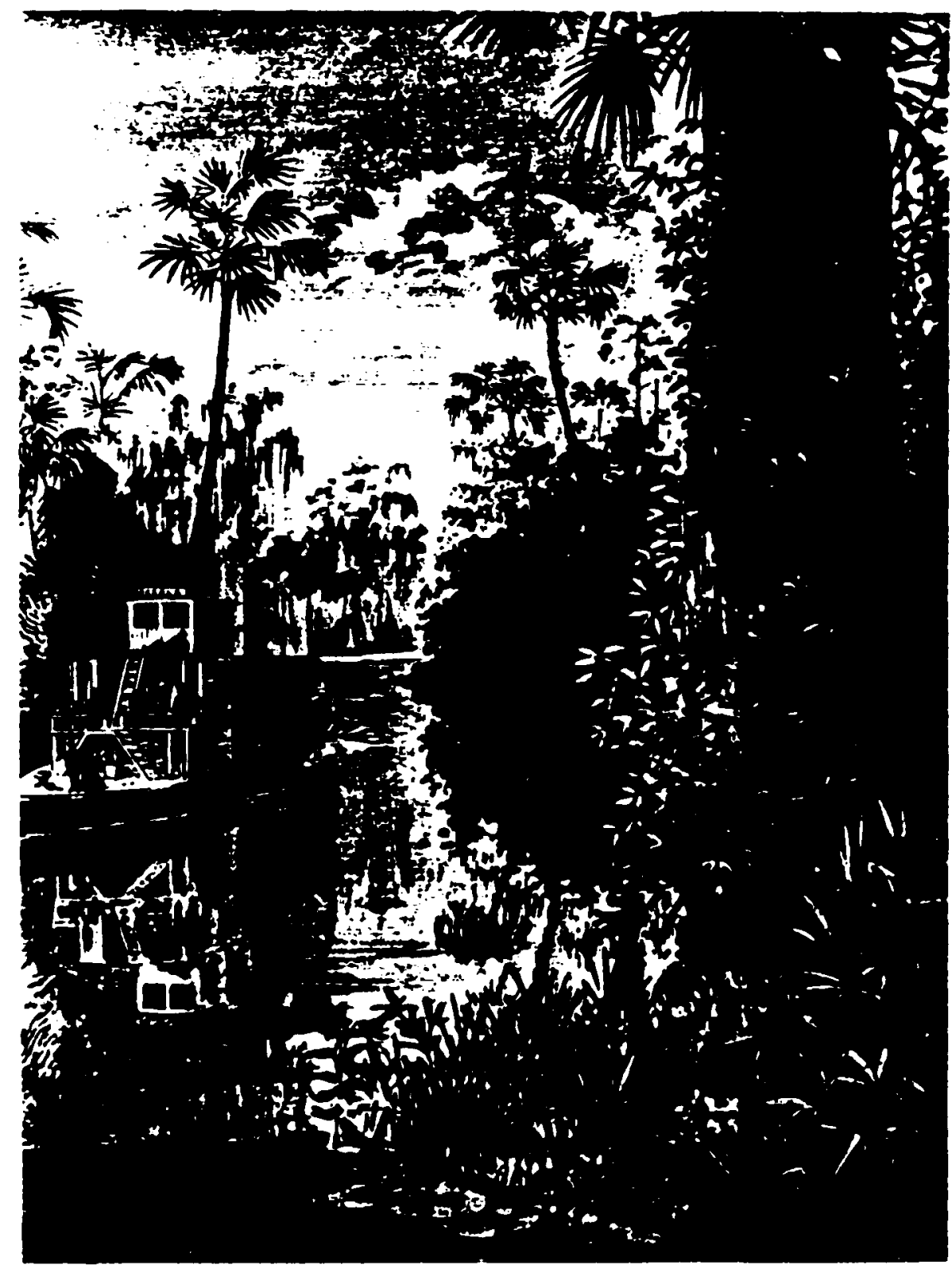

Figure 9

GENERAL GRANT IN FLORIDA - A TRIP ON THE OKLAWAHA

Frank H. Taylor. Black \& White Wash, 1880

Samuel P. Harn Museum, Gainesville, FL 


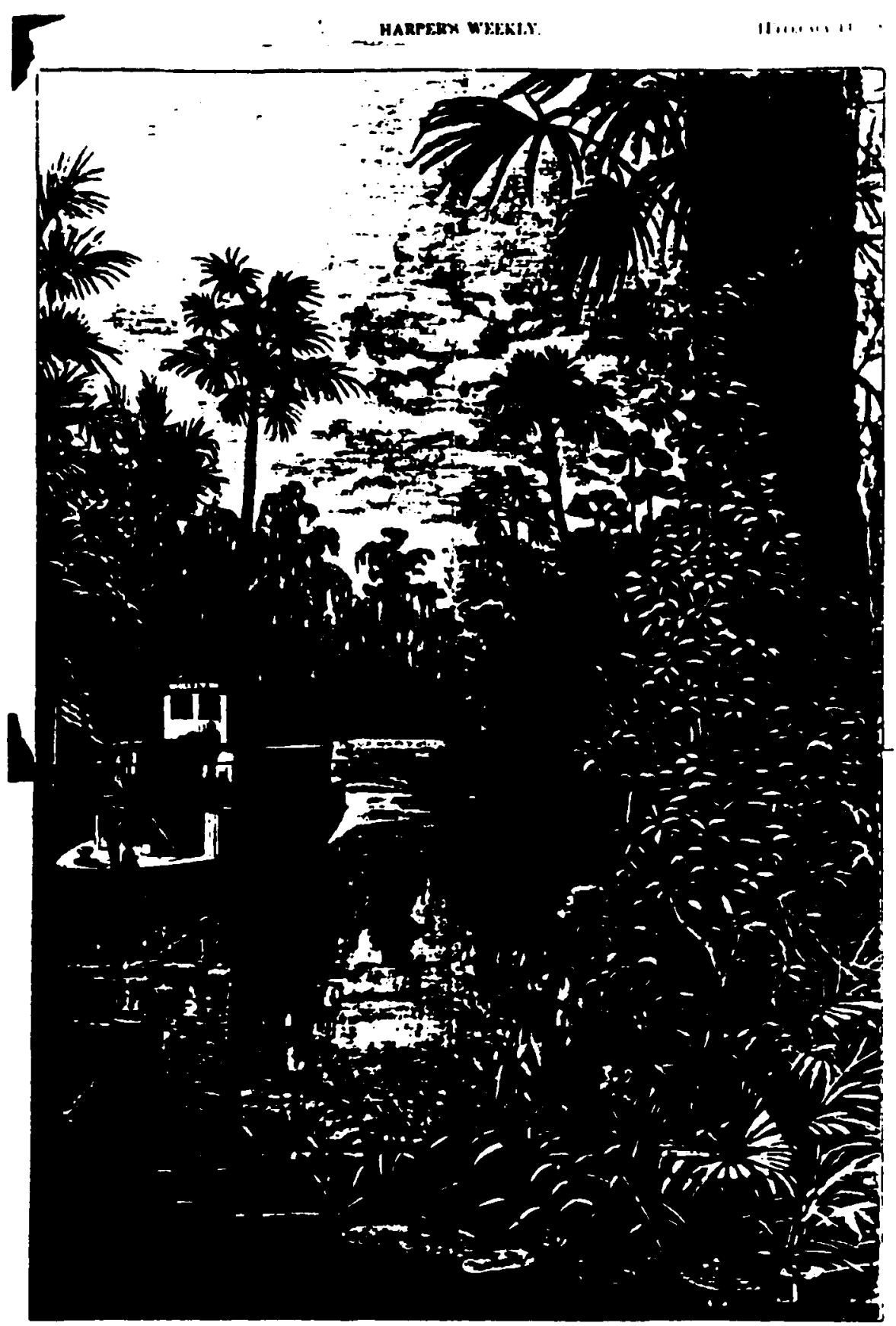

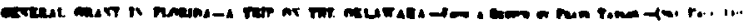

Figure 10

GENERAL GRANT IN FLORIDA - A TRIP ON THE OKLAWAHA Wood Engraving after sketch by Frank $H$. Taylor Harper's Weekiy. 14 February, 1880, p. 100 Samuel P. Harn Museum, Gainesville, FL 


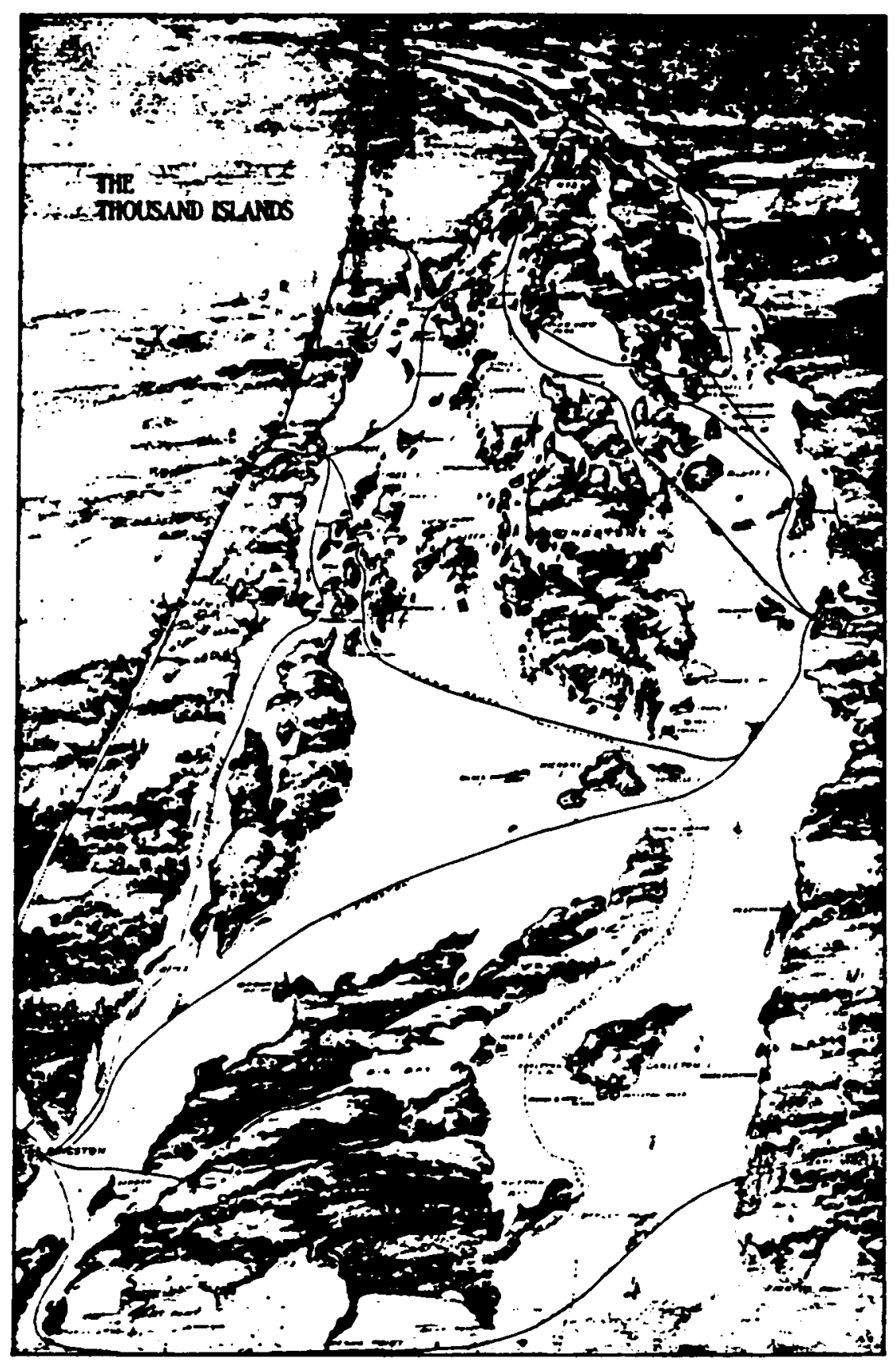

Figure 11

THE THOUSAND ISLANDS Frank $\mathrm{H}$. Taylor(?)

Black and White wash, c1885 


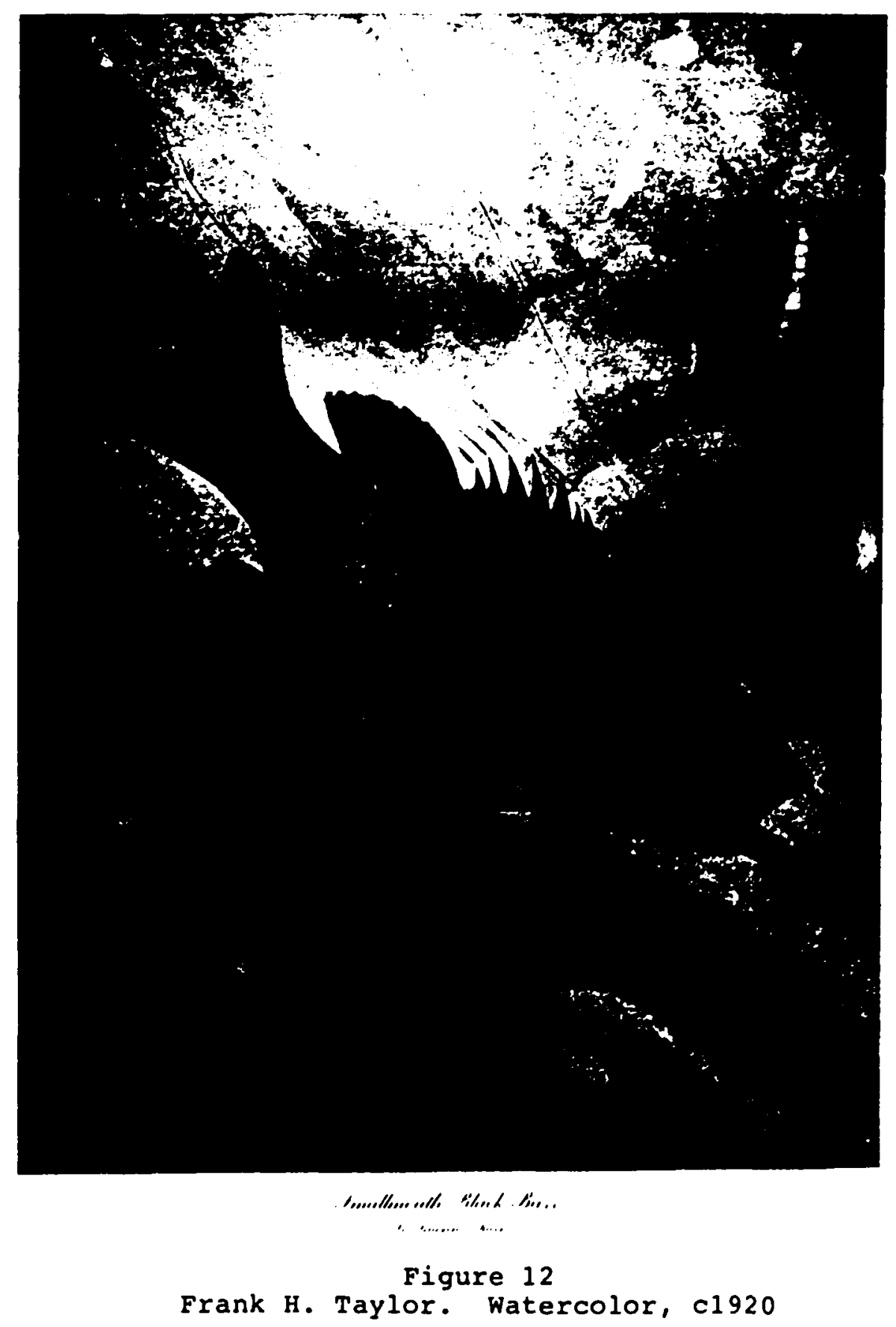




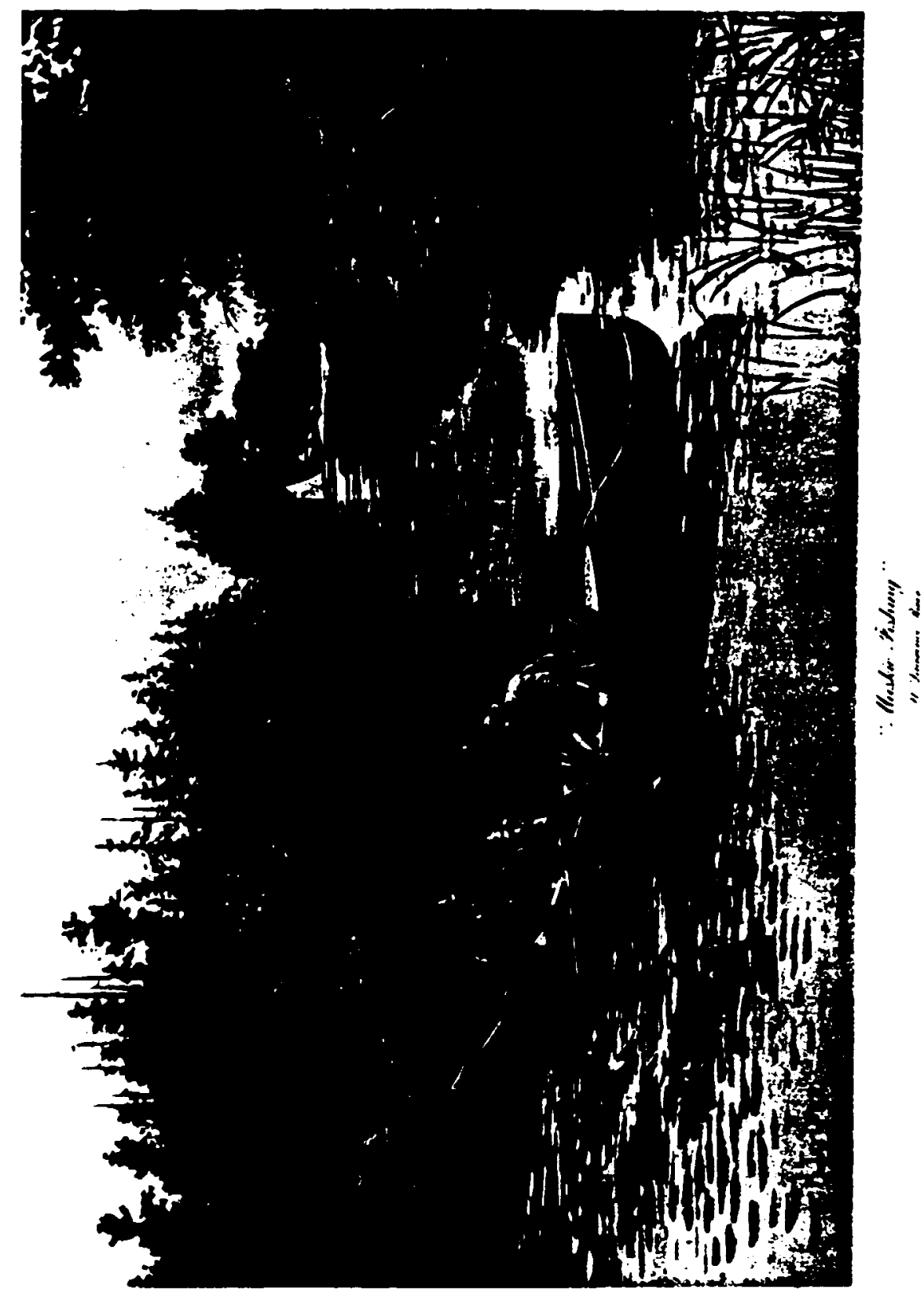

Figure 13

Frank H. Taylor. Watercolor, cl880 


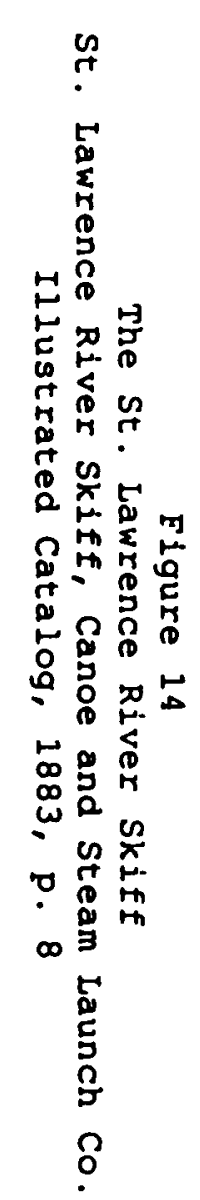

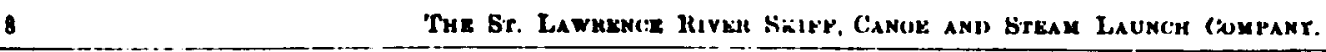

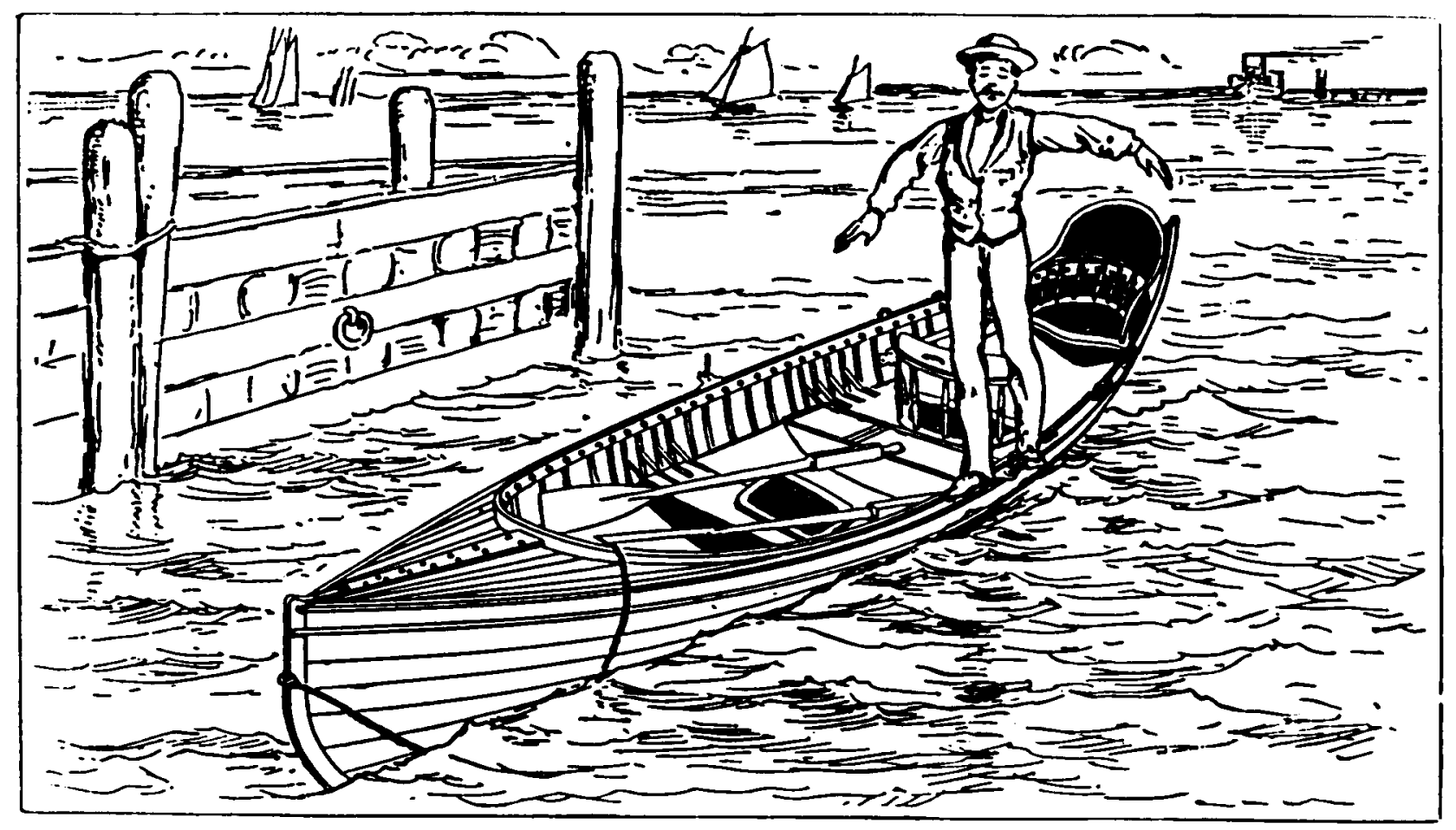

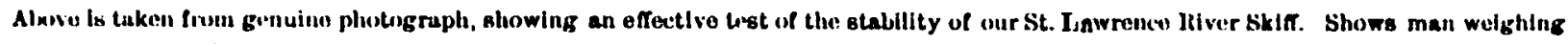

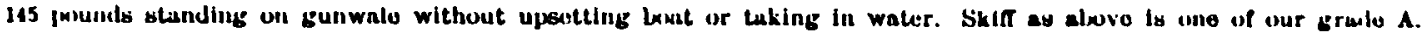
18 feet losus, 12 inch beam. No bellast. Nu Tuick. 


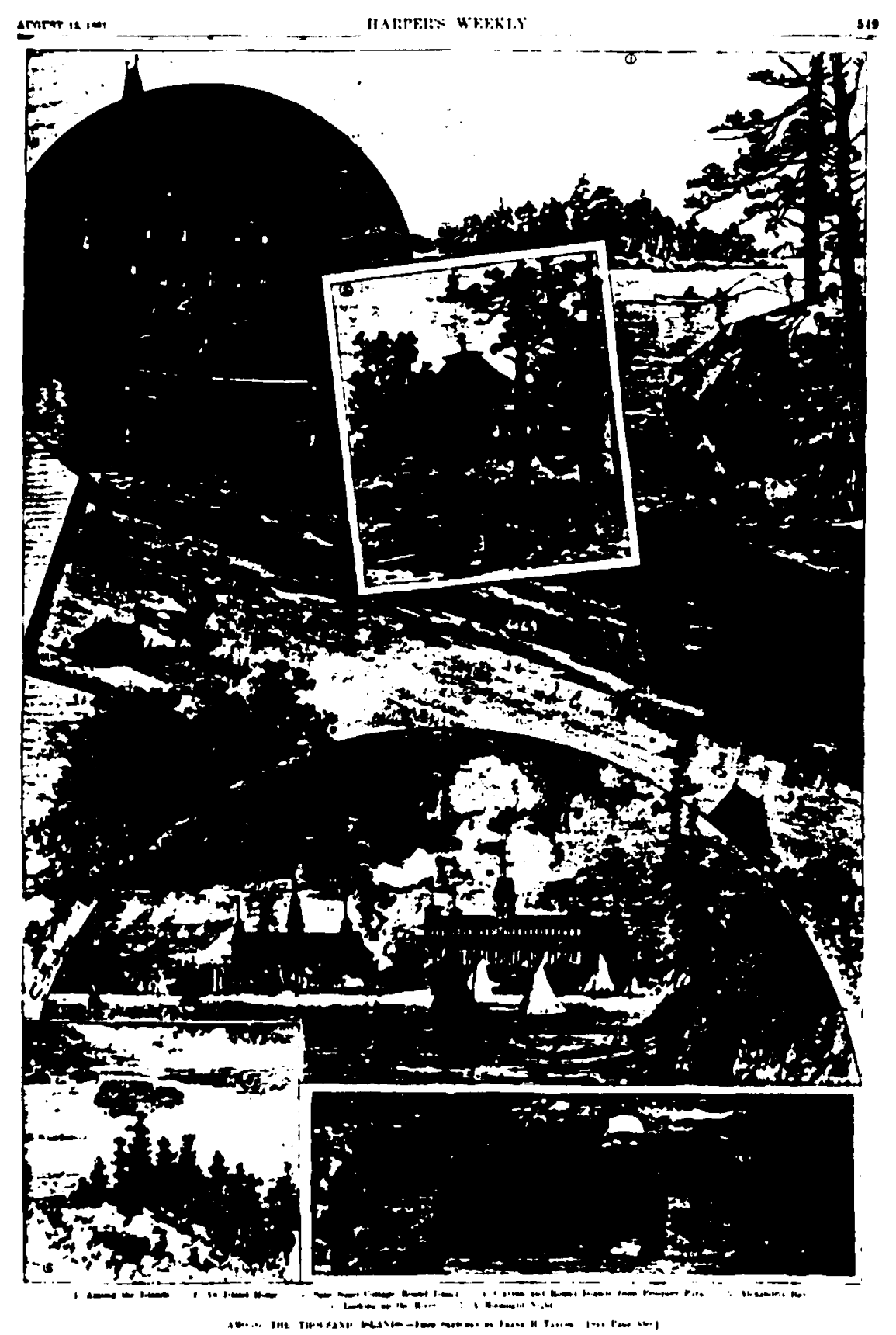

Figure 15 


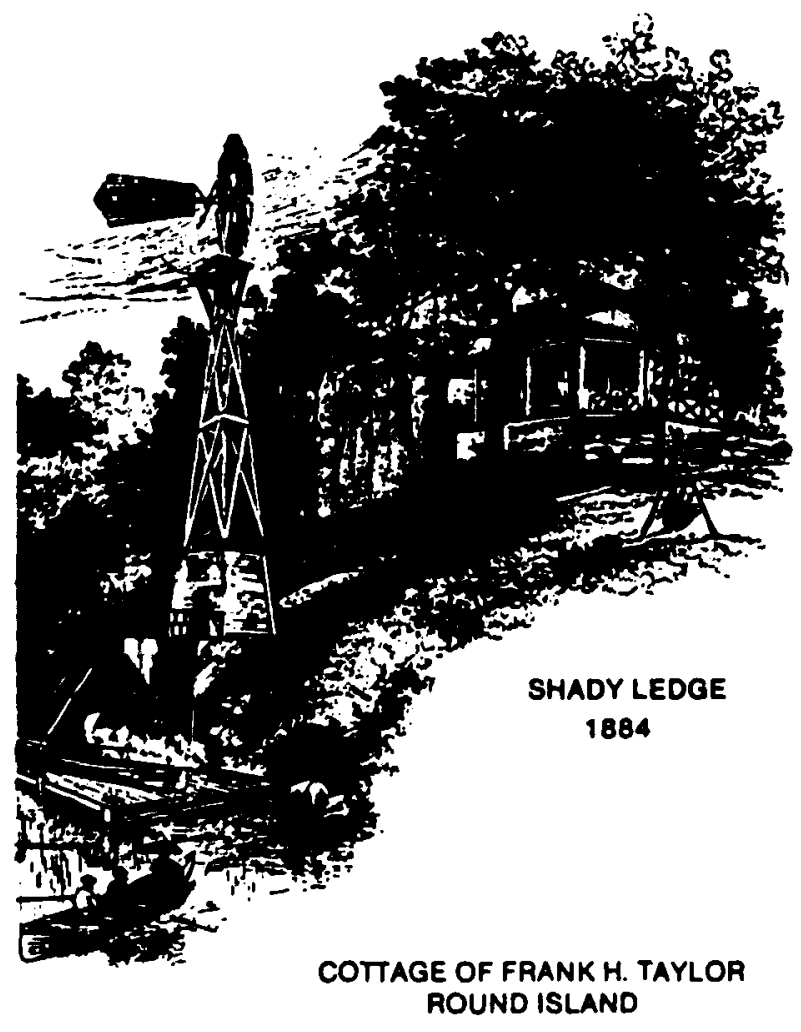

Elgure 16

SHADY LEDGE

Frank H. Taylor. Wood Engraving, 1884 Courtesy Theodore R. Cornell 


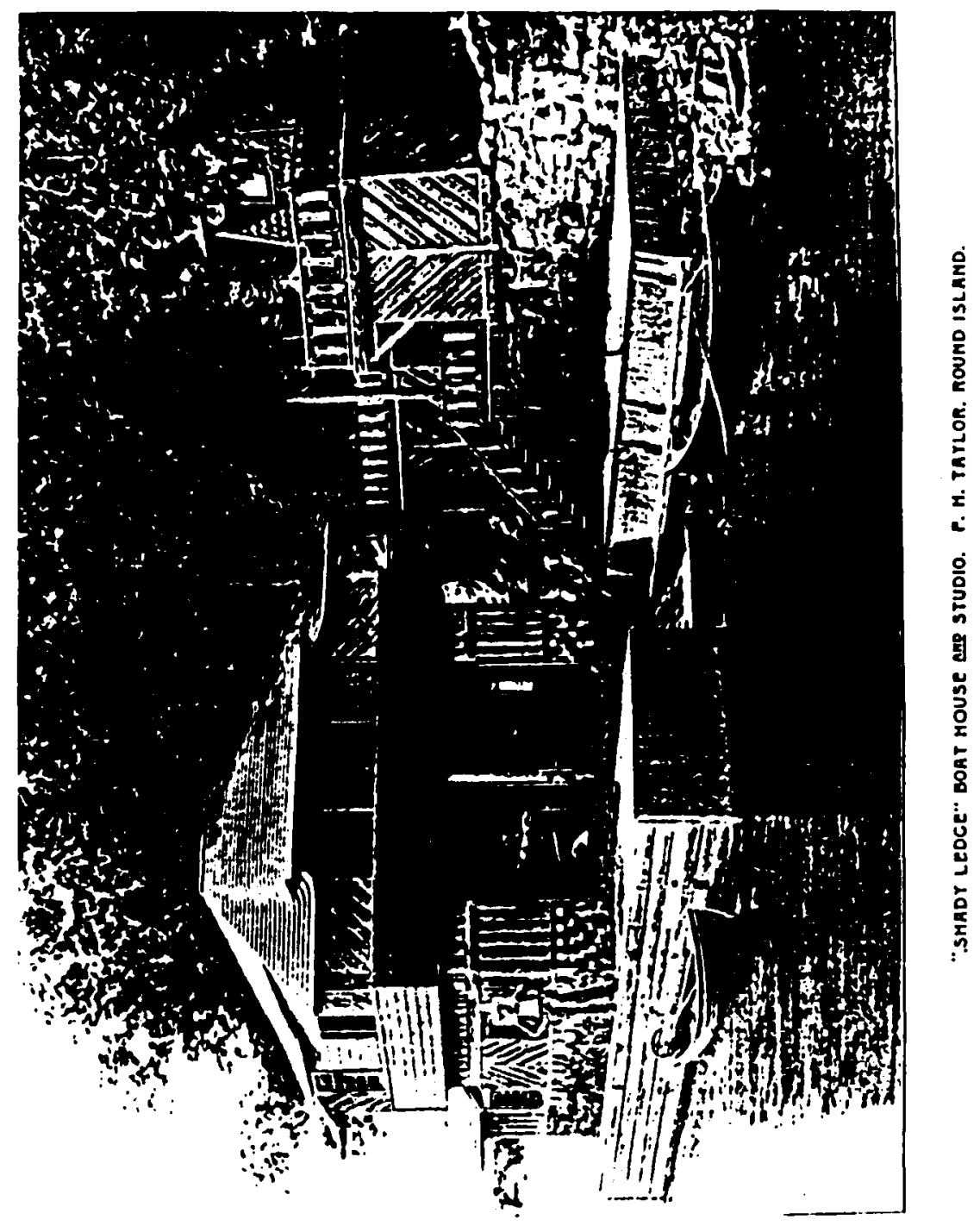

Figure 17

"SHADY LEDGE" BOAT HOUSE AND STUDIO

Photograph, c1900

Harold E. Herrick, Jr. Collection 


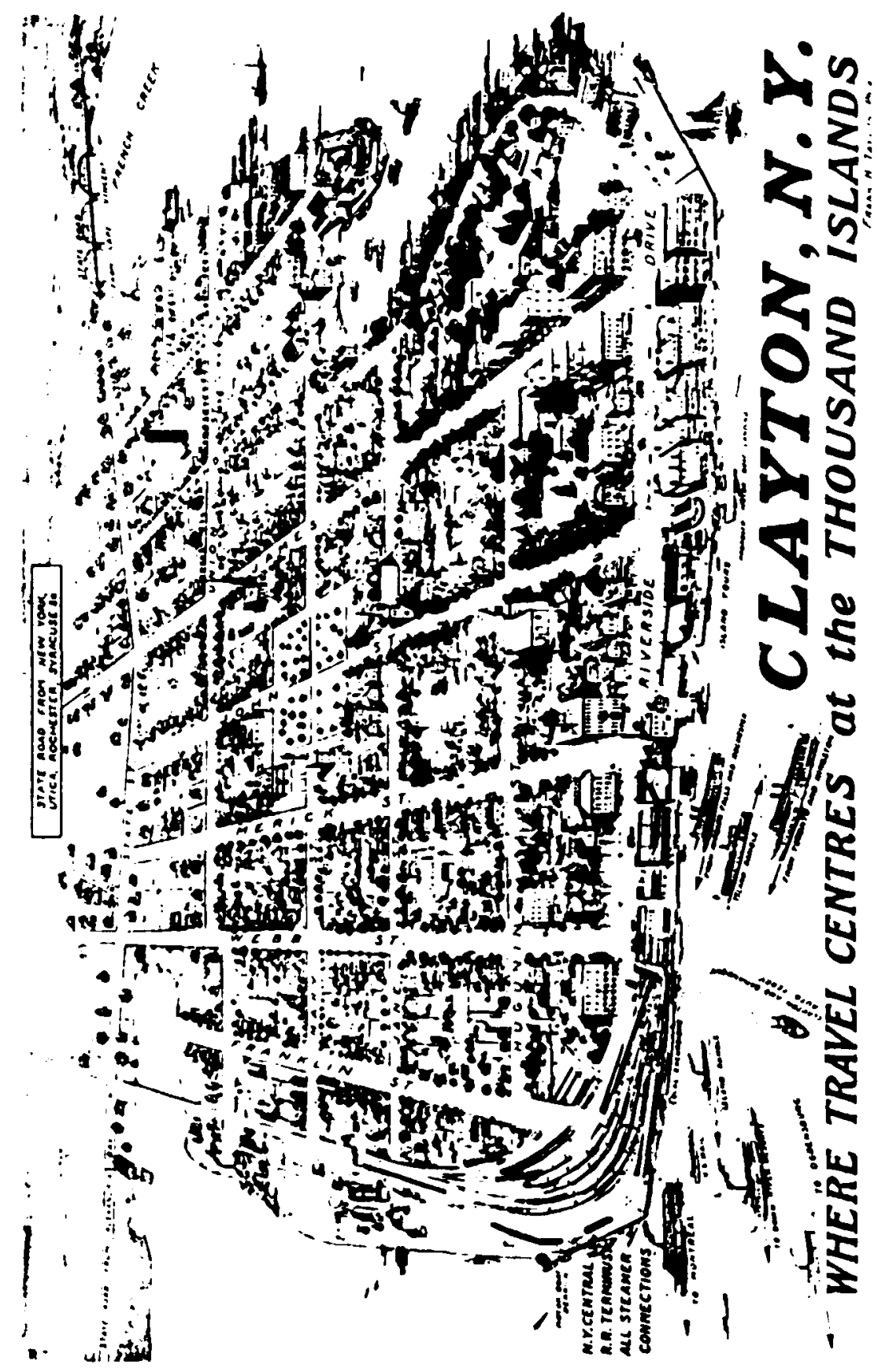

Figure 18

Frank H. Taylor. Black and white Wash, c1920 


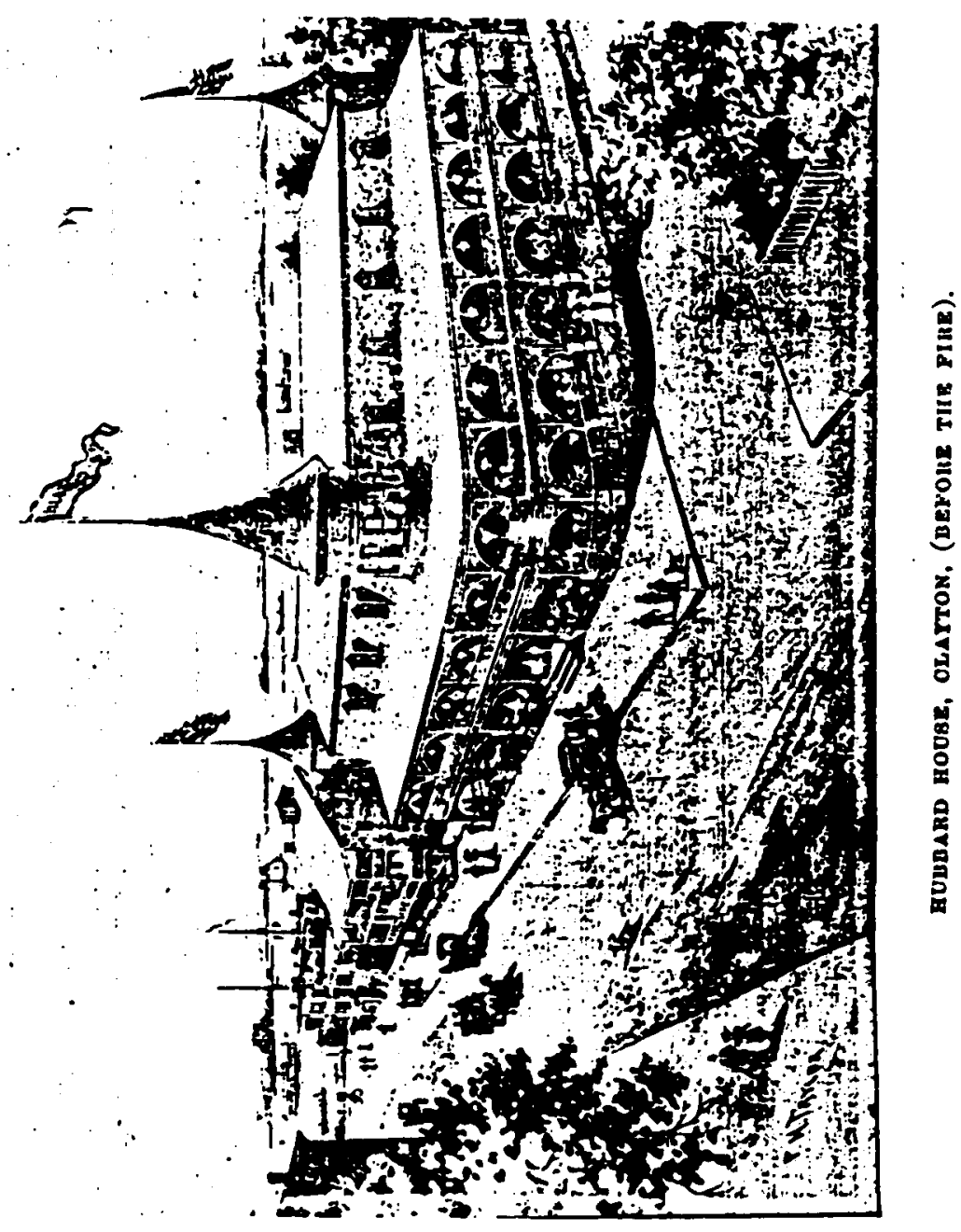

Figure 19

HUBBARD HOUSE, CLAYTON, (BEFORE THE FIRE)

Frank H. Taylor. Black and White Wash, 1895

Courtesy Lester J. Corbin Collection 


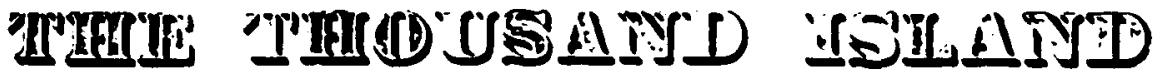

\section{ST. LAWRENCE RIVRR STEAMBOAT COMPANY,} (LIMITED, )

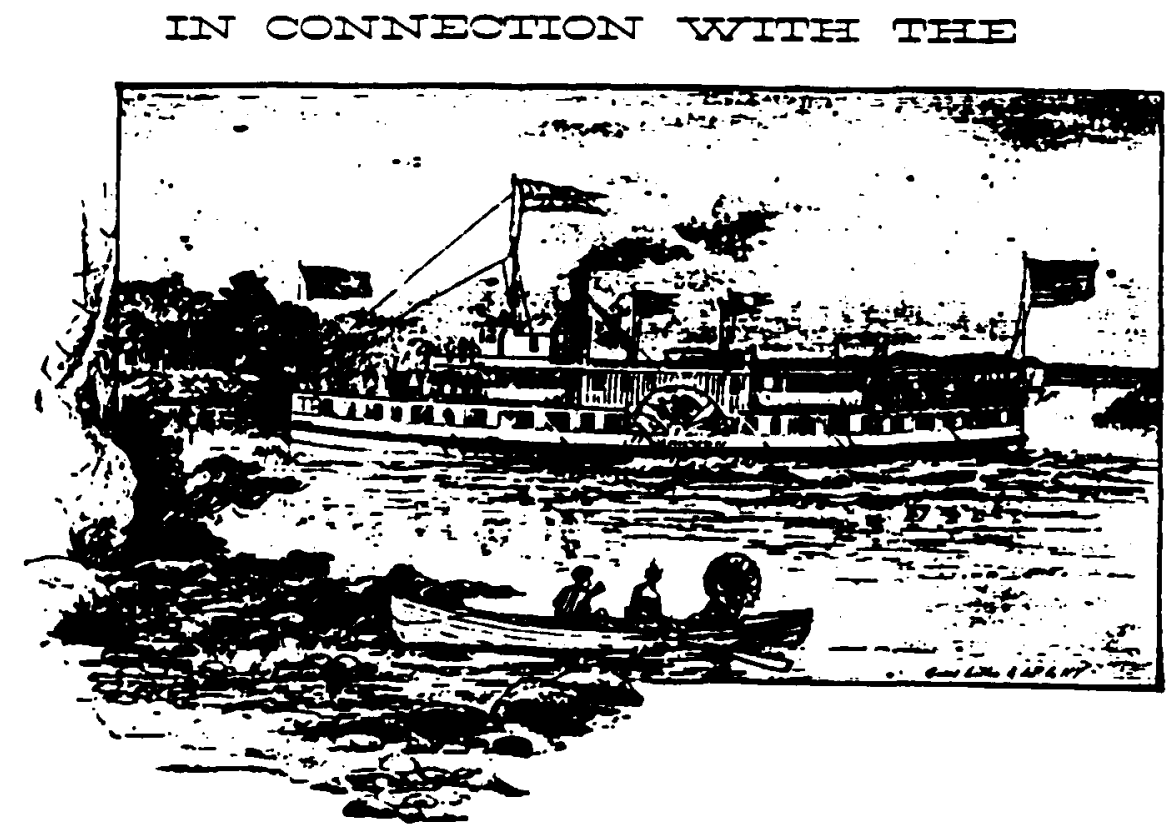

Rome, Watertown \& Ogdensburg IRATIEOAD.

Only Direct Route Between

Cape Vincent, Clayton, Alexandria Bay, Gananoque and Kingston. STEAMEFS:

8t. In

Figure 20

Broadside. The Thousand Island and St. Lawrence River Steamboat Company. Frank H. Taylor(?) c1895 


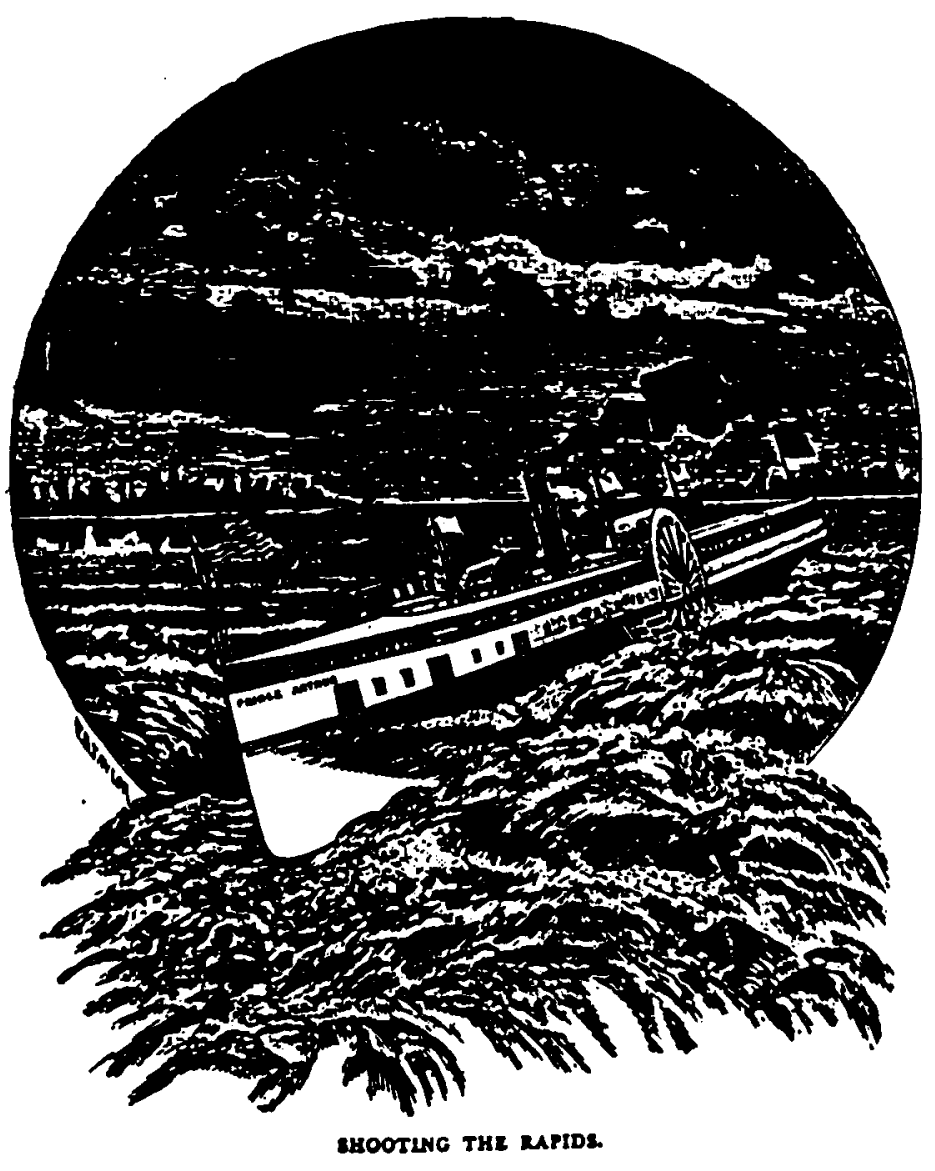

Figure 21

SHOOTING THE RAPIDS

Frank H. Taylor. Wood Engraving, c1895

The Antique Boat Museum, Clayton, NY 


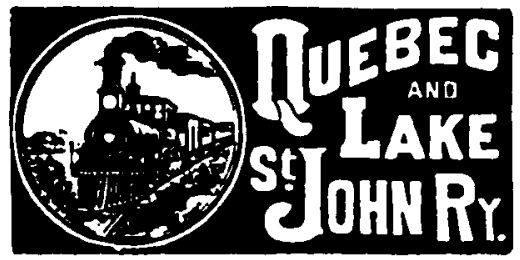

Upenidg of the Chicontimi Extension. July ?, Isgj.

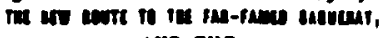
AND THE

O.XLY mil route to the deligheful oumsuer re. cons worth of Quebec, through the CANADIAN ADIRONDACKS.

Parlorand steeping Cars. Maguífced weuery. Besuttiful cliniate.

Hotel Roherval. Lake st. Johu. has hrst-clams acconinulation for 300 gneats. Delly communi. cation hy gew fast stemer croas the lake, with he lsla nd House. the ceptre of the "Unanawiche hotels. After July tst. trains will convect dailv at Chi. collithi with serveuay steaners for Quebec. doy.

light irip.
For idformation as to hotels apply to hotel menegers: for foldery and guide books to ticket areots of all principal cities. A besutifulty illus

ALEX. MARDY.

d. o. scott.

Ga r.d P. An, ser. a Yeoner.
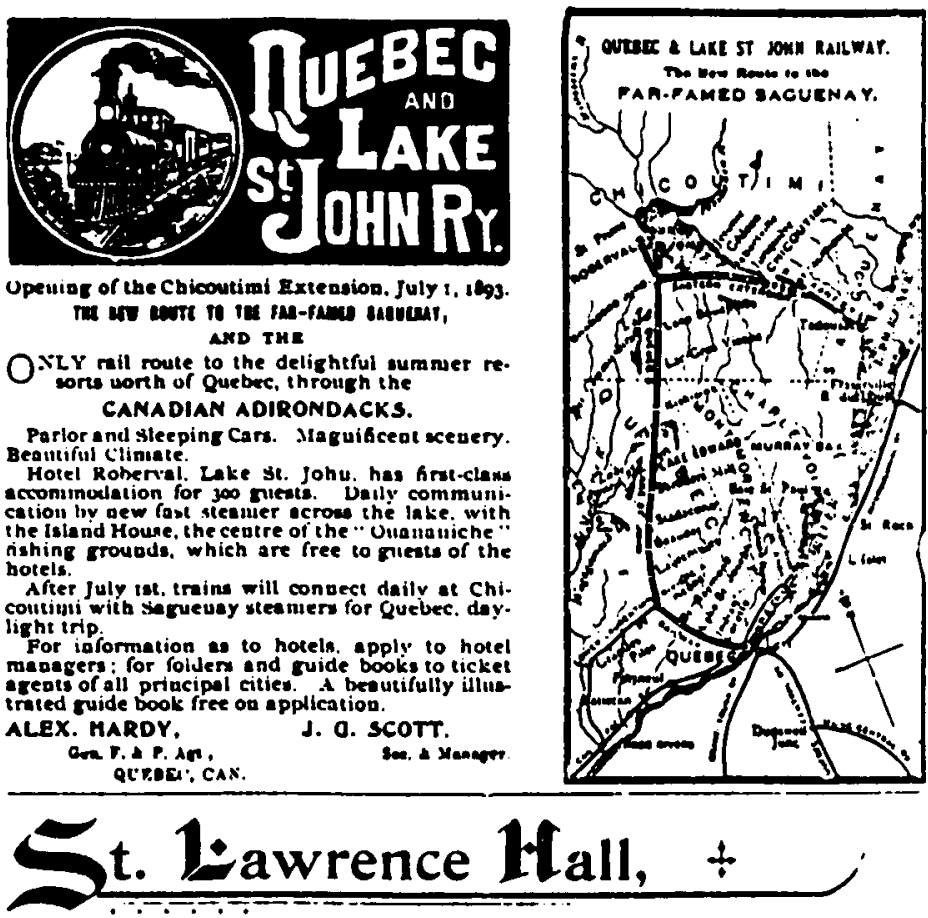

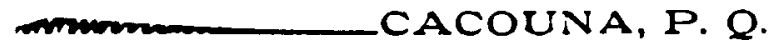

thou the take th. John and saynenay tonr in either directiou. it in well worth whils

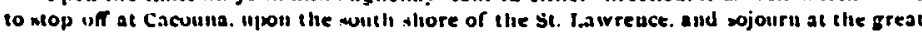
St. I-awreuce Hall, the principal liotel of the lower river.

Of all the places of rewort oll the lower st. Lawreuce none is more dewervedly popular thau Cacouma. Of the beally of the pusition chowev for the Hall and the nunieronw villa

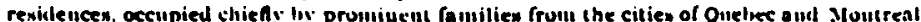
ibu much counch be snid. The wiile expouse of the majentic river, with the graud t.aure" tine outliue cul the uorth shore. uever ceanex to charm the eje from the early moril intil the last receding mys of the evelliug swilight. The gorgeoun sulumets renind one of thume witueswed from the sulumit of the Kighi. or ill the luvariat Alps. Then again. there in - Iways here all invigorating frexhulex iu the air, $c 0$ conducive to the resturation of health.

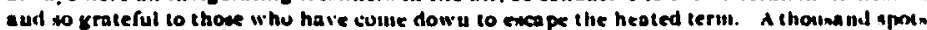
of nylun heanty with shade are 10 be foumd along this ridge. the beautiful drive to kiver du towp. the Portace and other places. In addition to all these naiural aclvautares, there is a great charm iu the nocial life which obcoius here. Happy groups are to be fowad on the lawn tenuis crounds of the private villas. thoronghly enjoying the gatme. The after. noonx are gellernlly devoted to the mally drives iu the neighiorhond. Alld almost every evening are found aswembled at the Hall a goodly numler frou the neightoring villas.

cicoune is reached lyy either steauer or wpecial train service from Moutrenl aud Quebec.

QUEBEC AND LAKE ST. JOHN RAILWAY -

THE NEW ROUTE TO THE FAR-FAMED SAGUENY

Estes' Standard Gutde to the Thousand Islands, 1893, R. 60

Hawn Memorial Library, Clayton, NY 


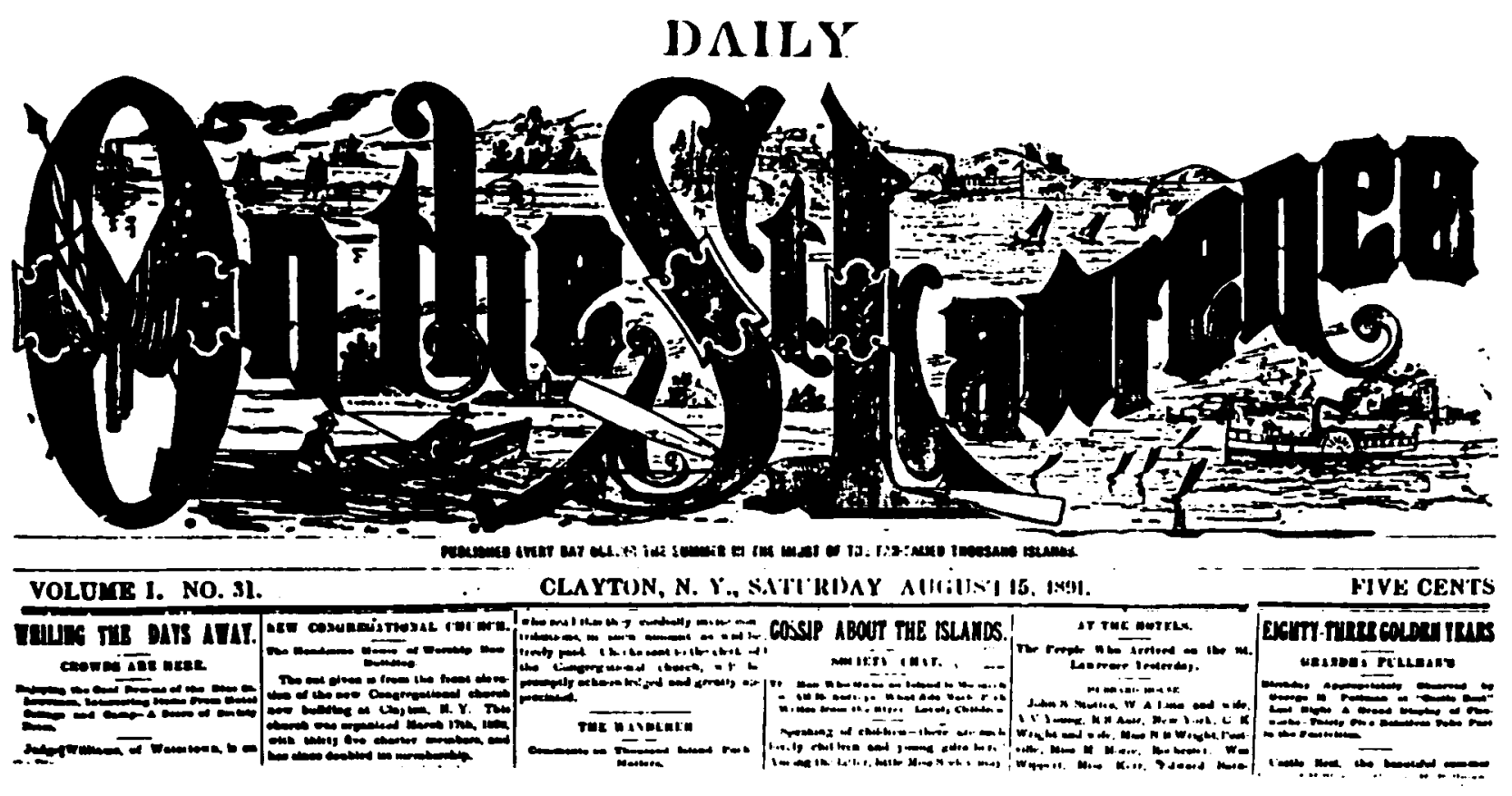




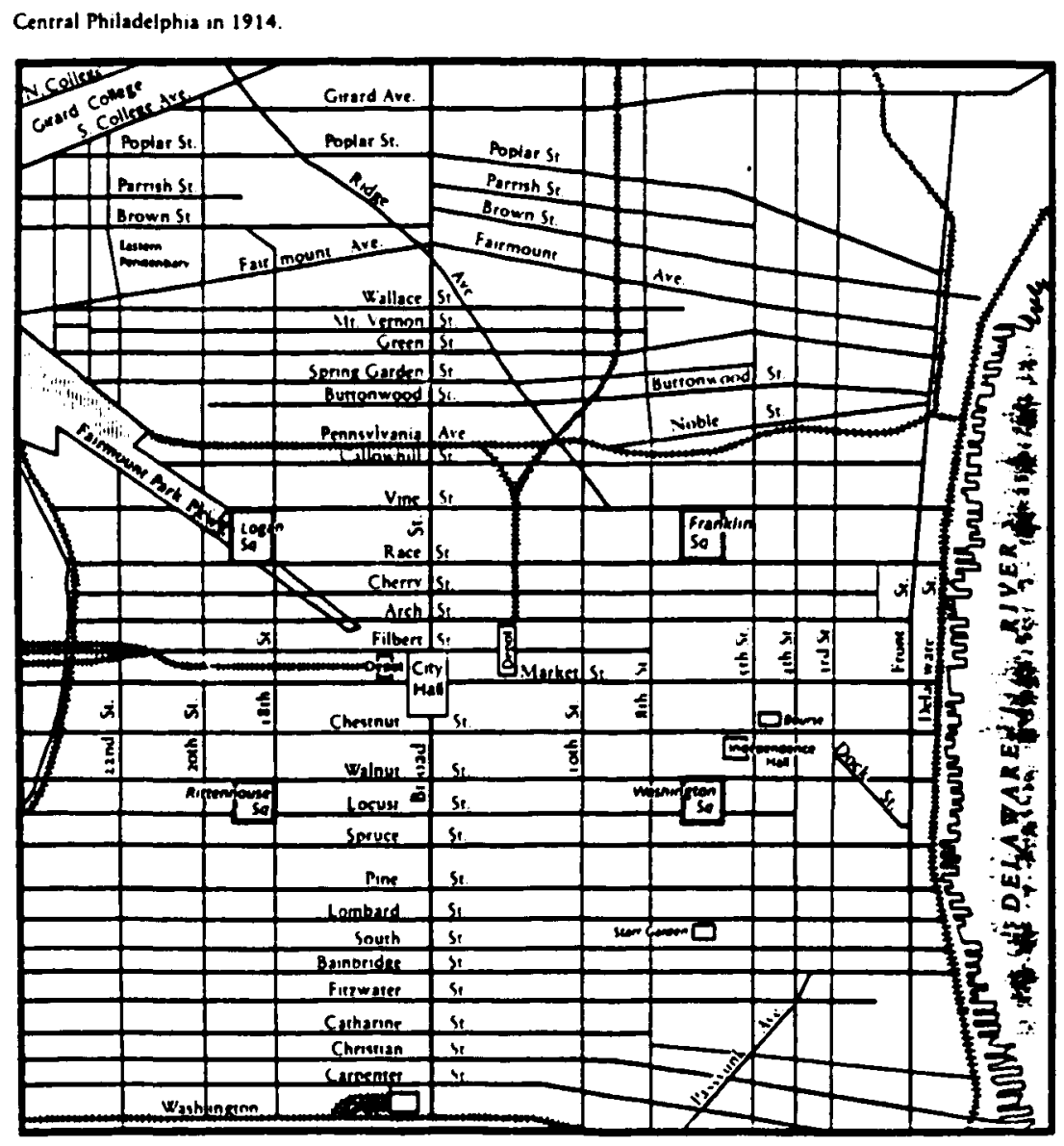

Figure 24

CENTRAL PHILADELPHIA IN 1914

O1983 by Temple University. Map drawn by Heidi Perov Reprinted by Temple University Press 
Philadelphia in 1896. showing the main developed aress.

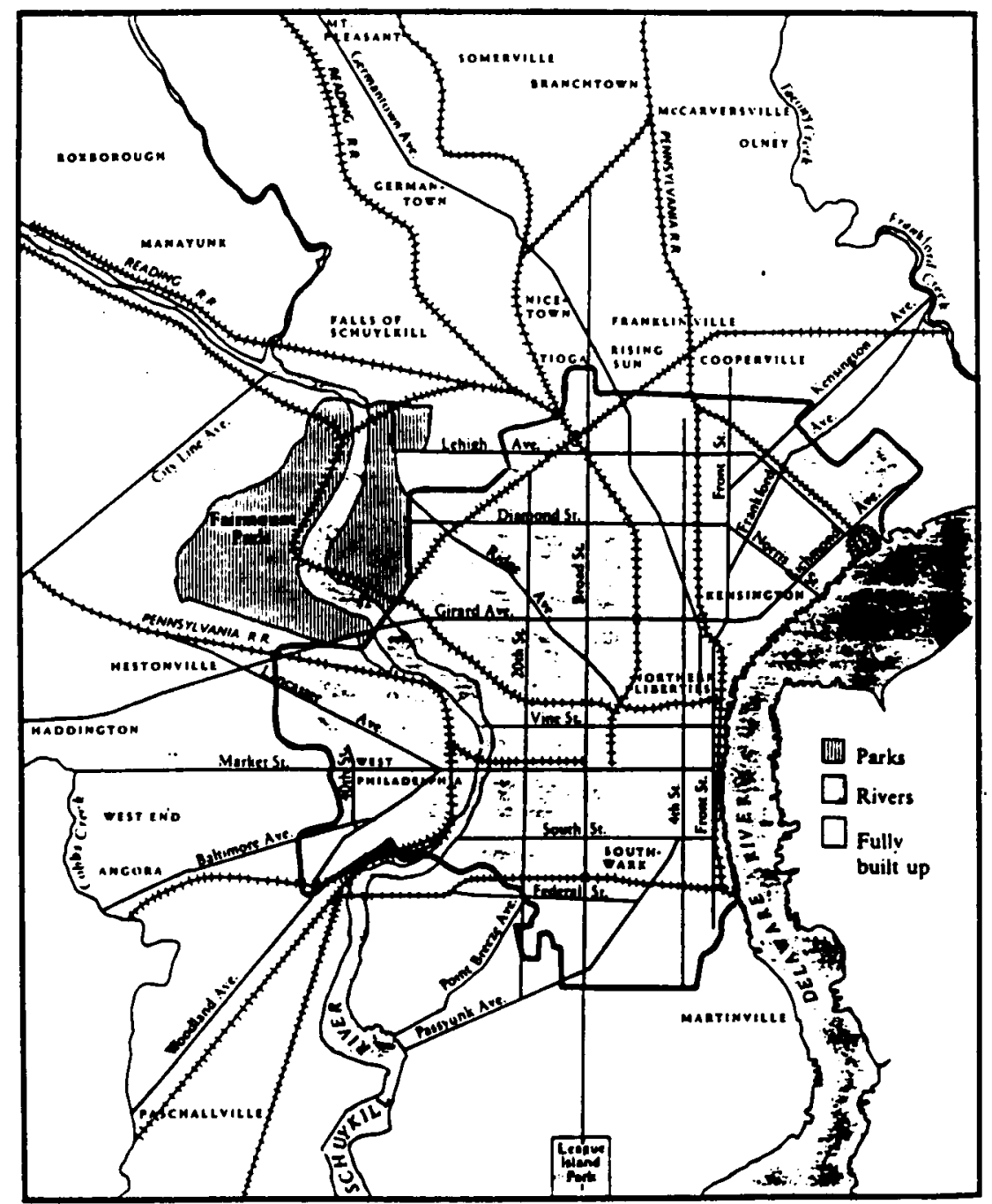

Figure 25

PHILADELPHIA IN 1896

O1983 by Temple University. Map drawn by Heidi Perov Reprinted by Temple University Press 


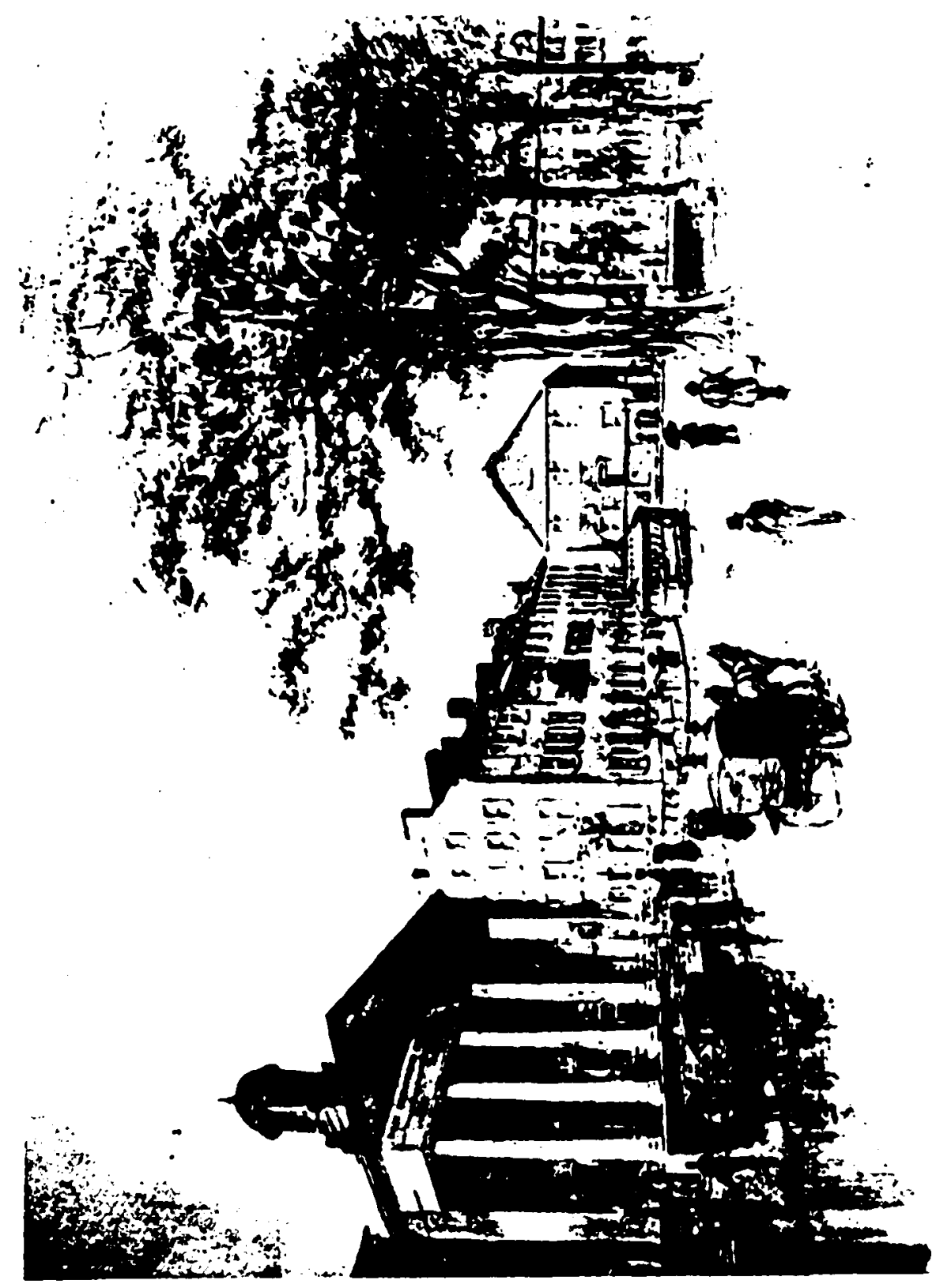

Figure 26

SOUTHWEST VIEW OF WASHINGTON SQUARE

Frank H. Taylor. Watercolor, 1925

The Athenaeum, Philadelphia, PA 


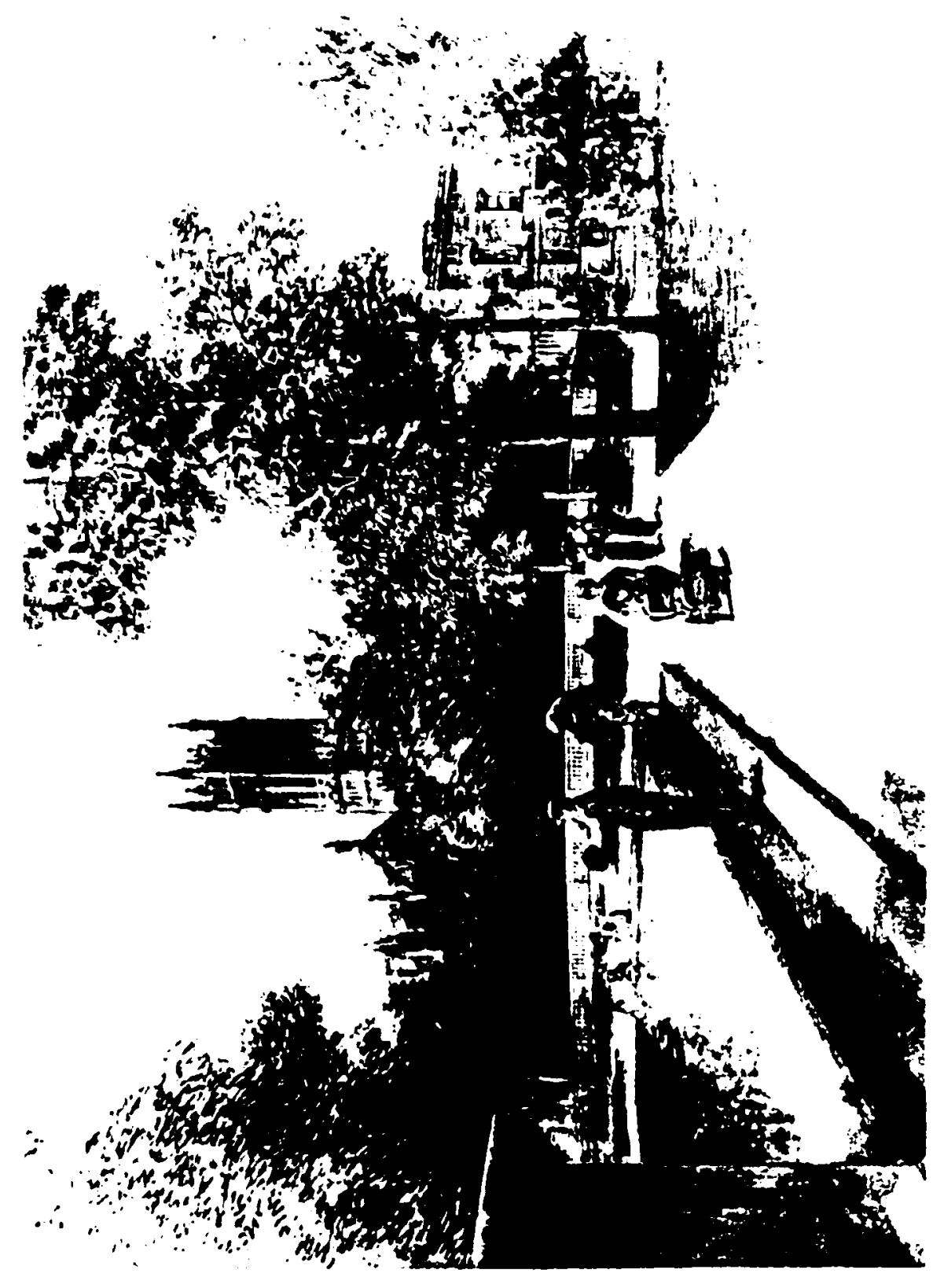

Figure 27

RITTENHOUSE SQUARE \#8

Frank H. Taylor. Black and white Wash, 1915

The Historical Society of Pennsylvania, Philadelphia 


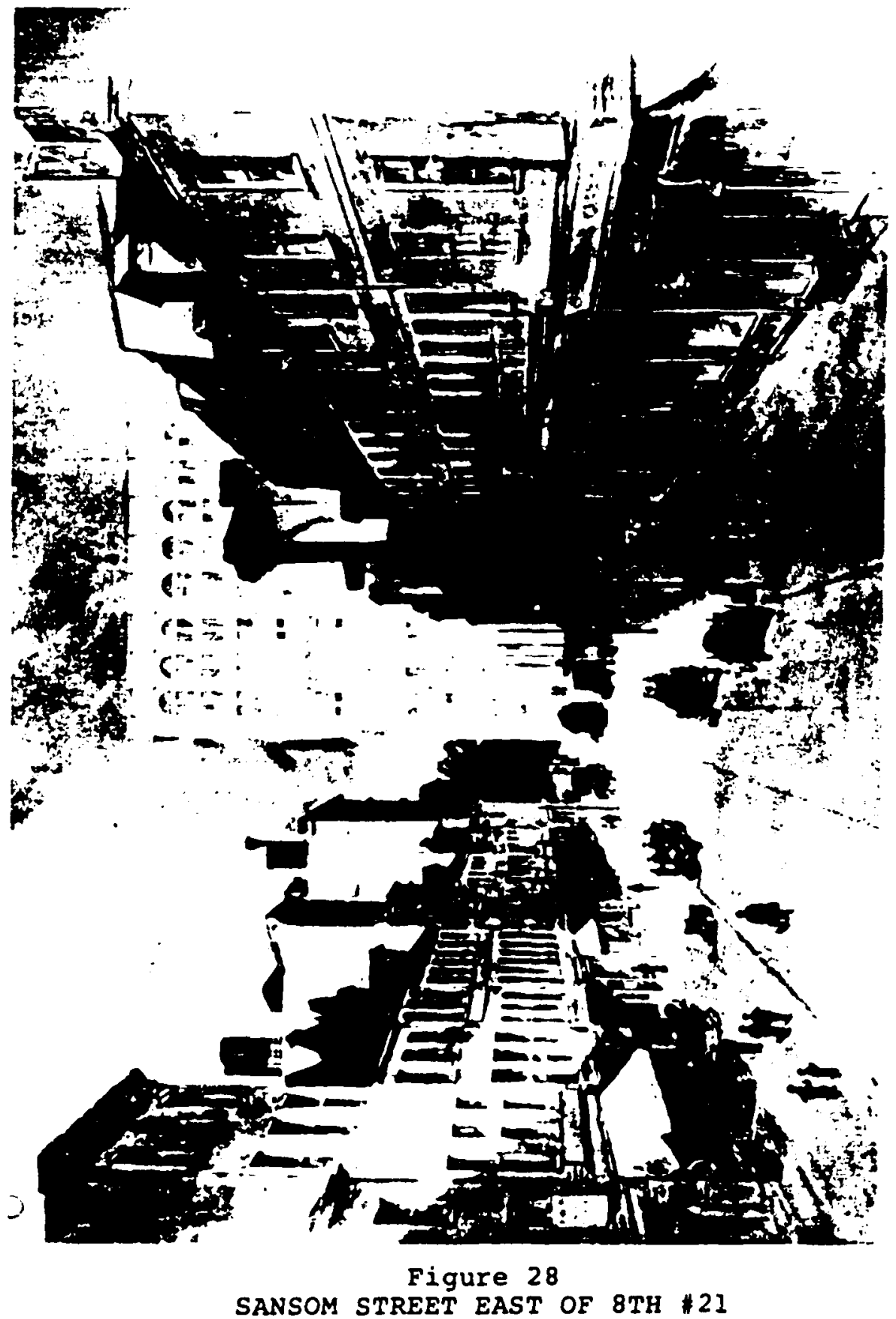

Frank H. Taylor. Black and White Wash, 1914

The Historical Society of Pennsylvania, Philadelphia 


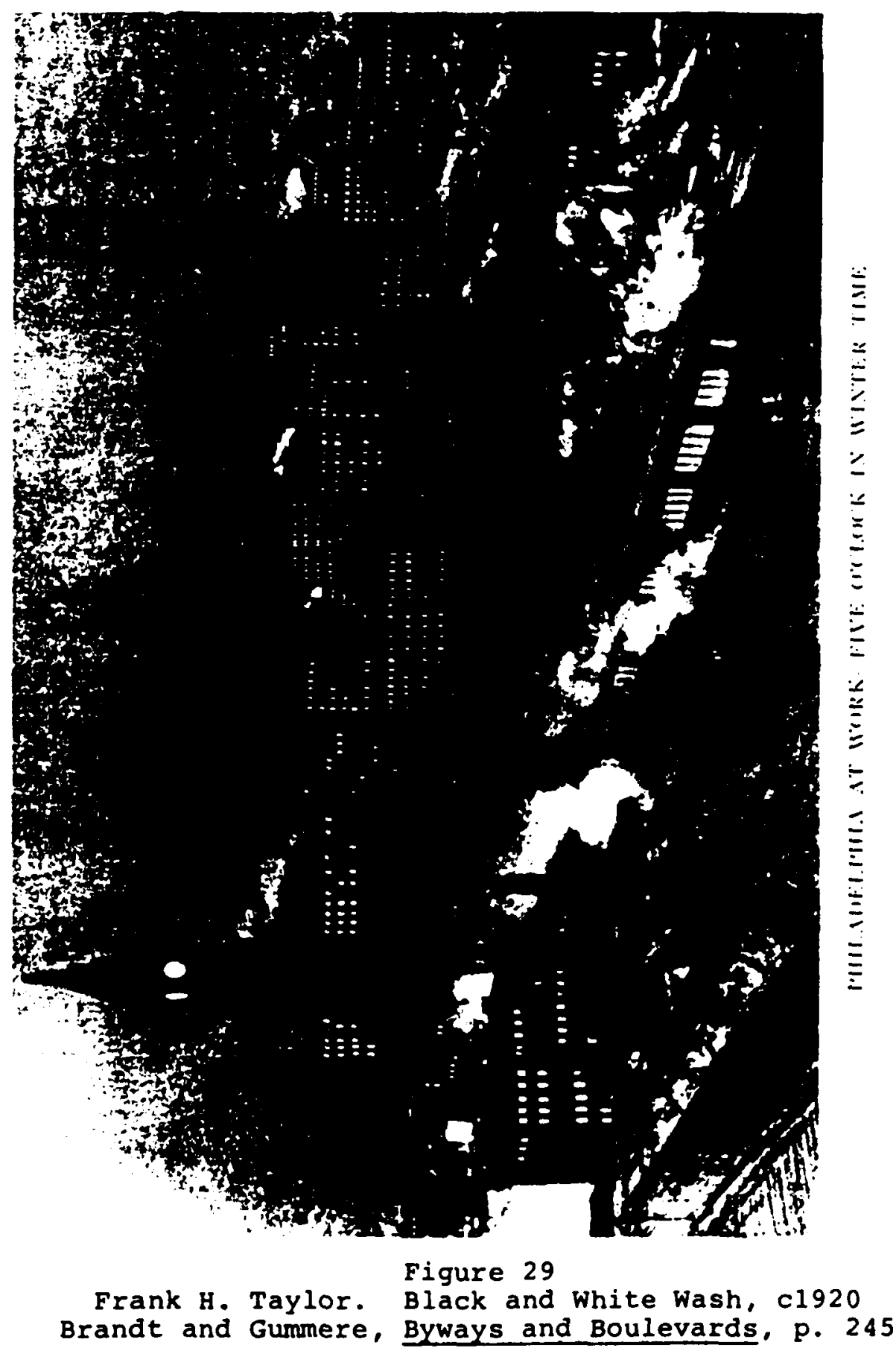




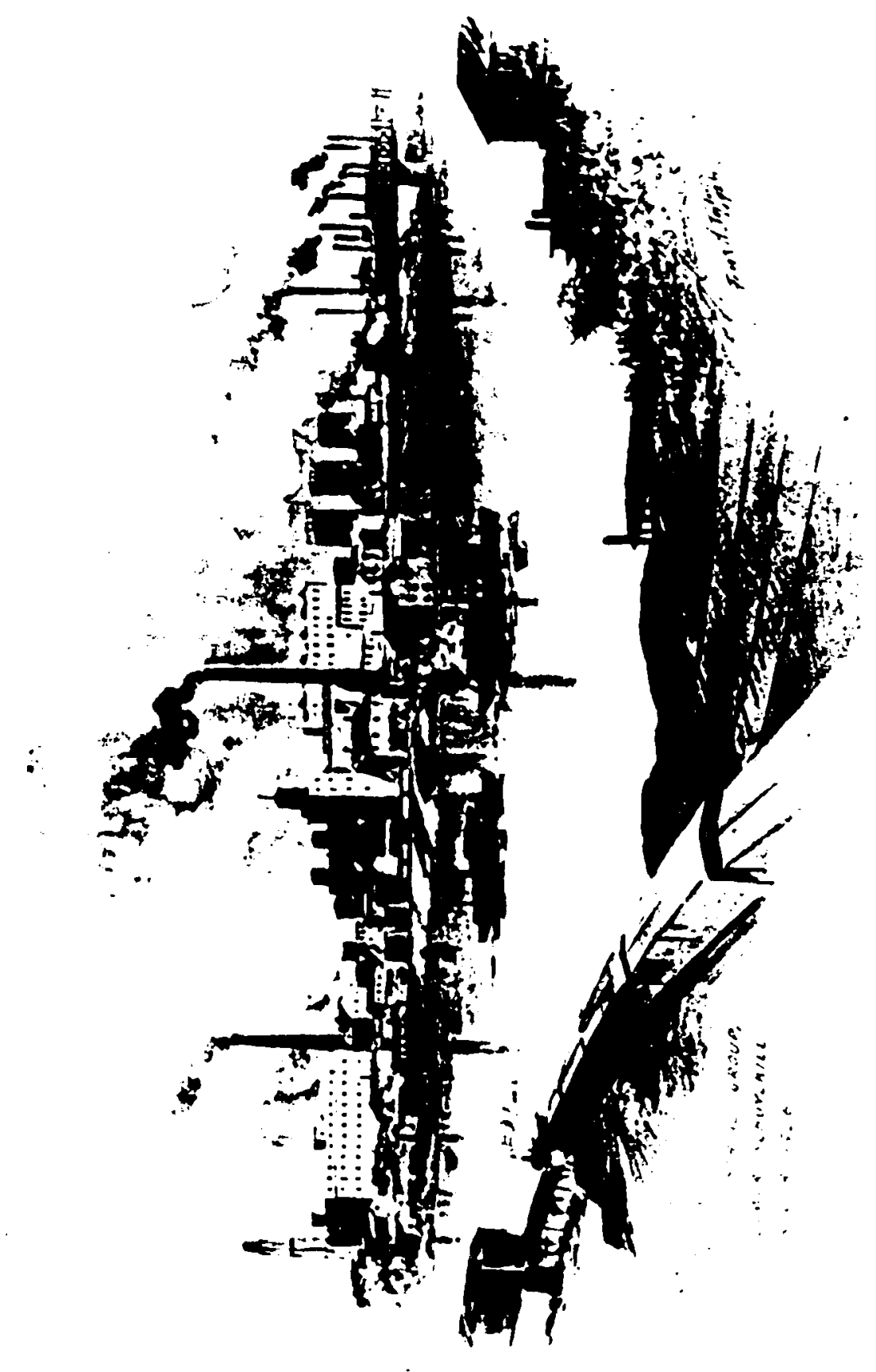

Figure 30

THE LOWER SCHUYLKILL $\$ 373$

Frank H. Taylor. Watercolor, 1926

The Historical Society of Pennsylvania, Philadelphia 


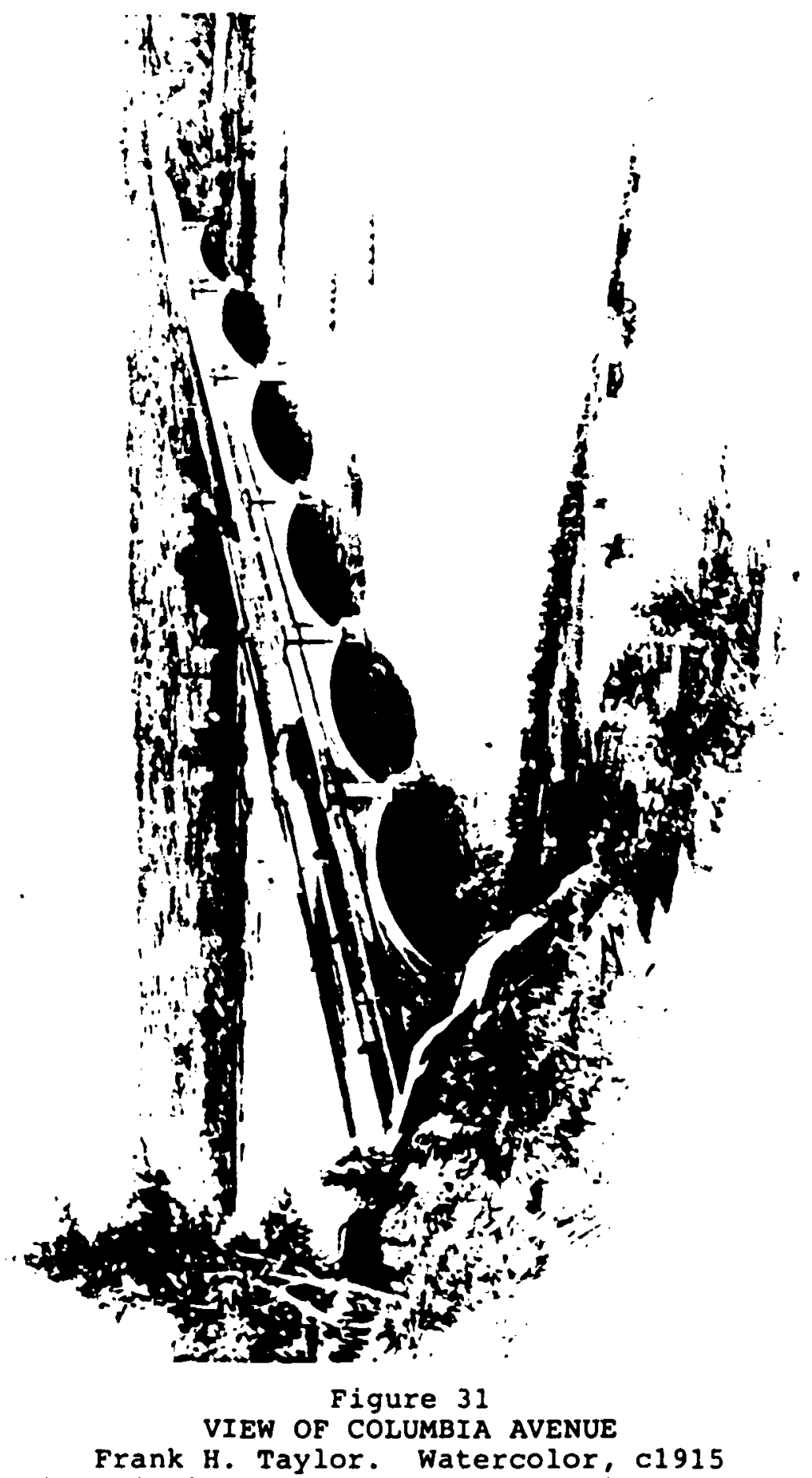

The Historical Society of Pennsylvania, Philadelphia 


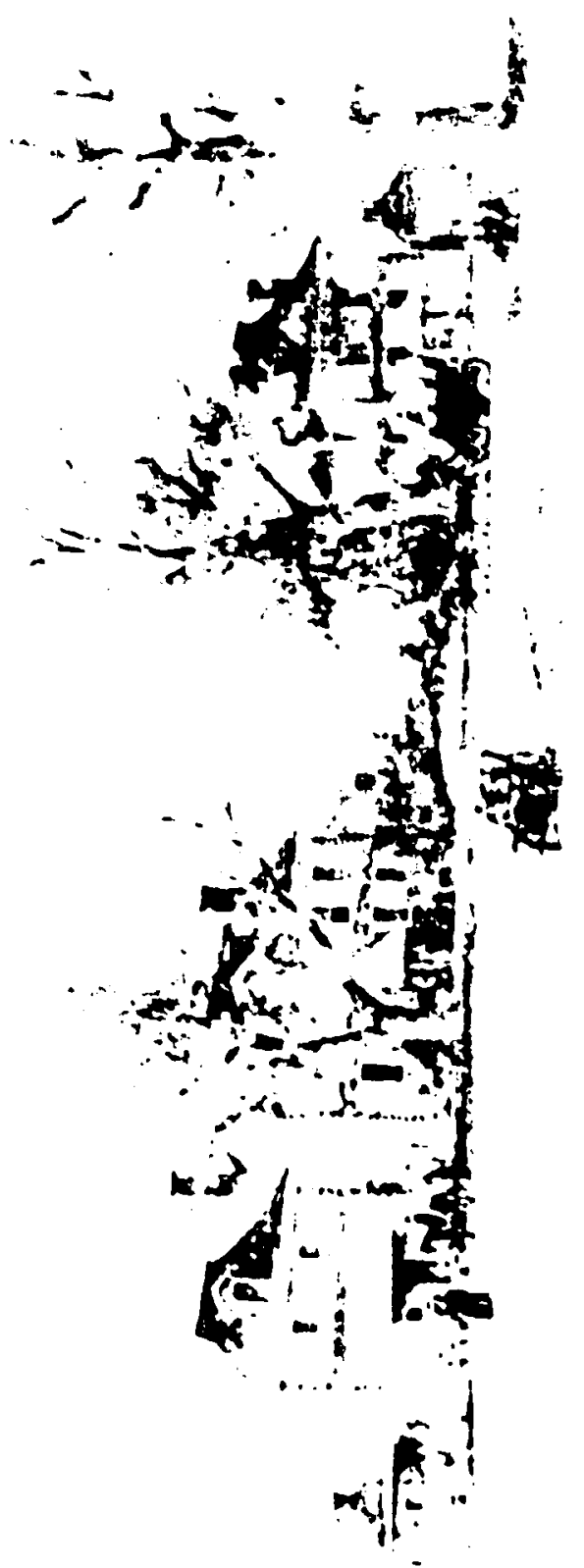

Figure 32

FIRST HORSELESS CARRIAGE IN FAIRMONT PARK Frank H. Taylor. Watercolor, 1920 Atwater Kent Museum, Philadelphia PA 


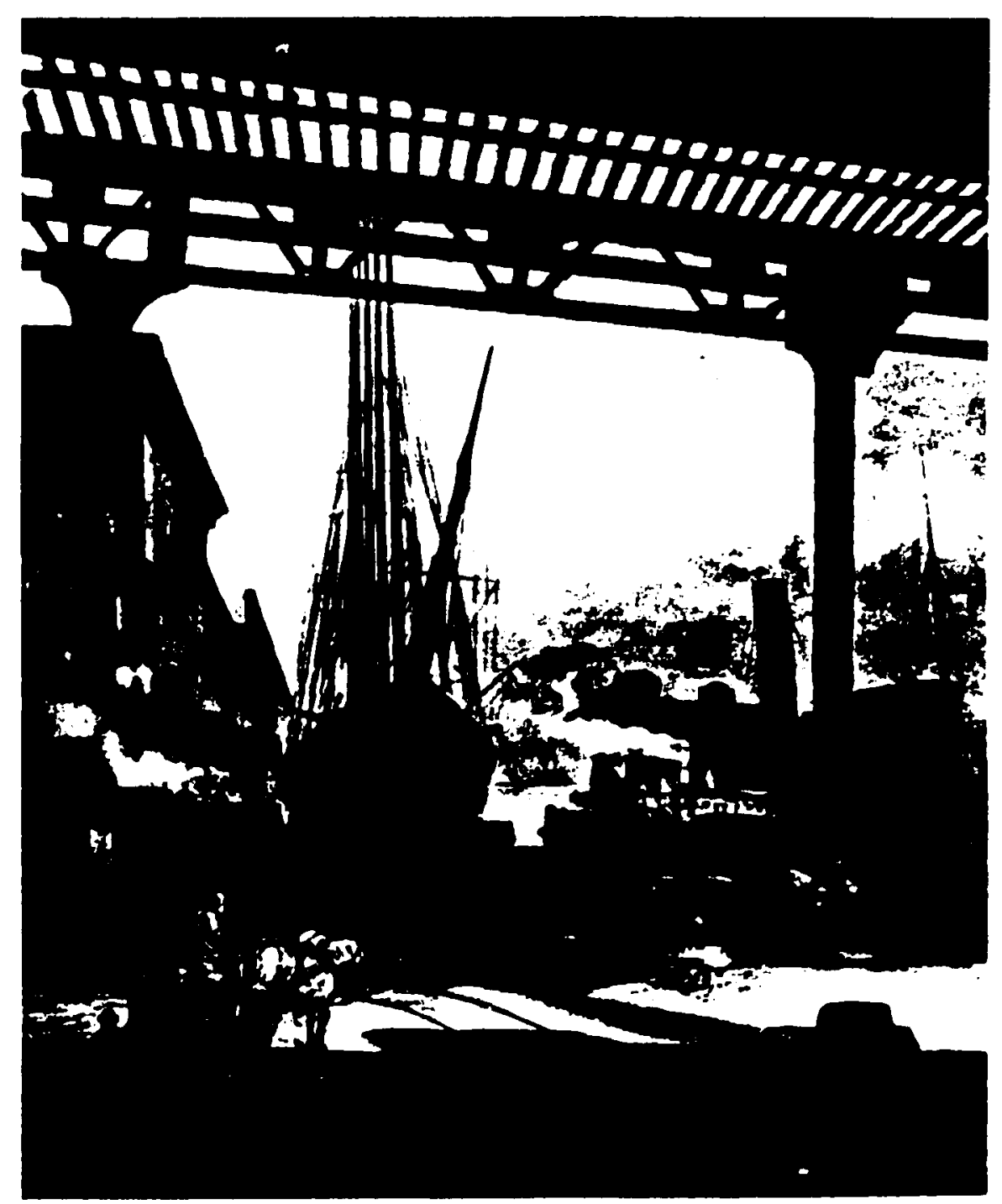

Figure 33

AT THE FOOT OF SOUTH STREET \#35

Frank H. Taylor. Black and white Wash, c1920

The Historical Society of Pennsylvania, Philadelphia 


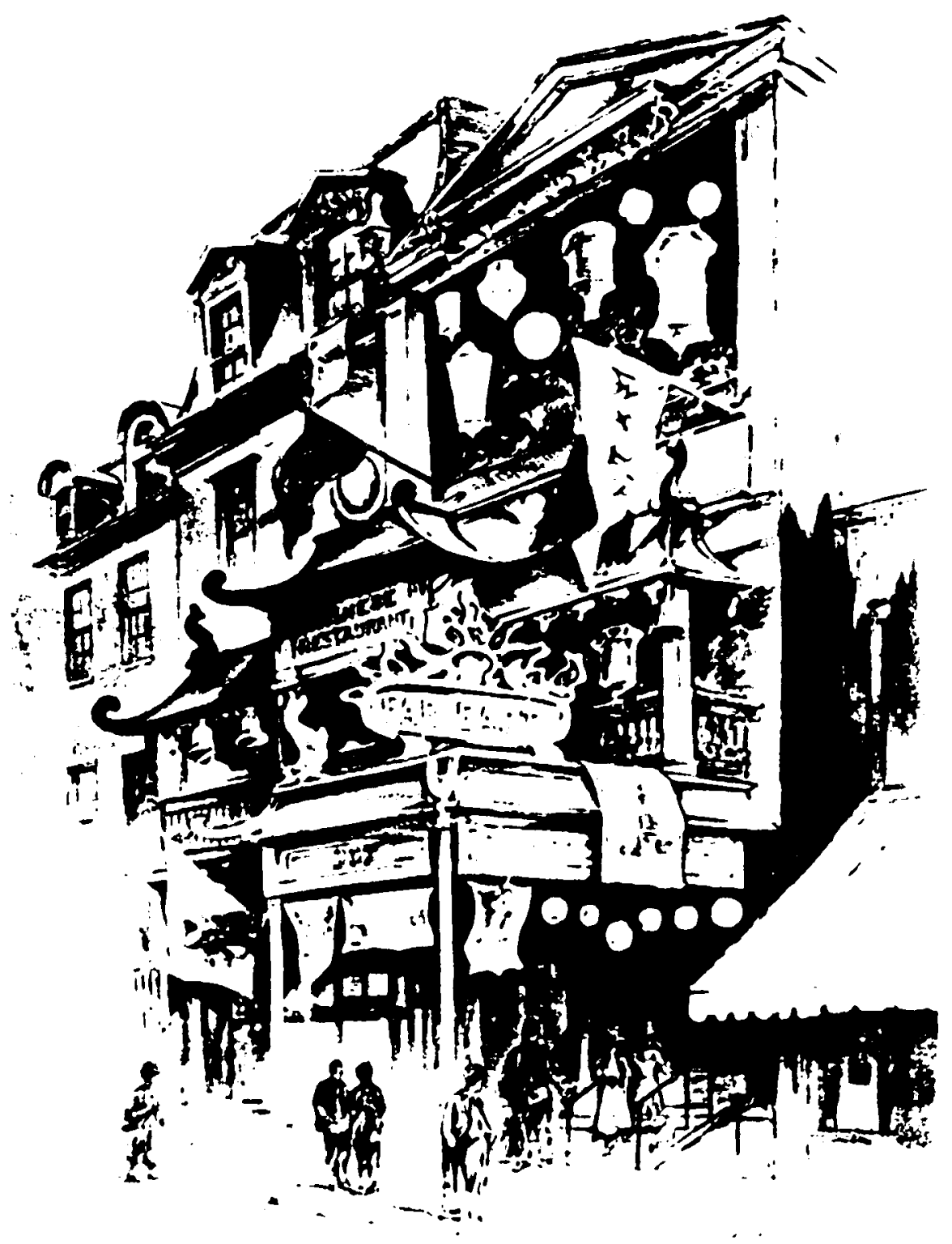

Figure 34

FAR EAST RESTAURANT

Frank H. Taylor. Watercolor, 1923

The Historical Society of Pennsylvania, Philadelphia 
APPENDIX B

"Ode TO Taylor."

Air: -- "Tit-Willow."

At the foot of Round Island an artist cried out

Camp fire! Camp fire! Camp fire!

So we said to him, Taylor, oh why do you shout

Camp fire! Camp fire! Camp fire!

Is it artistic intellect, Taylor we cried,

or a fiery desire which you can't override?

Then, with accents inviting, he quickly replied

Camp fire! Camp fire! Camp fire!

He piled on the logs as his friends gathered round

The Camp fire! Camp fire! Camp fire!

And they sat on the benches, or sprawled on the ground

At the flre! Camp fire! Camp fire!

He lighted a match and ignited the pile

Which blazed away grandly in most approved style

And shone o'er the water for more than a mile --

The Camp fire! Camp fire! Camp fire!

Then his violin tuned he, and joined in a song

At the fire! Camp fire! Camp fire!

And the campers foined in with a chorus so strong

'Round the fire! Camp fire! Camp fire!

Recitations were given and stories were told,

But no "chestnuts" allowed covered over with mould,

And no puns were permitted, or novel, or old

At the fire! Camp fire! Camp fire! 
Now all feel just as sure as that Taylor's their host That the fire! Camp fire! Camp fire!

Is the pleasantest feature Round Island can boast, The Camp fire! Camp fire! Camp fire!

May his shadow ne'er cease, may his camp fires -end To the Island their cheer while the air we will rend For Frank Taylor the artist and poet -- our friend -And his fire! Camp fire! Camp fire!

Now a word for our guests who are here from afar

At the fire! Camp fire! Camp fire!

They're both "Friendly" and "Nobby" - 'pon honor they are

At the fire! Camp fire! Camp fire!

We're delighted to greet them (dental's no use), Here's a welcome to Youmans, Heath, Dewey and Bruce, And to all who to-night to our pleasure conduce, At this fire! Camp fire! Camp fire!

Written for, and sung at Camp Racquette Camp fire, August $27 t h, 1887$

L. E. M.

A. S. E. 
APPENDIX C

CHRONOLOGY: FRANK H. TAYLOR

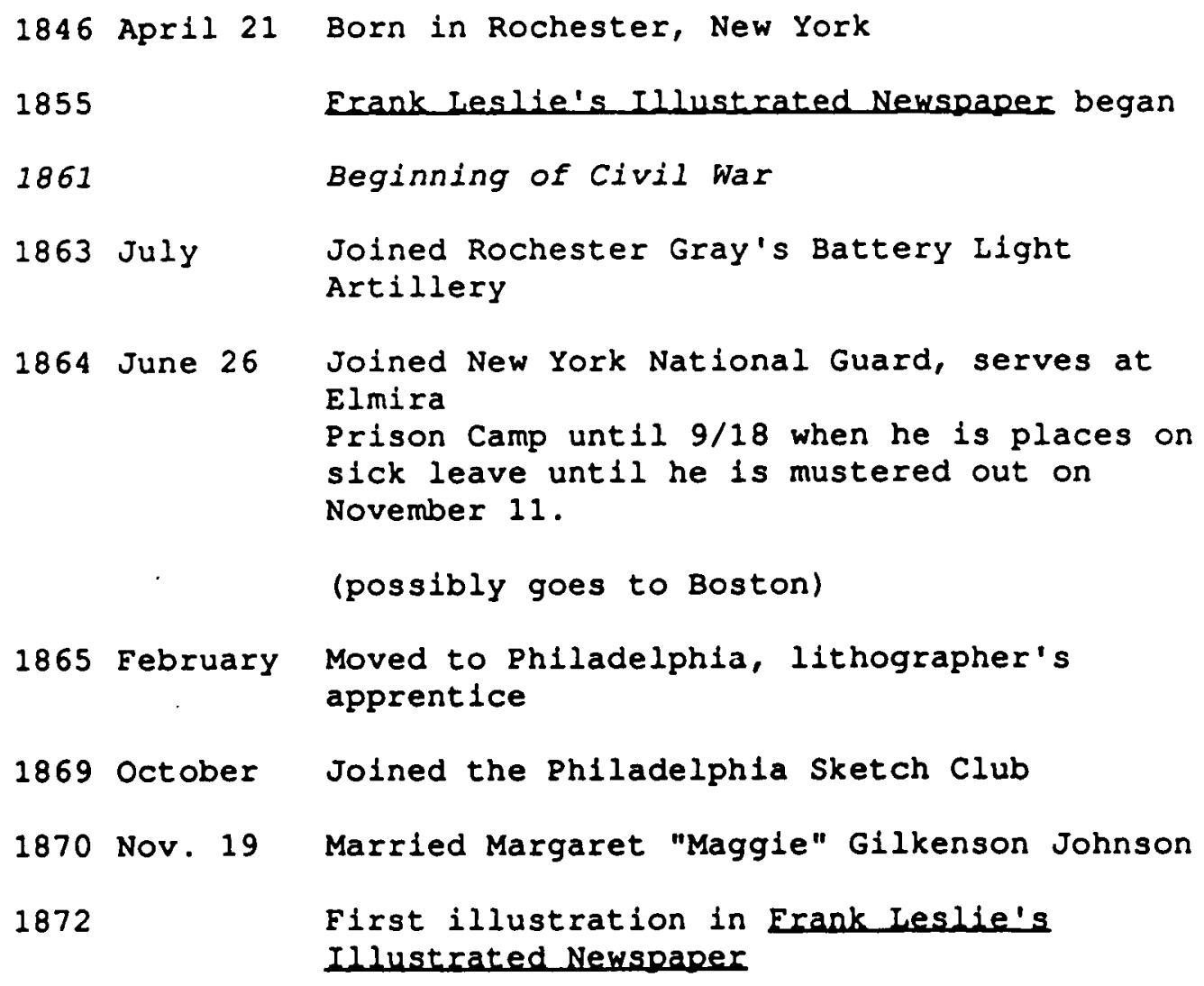

Begins association with NY Daily Graphic, in charge of news events in Philadelphia and southward.

March 8 Only son, Frank Walter Taylor born

October Taylor \& Smith exhiblt at Franklin Institute Exhibition 
1875 January

1876

1877

1878

1879

1880

1881

1882

1883

1893

$1903 / 04$

1905

1907

1913

1917
First issue of Philadelphia Sketch Club Rortfolio

Centennial Exposition

Accompanies American Society of Civil Engineers on trip to New Orleans, and publishes book on trip.

Writes and illustrates guidebook Autumn Leaves among the Lehigh.

Begins New York City connections

First published article in Harper's Weekly

First published article in Harper's Monthly

Assignment to cover Grant trip by Harper's Weekly

Harper's Weekly assignment to write on Thousand Islands

Summer home "Shady Ledge" built on Round Island

Covers visit of Porfirio Diaz to U.S.

Placed in charge of 1llustrative features for the Philadelphia Public Ledger

Exhibits two paintings of Bass with G. M. Skinner's award winning Fluted Trolling Spoons at Chicago World's Fair

Publishes three articles for Beokman's Magazine

First edition of Valley Forge: A chronicle of American Heroism

Applies for military pension

Publishes Rhiladelphia in the civil War

Son, F. Walter Taylor marries Elsie Carleton Megary 


\begin{tabular}{|c|c|c|}
\hline 1920 & January & $\begin{array}{l}\text { Elected president of the Philadelphia sketch } \\
\text { Club }\end{array}$ \\
\hline & March & Death of wife \\
\hline 1921 & July & Death of son \\
\hline 1923 & Nov. 20 & $\begin{array}{l}\text { Lecture to Philobiblon Club of Philadelphia on } \\
\text { lithography }\end{array}$ \\
\hline 1924 & & Testimonial at Sketch Club 55th anniversary \\
\hline 1926 & & $\begin{array}{l}\text { Confinement to Springfleld Ave. home } \\
\text { Sesqui-Centennial Exposition }\end{array}$ \\
\hline 1927 & March & $\begin{array}{l}\text { Declared "weak-minded." Moved to Burn Brae } \\
\text { Sanitarium }\end{array}$ \\
\hline
\end{tabular}


APPENDIX D

WOOD ENGRAVINGS AFTER SKETCHES BY FRANK H. TAYIOR *Denotes an original sketch is extant.

\section{Harper's Weekly: A Journal of Civilization}

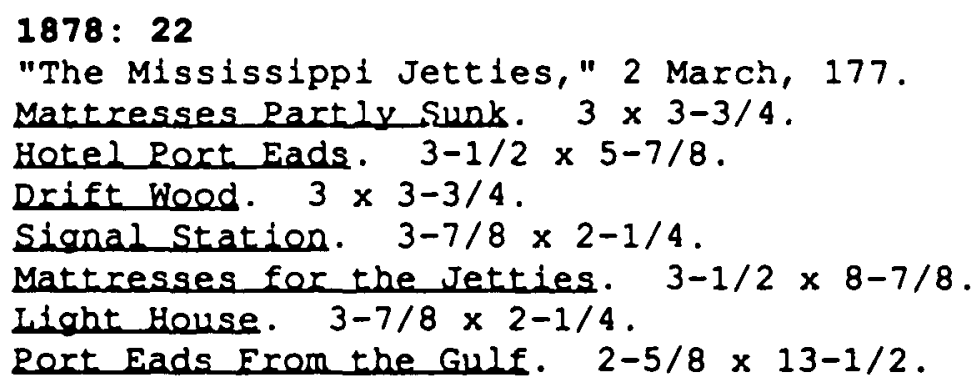

1879: 23

"A Tobacco Mart in Lynchburg, Virginia," 3 May: 345. The "Breaks." Auction of Leaf Tobacco. 3-1/2 x 5-7/16. Unleading Leaf. 3-1/2 x 3-9/16. calling to the "Breaks." 5-1/4 × 2-5/16. Iwisting Plua-Tebacco. 5-1/4 × 6-11/16. Signed by Snyder. Tobacce Wagons and Market. 4-1/8 $\times 5-1 / 8$.

Pressing Bales. Smoking -- Tobaces. 4-1/8 $\times 3-7 / 8$.

The Ovation te the Flags. 6-5/8 × 9-1/4. 5 July: 533.

"Law and Moonshine -- Crooked Whisky in Western North Carolina," 23 August: 665.

Cowrt Week. 3-3/4 × 9-1/4.

A.Mountain Stidl. 5-9/16 $\times 6-3 / 4$. Signed by Snyder. "I never seen no whiskey." $6 \times 2-1 / 4$.

Not Guilty. 4-3/8 × 3-1/4.

Law and Moonshine. $4-3 / 8 \times 6$.

"Bits of New Jersey Coast Scenery," 30 August: 692. Atantic city - The Inlet. 3-1/2 37 . Signed by $C$. Graham. Watting for a Breeze. 2-3/4 $2-7 / 8$. A Blackberry Party. 2-3/4 x 3 . After the Arrlval of the Mornting Papers. 2-3/4 $\times 2-7 / 8$. 
At Ocean Grove -- Meeting on the Beach. 3-1/2 × 7 . Signed by C. Graham.

en the Lily Pond. 2-3/4 x 4-1/2.

Willow Walk at Iuckerton. 2-3/4 × 4-1/2.

"Centennial Celebration of the Battle of Newtown," 20

September: 752 .

on the Way to the Battle-Field. 3-1/2 × 4-5/8.

The Athens Continentals - A Dusty March. 3-1/2 $34-5 / 8$.

The Monument. 4-3/4 $\times 3-9 / 16$.

The Grand stand. 4-9/16 x 4-9/16.

The Battle-Eleld. 4-9/16 x 4-9/16.

Meet lng of the Grand Army of the Republic in Philadelohia. $6-3 / 4 \times 9-1 / 4$. 1 November: 869 .

1880: 24

"General Grant in Florida," 7 February: 84.

Composite of five sketches: "Grave of "Light Herse" Harry

Lee. "Why, I Declare he Ain't no Taller than my

Charley!" "Dats Him Suab." Excurston Dungeness.

$14 \times 9-3 / 8$.

*General Grant in Florida - - A Trio on the Oklawaha. 13-5/8 × 9-1/16. Initialed G.P. 14 February: 100 .

"General Grant in Florida," 21 February: 117.

*The Vlsit to erange Park - Display of Eruits and Veretables. 5-7/16 $\times 6-13 / 16$.

*The Reception at Key West -- Torch-Liaht Procession in the Evening. 6-3/4 × 9-1/4. Signed Snyder.

"General Grant in Cuba -- The Visit to Havana," 28 February: 132 .

At the Pertal of the Captain-General's Palace, Havana. $6-1 / 2 \times 9-3 / 16$.

Afternoon Scene Upon the Prado, Havana. 6-3/16 x 9-3/16.

The original watercolor was listed by the old Print Shop in their sale catalog of March, 1968. (See list of

Taylor drawings and watercolors.) The watercolor, dated 1879, was incorrectly titled STREET SCENE IN NASSAU. Taylor was in Cuba in 1879 and no doubt saw no reason to redraw the scene. The confusion as to location probably 
arises from the fact that this work was offered by the old Print Shop along with four other Taylor watercolors of the Bahamas.

*Carnival in Havana - General Grant in the Precession.

6 March: cover. $10-7 / 8 \times 9-3 / 16$.

"Grant in Cuba, Trip to San Diego," 148.

"Ball by the Natives -- Dancing the "zapotee" 4-1/4 × 6-1/8.

"A Leading Oecupation" 4-1/4 × 3-1/16.

The Village Baths of San Diege. 4-1/4 x 9-3/16.

*On the Read to San Diege - Travelling by Velante. 4-1/4 $x$ 9-3/16. Initialed $S \& H$. (Schell \& Hogan) This is a reverse of the original drawing.

"Florida Oranges -- From the Grove to the Market," 13 March: 166.

Composite of five sketches: Packing Oranges. An Orange Grower's Home. Shlpping oranges on the toch Loosa. An orange cluster. Initialed C.G. Tramway Through an Qrange Grove. 3-7/8 x 6-9/16. Signed Graham del. $14 \times 9-3 / 16$.

"Grant's Visit to Mexico -- The Arrival at Vera Cruz," 27 March: 196.

The Arrival at Vera cruz. 3-9/16 x 9-3/16.

The Domes of Vera Cruz. $3 \times 4-3 / 4$. Initialed C.G.

The Entry linto Vera cruz. $3 \times 4-3 / 4$.

The city of Vere cruz - - Vlew from the Hot lands. 2-3/16 x 9-3/16. Initialed C.G.

Seeling the Town. $3 \times 4-3 / 4$.

A street corner. $3 \times 4-3 / 4$. Initialed C.G.

"From Vera Cruz to Mexico -- Scenes Along the Road," 3 April: 216-217.

*"Bull-Tailing" at Orizaba. 4-7/16 x 9-1/8. Signed Rogers del.

A Jacal in the Hot hands. $6-1 / 2 \times 4-1 / 2$. Signed T. L. Smart and C. Graham.

*Visit to the Market at exizaba. 6-13/16 × 9-3/16. Signed Rogers del.

*The Fall of Atoyac -- Mextcan Rallway. 6-1/2 x 4-7/16. Signed C. Graham.

*Ascending the Mountains. 6-13/16 x 9-13/16. Signed C. Graham. 
"The Battle-Flelds of Mexico," 17 April: 244.

Part of the eld Mill. 2-7/8 x 3-1/26.

*The Gate Stormed at Meline Del Rex. 3-1/4 × 5-7/8.

Chapultepece With old Spanish Aqueduct. 3-7/16 × 6-15/16.

The Valley of Mexice from chapultepec. 5-3/4 x 9-3/16. Signed Rogers.

"General Grant in Mexico -- Visit to Coffee Plantation," 24 April: 261.

*The coffee Plant. 6-1/4 x 4-3/4

A Mexican Home. 3-7/16 x 2-5/16.

*ide Through a Banana Grove. 6-7/8 × 4-7/16.

*The Shrine in the coffee Land. 3-7/16 × 2-5/16. Signed A. Sholt (?)

Drying and Hulling Coffee. 3-7/16 × 4-5/8. Signed Rogers.

Milton. Pennsylvania Destroyed by Fire May $14.6-3 / 4 \times$ 9-3/16. 5 June: 357 .

The Republican National Convention at Chicage. 13-5/8 × 20 . 19 June: 392-393.

"The Republican National Convention at Chicago," 396.

Composite of five sketches: "Delegates at Large:" "Really. Gentlemen, I am sorry, but the last square yard of Floor was Given out Elve Minutes Age." Delegates from South Carelina and Florida: "Should Auld Acqualntance be Eorgot?" The Exposition Bullding, Where the convention was Held. The crowded Hotels: The Gent lemen from Michigan has the Eloer. An Alternate's Alternative: Brown Pays for Forth Shaves, and gets Luxurtant Quarters in a Barber's Sher. $14 \times 9-3 / 16$.

"The Veteran Soldiers Reunion, Mllwaukee, Wisconsin." 3 July: cover.

Composite of three sketches: Came Reunion. Untitled. [parade] Signed Snyder. Head-Ovarters. $11 \times 9-3 / 16$.

The Democratic Convention at Cinclonat - - the Break for Hanceck. $14 \times 9-3 / 16.10$ July: 436 .

"All of Knights Templar at Chicago -- Camp De Molai and Other Scenes." 4 September: 572-573. 
Composite of four sketches: Competittve Drill. Eirewarks. The Review on Wabash Avenue. : amp De Molat. $14 \times 9-$ $3 / 16$.

The Knights Tamolar in chicage - Grand Ball at the Exposition Building. $14 \times 9-3 / 16$.

"Scenes in Rugby -- The English Colony in Tennessee." 16 October: 665 .

Central Avenue. $4-5 / 16 \times 9-3 / 16$.

The Hotel. 4-1/8 $\times 4-5 / 8$.

The English Garden. 4-7/16 x 9-3/16.

"In and About Rugby -- The English Colony in Tennessee." 6 November: 709 .

The Question of Iocation. 4-3/16 x 4-9/16.

Bachelors' Kitchen. 4-3/16 x 4-5/8.

White lak Eork. 5-3/4 × 4-5/16.

clear Eork. 4-3/4 × 9-3/16.

1881: 25

"Among the Thousand Islands." 18 August: 549.

Composite of seven sketches: 1 . smong the Islands; 2 . An Island Home; 3. Sans Soucl cottage, Round Is land; 4 clayton and Round Islands from Prospect Park; 5 . Alexandria Bay; 6. Looking ue the River; 7. A Moonlight Niaht. 13-5/8 x 9-1/16. Signed C. Graham.

1882: 26

The Canoe Regatta on Lake George. 6-7/8 x 9-3/16. 26 August: 533 .

\section{Harper's New Monthly Magazine}

"Street Scenes in Havana." 58 (1879): 682-686.

Merre Castle. $3 \times 4-1 / 4$. Signed C. Graham.

court-Yard of a cuban House. 4-3/8 x 3 . Initialed C.G. The Market. 3-1/2 × 4-1/4. Signed C. Graham.

Horses Bathing in the Surf. 3-7/8 x 4-3/8. A preliminary pencil sketch of this scene is found on the reverse of BREAD FOR THE POOR, a watercolor of Havana completed in 1880 as part of the Grant trip now in the Harn Museum collection.

chloese Eruit store. 4-1/4 × 3-3/8. Initialed JIH(?) 


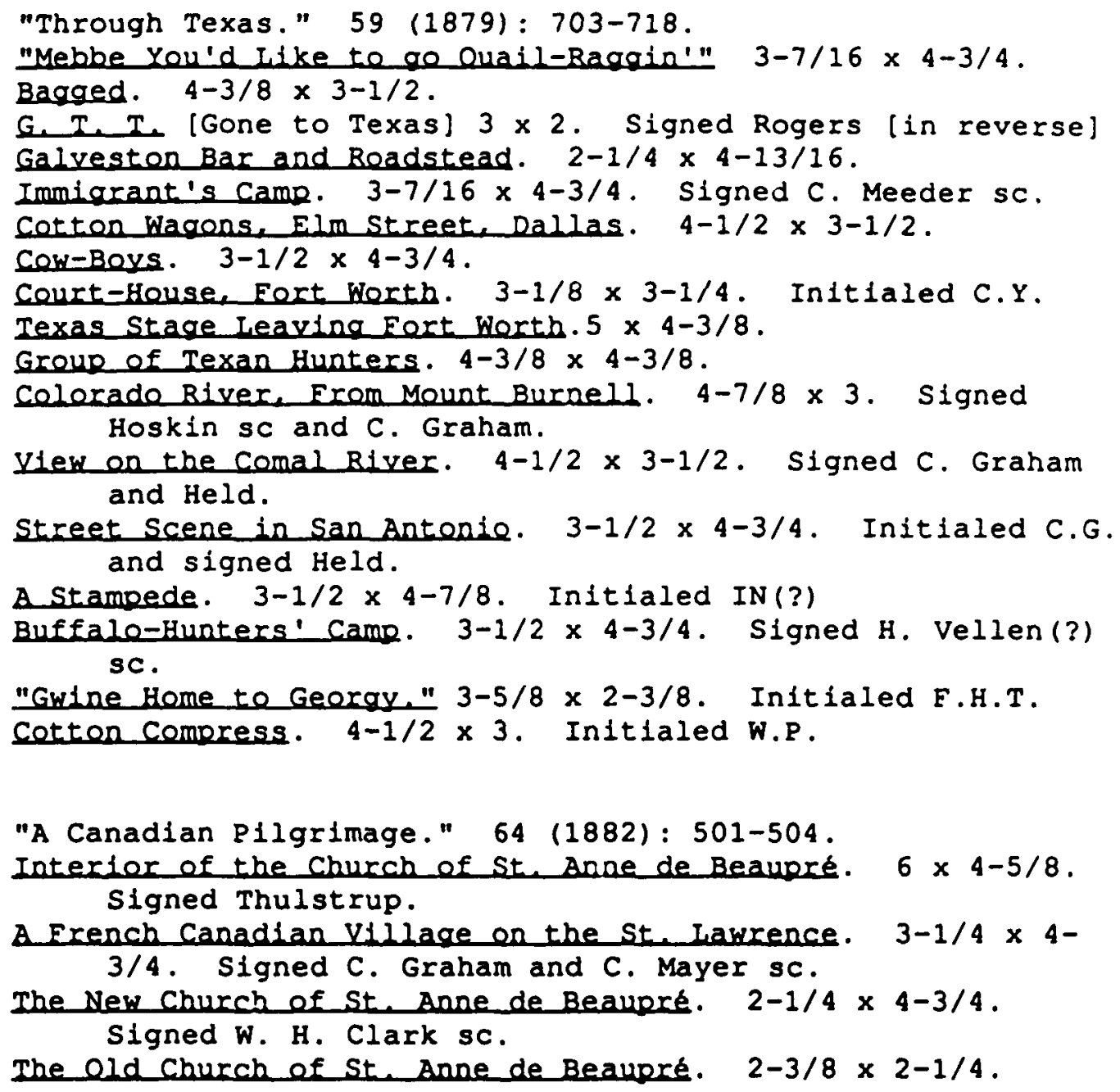

"A Canadian P1lgrimage." 64 (1882): 501-504.

Interior of the Church of St. Anoe de Beaupré. $6 \times 4-5 / 8$. Signed Thulstrup.

A. Erench canadian V1liage on the St Lawrence. 3-1/4 4 43/4. Signed C. Graham and C. Mayer sC.

The New church of St. Anne de Beaupré. 2-1/4 $\times 4-3 / 4$. Signed W. H. Clark sc.

The old church of St. Anne de Beaupré. 2-3/8 $2-1 / 4$.

The Mechanical News: An Illustrated Journal of Manufacturing, Engineering Millilog \& Molag

"St. Lawrence Skiff-Salling." 1 October, 1882: 1+. Sklffs and Skiff-Sailing on the St Lawrence. $6-3 / 8 \times 8-3 / 4$.

"Recollections of a Cuban Earthquake." 15 October 1886: 1+. Composite of four sketches: 1. A Street In Havana; 2. "Wreck of a Village; 3. *A. Tidal Whye; 4. *Making the Best of it. 
The Daily Graphic

"The Regatta of the Schuylkill Navy at Philadelphia, on Wednesday and Thursday Last." 22 June 1874: 857.

A composite of seven sketches: 1. Getting Beady at the "Falls"; 2. The Prizes; 3. The Start; 4. Character Sketches. Signed A. B. Erost; 5. The Einish at Bockland; 6 . Boat-House at Lemon H11l; 7. Watching the Race. Signed F. H. Taylor Phila. $13-3 / 4 \times 20$.

"A Cruise in the Buffalo: Professor King's Balloon Voyage from Cleveland, Ohio." 20 July 1875:138

A composite of ten sketches: 1. At Nen; 2. Public Interest in the Inflation Movement; 3. eff; 4. Dropotad Dispatches; 5 . Deacon's Hollow Our Elrst Landing; 6 . Drag Rope Episodes; 7. Iate Callfars; 8. Camo Birchard; 9. Aerial Photography; 10. Storm en the Mountain; 11. It Bained; 12 . Eriends in Need. Signed F. H. Taylor Phila.

\section{Erank Leslie's Illustrated Newspaper}

"Pennsylvania-Launch of the New Steamship 'Pennsylvania' at Philadelphia, August 15, 1972." 7 September 1872: 405. Launch of the "Pennsylvania." $7 \times 10-1 / 4$. 


\section{APPENDIX E}

FRANK H. TAYLOR WATERCOLORS \& DRAWINGS All sizes (when known) are given in inches.

\section{Extant}

The Antique Boat Museum, Clayton, Now York

CHAUMONT BOATWORKS

Watercolor, 1920. $9 \times 6$.

CHAUMONT BOATWORKS AT SUNSET

Watercolor, 1925. 13-1/4 × 9-1/4.

FISHING OFF CHAUMONT BRIDGE

Watercolor, 1922. 13-1/2 x 9-3/4.

BRIDGESCAPE OF CHAUMONT

Watercolor, 1920. $9 \times 6$.

THOUSAND ISLAND SHOREIINE

Watercolor, c1920. 14-1/4 × 10-1/4.

\section{The Athonaeum, Philadolphia, Pennsylvania}

A SOUTHWESTERN VIEW OF WASHINGTON SQUARE 18 Watercolor, 1925. 27-1/2 × 21-1/2.

Reproduced in Barton's Iittle Journeys Around $01 d$ Rhiladelphia and on National Park Service interpretive sign for Washington Square.

\section{Atwater Kont Museum, Philadelphia, Pennsylvania:}

SPRING STREET NORTH SIDE WEST OF FRONT STREET 307

Watercolor, 1923. 20-1/2 × 13-1/2.

OLD TAVERN 63RD AND MARKET STREET \$406

Pen and ink, 1925. 16-1/2 × 22-1/2.

THE ANGEL HOUSE \$361

Wash/pen and Ink, c1920. 19-3/4 × 14-3/4. 
KRUGER TAVERN 37TH ST. \& WOODLAWN AVENUE \$232 Watercolor, 1921. 14-3/4 x 19-7/8.

PAPER MILI, UPPER WISSAHICKON $\$ 371$

Black and white wash, c1920. 14-3/4 × 19-7/8.

SORREL HORSE HOTEL FIFTY-FIRST ST. \& WOODLAND AVE. \#183

Black and white wash, 1919. 13-7/8 $\times 19-7 / 8$.

OLD SWEDES MILL 172

Black and white wash, c1920. $14 \times 19-1 / 2$.

MC CALL HOUSE $\$ 344$

Watercolor, 1924. $17 \times 12-1 / 4$.

AT $6 \mathrm{TH}$ \& SANSOM $\$ 42$

Black and white wash, c1920. 13-5/8 $\times 19-7 / 8$.

SW CORNER OF BROAD \& CHESTNUT STREETS PRIOR TO 1879

Black and white wash, O1915. 19-3/4 × 25-1/2.

VIEW OF PHILADELPHIA FROM WEST PARK \$110

Pen and ink, 1917. 19-1/2 $25-5 / 8$.

ULRICH \& BROTHER $\$ 215$

Black and white wash, c1920. 21-1/2 x 27=1/2.

PARADE DOWN BROAD ST. \$11

Black and white wash, O1915. 21-5/8 $\times 27-1 / 2$.

GRAVEYARD $\$ 5$

Black and white wash, 01915. $22 \times 27-5 / 8$.

GRAVE OF REBECCA GRATZ 218

Black and white wash, c1920. $20 \times 25-5 / 8$.

FIRST HORSELESS CARRIAGE IN FAIRMONT PARK

Watercolor, 1920. 21-3/4 x 29-1/2.

NICE "BIG RED HOUSE" N.W. CORNER OF BROAD \& SOUTH STREETS \#16

Black and white wash, O1915. 21-1/4 × 27-1/2.

WALT WHITMAN'S GRAVE 103

Black and white wash, c1920. $20 \times 26$.

THE BARNWELL-RHETT HOME, BEAUFORT, S.C. WHERE SECESSION WAS

HATCHED. FEDERAL HOSPITAL DURING THE REBELLION

Black and white wash, 1878. 5-5/16 $\times 9-1 / 2$. 
S. E. EROM BELMONT CC GROUNDS SOUTH OF 51ST STREET EAST OF KING

Watercolor, 1895.

FACING CHESTER AVENUE NORTH OF 52ND STREET

Watercolor, 1905.

DEPARTURE OF GENERAL GRANT \$387

Black and white wash, 1879.

JONES HOMESTEAD, FLORENCE AVENUE NEAR 52ND STREET

Watercolor, 1897. $19 \times 13$.

OLD PEAR STREET AT DOCK STREET: A HISTORIC WOODWORKING CENTER 127

Black and white wash.

COLONNADE ROW, BUILT 1830, PARTLY REMOVED 1868 \#107

Black and white wash cl900. $27 \times 20$.

Reproduction of a lithograph of this drawing in Vaux,

Bittenhouse square, p. 9.

TWADDLIES' WEST SIDE OF BALTIMORE AVENUE, NORTH OF 46TH STREET 185

Watercolor, c1900.

MC GIRR RARE BOOK SHOP

Wash, pen and Ink, 1921.

COOPER SHOP SOLDIERS HOME

Black and white wash, c1910.

Reproduced in Taylor, Rhiladelohia in the civil War, after

p. 80 .

\section{Duane, Morris Beckscher, Philadelphia, Pennsylvania}

OLD MILL AT CARDINGTON, UPPER DARBY ON COBBS CREEK

Watercolor, 1901. 9-1/2 × 15-1/2.

BARTRAM'S GARDEN

Watercolor, 1894. $11 \times 17$.

JOHN KRIDER GUN SHOP

Wash/pen and ink, O1915. 22-1/2 × 17-1/2.

FRANKLIN'S HOME IN LONDON $\$ 93$

Wash/pen and Ink, c1915. 26-1/2 × 10-1/2. 
OLD BELEVUE AT NIGHT

Black and white wash, (1912. 14-3/4 $23-1 / 2$.

CRIST PUBLIC HOUSE

Wash/pen and ink, c1912. $21 \times 13$.

OLD CURIOSITY SHOP

Black and white wash, 1926. 18-3/4 4 13-3/4.

ORIGINAL SITE OF THE WEST END TRUST CO., PHILA. PA.

Watercolor, c1915. 19-1/2 × 27-1/4.

THE ATHENEUM FIFTH STREET BELOW CHESTNUT

Wash/pen and ink, c1915. 20-1/2 × 26-1/2.

HORTICULTURE HALL

Wash/pen and ink, 1927. 19-1/2 × 26 .

MARKOE HOUSE 180

Wash/pen and ink, c1915. $21 \times 26$.

H. J. PETTER \& SON (SILVERSMITHS) CHESTNUT AT 5TH

Wash/pen and ink, c1925. 19-1/2 × 24-1/2.

WEST SIDE OF PENN STREET SOUTH OF BELFIELD AVENUE

Wash/pen and ink, c1920. 11-3/4 x 18 .

PHILA. AND READING RR 9TH AND GREEN STREETS

Wash/pen and ink, c1920. 13-3/4 × 21.

HORSE GOODS STORE

Wash/pen and ink, 1923. 13-3/4 × 19.

RISING SUN HOTEL. WOODLAND AVE. BELOW 53RD STREET

Wash/pen and Ink, 1919. 13-1/2 × 21-1/4.

MOUNT PLEASANT. NW COB RIDGE AVE. AND HUNTINGTON PARK

AVE . 154

Wash/pen and ink, 1920. 11-3/4 × 18 .

BROAD \& PRIME ST. RAILROAD STATION ()

Wash/pen and ink, c1920. 21-3/4 × 12-1/2.

227 DOCK ST.

Wash/pen and ink, 1924. $21 \times 14-1 / 2$.

FRONT STREET BELOW CHESTNUT

Wash/pen and ink, c1920. $21 \times 13-1 / 2$. 
LOCUST STREET NEAR 9TH

Wash/pen and ink, 1922. 20-1/2 × 13-1/4.

Samuel P. Barn Museum of Art, University of Florida, Gainesville:

All works completed in 1880 unless otherwise noted.

DEPARTURE OF EX-PRESIDENT U. S. GRANT ON HIS WORLD TOUR Black and white wash, 1877. 9-3/8 x 14-1/4.

A FLORIDA BEACH (FERNANDINA?)

Black and white wash. 6-1/4 $\times 9-7 / 8$.

ARRIVAL OF GENERAL GRANT AT FERNANDINA FLORIDA

Black and white wash. 6-7/8 x 9-3/4.

THE FERNANDINA BAND "PUMPKIN" LEADER

Watercolor. 7 × 9-7/8.

"COME LONG TOTE JUS' FO TO SEE DAT GIN'L GRANT"

Black and white wash. $8-3 / 4 \times 6-7 / 8$.

"DAT'S HIM, SUAH"

Black and White wash. $9 \times 7$.

GENERAL GRANT AT THE GRAVE OF LIGHT HORSE HARRY LEE, DUNGENESS, GEORGIA

Black and white wash. 9-1/4 $\times 7$.

FISHERY ON THE ST. JOHNS RIVER, FLORIDA

Watercolor. $6-1 / 4 \times 9-1 / 4$.

GENERAL U. S. GRANT AND PARTY, SILVER SPRINGS, FLORIDA

Black and white wash. $7 \times 9-3 / 4$.

GENERAL GRANT IN FLORIDA - A TRIP ON THE OKLAWAHA

Black and white wash. 12-5/8 x 9-5/8

FORT MARION (SAN MARCOS), ST. AUGUSTINE, FLORIDA

Watercolor. 5-1/4 $\times 8-5 / 8$.

GATES OF THE CITY, ST. AUGUSTINE, FLORIDA

Watercolor. 5-1/2 $58-5 / 8$.

A STREET IN ST. AUGUSTINE, FLORIDA

Watercolor. 5-1/2 $\times 7$. 
GENERAL GRANT AND PARTY AND SHOWN SOME FLORIDA PRODUCTS Black and white wash. $7 \times 9-3 / 4$.

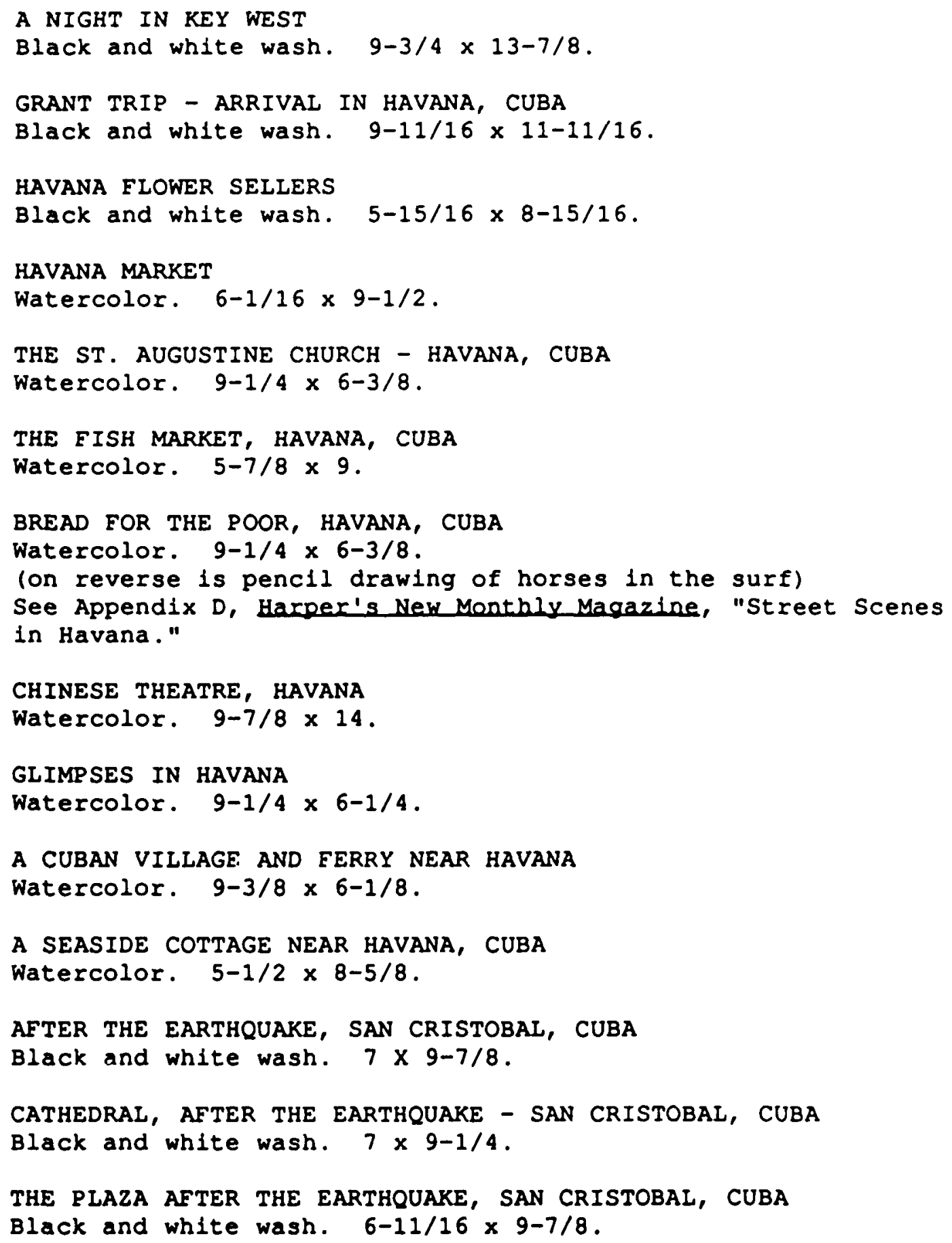


THE PRISON AFTER THE EARTHQUAKE, SAN CRISTOBAL, CUBA Black and white wash. $7 \times 9-1 / 4$.

A MEAL AFTER THE EARTHQUAKE, SAN CRISTOBAL, CUBA

Black and white wash. 6-11/16 × 9-15/16.

BACK COUNTRY TRAVEL IN CUBA

Black and white wash. $8-3 / 4 \times 12-1 / 4$.

THE CRANIVAL IN HAVANA

Black and white wash. $10 \times 14$.

VOYAGE TO VERA CRUZ, MEXICO

Black and white wash. 9-5/8 $\times 12$.

COL. FRED D. GRANT ON SHIP EN ROUTE TO MEXICO

Black and white wash. $6-7 / 8 \times 5-7 / 8$.

A DEPUTATION EROM MERIDA, YUCATAN

Black and white wash. 9-3/8 $\times 5-3 / 4$.

GRANT PARTY EN VOYAGE TO MEXICO

Black and white wash. $9 \times 5-7 / 8$.

GRANT AND PARTY - ARRIVAL IN HARBOR OF VERA CRUZ, MEXICO

Black and white wash. 7-3/4 $\times 13-3 / 4$.

PROSPECT NEAR CORDOVA

Black and white wash. 8-1/2 $\times 12$.

THE MARKET AT ORIZABA, VERA CRUZ, MEXICO

Black and white wash. 9-1/16 $\times 13-10 / 16$.

GRANT INSPECTING A COFFEE PLANTATION, CORDOVA, MEXICO

Black and white wash. 13-3/8 $\times 10$.

A COFFEE BRANCH SHOWING COFFEE BEANS

Black and white wash. 12-1/4 $\times 10$.

THE 'ZAPOTEO' (DANCERS AND MUSICIANS)

Black and white wash. 6-1/2 × 9-3/4.

A BULL-TAILING, ORIZABA, MEXICO

Black and white wash. 9-3/4 $\times 13-3 / 4$.

ASCENDING THE MOUNTAIN BY TRAIN ABOVE ORIZABA, MEXICO

Black and white wash. 9-3/8 $\times 13-5 / 16$. 
THE FALIS OF ATOYAC - ABOVE ORIZABA, MEXICO

Black and white wash. $13 \times 9-1 / 2$.

GENERAL GRANT'S RESIDENCE IN MEXICO CITY

Black and white wash. $9-1 / 2 \times 12-3 / 4$.

STAIRWAY OF HOUSE WHERE GRANT PARTY WAS HOUSED IN MEXICO CITY

Black and white wash. 11-1/4 $\times 7-5 / 8$.

VIEW EROM VERANDA OF GRANT'S RESIDENCE IN MEXICO CITY

Black and white wash. 9-9/16 $\times 12-3 / 4$.

INTERIOR DRAWING ROOM OF GRANT'S RESIDENCE IN MEXICO CITY

Black and white wash. $9 \times 13-3 / 4$.

THE THIEVES MARKET IN MEXICO CITY

Black and white wash. 5-7/8 $\times 8-1 / 4$.

GATE AT MOLINO DEL REY

Black and white wash. 8-3/4 $\times 10-1 / 8$.

OFFICIAL CALL OF GENERAL U. S. GRANT, GENERAL SHERIDAN, AND PARTY ON PRESIDENT DIAZ OF MEXICO AT THE NATIONAL PALACE IN MEXICO CITY

Black and white wash. $10 \times 13-3 / 4$.

\section{Bistorical Society of Ponnsylvania, Philadalphia.}

OLD UNITED STATES NAVY YARD $\$ 51$

Watercolor, c1920.

Reproduced in Taylor, Rhiladelphia in the civil War, after p. 200.

FLORIST STREET

Watercolor, 1923. 13-1/2 x 15-1/2.

BOHL BOHLEN'S STORE 158

Watercolor, c1920. 20-1/4 x 14-1/4.

FORT DELAWARE (MIFELIN?)

Watercolor, 1920. 11-1/8 X 19 .

BOLTON'S STORES AND COAL WHARVES SCHUYLKILL RIVER NEAR THE UPPER FERRY BRIDGE \$124

Watercolor, 1918. $13 \times 19$.

PERKIOMEN BRIDGE HOTEL \$238

Watercolor, 1921. 13-1/2 x 19-1/4. 


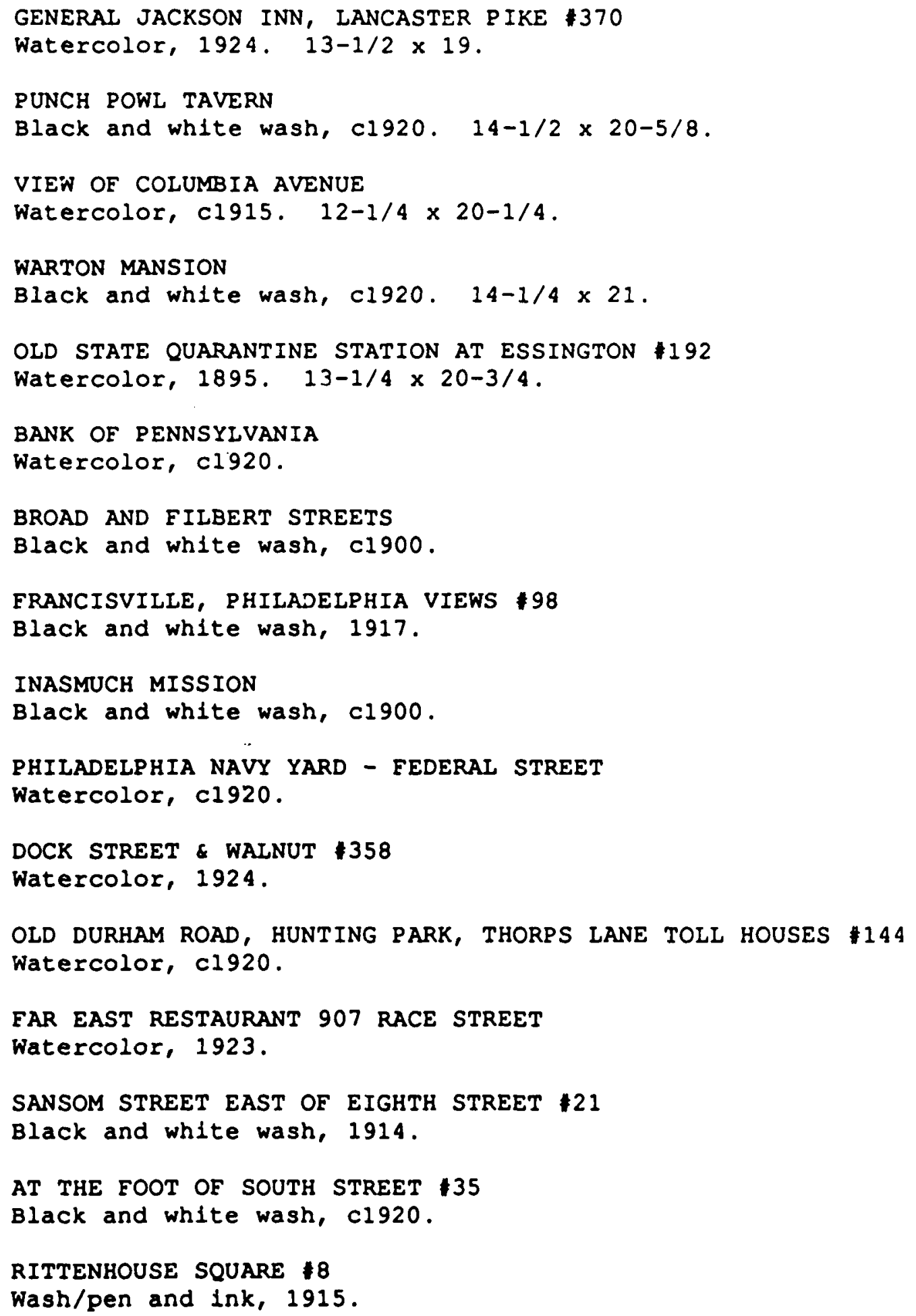


WHERE OLD PHILADELPHIA STILL CLINGS TO THE SOIL Wash/pen and ink, 1911, 01915

RESIDENCE OF THOMAS I WHARTON, 130 S. SIXTH STREET

PHILADELPHIA: BIRTHPLACE OF THE HISTORICAL SOCIETY OE

PENNSYLVANIA, DEC. 1824, BLDG. REMOVED IN 1909.

Watercolor, c1920.

CAMP BALLIER

Black and white wash, c1920.

Reproduced in Taylor, Rhiladelohia to the civil War, after

p. 112 .

PHILADELPHIA STREET

Watercolor, 1923.

WILIIAM LOGAN HOUSE 2ND \& SANSOM

Black and white wash, c1920.

INDUSTRIAL GROUP, LOWER SCHUYLKILI RIVER \#373

Watercolor, 1926.

SOUTHEAST FROM LOGAN SQUARE 15

Wash/pen and Ink, 1915.

THE WEDGE BUTTONWOOD STREET

Wash/pen and Ink, c1920

Kanney Botel, Jones Falls, Ontario, Canada:

HOTEL KENNEY AT JONES FALLS

Watercolor, 1895.

STEAMER "JAMES SWIFT" IN THE JONES FALLS LOCKS

Watercolor, 1896.

Royal Ontario Museum, Toronto, Canada:

VIEW OF TADOUSSAC FROM THE ROAD

Wash/pen and ink, c1880. 8-15/16 × 11-15/16.

CHICOUTIMI SEEN FROM THE BAY

Black and white wash, c1880. 8-15/16 x 11-15/16. 


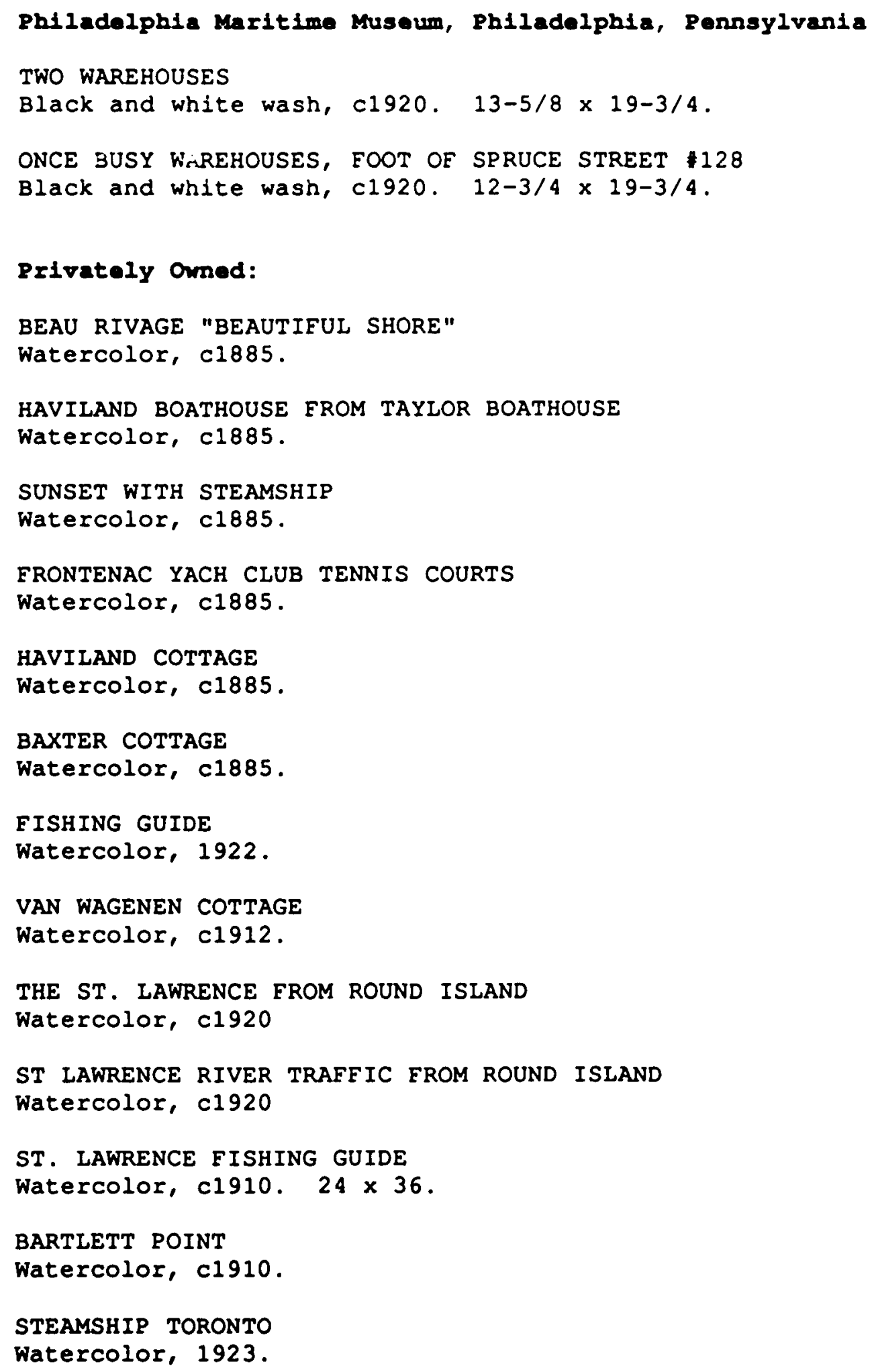




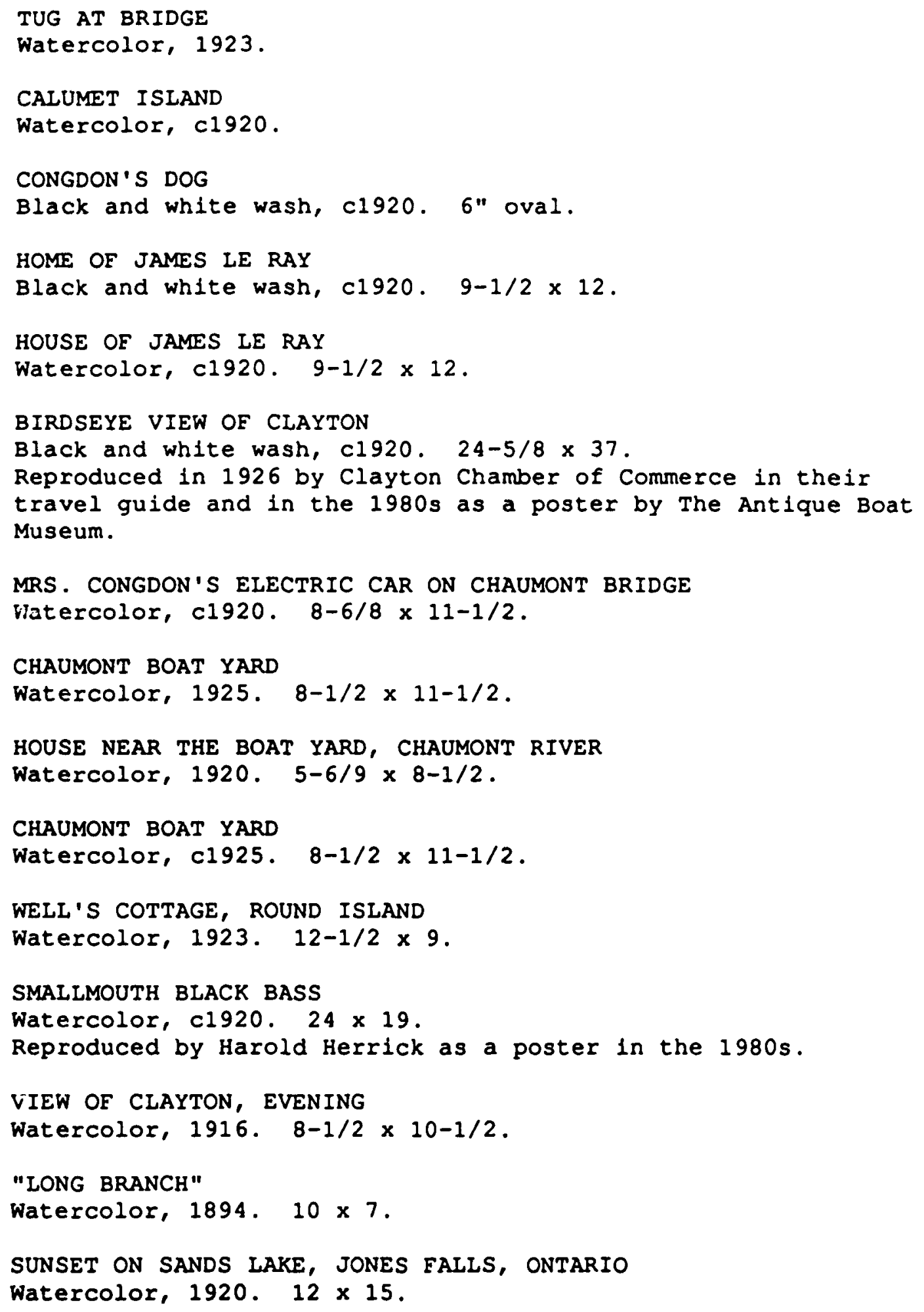




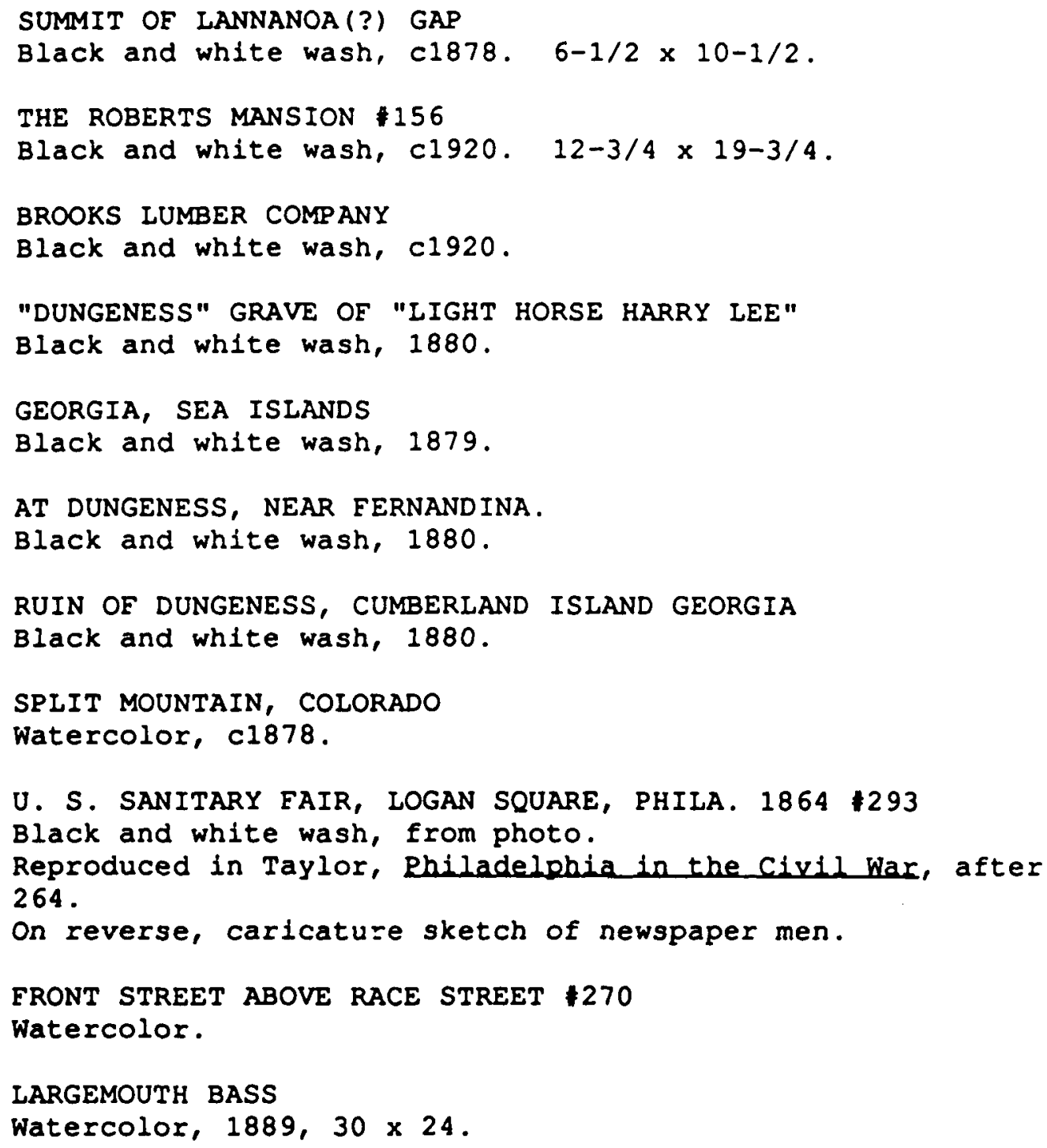


SPONGE FISHING (in BAHAMA waters)

Watercolor, 1881. $13 \times 19-3 / 4$.

DIVING FOR SHELLFISH - SPONGES IN BAHAMA WATERS

Watercolor, 1881. $20 \times 13-1 / 2$.

THE OCEAN FLOOR OF THE CRYSTAL CLEAR WATERS OF NASSAU

Watercolor, 1881. $18 \times 13-3 / 4$.

10 (1951): 206-207.

"r. B. Taylor watercolors, Four Southern Views"

HOUSES AT BEAUFORT, SOUTH CAROLINA

Watercolor, c1870. $7 \times 9-3 / 4$.

LOOKOUT MOUNTAIN, TENNESSEE

Watercolor, c1870. 6-7/8 $\times 9-7 / 8$.

OLD COTTON PRESS, GEORGIA

Watercolor, c1878. $7 \times 9-3 / 4$.

THE FRENCH ROAD, NEAR ASHEVILLE, NORTH CAROLINA

Watercolor, c1870. 6-7/8 x 9-7/8.

11 (1952): 166-167.

"Maple Sugaring: Jour Original Drawings by Frank Hamilton

Taylor"

EMPTYING THE BUCKETS

Black and whlte wash, c1880. $8 \times 10-1 / 2$.

A SUGAR BUSH AND CAMP

Black and white wash, c1880. $8 \times 10-1 / 2$.

SYRUPING DOWN

Black and white wash, c1880. $8 \times 10-1 / 2$.

BOILING TO A "FEATHER"

Black and white wash, c1880. $8 \times 10-1 / 2$.

10 (1951): 161-164

"A Philadelphia Artist in Texas"

QUEEN CITY OF THE SOUTH

Pencil drawing, 1880. 5-1/4 × 7-7/8.

COUNTRY GROCERY STORE IN TEXAS

Black and white wash, c1870. 5-1/2 x 8-3/4. 
STAGE COACH AT THE STAGE OFEICE, EL PASO, TEXAS

Pencil drawing, c1870. 6-1/8 x 10-3/8.

THE SAN ANTONIO RIVER IN THE CITY

Pen and ink, c1870. 6-3/4 x 9-7/8.

GARRISON AT SAN ANTONIO, TEXAS

Watercolor, c1870. $7 \times 9-2 / 3$.

\section{Paintings dealing with the Thousand Islands:}

A MOTOR BOAT SPIN AMONG THE ISLANDS

Watercolor, 1905. Reproduced in the crossmon, 1905

The painting supposedly hung in the Frontenac Yacht club.

ALSTER TOWER, HEART ISLAND. GEO. BOLDT, NEW YORK and HEART ISLAND, BOAT SHELTER OF GEORGE BOLDT, NEW YORK CITY

Watercolors. Reproduced in "A Palace on the St. Lawrence."

Leslie's Weekly 27 Aug. 1899: 338; The Crossmon, 1901; and Souvenir of the Thousand Islands \& River St Lawrence, n.d.

THE CAPTAIN VISGER

Black and white wash(?). Reproduced on cover of Daily 1000 Island Tours of the Excursion Yacht captain Visger, 1900 .

CALUMET ISLAND

Watercolor, 1895. Photographed by Les Corbin.

MUSKIE FISHING ON THE ST. LAWRENCE

Watercolor. c1880.

Reproduced as a notecard by West Surf Publications, as a postcard by The Antique Boat Museum, and "Rlver Rat" Cheese, and as a poster by Harold Herrick. The original print was purchased by Mr. Herrick from the old Print Shop in New York City.

HUBBARD HOUSE, CLAYTON, (BEFORE THE FIRE)

Black and white wash, 1895 .

According to Lester $J$. Corbin, the drawing appeared in On the St. Lawrence on June 12, 1896.

THE THOUSAND ISLANDS

Black and white wash, cl900.

Reproduced as notecards by West Surf Publications, and as a poster. 


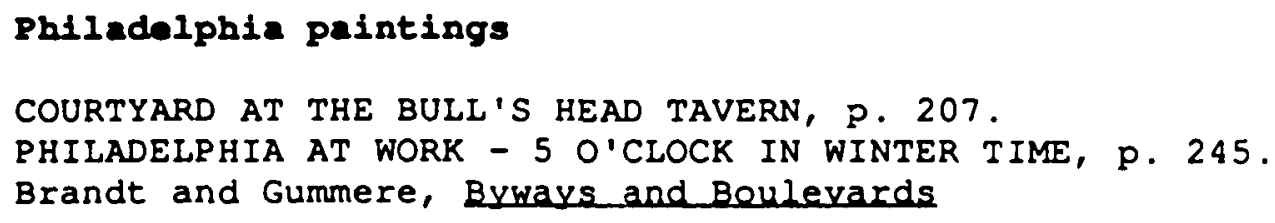

CAMP STANTON, 19TH CAVALRY, ISLINGTON LANE, after p. 136.

SCHOOL FOR THE SELECTION OF OFFICERS OF COLORED REGIMENTS, 1210 Chestnut Street, after p. 184 .

FORT MIFELIN, A. PRISON FOR DESERTERS, after p. 192.

THE NEW POST OFFICE, after p. 216.

All of the above reproduced in Taylor, Philadelobla in the sivil War.

The following drawings were reproduced as lithographs by Taylor and sold through two Philadelphla galleries, J. E. Barr \& Co., and Charles Sessler. They were given a number which usually appears on the original drawing. These numbers have been provided on the extant art works. Listed below are the drawings for which the original has not yet surfaced. The Library Company of Philadelphia has a complete set of the original lithographs, and the Atwater Kent Museum has a set of the original negatives. $A$ * in place of a number indlcates the original is extant and documented above. otherwise, a missing number means no drawing was listed by elther gallery.

1. ELECTION NIGHT, AT CITY HALL SQUARE

2. FILBERT STREET ROW ON NORTH SIDE OF CITY HALL

3. MERRICK'S ROW, 1820, WEST OF CITY HALL 
4. A HUDDLE OF OLD HOUSES SOUTHWEST FROM FIFTEENTH AND MARKET STREETS

6. LAST NIGHT OF THE OLD BELLEVUE

7. NORTHWEST CORNER OF BROAD AND CHESTNUT STREETS

$\star$

10. THE MORRIS RESIDENCE IN EIGHT STREET. Reproduced in Brandt and Gummere, Byways and Beulevards, p. 185.

12. CLINTON STREET. Reproduced in Morley, Travels in Bhiladelphia, after p. 50.

13. THE YELLOW MANSION. BROAD AND WALNUT STREETS.

14. EAST RITTENHOUSE SQUARE

$\star$

17. SOUTHEAST CORNER SIXTH AND WALNUT STREETS IN 1912

^. SWANWICK STREET

20. THE GEORGE MIFFLIN HOUSES

*

22. FRANKLIN'S FIRST HOME IN PHILADELPHIA

23. AT SECOND AND DOCK STREETS

24. CUTHBERT STREET, EAST FROM SECOND STREET

25. EPIPHANY CHURCH

26. PENN TREATY TREE - 1810

27. SOUTH CAMAC STREET

28. CHERRY TREE TAVERN

29. LOCUST STREET, WEST FROM THIRTEENTH STREET

30. OLD WAREHOUSE - FOOT OF RACE STREET

31. RITTENHOUSE MANSION. SEVENTH AND ARH STREETS

32. LAST HOME OF ROBERT MORRIS, 32 SOUTH TWELETH STREET

33. OLD SCOTS' CHURCH

34. KEENE MANSION AND FRANKLIN MARKET

* DUMONT'S MINSTREL HOUSE (FORMERLY CARNCROSS AND DIXEY'S)

37. HERKNESS BAZAAR

38. "INTERNED" - A GERMAN SHIP IN THE PORT OF PHILADELPHIA

39. RETURN OF THE LIBERTY BELL FROM THE PACIFIC COAST

40. ACADEMY OF FINE ARTS ON CHESTNUT STREET

41. AT ERONT AND PINE STREETS

$\star$

$\star$

44. NORTHEAST CORNER OF BROAD AND CHESTNUT STREETS

45. OLD SHACKS WHICH ONCE STOOD WHERE MERCANTILE IIBRARY NOW EXISTS

46. OLD BUILDINGS ON CHERRY STREET, WEST OF THIRTEENTH STREET 
47. SITE OF UNION LEAGUE BUILDING IN 1864. Reproduced in Taylor, Philadelobia in the civil War, after p. 240.

48. THE LA PIERRE HOTEL, 1876

49. GIRARD BANK - 1853

50. INDIAN KING TAVERN AT HADDONFIELD

52. SIX O'CLOCK - NIGHT VIEW OF MODERN OFFICE BUIIDINGS

53. POOR RICHARD CLUB, CAMAC STREET

54. BALDWIN'S FIRST LOCOMOTIVE SHOP

55. NORTHEAST CORNER OF SECOND AND CHESTNUT STREETS

56. OLD HOUSES AT SEVENTH AND FILBERT STREETS

57. OLD RESIDENCE, SEVENTH AND WALNUT STREETS. Reproduced in Lippincott, Early Philadelphia, after p. 264.

58. THE NATATORIUM, BROAD STREET

59. NORTHWEST CORNER OF FOURTH AND WALNUT STREETS

60. FIRST UNITED STATES MINT, SEVENTH STREET. Reproduced in Fairbairn, Rhiladelobla, p. 50.

61. SOUTHWEST CORNER OF SEVENTH AND MARKET STREETS (THOMAS JEFEERSON HOUSE)

62. SMITH'S ISLAND, DELAWARE RIVER

63. OLD REDEMPTION CHURCH

64. HALL OF THE GERMAN SOCIETY, SEVENTH STREET

65. OLD LUTHERAN SCHOOL, CHERRY STREET

66. ALONG LOWER CHESTNUT STREET - 1853.

67. THE BELL TAVERN, EIGHTH STREET

68. UNITED STATES MINT ON CHESTNUT STREET

70. ANTHONY MORRIS' BREW HOUSE

72. HEART OF THE OLD CHESTNUT STREET TRADE - 1853.

73. LODGE STREET AND THE PENNSYLVANIA BANK

74. THE PEROT ENGINE, FIRST IN THE UNITED STATES

75. ZION CHURCH

76. SOUTHEAST CORNER OF SEVENTH AND CHESTNUT STREETS (BARNUM'S MUSEUM)

77. FIRST AMERICAN PHOTO, SAXTON, 1839.

79. SWAIM'S LABORATORY AND BATHS, SEVENTH AND SANSOM STREETS

80. NOTED RESIDENCES, NOW GREEN'S HOTEL

81. BIJOU THEATRE (FIRST "MOVIE" PICTURES SHOWN HERE IN 1895)

82. NORTHEAST CORNER OF FIFTH AND CHESTNUT STREETS

83. BULL'S HEAD HOTEL (EIRST EXPERIMENTAL RAILWAY TRACK). Reproduced in Brardt and Gummere, Byways and Boulevards, 207.

84. NORTHWEST CORNER OF THIRD AND CHESTNUT STREETS

85. FRANKLIN COURT. Reproduced in Brandt and Gummere, Byways and Bowleyards, 90.

86. MECHANICAL APPARATUS INVENTED BY BENJAMIN FRANKLIN 
87. INDIAN KING TAVERN AND FIRST PRESBYTERIAN CHURCH, HIGH STREET

88. OFFICE AND RESIDENCE OF STEPHEN GIRARD

89. GRAVE OF BANJAMIN FRANKLIN. Reproduced in Morley, Travels in Philadelobia, frontispiece.

90. OLD STABLE SUPPOSED TO HAVE BEEN USED BY FRANKLIN AS A PRINTERY

$\star$

92. FIRST PUBLIC SCHOOI, CHESTER STREET

94. GRIFFITH JONES' HOUSE NEAR LOGAN (EARLY MAYOR)

95. PEWTER PLATTER ALLEY

96. OLD PRINTERY IN BURLINGTON WHERE BENJAMIN FRANKLIN WORKED

97. FIRST PHILADELPHIA CHARITY AND PENN'S HOUSE IN LETITIA COURT

^9. WOODLANDS' AND BARTRAMS' RESIDENCES

100. HOUSE IN NINTH STREET WHERE JOSEPH BONAPARTE LIVED

101. CHESTNUT STREET THEATRE

102. HOME OF GOVERNOR JENNINGS AT BURLINGTON

104. WRECK OF THE "AUGUSTA" AT GLOUCESTER

105. MEDICO-CHI BUILDINGS, CHERRY STREET

106. COLONNADE HOTEL

^

108. LANDING AVENUE, FAIRMOUNT

109. A NOTED SPRUCE STREET RESIDENCE

111. FAIRMONT MARKET

112. HORTICULTURAL HALI, BROAD STREET

113. GROUP OF SCULPTURES ONCE ADORNING THE FIRST CHESTNUT STREET THEATRE

114. MUSICAL FUND HALL

115. PRUNE STREET THEATRE

116. PETTY'S ISLAND IN 1917

117. GIRARD ROW

118. TWO WALNUT STREET RESIDENCES

119. BLUE ANCHOR TAVERN

120. AMATURE DRAWING ROOM

121. EXCHANGE HOTEL, DOCK STREET

122. MERCHANTS' HOTEL, FOURTH STREET

123. FRANKLIN HOTEL, CHESTNUT STREET

*

129. COPE IINER "TONAWANDA"

130. COPE IINER "WYOMING"

131. COPE IINER "TUSCARORA" 
132. "ALL ABOARD FOR PITTSBURGH" IN 1837

133. SWEDISH BLOCK-HOUSE, MARCUS HOOK

$\star$

135. CRESCENTVILLE, ON TACONY CREEK

136. THE ATHENIAN BUILDING, IN FRANKLIN COURT

137. WHITALL HOUSE, RED BANK

138. CONTRIBUTIONSHIP BUILDING, FOURTH STREET

139. CASPAR WISTAR HOUSE, FOURTH STREET

140. THE "CANNON BALL HOUSE"

141. GERMANTOWN'S "KING OF PRUSSIA"

142. KRIDER GUN SHOP

*

145. BELMONT CRICKET CLUB HOUSE

146. THE ATHENEUM BUILDING, SIXTH STREET

147. KUGLER'S ON THE DELAWARE

148. "LAWYER'S ROW," WALNUT AND SIXTH STREETS

149. A BIT OE OLD FRONT STREET

150. THE TABERNACLE, BROAD AND SO. PENN SQUARE

151. OLD PHILADELPHIA BANK AT FOURTH AND CHESTNUT STREETS

152. LOGAN RESIDENCE, SECOND STREET

153. STEPHEN GIRARD'S FARM HOUSE

156. LITTLE DOCK AND SPRUCE STREETS

157. FARMERS' MARKET, ON MARKET STREET BELOW TWELFTH STREET

$\star$

160. CLARK HALI, THIRD AND CHESTNUT STREETS

161. GRAYS FERRY HOTEL AND THE BARTRAM HOMESTEAD

162. SECKEL PEAR TREE IN PASSYUNK

163. APPRENTICES' LIBRARY, FIFTH AND ARCH STREETS

164. OLDEST HOUSE IN PHILADELPHIA

165. RICHMOND HALL, THE BALL HOMESTEAD

166. SPARKS' SHOT TOWER

167 TO 170. FARM HOUSES IN THE KINGSESSING DISTRICT

171. THE WISTER RESIDENCE NOW HOME OF THE GERMANTOWN SITE AND RELIC SOCIEIY

$\star$

173. ROBERTS' MILL, GERMANTOWN

174. OLD "PUBLIC LEDGER" BUILDING, THIRD AND CHESTNUT STREETS

175. COLOSSEUM AND AUDITORIUM ON BROAD STREET, 1876

176. MARSHALL'S MILI, DELAWARE COUNTY

177. FALSTAFF HOTEL, SIXTH AND JAYNE STREETS

178. RED LION HOTEL, BRISTOL PIKE

179. FRONT STREET ABOVE PINE STREET

$\star$

181. RISING SUN TAVERN

182. FARM HOUSE, FIFTY-FIRST STREET AND SPRINGFIELD AVENUE 


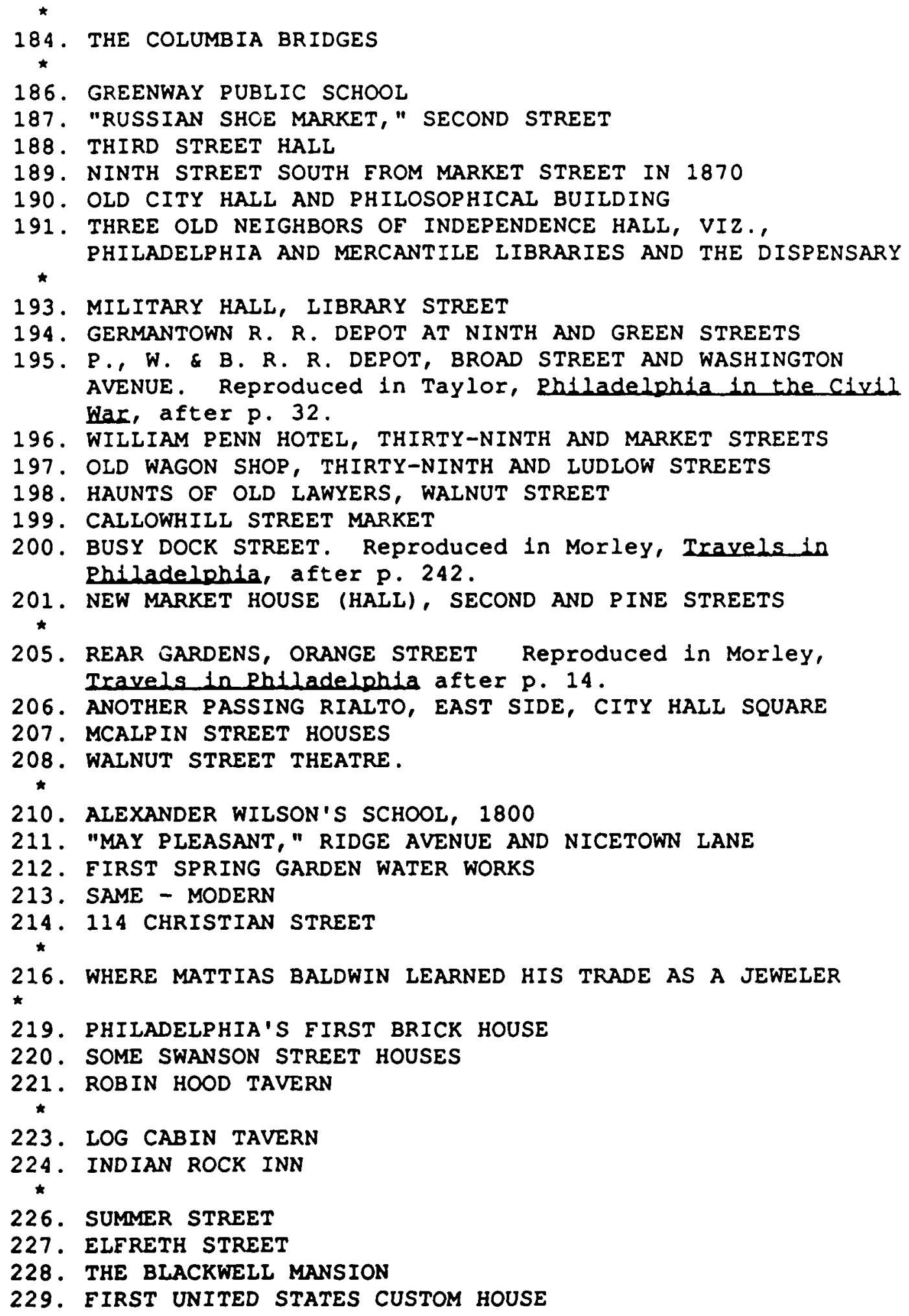


230. AT SECOND AND COATES STREETS, 1806

231. THE STAR TAVERN WOODLAND AVENUE

233. THONE KUNDER'S HOUSE, GERMANTOWN

234. HAGNER'S DRUG MILL

235. OLD DWELLING ON FIFTH STREET 3 ZLOW WALNUT STREET

236 and 237. OLD BUIIDINGS AT FIFTH AND LOCUST STREETS

239. THE TRAPPE MEETING

240. WISTER AND CADWALLANDER HOUSES ON FOURTH STREET

242. SOME THIRD STREET DWELLINGS

243. WASH DAY, SHARP'S AVENUE

244. IN SOUTH CIIFTON STREET

245. HOFFMAN RESIDENCE ON COBB'S CREEK PARKWAY

246. THE FIRST EXECUTIVE MANSION, HIGH STREET

247. A NICETOWN LANE MANSION, HATFIELD

248. FRIENDS' ORTHODOX MEETING HOUSE

249. THREE QUINCE STREET HOUSES

250. COULTZ LOG HOUSE

251. EARLY HOUSE AT FIFTY-EIGHTH STREET AND SPRINGFIELD AVENUE

252. SWAN TAVERN, RIDGE ROAD

253. WARREN TAVERN

254. MC ARAN'S PLEASURE GARDEN

255. LIP'S BREWERY, WEST PHILADELPHIA

256. DWELLINGS ABOVE FLORIST STREET

257. TWO OLD TIMERS IN JUNIPER STREET

258. THE EPISCOPAL ACADEMY, LOCUST STREET

259. FLORIST STREET HOMES

260. DWELLING, LOCUST STREET ABOVE BROAD STREET

261. WINDEMERE HOTEL

262. NORTHWEST CORNER OF TENTH AND CLINTON STREETS

263. LIVEZY (SIC) WAREHOUSES AT THE FOOT OF RACE STREET

264. RITTENHOUSE HOME, WISSAHICKON

265. THE MONASTERY

266. RANDOLPH STREET

267. GEN. WAYNE TAVERN

269. OLD CHESTNUT STREET THEATRE

279. EASTERN MARKET, FIFTH STREET ABOVE CHESTNUT STREET

280. IN SOUTH ERONT STREET

281. WATER STREET ABOVE MARKET STREET

$\star$

283. COLLEGE OF PHARMACY, SEVENTH STREET

285. RANDOLPH HOUSE, $212 \mathrm{~N}$. SECOND STREET

$\star$

287. THE BRIDGE TOWERS, FOOT OF RACE STREET, IN DECEMBER, 1923 
288. THE PARKWAY AND ITS FOUNTAIN

290. OLD SWEDES CHURCH

292. STUDY OF CHIMNEYS, LOCUST STREET

$\star$

294. MERCHANTS' EXCHANGE, THIRD AND DOCK STREETS

295. COLLEGE OF PHYSICIANS, 13TH AND LOCUST STREETS

296. THE ARCADE IN CHESTNUT STREET

298. BALCONY. THE CONTINENTAL HOTEL

299. DA COSTA HOME IN FRONT STREET

301. IN CHINATOWN, RACE STREET

303. RESIDENCES, SOUTH RITTENHOUSE SQUARE

305. A BENTON STREET VISTA

306. BIRTHPLACE HOUSE OF JOSEPH JEFFERSON

*

308. FLORIST STREET WEST OF FRONT STREET

309. FRIENDS' MEETING IN DARBY

310. HUMPHREY'S HOUSE, NEAR HAVERFORD

311. LIVEZEY HOUSE, NEAR THE WISSAHICKON

312. CUTHBERT STREET

313. BINGHAM HOUSE AND EIRST PENNA. R. R. STATION

314. IN PENT-UP PLACES

315. TWO OLD TAVERNS ON THE CHESTER ROAD

316. ST. GEORGE'S METH. CHURCH, FOURTH STREET

317. ST. AUGUSTINE'S CATHOLIC CHURCH ON FOURTH STREET

319. EARLY TYPE OF LOCOMOTIVE

320. CHESTNUT STREET AT 44TH STREET IN 1888.

321. JEFFERSON COLLEGE IN TENTH STREET

322. SOME SECOND STREET STORES

323. TWO MASCHER STREET GROUPS

324. MILITARY MAP. CAMPS AND BARRACKS. PHILADELPHIA IN THE CIVIL WAR PERIOD. Reproduced in Taylor, Rbiladelphia in the civil War, foldout on back inside cover.

325. OLD MILLS ALONG COBB'S CREEK

326. "VILLAGES" IN PHILADELPHIA

327. DOCK STREET MARKET

328. OLD RESIDENCES, WEST PHILADELPHIA

329. FOX CHASE TAVERN

330. COLONIAL FIREPLACE ("GRANDPA'S CORNER")

331. HEMESTEAD, PASCHALL AVENUE

332. ROCK HOUSE, WINGOHOCKING

*

334. FRANKIIN INSTITUTE

335. A CENTURY-OLD HOME (MASCHER STREET)

336. MARKET BUILDING, MARKET AND FIFTEENTH STREETS

337. ALONG THE WISSAHICKON

338. DONNER'S HOTEL

339. A SURVIVAL OF THE STONE AGE

340. PINE STREET MEETING 
341. IN WALNUT COURT

342 NORTHWEST FROM CHESTNUT AND SEVENTH STREETS

*

345 SILVER STREET

346. N. E. CORNER MARKET AND THIRD STREETS

347. S. W. CORNER MARKET AND THIRD STREETS

348. WHERE THE CIVIL WAR WAS FINANCED. THIRD STREET. Reproduced in Taylor, Philadelohta in the civil War, after p. 216.

349. INN, WISSAHICKON STREAM AT RIVER DRIVE

350. TUN TAVERN (EARLY MASONIC)

351. CONTINENTAL HOTEL

352. CHESTNUT STREET ABOVE THIRD STREET, SOUTH SIDE

353. CARPENTERS' HALL

354. ST. PAUL'S CHURCH, THRID STREET

355. ST. JOSEPH'S CHURCH, WILIING'S ALLEY

356. BILLY WIGGLESWORTH'S TOY SHOP

357. CORN EXCHANGE NATIONAL BANK

359. OXFORD TRINITY CHURCH

360. CADBURY HOUSE, MORRESTOWN, N.J.

362. SIDE OF PASTORIUS' HUT

363. NEWKIRK MONUMENT

364. STORE AND POSTOFFICE (sic) AT ITHAN

365. BIRMINGHAM MEETING

366. OLD MILL, FORT WASHINGTON

367. FRIENDS' MEETING, GWYNEDD

368. HOME OF W. P. DEWEES

369. SITE OF FIRST GRIST MILL, COBB'S CREEK

372. WHERE POE WORKED

374. A FAIR BREEZE TO THE CAPES - MARINE

375. HORSE CAR, 1872

376. OLDEST TOBACCO STORE

377. P. \& R. FERRY, SOUTH STREET

378. OUTWARD BOUND (SAILING SHIP)

379. INTERIOR, INDEPENDENCE HALL

380. A GALLANT SURVIVOR, SAILING SHIP

381. A CIVIL WAR BLOCKADER, SAILING SHIP

382. CHRIST CHURCH

383. HOMEWARD BOUND (SAILING SHIP)

384. TRAVEL IN 1825

385. "TO PITTSBURCH OR BUST!"

386. HOME OF THOMAS GRIFFITH

388. BLOCKHOUSE, CLAYMONT, DELAWARE

389. POE'S HOME, SEVENTH AND BRANDYWINE STREETS 
390. BECALMED (SAILING SHIP)

391. SEVEN STARS HOTEL, FRANKFORD

392. RAPID TRANSIT, CENTENNIAL PERIOD

393. "MONDAY MORNING."

394. HOME OF THE COLONIAL DAMES

395. DRYING SAILS (SHIP IN PORT)

396. THE PROVISION DISTRICT

397. AESULAPIAN CLUB

402. SAILING SHIP (YORK SUBJECTS)

403. HUTCHINSON STREET

404. SECOND AND CHESTNUT STREETS

405. FIRST BAPTIST CHURCH 